\title{
Synthesis and Coordination of Bicyclic \\ Phosphorus-Nitrogen Ligands
}

by

Almas Ismaeil Zayya

A thesis

submitted to the Victoria University of Wellington in fulfilment of the requirements for the degree of Doctor of Philosophy in Chemistry

Victoria University of Wellington

2009 


\section{Abstract}

This thesis describes the synthesis and coordination chemistry of bicyclic phosphorus-nitrogen $(\mathrm{PN})$ ligands containing the rigid and preorganised bicyclo[3.3.1]nonan-9-one framework.

The PN ligands were prepared via the Mannich condensation reaction of four different phosphorinanone classes with amines and aldehydes. The phosphorinanone compounds, 2,6-dimethyl-3,5-diphenyl-4-phenyl-4phosphacyclohexanone (isomers 50 and 51), 3,5-diphenyl-4-phenyl-4phosphacyclohexanone $(\mathbf{4 4}, \mathbf{4 5})$ and 4-phenyl-4-phosphacyclohexanone (42) were prepared by literature methods, whereas the isomers of 4-t-butyl-2,6di(carbomethoxy) - 3,5 - bis ( $p$ - dimethylaminophenyl) - 4- phosphacyclohexanone $(\mathbf{5 3}, \mathbf{5 4})$ were synthesised by the reaction of $\mathrm{Bu}^{\mathrm{t}} \mathrm{PH}_{2}$ with 2,4-di(carbomethoxy)1,5-bis( $p$ - dimethylaminophenyl)penta - 1,4 - dien-3 - one (38). The Mannich reactions of phosphorinanones 50 and 51 were not successful, whereas the reactions of 44,45 and 42 produced unidentifiable products. The reaction of phosphorinanone 53 with methylamine and formaldehyde produced the bicyclic PN compound 7-t-butyl-1,5-di(carbomethoxy)-6,8-bis( $p$-dimethylaminophenyl)3 - methyl - 3 - aza - 7 - phosphabicyclo[3.3.1]nonan-9 - one (65). The identical Mannich reaction of phosphorinanone 54 also yielded 65, as well as the PN compound 4-t-butyl-6-carbomethoxy-5-( $p$-dimethylaminophenyl)2-methyl-2-aza-4-phosphacyclohexanone (66) and the $E / Z$ isomers of 3-( $p$-dimethylaminophenyl)methyl-2-propenoate $(\mathbf{6 7})$. 


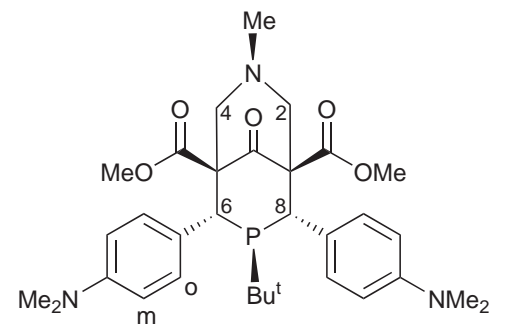

65

The bicyclic PN ligand 65 adopts a chair-chair conformation in solution and the solid state as confirmed by $X$-ray crystallography. The coordination chemistry of this ligand was comprehensively explored with rhodium, palladium and platinum, and a wide range of complexes were synthesised including $\left[\mathrm{ML}_{2}(\mathbf{6 5})\right](\mathrm{M}=\mathrm{Pd}, \mathrm{Pt} ; \mathrm{L}=\mathrm{Cl}, \mathrm{Me}),[\mathrm{ML}(\mathbf{6 5})](\mathrm{M}=\mathrm{Rh}, \mathrm{Pd}, \mathrm{Pt}$; $\mathrm{L}=\mathrm{C}_{2} \mathrm{H}_{4}$, cod, dba, norb $)(\operatorname{cod}=$ cycloocta-1,5-diene, dba $=$ trans,transdibenzylideneacetone, norb $=$ norborn-2-ene $),\left[\operatorname{Pd}\left(\eta^{3}-\mathrm{C}_{3} \mathrm{H}_{5}\right)(\mathbf{6 5})\right] \mathrm{X}(\mathrm{X}=\mathrm{Cl}$, $\left.\mathrm{SbF}_{6}\right)$ and $[\mathrm{PtL}(65)] \mathrm{CH}\left(\mathrm{SO}_{2} \mathrm{CF}_{3}\right)_{2}\left(\mathrm{~L}=1-\sigma, 4-5-\eta-\mathrm{C}_{8} \mathrm{H}_{13}, 1-3-\eta-\mathrm{C}_{8} \mathrm{H}_{13}\right)$.

Cycloplatination at the ortho-position of the 6,8-dimethylaminophenyl substituents was an interesting feature of the coordination chemistry of PN ligand 65. Ortho-metallation at both dimethylaminophenyl groups led to the formation of complex $\left[\mathrm{Pt}\left(\mathrm{C}_{2} \mathrm{H}_{4}\right)(\mathbf{6 5}-2 \mathrm{H})\right](\mathbf{7 6})$, whereas metallation of only one aryl group produced the complex $\left[\mathrm{Pt}\left(\mathrm{C}_{8} \mathrm{H}_{13}\right)(\mathbf{6 5}-\mathrm{H})\right](\mathbf{8 7})$. Further reaction of complex 76 yielded the trans- and cis-hydroxo-bridged dimers $\left[\mathrm{Pt}_{2}(\mu-\mathrm{OH})_{2}(\mathbf{6 5}-\mathrm{H})_{2}\right](\mathbf{9 8}$, 101). The nitrogen donor atom is not coordinated to the platinum metal centres in the cyclometallated PN complexes.

Protonation of $\left[\mathrm{Pt}\left(\mathrm{C}_{2} \mathrm{H}_{4}\right)(\mathbf{6 5})\right]$ (75) with $\mathrm{CH}_{2}\left(\mathrm{SO}_{2} \mathrm{CF}_{3}\right)_{2}$ produced the hydride complex $\left[\mathrm{PtH}\left\{\mathrm{CH}\left(\mathrm{SO}_{2} \mathrm{CF}_{3}\right)_{2}\right\}(\mathbf{6 5})\right]$ (92) and the agostic ethyl complex $\left[\mathrm{Pt}\left(\mathrm{C}_{2} \mathrm{H}_{5}\right)(\mathbf{6 5})\right] \mathrm{CH}\left(\mathrm{SO}_{2} \mathrm{CF}_{3}\right)_{2} \quad(\mathbf{9 3})$. Similarly, protonation of [Pt(norb)(65)] (74) with $\mathrm{CHPh}\left(\mathrm{SO}_{2} \mathrm{CF}_{3}\right)_{2}$ gave the norbornyl agostic complex $\left[\mathrm{Pt}\left(\mathrm{C}_{7} \mathrm{H}_{11}\right)(\mathbf{6 5})\right] \mathrm{CPh}\left(\mathrm{SO}_{2} \mathrm{CF}_{3}\right)_{2}(\mathbf{9 4})$ as confirmed by $X$-ray crystallography. 
In addition, hydrated analogues of some of the coordination complexes of PN ligand 65 mentioned previously were also observed. In such complexes, the central carbonyl group at position 9 was hydrated to form a geminal diol. The hydrated complexes exhibited similar chemical characteristics to their ketone counterparts.

The ${ }^{15} \mathrm{~N}$ NMR chemical shifts of the nitrogen donor atom in PN ligand $\mathbf{6 5}$ and its various metal complexes were obtained from inversely-detected ${ }^{1} \mathrm{H}-{ }^{15} \mathrm{~N}$ HMBC experiments. The NMR data showed no explicit relationship between the coordination mode of the nitrogen group and the ${ }^{15} \mathrm{~N}$ chemical shift. 
Ta my parents:

In laving memary of my father, Ismaeil Zayya Fela. wha instilled in me the loue of learning and taught me to aim high.

And ta my mother, Khaza Keryakas Bahram, the brawest waman? lenour, wha gave me the chance for a necu life. 


\section{Acknowledgments}

The completion of my doctoral studies would not have been possible without the help and support of so many people. First and foremost, I have to thank my supervisor, Prof. John L. Spencer, for his guidance and support throughout the years, and also for my generous $\mathrm{PhD}$ scholarship.

Secondly, I would like to thank the members of my research group, Kathryn, Brad, Sarah, Teresa, and Chris for providing a stimulating and fun environment to work in, for sharing the good times and bad and for being great friends. Special thanks to Kathryn for her meticulous editing of my writing. I also need to thank the past members of the group, Kirsten, Ellie, Ray V. and Ray M., for their help in the lab when I first started my PhD.

Special thanks to Dr. Joanna Wojnar for teaching me so much about NMR and column chromatography, for her interest in my work, for all the helpful questions and suggestions, for her detailed editing of my thesis, and also for being a great friend.

I would like to express my gratitude to the members of the Marine Natural Products group for all their help and support with NMR. Firstly, thank you to Assoc. Prof. Peter Northcote for his trust in my NMR skills. Secondly, thank you to Dr. John Ryan for his tremendous help with NMR and $\mathrm{ATEX}_{\mathrm{E}}$. Thank you to Dr. Wendy Popplewell and Jonathan for answering all my NMR questions and for being good friends.

The general and academic staff of SCPS have been invaluable. Thank you 
to Darren, Liza, Helen, Teresa, Jackie, Allan, Manu, Sally, Gordon, Lisa, Bill, Jenny and Rhys. Also, special thanks to Dr. Jim Pearce, Em. Prof. Brian Halton, Em. Prof. Neil Curtis, Dr. Joanne Harvey, Assoc. Prof. Kate McGrath and Dr. Brendan Burkett for their help throughout the years.

Thank you to Drs. John Beal and Teck Lim for sharing the ups and downs of research and for being good friends. Thank you also to Dr. Matthew Cairns for all his help with $\mathrm{LT}_{\mathrm{E} X}$.

A big thank you to my friend Pascale for her encouragement and support all the way from France.

I would also like to thank my family for their understanding and endless love and support through the duration of my studies. I am eternally grateful to my mother for all her sacrifices and hard work. Thank you to my sister, Nibras, for always believing in me and encouraging me to follow my passion for science. Thank you to my brothers, Aras, Idmon and Ramon, and my brother-in-law, Salem, for their unwavering support. Thank you to my sisters-in-law, Siham and Bella, for always being there for me. Thank you to my nephews, Addison and Ishmael, and my nieces, Kristie and Ashanti, for enriching my life and making me smile. Special thanks to my parents-in-law and the rest of my family-in-law for all their love and support.

Finally, I owe my most sincere gratitude to my husband Sargon. Thank you for your confidence in me. Thank you for all the sacrifices you have made. And most importantly, thank you for your unconditional love, patience and unfailing and unquestioning support. 


\section{Contents}

$\begin{array}{lll}\text { Abstract } & \text { ii }\end{array}$

Dedication $\quad$ v

Acknowledgments vi

Table of Contents viii

List of Figures $\quad x$

List of Key Structures xi

List of Schemes $\quad$ Xv

List of Tables $\quad$ xvii

Glossary $\quad$ xviii

1 Introduction 1

1.1 Coordination complexes . . . . . . . . . . . . . . 1

1.2 Phosphorus-nitrogen ligands . . . . . . . . . . . . . . . 3

1.3 Bispidinone chemistry . . . . . . . . . . . . . . . . . . . . . . . . . . . . . 9

1.4 Bicyclic PN compounds . . . . . . . . . . . . . . . . . . 16

1.5 Research objectives . . . . . . . . . . . . . . . . . . . . . 21

1.6 Concluding remarks . . . . . . . . . . . . . . . . . 21

2 Synthesis of Bidentate Phosphorus-Nitrogen Ligands 22

2.1 Phosphorinanone synthesis . . . . . . . . . . . . . . . 23

2.1.1 4-Phenylphosphorinanone compound . . . . . . . . . 23

2.1.2 3,5-Diphenyl phosphorinanone system . . . . . . . . . . 24

$2.1 .32,6$-Dimethyl phosphorinanone system . . . . . . . . 25

2.1 .4 2,6-Diester phosphorinanone system . . . . . . . . . . . 27

2.2 PN ligand synthesis . . . . . . . . . . . . . . . . . . . 35

2.2.1 4-Phenylphosphorinanone . . . . . . . . . . . 35

$2.2 .2 \quad 3,5$-Diphenyl phosphorinanones . . . . . . . . . . . . . 36

2.2 .32 ,6-Dimethyl phosphorinanones . . . . . . . . . . . 36

$2.2 .42,6$-Diester phosphorinanones . . . . . . . . . . . 40

2.3 Concluding remarks . . . . . . . . . . . . . . . . . . . . . . 48 
3 Transition Metal Complexes of Phosphorus-Nitrogen Ligands 50

3.1 Metal(II) complexes . . . . . . . . . . . . . . . . 50

3.2 Rhodium complexes . . . . . . . . . . . . . . . 60

3.3 Alkene complexes . . . . . . . . . . . . . . . . . . . 63

3.4 Palladium allyl complexes . . . . . . . . . . . . . . . . . . 68

3.5 Metallation reactions . . . . . . . . . . . . . . . . 73

3.6 Protonation reactions . . . . . . . . . . . . . . . . . . . 78

3.7 Hydroxo-bridged platinum complexes . . . . . . . . . . . . . . . . 92

3.8 Bis(phosphorus-nitrogen) ligand complexes . . . . . . . . . . . . . 102

3.9 Ligand hydration . . . . . . . . . . . . . . . . . . . . . . 102

3.10 Coordination chemistry of $\mathrm{PN}$ ligand 66 . . . . . . . . . 103

3.11 Concluding remarks . . . . . . . . . . . . . . . 107

4 Nitrogen NMR Spectroscopy of Transition Metal Complexes 109

4.1 Nitrogen NMR spectroscopy . . . . . . . . . . . . . . . . . . . 109

$4.2{ }^{15} \mathrm{~N}$ NMR of $\mathrm{PN}$ compounds . . . . . . . . . . . . . . . . . . . . 110

$4.3{ }^{15} \mathrm{~N}$ NMR of metal complexes . . . . . . . . . . . . . . . . . . 112

4.4 Concluding remarks . . . . . . . . . . . . . . . . . 115

$\begin{array}{llr}5 & \text { Conclusion } & 116\end{array}$

$\begin{array}{llr}6 & \text { Experimental } & 119\end{array}$

$\begin{array}{lr}\text { Bibliography } & 162\end{array}$ 


\section{List of Figures}

1.1 Possible conformations of bispidinone compounds. . . . . . . . . . 11

1.2 Biologically active bispidinone derivatives. . . . . . . . . . . . . 12

2.1 Different phosphorinanone compounds. . . . . . . . . . . . . . . 23

$2.2{ }^{1} \mathrm{H}$ NMR spectrum of phosphorinanone isomer 54. . . . . . . . . 30

2.3 Coupled HSQC 1D traces for phosphorinanone isomer 54. . . . . 32

2.4 Keto-enol tautomers of piperidinones and thiopyrans. . . . . . . . 35

2.5 Variable temperature ${ }^{1} \mathrm{H}$ NMR spectra of PN compound 65 . . . 43

2.6 ORTEP diagram of PN compound 65 . . . . . . . . . . . . . 43

2.7 Different crystallographic views of PN compound 65 . . . . . . 45

3.1 ORTEP diagram of $\left[\mathrm{PdCl}_{2}(65)\right]$ complex . . . . . . . . . . . 54

3.2 Different crystallographic views of $\left[\mathrm{PdCl}_{2}(65)\right]$ complex . . . . . . 56

3.3 HMBC correlations for the hydrated analogue of $\left[\mathrm{PdCl}_{2}(\mathbf{6 5})\right]$. . . 57

$3.4{ }^{1} \mathrm{H}$ NMR spectra of $\left[\mathrm{PdCl}_{2}(\mathbf{6 5})\right]$ complex . . . . . . . . . . 58

$3.5{ }^{1} \mathrm{H}$ NMR spectra of hydrate form of $\left[\mathrm{Pd}\left(\eta^{3}-\mathrm{C}_{3} \mathrm{H}_{5}\right)(65)\right] \mathrm{Cl} \ldots 72$

$3.6{ }^{1} \mathrm{H}$ NMR spectra of ethene-platinum complexes $\mathbf{7 5}$ and $\mathbf{7 6}$. . . . 75

3.7 Possible structures of complex 93 . . . . . . . . . . . . . . 83

3.8 ORTEP diagrams of norbornyl agostic complexes $\mathbf{9 4}$ and $\mathbf{9 5}$. . . 86

3.9 Crystallographic views of norbornyl agostic complexes $\mathbf{9 4}$ and $\mathbf{9 5} 90$

3.10 ORTEP diagrams of hydroxo-bridged platinum complex 98 . . . 97

3.11 Molecular conformation of hydroxo-bridged platinum complex $\mathbf{9 8} 99$

3.12 Possible metallacycles of PN ligand 66 . . . . . . . . . . . . 104

$4.1{ }^{1} \mathrm{H}-{ }^{15} \mathrm{~N}$ HMBC correlations for PN compound 65 . . . . . . . 111

$4.2{ }^{15} \mathrm{~N}$ NMR chemical shifts of bispidinone compounds. . . . . . . . . 111

$4.3{ }^{1} \mathrm{H}_{-}{ }^{15} \mathrm{~N}$ HMBC correlations for $\left[\mathrm{PtMe}_{2}(65)\right]$ complex . . . . . . . 114 


\section{List of Key Structures}

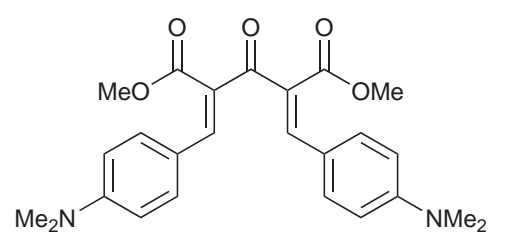

38
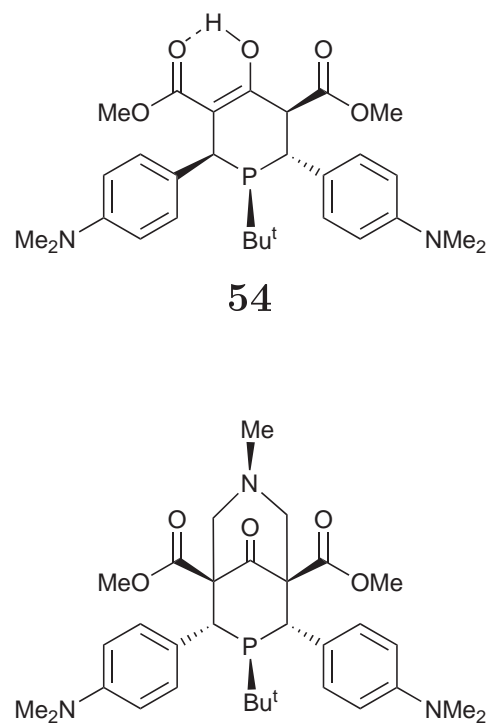

65

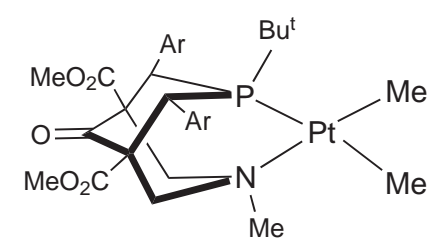

68

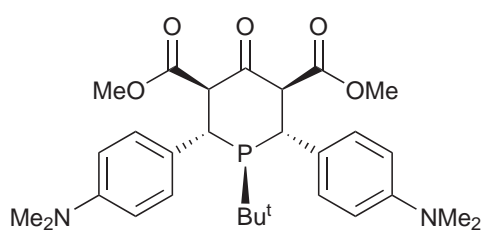

53

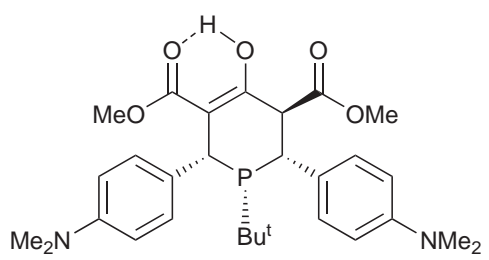

57<smiles></smiles>

66

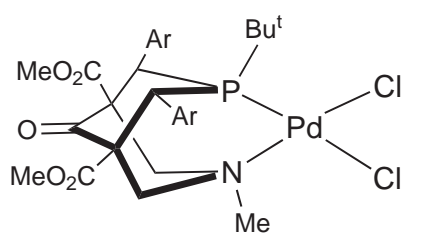

69 


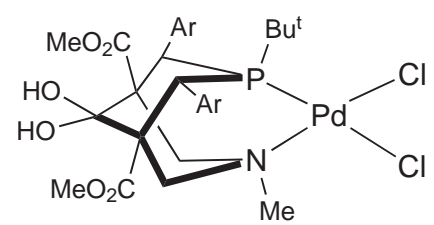

70

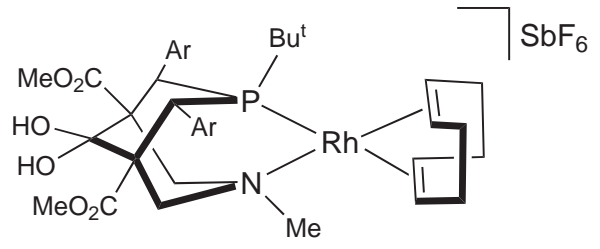

73

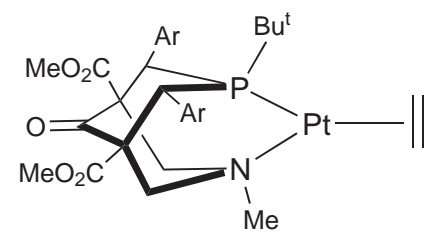

75

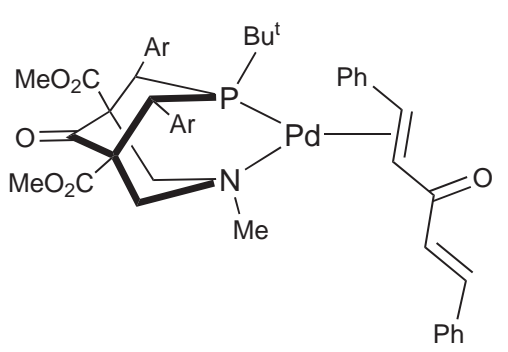

77

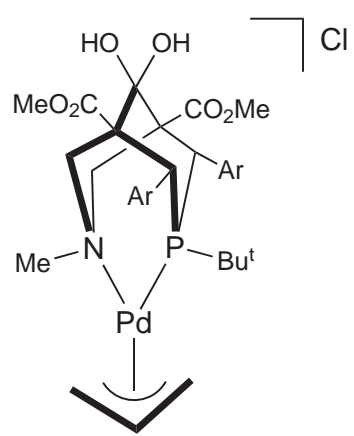

83

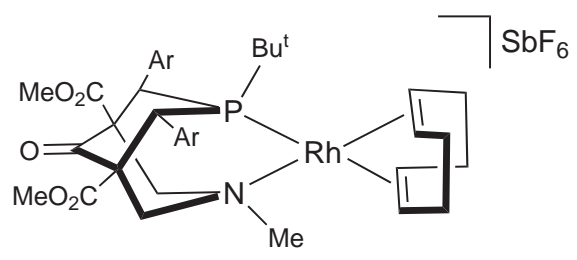

71

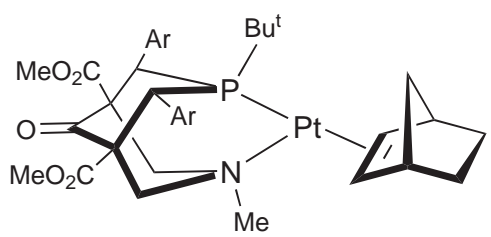

74

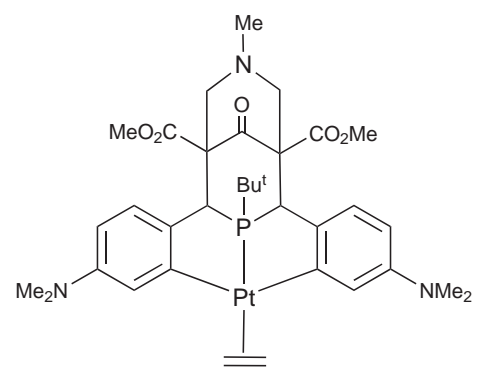

76

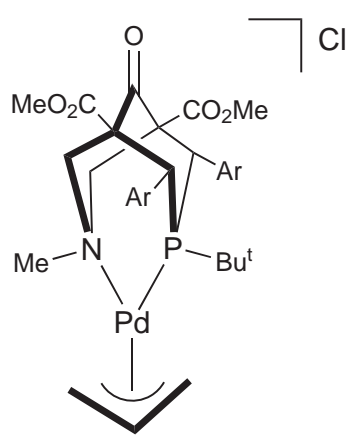

79

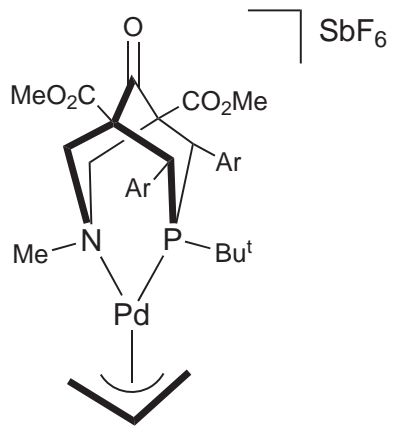

84 


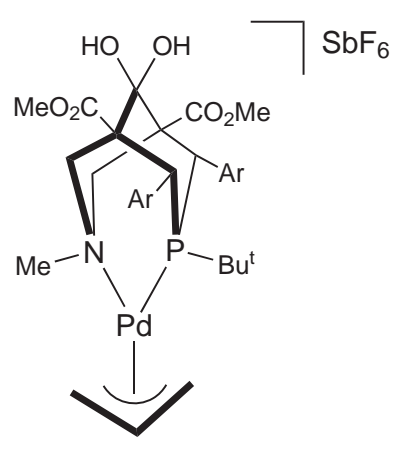

85

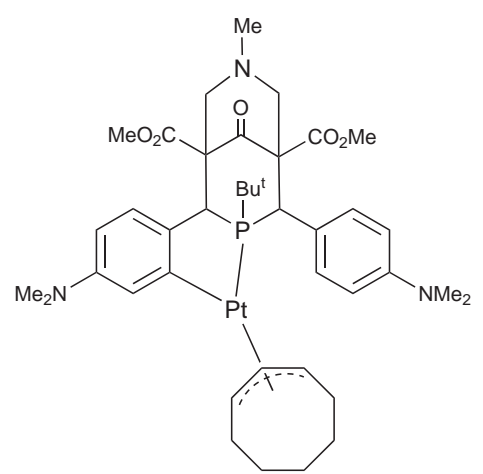

87

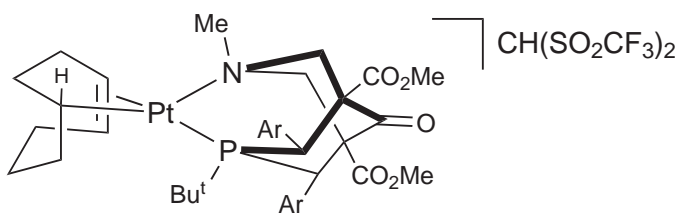

88

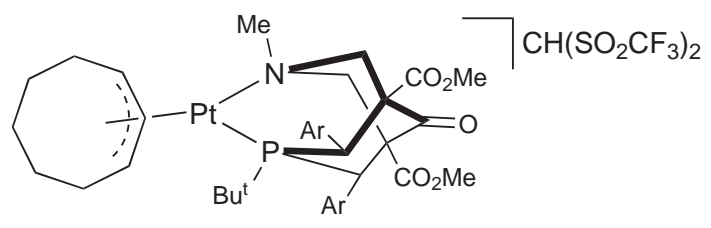

89

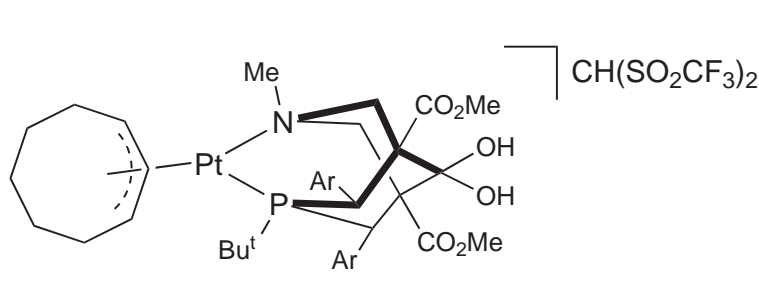

90

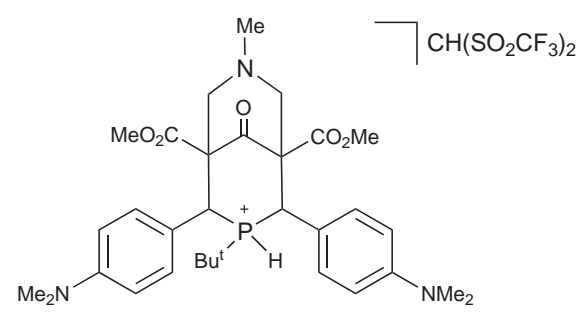

91

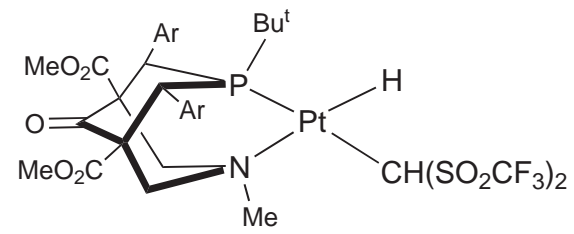

92

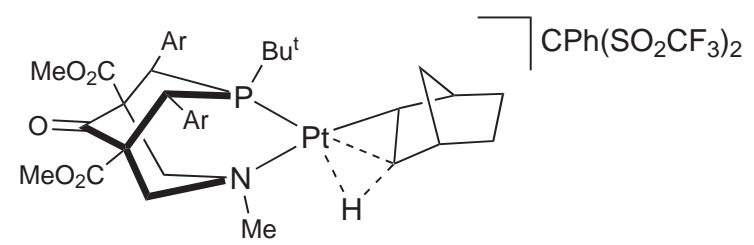

94

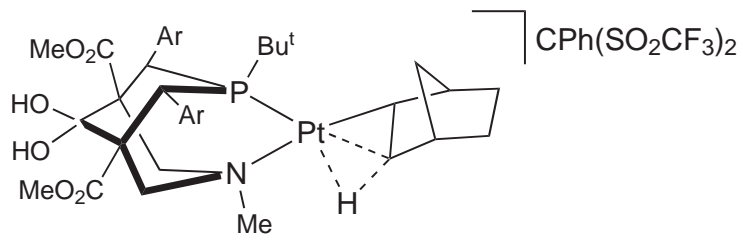




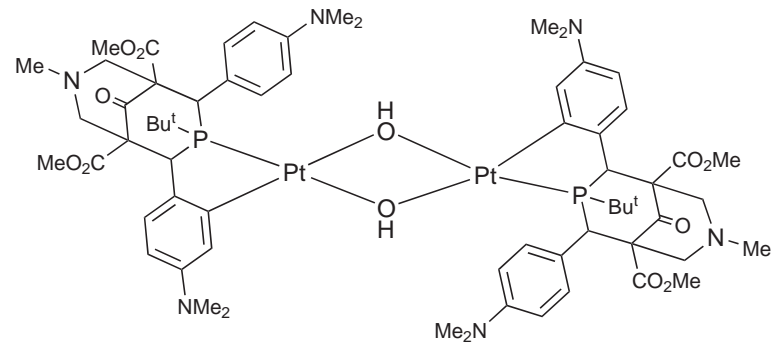

98

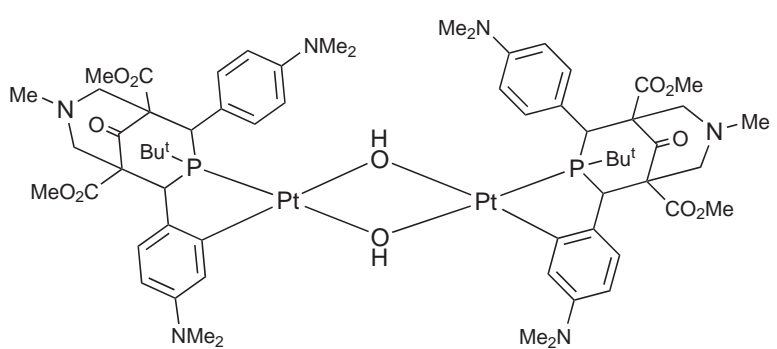

101

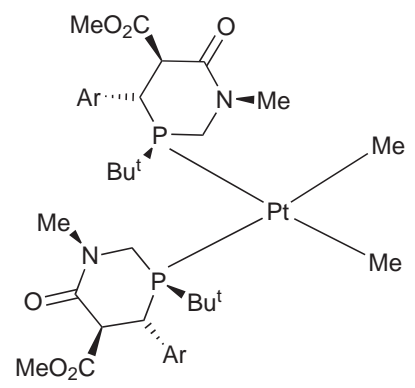

102 


\section{List of Schemes}

1.1 Allylic substitution reaction catalysed by PN ligands . . . . . . . 4

1.2 General behaviour of hemilabile PN ligands . . . . . . . . . . . 5

1.3 Examples of hemilabile PN-metal complexes . . . . . . . . . 5

1.4 Formation of multiple products from a hemilabile PN complex . . 6

1.5 Palladium-PTN complexes . . . . . . . . . . . . . . 8

1.6 The general Mannich reaction . . . . . . . . . . . . . . . 10

1.7 Simplified scheme of the Mannich reaction . . . . . . . . . . . . . 11

1.8 Catalytic aziridination by bispidinone-copper complexes . . . . . . 14

$1.9 \mathrm{C}-\mathrm{H}$ activation by a palladium-bispidinone complex . . . . . . . 15

1.10 General synthetic methodology for 4-phosphorinanones . . . . . . 17

1.11 Diastereoselective complexation of phosphorinanone ligands . . . . 18

1.12 Synthetic method for PN compounds . . . . . . . . . . . . 19

2.1 Synthesis of 4-phenylphosphorinanone . . . . . . . . . . . . . . 24

2.2 Synthesis of 3,5-diphenyl phosphorinanones . . . . . . . . . . . 25

2.3 Synthesis of dba derivative $46 \ldots \ldots$. . . . . . . . . . 26

2.4 Michael reactions of 2,6-dimethyl phosphorinanone system . . . . 27

2.5 Synthesis of 2,6-diester phosphorinanones . . . . . . . . . . . . 28

2.6 Mannich reaction of 4-phenylphosphorinanone . . . . . . . . . . 36

2.7 Mannich reactions of piperidinones . . . . . . . . . . . . . . . . 39

2.8 Synthesis of bicyclic PN compound 65 . . . . . . . . . . . . . . . 42

2.9 Mannich reaction of phosphorinanone isomer $54 \ldots 47$

3.1 Synthesis of $\left[\mathrm{PtMe}_{2}(\mathbf{6 5})\right]$ complex . . . . . . . . . . . . . . . 51

3.2 Synthesis of $\left[\mathrm{PdCl}_{2}(\mathbf{6 5})\right]$ complex . . . . . . . . . . . . . . 53

3.3 Synthesis of $[\mathrm{Rh}(\mathrm{cod})(\mathbf{6 5})] \mathrm{SbF}_{6}$ complex . . . . . . . . . . 61

3.4 Rhodium complexes of PTN . . . . . . . . . . . . . . . 62

3.5 Synthesis of $[\mathrm{Pt}($ norb $)(\mathbf{6 5})]$ complex . . . . . . . . . . . . . 64

3.6 Ethene-platinum complexes of $\mathrm{PN}$ ligand 65 . . . . . . . . . 65

3.7 Synthesis of $[\mathrm{Pd}(\mathrm{dba})(65)]$ complex . . . . . . . . . . . . 65

3.8 Dynamic behaviour of palladium-dba complex $78 \ldots 68$

3.9 Palladium-allyl complexes of PN ligand 65 . . . . . . . . . . . 69

3.10 Palladium-allyl complexes bearing an oxazoline-based PN ligand . 70

3.11 Metallated ethene-platinum complex of PN ligand 65 . . . . . . 74

3.12 COD-platinum complexes of $\mathrm{PN}$ ligand 65 . . . . . . . . . 76

3.13 Intramolecular rearrangement of ethyl agostic complexes . . . . . 84

3.14 Intramolecular rearrangement of norbornyl agostic complexes . . . 91

3.15 Hydrogenation reaction of complex $\left[\mathrm{Pt}\left(\mathrm{C}_{2} \mathrm{H}_{4}\right)(65-2 \mathrm{H})\right] \ldots 93$ 
3.16 Synthesis of hydroxo-bridged platinum complex 98 . . . . . . . 95

3.17 Proposed synthetic pathway for the formation of complex 98 . . . 101

3.18 Synthesis of $\left[\mathrm{PtMe}_{2}(\mathbf{6 6})_{2}\right]$ complex . . . . . . . . . . . . 105

3.19 Synthesis of a 4-membered metallaphosphabicyclic complex . . . . 106 


\section{List of Tables}

$2.1{ }^{1} \mathrm{H}$ NMR data of 2,6-diester phosphorinanones . . . . . . . . . . . 34

$2.2{ }^{13} \mathrm{C}$ NMR data of 2,6 -diester phosphorinanones . . . . . . . . . . . 34

2.3 Mannich reactions of 3,5-diphenyl phosphorinanones . . . . . . . . 37

2.4 Mannich reactions of 2,6-dimethyl phosphorinanones . . . . . . . 38

2.5 Exchange experiments of 2,6-dimethyl phosphorinanone 51 . . . 41

2.6 Selected bond distances and angles for PN compound 65 . . . . . 45

2.7 Crystallographic data for PN compound 65 . . . . . . . . . . 46

3.1 Selected bond distances and angles for $\left[\mathrm{PdCl}_{2}(\mathbf{6 5})\right]$ complex . . . 54

3.2 Crystallographic data for $\left[\mathrm{PdCl}_{2}(65)\right]$ complex . . . . . . . . . . 55

3.3 NMR data of $[\mathrm{Pd}(\mathrm{dba})(\mathbf{6 5})]$ complex and free dba . . . . . . . 66

3.4 Crystallographic data of norbornyl agostic complexes 94 and 95 . 87

3.5 Interatomic distances and angles for norbornyl agostic complexes . 88

3.6 Bond distances of norbornyl agostic complexes $\mathbf{9 4}$ and $\mathbf{9 6}$. . . . . 90

3.7 Crystallographic data of hydroxo-bridged platinum complex 98 . . 98

3.8 Bond distances and angles for complex 98 . . . . . . . . . . . . 99

$4.1{ }^{15} \mathrm{~N}$ NMR chemical shifts of PN-metal complexes . . . . . . . . . . 113 


\section{Glossary}

Ar

p-dimethylaminophenyl $\left(p-\left(\mathrm{Me}_{2} \mathrm{~N}\right) \mathrm{C}_{6} \mathrm{H}_{4}\right)$

COD cycloocta-1,5-diene

dba trans,trans-dibenzylideneacetone

E electrophile

ESI electrospray ionisation

HMBC heteronuclear multiple-bond correlation $\left({ }^{1} \mathrm{H}\right.$ to ${ }^{13} \mathrm{C}$ or ${ }^{15} \mathrm{~N}$ correlations depicted by $\curvearrowright$ )

HRESIMS high resolution electrospray ionisation mass spectrometry

HSQC gradient heteronuclear single-quantum correlation

I $\quad$ spin quantum number (NMR spectroscopy)

$m / z \quad$ mass to charge ratio

norb norborn-2-ene

PN phosphorus-nitrogen (ligand) 


\section{Chapter 1}

\section{Introduction}

This thesis gives an account of my research into the synthesis and coordination of a new class of bicyclic phosphorus-nitrogen (PN) ligands based on the rigid framework of bicyclo[3.3.1]nonan-9-one. The coordination mode of the PN ligands towards rhodium, palladium and platinum metals was specifically explored. NMR spectroscopy was a vital tool in the characterisation of ligands and the resultant metal complexes.

\subsection{Coordination complexes}

The chemistry of coordination complexes is very rich and diverse. It is determined by the nature of the metal and the type of ligands present in the complex. The metal atom may have a number of roles based on its oxidation state, coordination geometry and magnetic and electronic properties. Ligands also have a strong influence on a metal complex. The binding mode of individual ligands, the number of donor atoms and donated electrons, and the electronic and steric properties of ligands are important factors in determining the chemical characteristics of metal complexes. Consequently, understanding the properties of metals and ligands allows the design of metal complexes that are tailored for specific purposes. 
Coordination complexes have a wide range of technological and industrial applications ranging from catalysis ${ }^{1,2}$ to anti-cancer drugs. ${ }^{3}$ Coordination compounds are able to catalyse chemical transformations because of the dramatic change in reactivity of substrate molecules upon coordination to a metal. Highly reactive species can be stabilised to react further in a controlled and productive manner, and the ligands present may exert control on the occurring reactions to achieve selective transformations.

Bidentate ligands are very important in transition metal coordination chemistry. They can act as chelating ligands when both donor atoms are able to bind to the same metal. The distance between and orientation of the donor atoms influence the nature of the interactions between the metal and the ligand. An important parameter of bidentate ligands is the bite angle, ${ }^{4}$ which is defined as the ligand-metal-ligand angle formed when a bidentate ligand coordinates to a metal centre. The magnitude of the bite angle can have a pronounced effect on the rate and selectivity of metal-catalysed reactions.

Complexes with chelating bidentate ligands are thermodynamically more stable than those with an equivalent number of comparable monodentate ligands due to the chelate effect. This is one of the oldest concepts in coordination chemistry and has been successfully explained largely in terms of the entropy change involved in the chelation process. ${ }^{5}$ Once one end of a bidentate ligand is attached to a metal, the second end is in the vicinity of the metal and can bind without all the translational and rotational entropy cost of the first binding interaction. Thus, chelate binding by a bidentate ligand can have a Gibbs energy more than twice that of the monodentate analogue. This results in a considerably stronger chelate binding than in monodentate binding. Another advantage of chelate binding by bidentate ligands is the well-defined geometry of the resulting complex compared with the variable and often unpredictable geometry available in monodentate binding. The well-defined geometry of the metal complex can 
be used to direct chemical reactions and enhance their rates and selectivities.

Bidentate ligands may contain the same type of donor atom such as in bis-phosphine ${ }^{6}$ and bis-nitrogen ${ }^{7,8}$ ligands. These ligands are ubiquitous in coordination chemistry as their metal complexes are reactive in homogeneous catalysis. Bidentate ligands can also have two different donor atoms to produce heterobidentate or hybrid ligands. ${ }^{9}$ A distinguished and highly studied family of hybrid ligands are the phosphorus-nitrogen (PN) chelates. ${ }^{10-12}$

\subsection{Phosphorus-nitrogen ligands}

Phosphorus-nitrogen ligands are excellent chelates for transition metals because they possess many unique characteristics. They are endowed with soft phosphorus and hard nitrogen donor atoms, which results in clearly differentiated coordination sites in the respective trans-positions on the metal. They combine the individual characteristics of bis-phosphine and bis-nitrogen chelating ligands to display a new mode of complexation to transition metals. The -acceptor character of the phosphorus donor atom can stabilise metal centres in low oxidation states, while the $\sigma$-donor ability of the nitrogen donor atom can stabilise electron-poor metals. Many different phosphorus and nitrogen donor moieties have been used for the synthesis of PN ligands. Nitrogen donors include amines, imines, pyridines, amides and nitriles, while the great majority of phosphorus donors are diaryl and dialkylphosphino groups or heteroatom bound phosphorus donors.

Many PN ligands have been reported, making it impossible to comprehensively mention all the different types, therefore only a few examples will be briefly noted here. PN ligands containing the oxazoline unit constitute a very successful ligand class in asymmetric synthesis. ${ }^{11,13}$ The modular structure of these ligands allows extensive variation of the oxazoline ring. They are stable 
towards oxidation and hydrolysis, and are applicable to a wide range of reactions in which high enantioselectivities are obtained. For example, the palladiumcatalysed allylic substitution reaction ${ }^{13-16}$ of 1,3-diphenyl-2-propenylacetate (1) with different nucleophiles affords $\mathbf{2}$ in more than $90 \%$ yield and high enantiomeric excess (Scheme 1.1).

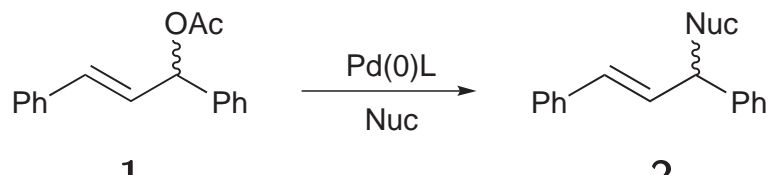

1<smiles>Pc1cccc(C2=NC(P)CO2)c1P</smiles>

$\mathrm{R}=\mathrm{Ph}, \mathrm{Bu}^{\mathrm{t}}, \mathrm{Pr}^{\mathrm{i}}$

\section{Scheme 1.1}

Phosphorus-nitrogen ligands also have the potential to be hemilabile. The concept of ligand hemilability was first introduced by Jeffrey and Rauchfuss ${ }^{17}$ in 1979. It is based on small energy differences, of the order of $50 \mathrm{~kJ} / \mathrm{mol}$, that are involved in the dynamic processes of dissociation and recoordination of the weakly bonding group. The labile group stabilises the reactive transition metal centre in the absence of substrates and provides an additional vacant coordination site as it can be easily displaced by coordinating substrate or solvent molecules. Meanwhile, the inert group anchors the hemilabile ligand to the metal centre. In the case of PN ligands, the substitutionally inert phosphorus moiety maintains the strong coordination to the metal while the nitrogen group binds weakly and therefore is easily displaced by other coordinating ligands or solvent molecules, but remains available for recoordination to the metal centre (Scheme 1.2).

The hemilabile behaviour of PN ligands is the result of either fluxional ligand 


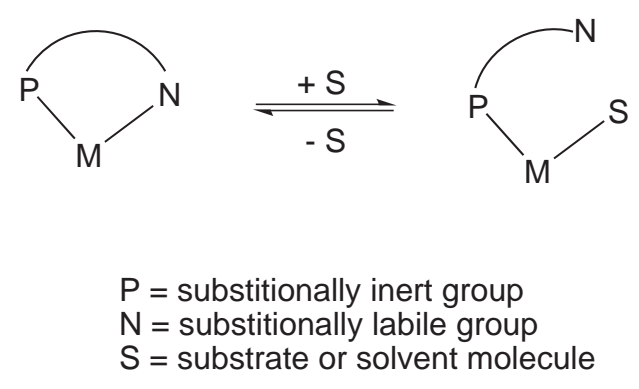

\section{Scheme 1.2}

exchange processes or ligand displacement reactions involving small molecules. For example, complex 3 was observed to undergo a fluxional ligand exchange reaction ${ }^{18}$ of bound and unbound amino groups at room temperature in $\mathrm{CD}_{2} \mathrm{Cl}_{2}$ (Scheme 1.3). On the other hand, upon the reaction of complex 4 with $\mathrm{CO},{ }^{19}$ the pyridine moiety rather than the ether group is displaced due to the strong trans-effect of the triphenylphosphine ligand (Scheme 1.3).
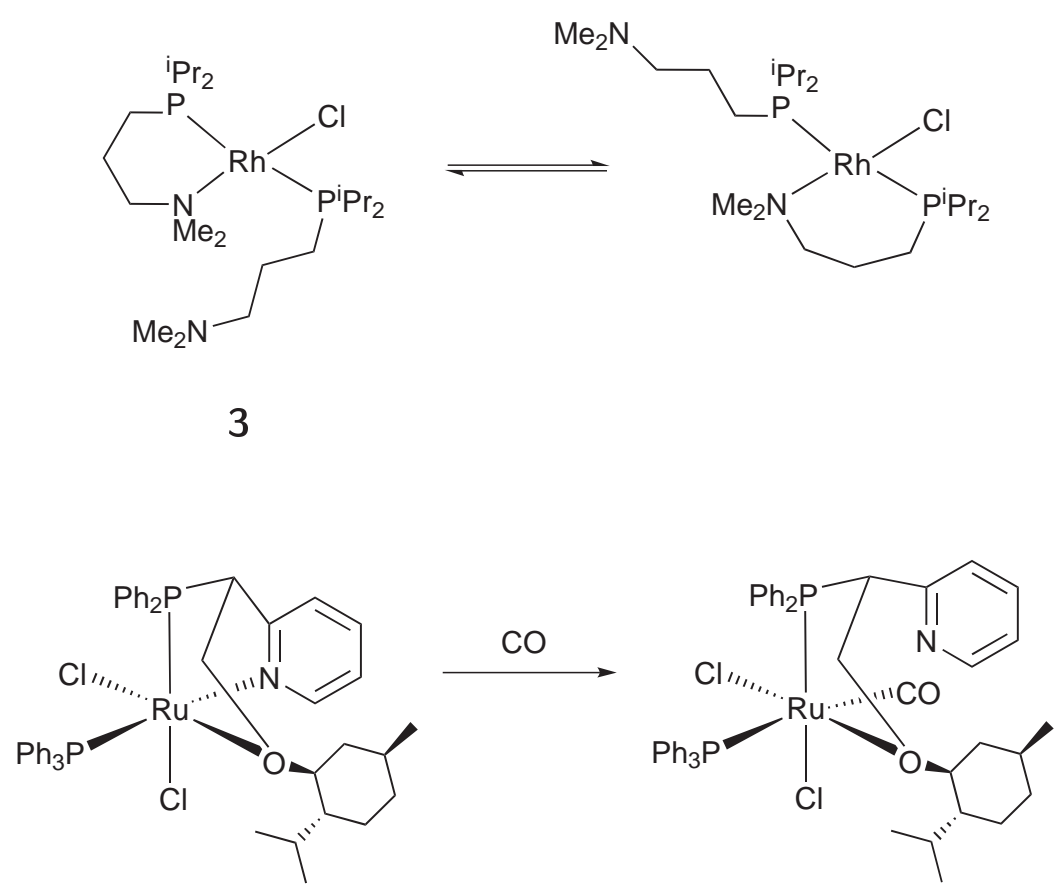

4

Scheme 1.3

In addition, the hemilability of the nitrogen group in PN ligands could 
potentially lead to the formation of unexpected new complexes. For instance, upon the dissociation of the nitrogen arm of PN ligand $\mathbf{5}$ in complex $\mathbf{6}$, the chloro-bridged dimer $\mathbf{7}$ is formed. ${ }^{20}$ The recoordination of the nitrogen arms in $\mathbf{7}$ in turn results in the formation of two more dinuclear derivatives 8 and $\mathbf{9}$ (Scheme 1.4).

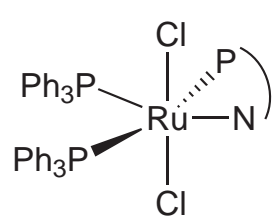<smiles>C[PbH2]</smiles><smiles></smiles>

6

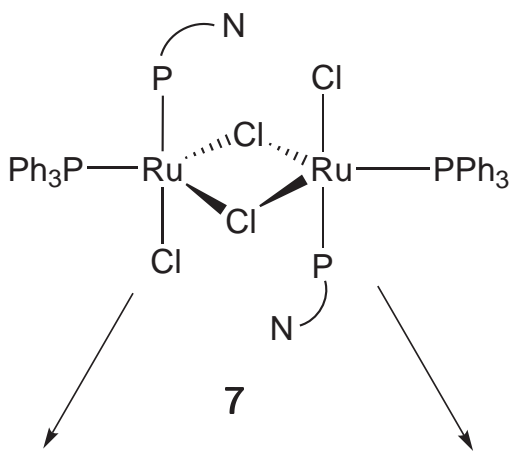<smiles>CCCC</smiles>

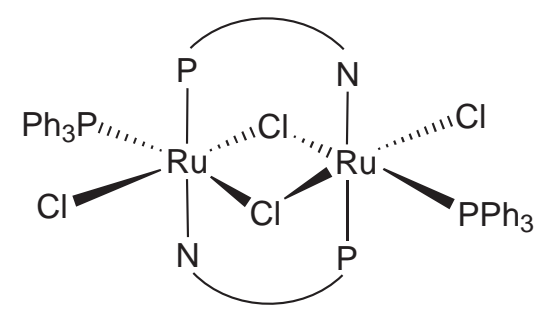

8

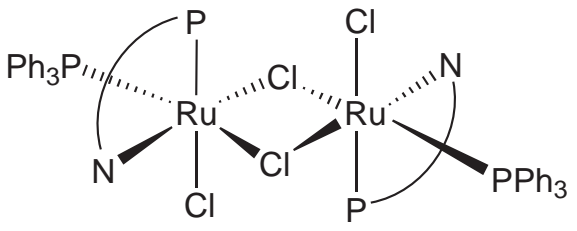

9<smiles>Cn1ccnc1P[Pb]([PH])c1ccccc1</smiles>

5

Scheme 1.4 
An interesting bicyclic PN ligand is the open cage aminophosphine 7-phospha-1,3,5-triazabicyclo[3.3.1]nonane (10), which is known as PTN. ${ }^{21}$ It is derived from the water-soluble phosphine ligand 1,3,5-triaza7-phosphaadamantane (11), which is usually abbreviated as PTA. ${ }^{22}$ PTN has the potential to be used in green aqueous catalytic systems as it is a bidentate hemilabile PN ligand featuring similar stereoelectronic properties and water solubility as PTA.

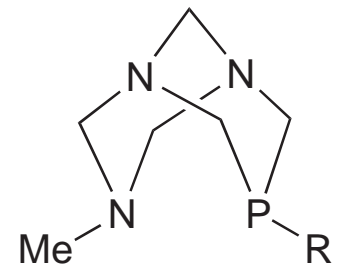

10

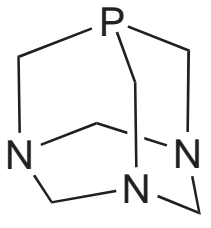

11

The coordination chemistry of the PTN ligand has been explored with a few transition metals including $\mathrm{Mo}, \mathrm{Ru}, \mathrm{Rh}, \mathrm{Os}, \mathrm{Pd}$ and $\mathrm{Au} .{ }^{23-25}$ The PTN ligand can adopt either a mono- or bidentate coordination mode depending on the metal precursor and the reaction conditions. It is also possible to form 2:1 ligand to metal PTN complexes in which either one or both coordination modes are present. For example, complex 12 features two monodentate units of PTN (Scheme 1.5). ${ }^{24}$ Upon chloride abstraction, complex 13 is formed in which monoand bidentate PTN units are observed. Addition of water to 13 results in the formation of complex 14, which suggests hemilabile behaviour of the bidentate PTN unit.

Furthermore, rhodium-PTN complexes such as $\mathbf{1 5}$ have been employed in homogeneous catalysis in biphasic organic/water solvent systems. ${ }^{23}$ The complexes had comparable results to analogous rhodium-PTA compounds in olefin hydroformylation reactions, and similar activities as other aminophosphine rhodium catalysts in transfer hydrogenation tests. Moreover, the anti-cancer 


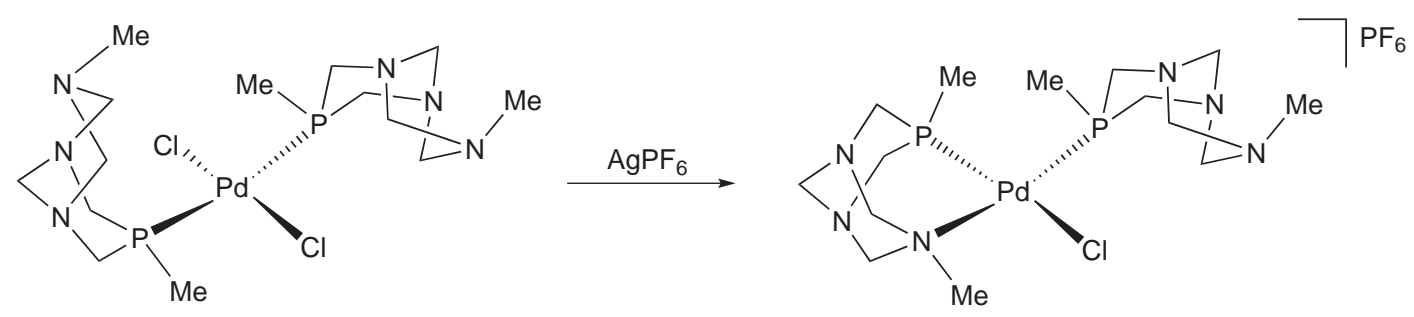

12

13

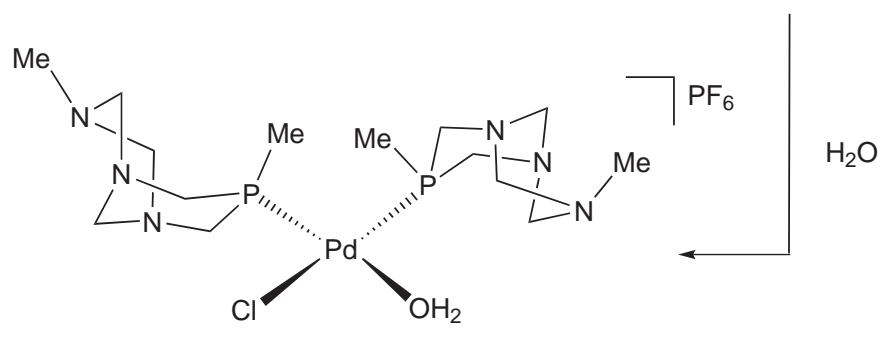

14

Scheme 1.5

activity of ruthenium (16) and osmium (17) PTN compounds was evaluated and contrasted with PTA complexes in order to study the effect of forming a PN chelate complex without significantly altering the water solubility and acidbase properties of the resulting complexes. ${ }^{25}$ Metal-based drugs can either react with proteins, such as ubiquitin, or bind to DNA bases. Osmium complexes showed no or very low reactivity toward both proteins and DNA. The rutheniumPTN compounds showed comparable reactivity toward ubiquitin as their PTA analogues, but a much lower reactivity toward DNA.

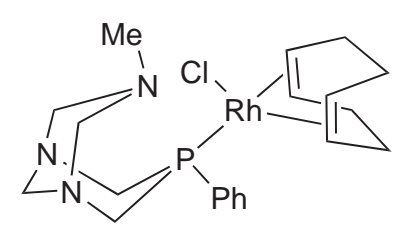

15

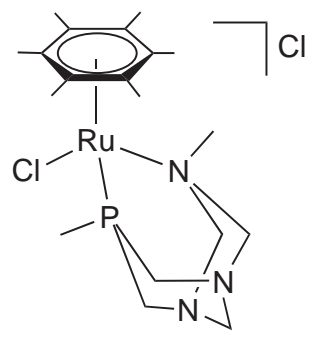

16

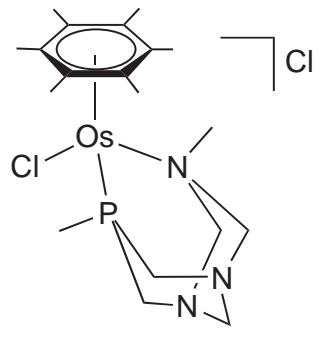

17 
In addition to all the advantageous properties of phosphorus-nitrogen ligands, their study is assisted by NMR spectroscopy. As the ${ }^{31} \mathrm{P}$ nuclide is NMR active, its effect on the proton and carbon nuclei present in a molecule are reflected in the ${ }^{1} \mathrm{H}$ and ${ }^{13} \mathrm{C}$ NMR spectra respectively. Detailed structural and bonding information can also be obtained from the ${ }^{31} \mathrm{P}-{ }^{1} \mathrm{H}$ and ${ }^{31} \mathrm{P}-{ }^{13} \mathrm{C}$ coupling constants. Moreover, the ${ }^{31} \mathrm{P}$ NMR spectrum is very important and useful as any chemical changes around the phosphorus atom will be reflected in the ${ }^{31} \mathrm{P}$ NMR chemical shift. On the other hand, valuable information about the nitrogen chemical environment can be acquired from ${ }^{15} \mathrm{~N}$ NMR spectroscopy. This is an insensitive technique and samples generally need to be enriched with the NMR active ${ }^{15} \mathrm{~N}$ nuclide. Inversely-detected ${ }^{1} \mathrm{H}-{ }^{15} \mathrm{~N} 2 \mathrm{D}$ NMR experiments present an opportunity to analyse normal NMR samples to obtain the ${ }^{15} \mathrm{~N}$ chemical shifts of different compounds containing the same PN ligand. Analogous to the ${ }^{1} \mathrm{H}-{ }^{13} \mathrm{C}$ correlations, the ${ }^{1} \mathrm{H}-{ }^{15} \mathrm{~N}$ correlations can provide further insight into the nitrogen bonding environment.

\subsection{Bispidinone chemistry}

A prominent group of compounds containing the bicyclo[3.3.1]nonan-9-one framework are the bispidinones. These are bis-nitrogen chelating ligands upon which the target phosphorus-nitrogen ligands discussed in this thesis are modelled.

\section{Synthesis and conformation}

Bispidinone compounds were first reported by Mannich and Mohs in $1930 .{ }^{26}$ They contain the rigid diazaadamantane-based framework found in the natural product sparteine (18), but with a carbonyl group at the bridge head position (19). 


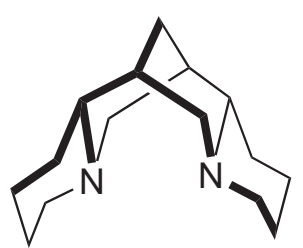

18

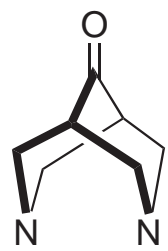

19

In general, bispidinone compounds can be easily prepared by the Mannich condensation reaction (Scheme 1.6). ${ }^{27,28}$ The reaction of a ketone with acidic $\mathrm{C}-\mathrm{H}$ protons, an aldehyde and a primary amine in the ratio of 1:2:1 in a protic solvent leads to a piperidinone (20). ${ }^{29}$ This intermediate can either be isolated or condensed further with two equivalents of an aldehyde and one equivalent of a primary amine to produce diazabicyclo[3.3.1]nonan-9-one (21). In total, four Mannich condensations are required to yield the final bispidinone.

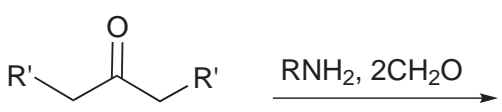<smiles>[R]C1CN([R])CC([R])C1=O</smiles>

20<smiles>[R]N1CC2([R])CN([R])CC([R])(C1)C2=O</smiles>

21

\section{Scheme 1.6}

The mechanism ${ }^{28,30}$ of the Mannich reaction consists of a complex series of equilibria controlled by the nature of the reactants and the reaction conditions. A simplified mechanism is given in Scheme 1.7. The accepted mechanism proceeds via the formation of an iminium ion (22) formed in small amounts in situ by the attack of the amine on the aldehyde. This then reacts with the enol tautomer of the ketone $\mathbf{2 3}$, also present in small concentrations, to give the hydrochloride salt of the -aminocarbonyl compound $\mathbf{2 4}$. To produce cyclic products, primary amines are used which can undergo two Mannich reactions 
to first yield a secondary amine then a tertiary amine and form the cyclic end product. The substitution pattern around the bicyclic bispidinone framework is variable to a large extent. Different amines, aldehydes and ketones have been employed to synthesise a wide range of bispidinone compounds. ${ }^{27,31-34}$

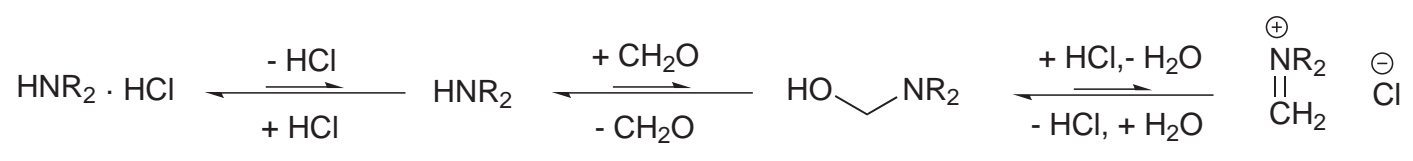<smiles>[R7]C=C(O)C[R]CC#CCPCC(=O)C[R]</smiles>

23

22<smiles>NCC(P)C(=O)CBr</smiles>

24

\section{Scheme 1.7}

Bispidinone compounds can theoretically exist in any of the three conformations depicted in Figure 1.1. The chair-chair (cc), chair-boat (cb) and boat-boat (bb) conformations are stable and free from angular strain. The most stable geometry is the chair-chair conformation, however depending on the size and nature of the substituents, the chair-boat conformation has also been observed in solution. The boat-boat conformation has not been observed, probably due to steric hindrance.

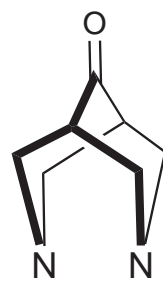

CC

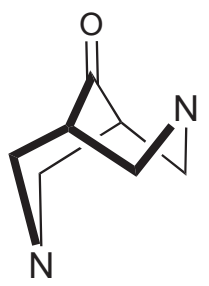

$\mathrm{cb}$

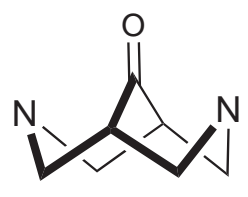

bb

Figure 1.1. Possible conformations of bispidinone compounds. 


\section{Medical and chemical applications}

Some bispidinone derivatives were found to possess useful biological activities. ${ }^{27}$ A series of 3,7-diazabicyclo[3.3.1]nonan-9-ones were reported to have analgesic properties as they displayed selective affinity for the opioid receptors. ${ }^{35-38}$ One of the most studied compounds is HZ2 (Figure 1.2), which exhibited strong antinociceptive characteristics with a potency comparable to morphine. ${ }^{36}$ Other sulfur ${ }^{39}$ and selenium ${ }^{40}$ derivatives containing the bispidinone bicyclic backbone possessed good antiarrhythmic potencies but were also found to be quite toxic (Figure 1.2).<smiles>COC(=O)C12CCN(C(C)=O)CC1(C(=O)OC)C(c1ccccn1)N(C)C2c1ccccn1</smiles>

HZ2<smiles>CPCN1CC2CCSCC(C1)C2=O</smiles><smiles>O=C1C2C[Se]CC1CN(P)C2</smiles>

Figure 1.2. Biologically active bispidinone derivatives.

The coordination chemistry of bispidinone compounds has been extensively explored. ${ }^{33}$ The rigid and highly preorganised bispidinone ligands form very stable metal complexes in which they adopt the chair-chair conformation $(\mathbf{2 5})$.

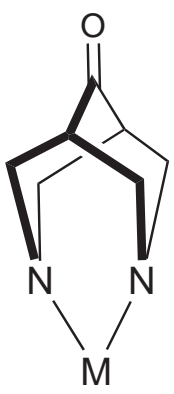


The rigidity of the bispidinone ligands in the metal complexes is measured by the distance between the two nitrogen donor atoms. The distance range is 2.7-3.0 $\AA$, but on average it is $2.9 \AA$. It is very similar for free and coordinated bispidinone ligands and is practically constant in most metal complexes. This shows that the ligand structure does not change significantly upon metal coordination, hence the degree of ligand preorganisation is transferred onto the resultant metal complexes. Furthermore, the size of the ligand cavity can be finely tuned by the nitrogen substituents, such that sterically demanding groups result in slightly longer $\mathrm{N}-\mathrm{N}$ distances.

A large variation in the bond distances from the metal centres to the two nitrogen donor atoms is observed, but the individual bond lengths are generally in the expected ranges for the respective metal ions. This results in considerable elasticity in the coordination sphere of the rigid bispidinone ligands, thus metal ions of quite different sizes can fit into the ligand cavity without inducing much steric strain. ${ }^{33}$ In addition, due to their fairly easy synthesis and the wide range of reactants that could be employed, bispidinone compounds can be designed and synthesised with substituents that occupy the space above and below the metal coordination plane to provide further metal protection and lead to stable metal complexes. Also, a series of related metal complexes can be readily prepared to investigate substituent effects on the stability of the metal complexes and to tune their chemical and physical properties.

Numerous bispidinone metal complexes have been reported with first row transition metals and palladium and platinum. Complexes of alkali and heavier transition metal ions as well as lanthanides have also been described but not structurally characterised. ${ }^{33}$ Iron and copper bispidinone coordination chemistry has been of particular interest in catalysis and biomimetics. Tetradentate bispidinone derivatives such as $\mathbf{2 6}$ provide a rigid backbone and enforce cisoctahedral or square pyramidal coordination geometries. ${ }^{41,42}$ Copper complexes 
of the type $[\mathrm{CuCl}(\mathbf{2 6})]$ are active in the synthesis of aziridines (Scheme 1.8), the nitrogen analogues of epoxides. ${ }^{43}$ Furthermore, bispidinone-copper complexes have been used as models to study electron transfer and dioxygen activation in copper proteins, ${ }^{44,45}$ while iron complexes containing similar tetradentate bispidinone ligands have been investigated as catalysts for the oxidation of hydrocarbons by hydrogen peroxide as high-valent iron oxidants are known to be catalytically active species in heme enzymes. ${ }^{46,47}$

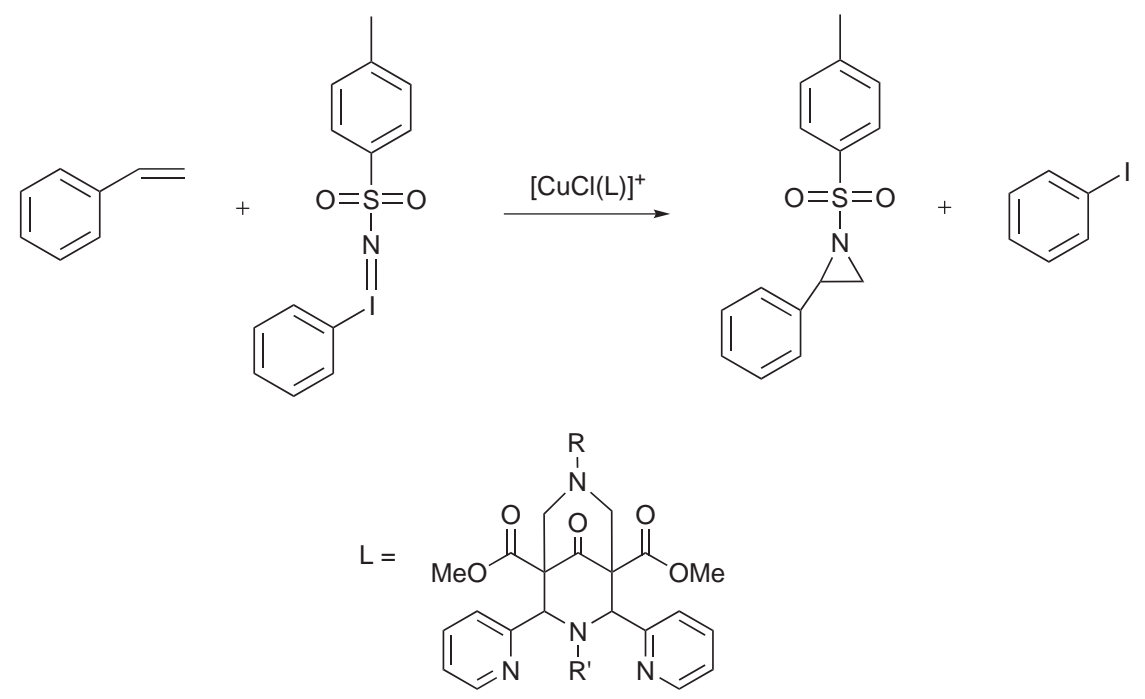

26

Scheme 1.8

Few reports concerning bispidinone complexes of palladium and platinum metals have been published. The complexes were prepared easily through general ligand displacement reactions using appropriate metal precursors. These include dihalide complexes ${ }^{31,48}$ of general structure $\mathbf{2 7}$, as well as palladium allyl complexes, which were synthesised to study the dynamic behaviour of the allyl system. ${ }^{32,48-50}$

In addition, Shen ${ }^{51}$ reported the synthesis of some bispidinone complexes for the purpose of $\mathrm{C}-\mathrm{H}$ activation of small molecules. For example, the palladium dichloro complex 28 promoted $\mathrm{C}-\mathrm{H}$ activation of $\mathrm{CH}_{2} \mathrm{Cl}_{2}$ (Scheme 1.9). In 


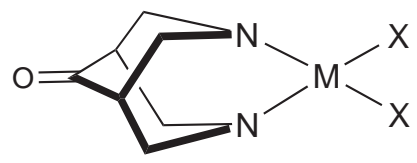

27

contrast, the platinum analogues showed no potential in small molecule $\mathrm{C}-\mathrm{H}$ activation.

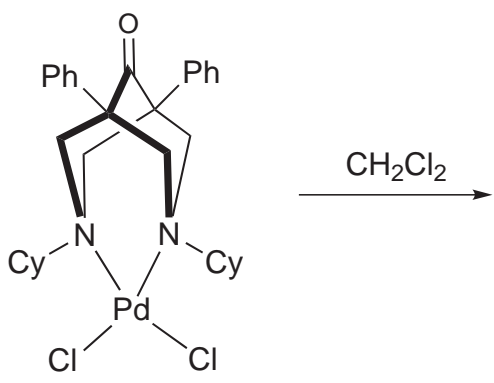

28

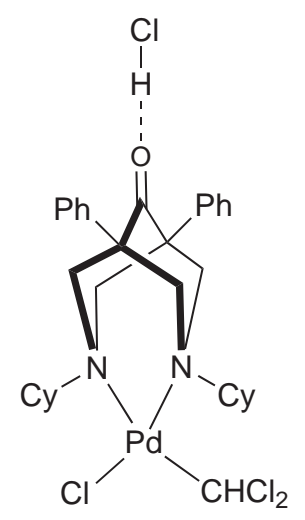

Scheme 1.9

\section{Bispidinone derivatives}

Replacement of one of the nitrogen atoms in bispidinone compounds with a heteroatom leads to 3 -aza-7-heterobicyclo[3.3.1]nonan-9-ones. ${ }^{27,52}$ Oxygen, ${ }^{53}$ sulfur ${ }^{39,54}$ and selenium ${ }^{40}$ analogues have been prepared by the Mannich reaction starting from the respective 4-heterocyclohexanones. These bispidinone analogues were used for conformational studies and were tested for potential biological activity. Furthermore, modifications of the central ketone group in bispidinones can result in additional analogues. ${ }^{33}$ Wolff-Kishner reduction of the carbonyl group leads to the corresponding bispidines (29), while reduction of bispidinones with $\mathrm{LiAlH}_{4}$ or $\mathrm{NaBH}_{4}$ yields bispidoles (30). The reduction procedures are also applicable to the bispidinone analogues. 


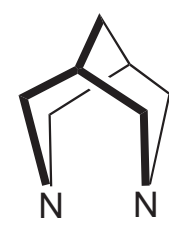

29

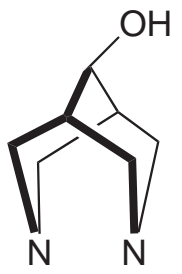

30

\subsection{Bicyclic PN compounds}

\section{Phosphorinanones}

Phosphorus-nitrogen compounds containing the bicyclic bispidinone framework are the synthetic targets for this research project. The bispidinone synthetic method is not chemically viable to prepare the analogous PN compounds because there is no equivalent for the iminium ion in phosphorus chemistry due to the weakness of $\mathrm{P}=\mathrm{C}$ bonds. Thus, a different route must be developed to obtain the 3-aza-7-phosphabicyclo[3.3.1]nonan-9-ones (31).

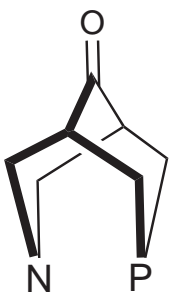

31

The Mannich reaction used to construct the bispidinone compounds yields a piperidinone as an intermediate which can undergo two further Mannich condensations to produce the bicyclic end product. The phosphorus analogues of the piperidinones (32 and 33), known as 4-phosphorinanones, could potentially be used to synthesise the target bicyclic PN compounds.

Phosphorinanones were first reported by Welcher, Johnson and Wystrach $^{55}$ in 1960. They were prepared by the Thorpe-type cyclisation 
of bis(2-cyanoethyl)phosphine $\mathbf{3 4}$ (Scheme 1.10) to give the simple phosphorinanone 32. An improved synthetic methodology was later reported by Welcher and Day ${ }^{56}$ in 1962 in which a primary phosphine was added to a conjugated dienone (35) to produce the substituted phosphorinanone 33 (Scheme 1.10). As can be seen from the reaction scheme, changing the phosphorus substituent as well as using more elaborate dienone derivatives would result in different phosphorinanone compounds.
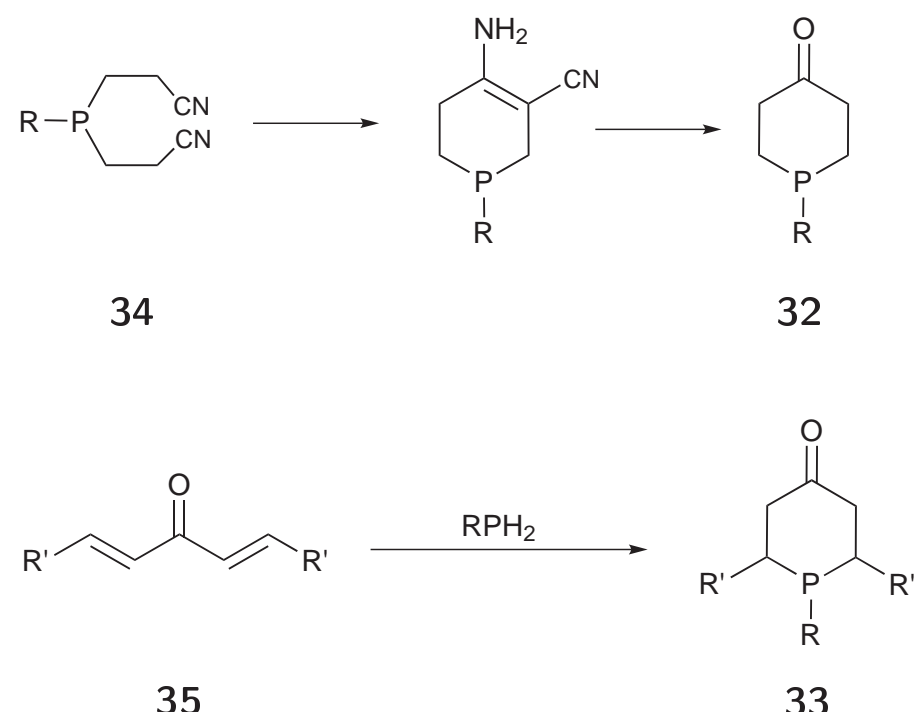

Scheme 1.10

Most of the published work on phosphorinanone compounds has primarily been concerned with ring conformational analysis. ${ }^{57-61}$ Specifically, the studies investigated the configurational preferences of the phosphorus substituents and those located around the heterocyclic ring. It was found that a phenyl group on phosphorus would normally occupy an axial position, but upon oxidation and sulfurisation, the $\mathrm{P}-\mathrm{Ph}$ bond became equatorial. This was attributed to the presence of a minor equatorial conformer in solution. Phosphorinanone conformations also ranged from a perfect chair to a twist-boat depending on the nature and number of substituents.

The palladium and platinum coordination chemistry of phosphorinanones 
was explored by Pringle and co-workers. ${ }^{61}$ They reported diastereoselective complexation of the rac-form of ligand 36 over the meso-form (Scheme 1.11). This was explained by the accessibility of the phosphorus electron lone pair being hindered in the meso-form because of the cis-phenyl substituents.

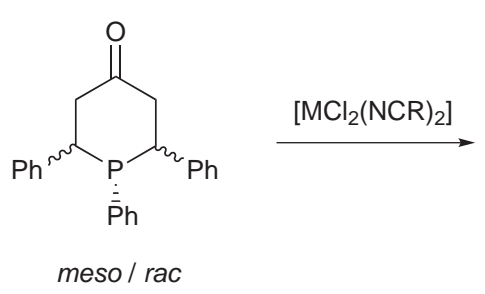

36

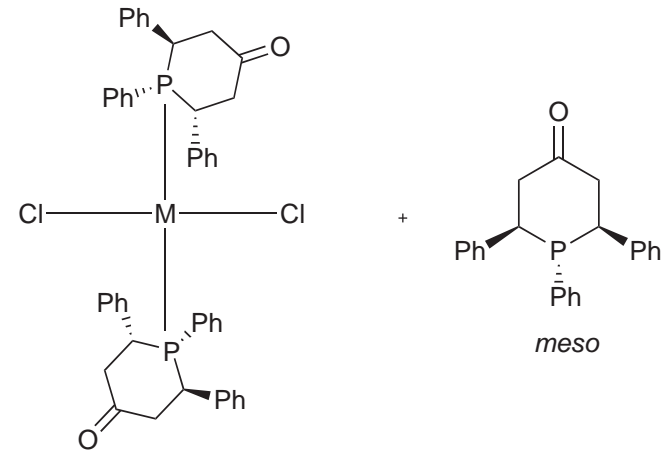

Scheme 1.11

\section{Synthetic methodology of PN compounds}

Until recently, bispidinone derivatives containing phosphorus and nitrogen as the donor atoms were not known. The first example of a 3-aza-7-phosphabicyclo[3.3.1]nonan-9-one compound (37) was prepared by Vagana $^{48}$ in 2005 as shown in Scheme 1.12. The first step required a Michael addition reaction between dienone derivative 38 and phenylphosphine to produce phosphorinanone 39. This intermediate was then subjected to two Mannich condensation reactions in the second step with two equivalents of formaldehyde and one equivalent of a primary amine to yield the bicyclic PN compound. Different primary amines were used in the synthesis and it was found that steric bulk at the nitrogen donor atom had no influence on the rate and yield of the Mannich reaction. The new PN compounds favoured the twin-chair conformation both in solution and the solid state, and there was no evidence for the presence of other conformers.

The coordination chemistry of the new 3-aza-7-phosphabicyclo[3.3.1]nonan- 
<smiles>COC(=O)C(=Cc1ccc(N(C)C)cc1)C(=O)C(=Cc1ccc(N(C)C)cc1)C(=O)OC</smiles>

38<smiles>COC(=O)C1C(=O)C(C(=O)OC)P(c2ccccc2)C(c2ccc(N(C)C)cc2)C1c1ccc(N(C)C)cc1</smiles>

39

39

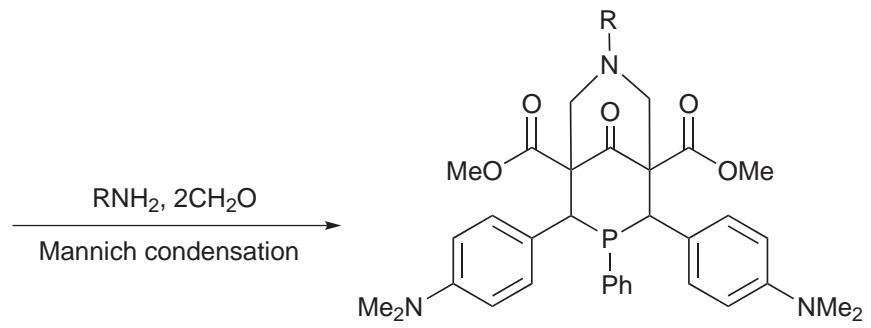

37

\section{Scheme 1.12}

9-ones was very briefly explored by Vagana. ${ }^{48}$ Dimethylplatinum and dichloropalladium complexes (40) were prepared in moderate yields in which the PN ligands were bound via both donor atoms.

In addition, a gold(I) complex (41) was synthesised by Lim and co-workers, ${ }^{62}$ where the PN ligand was monodentate as it was bound through the phosphorus atom only. This was not surprising as $\mathrm{Au}(\mathrm{I})$ is a soft Lewis acid, hence preferring to bind to soft donor atoms such as phosphorus.

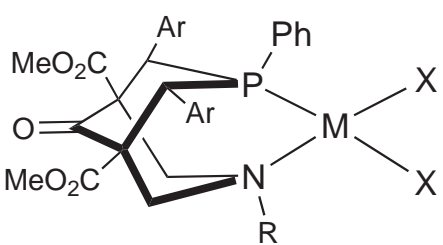

40

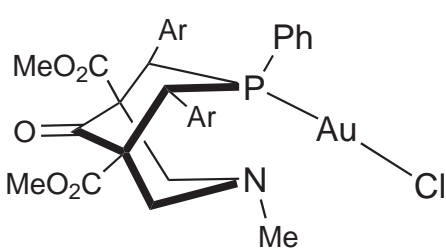

41

$$
\begin{aligned}
& \mathrm{M}=\mathrm{Pd}, \mathrm{Pt} \\
& \mathrm{X}=\mathrm{Me}, \mathrm{Cl} \\
& \mathrm{R}=\mathrm{Me}, \mathrm{Et}, \mathrm{Bu}^{\mathrm{i}} \\
& \mathrm{Ar}=p-\left(\mathrm{Me}_{2} \mathrm{~N}\right) \mathrm{C}_{6} \mathrm{H}_{4}
\end{aligned}
$$




\section{3-Aza-7-phosphabicyclo[3.3.1]nonan-9-ones}

Phosphorus-nitrogen compounds based on the bispidinone backbone are attractive synthetic targets as heterobidentate ligands for transition metals. The presence of both phosphorus and nitrogen donor atoms ensures great complex stability for various metal oxidation states. The different characteristics of the donor atoms, nitrogen being a hard centre while phosphorus is soft, and their contrasting trans-influences will induce electronic differentiation on the metal centre and the respective trans-positions. Moreover, it is feasible for the nitrogen group to be hemilabile as the hard ends are weakly coordinated to soft metal centres and can be easily dissociated in solution. This provides a vacant coordination site on the metal whenever demanded, but the reversible binding of the nitrogen group confers stability to the metal centre in the absence of substrate.

In addition, the rigid bicyclo[3.3.1]nonan-9-one framework is expected to provide extra stability to resultant metal complexes due to its high degree of preorganisation and complementarity. Metal ions of different sizes can fit into the ligand cavity without inducing much steric strain in the ligand. This is attributed to the elasticity of the ligand coordination sphere where the structure of the ligand backbone remains constant while the metal donor bonds vary in the expected ranges. Furthermore, the potential for substitution around the heterobicyclic ring presents the opportunity to design PN ligands with bulky substituents that could provide out-of-plane protection to the metal centre. The rigid framework can also enforce certain coordination geometries that can stabilise unusual electronic structures of transition metal complexes. Therefore, incorporation of phosphorus and nitrogen donor atoms in the bicyclic bispidinone framework should lead to stable metal complexes with interesting properties. 


\subsection{Research objectives}

The aims of this project are to design and synthesise a new class of bicyclic phosphorus-nitrogen ligands based on the bicyclo[3.3.1]nonan-9-one framework, and to explore extensively their coordination chemistry with rhodium, palladium

and platinum. PN compounds with different substitution patterns around the bicyclic backbone will be prepared to compile a ligand library from which general conclusions will be drawn about this novel class of PN ligands. Finally, the binding mode and the hemilability potential of the nitrogen group will be studied by ${ }^{15} \mathrm{~N}$ NMR spectroscopy.

\subsection{Concluding remarks}

Phosphorus-nitrogen ligands are very important in coordination chemistry. Their aptitude to display hemilabile behaviour in the coordination sphere of a metal complex and the electronic differentiation imposed by the different donor atoms renders their metal complexes potentially useful in a wide range of chemical applications. PN compounds containing the bicyclo[3.3.1]nonan-9-one backbone are expected to be rigid and highly preorganised. The combination of this advantageous framework with the different properties of phosphorus and nitrogen donor atoms is anticipated to produce excellent chelating ligands for rhodium, palladium and platinum metals. 


\section{Chapter 2}

\section{Synthesis of Bidentate}

\section{Phosphorus-Nitrogen Ligands}

Phosphorus-nitrogen (PN) compounds containing the bicyclo[3.3.1]nonan-9-one organic framework are attractive synthetic targets as ligands for transition metal complexes. The combination of the rigid bicyclic backbone and the different features associated with each donor atom is expected to provide unique reactivity to the resultant metal complexes. The synthetic methodology of such PN ligands consists of two steps: first a Michael addition reaction between an , unsaturated carbonyl compound and an aryl- or alkylphosphine (or a derivative) to produce a phosphorinanone intermediate, which is then combined with an aldehyde and a primary amine in the Mannich condensation reaction to give the bicyclic PN compound.

Four different phosphorinanone classes (Figure 2.1) were employed in the synthesis of the phosphorus-nitrogen ligands. The six-membered phosphorinanone rings varied in the substituents at the 2,6- and 3,5-positions with respect to the carbonyl moiety as well as different groups on the phosphorus atom. The Mannich reaction was attempted with each phosphorinanone class to produce PN compounds with different substitution patterns around the bicyclic framework. 


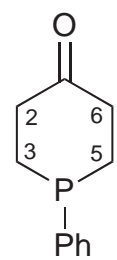<smiles>O=C1CC(c2ccccc2)P(c2ccccc2)C(c2ccccc2)C1</smiles><smiles>CC1C(=O)C(C)C(c2ccccc2)P(c2ccccc2)C1c1ccccc1</smiles><smiles>COC(=O)C1C(=O)C(C(C)=O)C(c2ccc(N(C)C)cc2)P(Cc2ccccc2)C1c1ccc(N(C)C)cc1</smiles>

Figure 2.1. Different phosphorinanone compounds.

\subsection{Phosphorinanone synthesis}

The Michael addition reaction was used to prepare most of the phosphorinanone compounds employed in the synthesis of the bicyclic PN ligands. This reaction involves the addition of a nucleophile to the -position of a double bond of an , -unsaturated carbonyl group. ${ }^{63}$ The phospha-Michael (P-Michael) reaction, i.e. the addition of a phosphorus nucleophile to the , -unsaturated carbonyl compound, represents one of the most important tools for the formation of $\mathrm{P}-\mathrm{C}$ bonds. ${ }^{64}$ In this section, aryl- and alkylphosphine nucleophiles or their derivatives were used in the $P$-Michael additions. In such reactions, the phosphorus nucleophile undergoes two sequential Michael additions - first inter- and then intramolecularly - to form the six-membered phosphorinanone compounds.

\subsubsection{4-Phenylphosphorinanone compound}

At the outset, the simple unsubstituted 4-phenylphosphorinanone (42) was prepared by a known literature route ${ }^{65}$ as shown in Scheme 2.1. The P-Michael reaction was not used in this case because of the synthetic and handling problems 


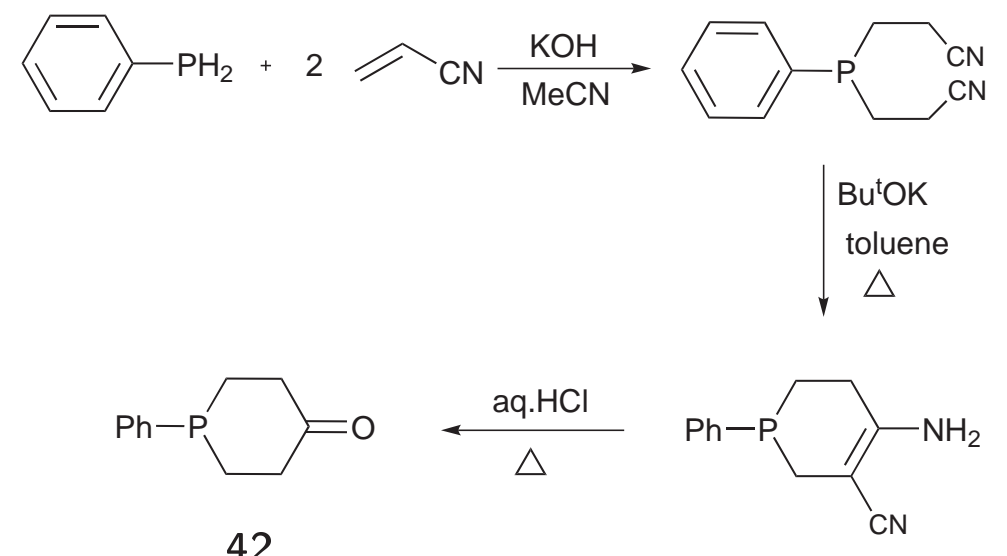

Scheme 2.1

associated with preparing the required , -unsaturated carbonyl compound, 1,4pentadien-3-one (also known as divinyl ketone). ${ }^{66,67}$ Furthermore, there is no precedence for the use of divinyl ketone to prepare phosphorinanone 42 in the literature.

\subsubsection{3,5-Diphenyl phosphorinanone system}

To gradually introduce substituents in the six-membered phosphacycles, phosphorinanone compounds with phenyl groups at the 3,5-positions were prepared. The reaction of dibenzylideneacetone (43), usually abbreviated as dba, with either phenylphosphine or bis(hydroxymethyl)phenylphosphine* produced the phosphorinanone isomers 44 and $\mathbf{4 5}$ (Scheme 2.2). ${ }^{58,60,61}$ Although the asymmetric isomer of 3,4,5-triphenylphosphorinanone (44) was the major product from the $P$-Michael reaction, pure samples of each isomer could not be obtained. Thus, all Mannich reactions were performed with phosphorinanone samples containing both 44 and $\mathbf{4 5}$.

${ }^{*}$ Bis(hydroxymethyl)phenylphosphine is frequently used as a proxy for $\mathrm{PhPH}_{2}$. 


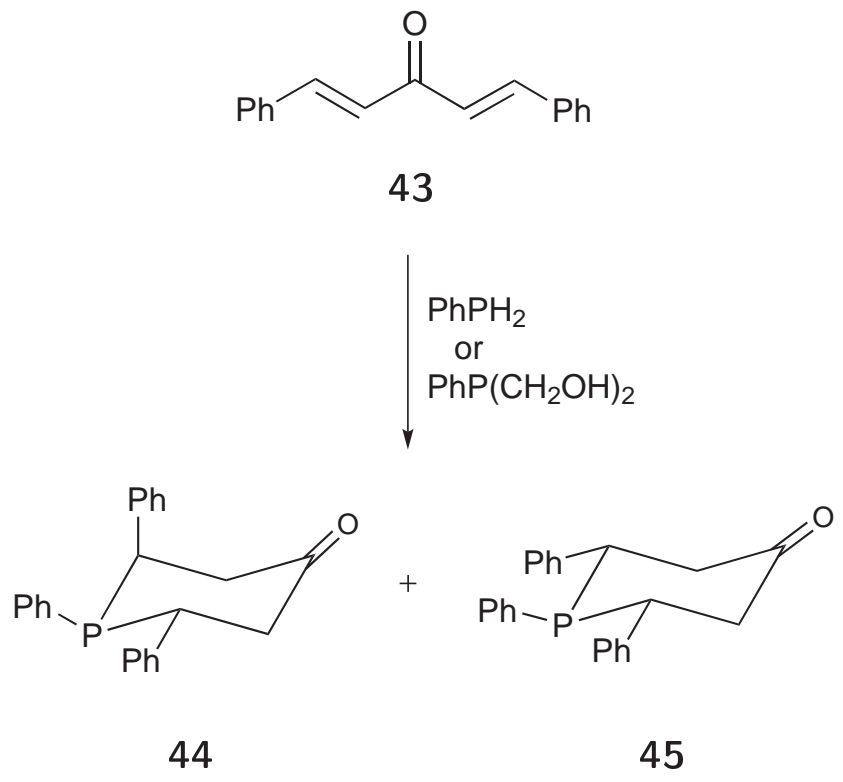

\section{Scheme 2.2}

\subsubsection{2,6-Dimethyl phosphorinanone system}

To further increase the substitution pattern around the phosphacycles, phosphorinanone compounds with methyl groups at the 2,6-positions as well as 3,5-phenyl substituents were prepared using 2,4-dimethyl-1,5-diphenyl-1,4pentadien-3-one (46). The general procedure of Japp and Maitland ${ }^{68}$ was used to prepare compound 46 and is outlined in Scheme 2.3. In our hands, three different products were obtained via this route, the structures of which were elucidated by NMR spectroscopy. They included the desired dba derivative $\mathbf{4 6}$, which was produced in very low yields (17\%), and compounds 47 and 48 . All products were white crystalline solids, but had very different morpholgies: dba derivative 46 formed as glistening flat plates, compound 47 had the appearance of a 'fluffy' solid made up of very small needles, and finally compound 48 was produced as long fine needles.

Compound 47 was first reported by Otto and Ebner ${ }^{69}$ in 1976 and was produced by the identical reaction of -pyrone derivative 49 with $\mathrm{KOH}$ in ethanol. The formation of compound 48 as a by-product was mentioned by 
2

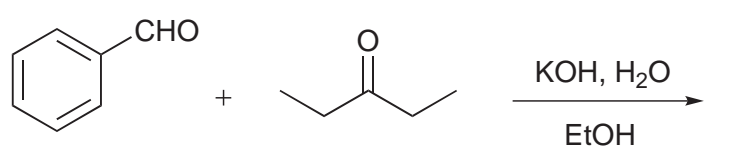<smiles>CC1C(=O)C(C)C(c2ccccc2)OC1c1ccccc1</smiles>

49

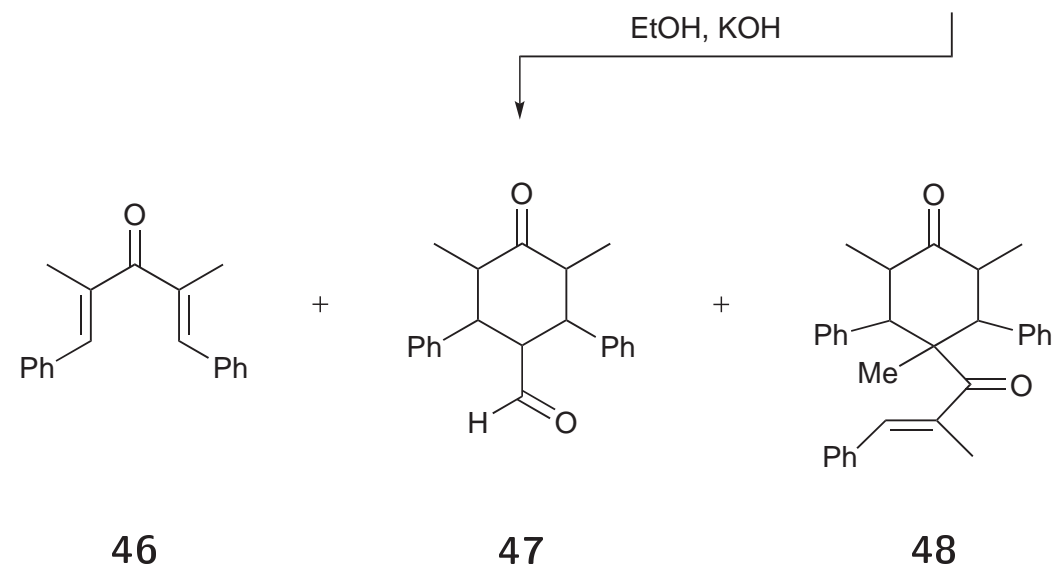

Scheme 2.3

Japp and Maitland in 1904 but the quantity obtained was too small for further examination. Compound 48 was also noted later by Yates and co-workers ${ }^{70}$ in 1958 but no structural information was given.

The $P$-Michael addition reaction of dba derivative 46 with $t$-butylphosphine in pyridine was not successful (Scheme 2.4). This was not surprising as the same result was observed previously with phenylphosphine. ${ }^{59}$ However, if phenylphosphine is converted to bis(hydroxymethyl)phenylphosphine, then reacted with compound 46, the desired 4-phenylphosphorinanones can be formed. ${ }^{59}$ Thus, t-butylphosphine was converted to $\mathrm{Bu}^{t} \mathrm{P}\left(\mathrm{CH}_{2} \mathrm{OH}\right)_{2}$, which then was reacted with 46. Many products were formed, as shown by a plethora of peaks in the ${ }^{1} \mathrm{H}$ and ${ }^{31} \mathrm{P}$ NMR spectra, which could not be separated nor identified. For this reason, the previously reported 4phenylphosphorinanones $\mathbf{5 0}$ and $\mathbf{5 1}$ were used instead. ${ }^{59}$ However, $\mathbf{1 0 0 \%}$ pure samples of each phosphorinanone isomer could not be obtained despite many cycles of crystallisations from ethanol. Subsequently, samples containing 


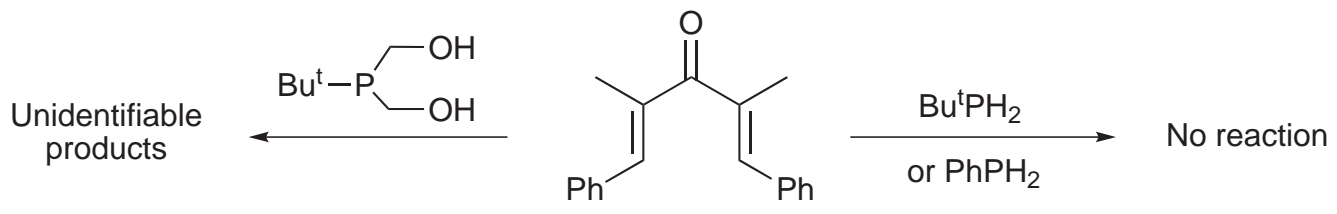

46
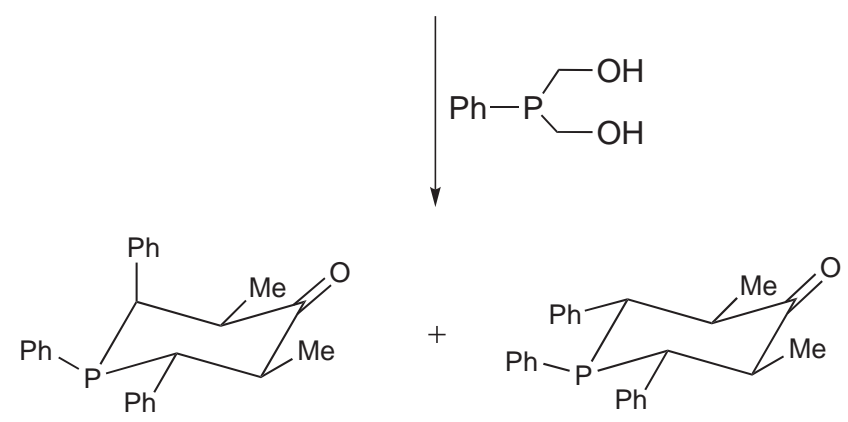

50

51

\section{Scheme 2.4}

different ratios of isomers $\mathbf{5 0}$ and $\mathbf{5 1}$ were used in the Mannich reactions.

\subsubsection{2,6-Diester phosphorinanone system}

Finally, considerable success had been achieved with the use of 2,4di(carbomethoxy)-1,5-bis( $p$-dimethylaminophenyl)penta-1,4-dien-3-one as the acidic $\mathrm{C}-\mathrm{H}$ component in the $P$-Michael reaction to prepare phosphorinanone compound 39 (Scheme 1.12). ${ }^{48}$ Thus, a similar synthetic procedure was adopted using $t$-butylphosphine instead of phenylphosphine as the phosphorus source.

Compound 38 was synthesised via the condensation of dimethyl 1,3acetonedicarboxylate (52) with $p$-dimethylaminobenzaldehyde (Scheme 2.5). The $P$-Michael addition reaction of $\mathbf{3 8}$ and $t$-butylphosphine in pyridine at room temperature produced phosphorinanones 53 and 54 in a 2:1 ratio based on isolated yields. The keto tautomer of $\mathbf{5 4}$ is a diastereoisomer of phosphorinanone 53. Most of compound $\mathbf{5 3}$ precipitated from the reaction mixture as a white solid, while isomer 54 remained in solution. Removal of solvent and several cycles 
<smiles>COC(=O)CC(=O)CC(=O)OC</smiles>

52

$\downarrow$<smiles>COC(=O)C(=Cc1ccc(N(C)C)cc1)C(=O)C(=Cc1ccc([N+](=O)[O-])cc1)C(=O)OC</smiles>
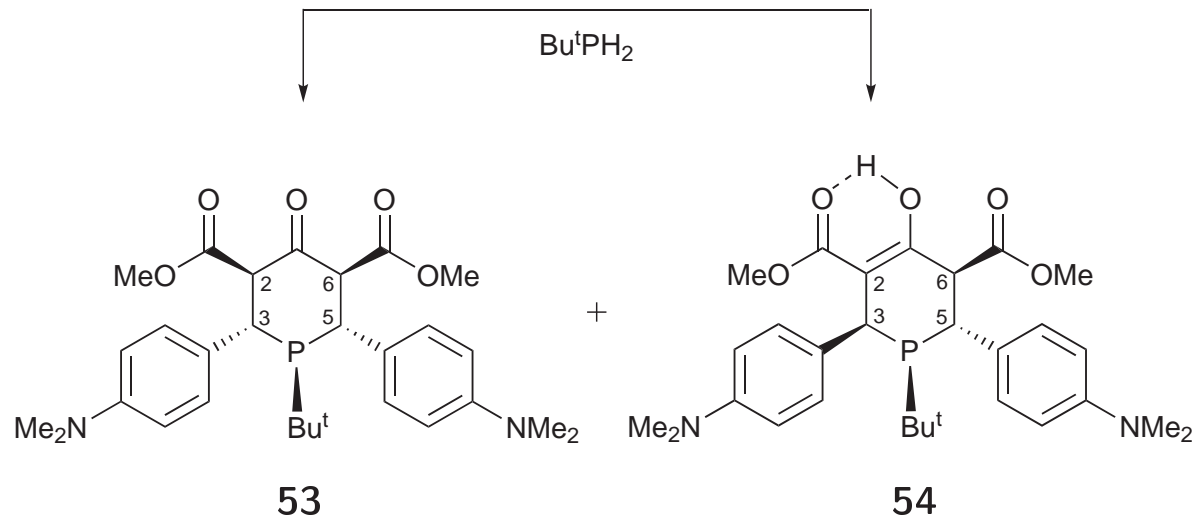

Scheme 2.5

of crystallisation from hot methanol yielded $\mathbf{5 4}$ as air stable fine white needles. The filtrate still contained small amounts of $\mathbf{5 3}$ and $\mathbf{5 4}$ plus potentially other diastereoisomers as evident from the signals in the ${ }^{1} \mathrm{H}$ and ${ }^{31} \mathrm{P}$ NMR spectra. The isolation of the other isomers was not practical as they were present in very small amounts.

Phosphorinanone isomer $\mathbf{5 3}$ exists in the ketone form with normal IR carbonyl stretches for a ketone at $1707 \mathrm{~cm}^{1}$ and an ester at $1755 \mathrm{~cm}{ }^{1}$. The ${ }^{1} \mathrm{H}$ NMR spectrum of 53 in benzene- $\mathrm{d}_{6}$ was simple owing to the presence of a plane of symmetry, while the ${ }^{31} \mathrm{P}$ NMR spectrum showed one resonance at $13.0 \mathrm{ppm}$. The methyl substituents in the dimethylaminophenyl and carbomethoxy groups resonated at 2.91 and $3.51 \mathrm{ppm}$ respectively. The pairs of equivalent protons 
$\mathrm{H}_{3} / \mathrm{H}_{5}$ and $\mathrm{H}_{2} / \mathrm{H}_{6}$ appeared as doublets of doublets at 3.59 and $3.97 \mathrm{ppm}$ respectively, each with $J_{\mathrm{HH}}$ coupling of $12.7 \mathrm{~Hz}$. This large diaxial coupling constant indicates that the bulky carbomethoxy and dimethylaminophenyl groups are in equatorial positions. Two doublets $\left(J_{\mathrm{HH}} 8.5 \mathrm{~Hz}\right)$ were observed at 6.62 and $7.21 \mathrm{ppm}$ for the eight aromatic protons in a ratio of 1:1, implying that both of the aryl rings are rotating freely. A summary of the NMR data for phosphorinanone isomer 53 is given in Tables 2.1 and 2.2 on page 34 .

From previous conformational analysis work on six-membered phosphacycles, ${ }^{61,71}$ the bulky $\mathrm{Bu}^{\mathrm{t}}$ group on phosphorus is expected to occupy an equatorial position. Quin et al. ${ }^{71}$ showed that 1-R-phosphorinanes $\left(\mathrm{R}=\mathrm{CH}_{3}, \mathrm{C}_{2} \mathrm{H}_{5}\right.$, $i-\mathrm{C}_{3} \mathrm{H}_{7}, \mathrm{C}_{6} \mathrm{H}_{5}$ ) gave a single ${ }^{31} \mathrm{P}$ NMR signal at $300 \mathrm{~K}$, but on lowering the temperature, separate sharp signals for the axial-R and equatorial-R conformers were observed. However, in the case of 1-t-butylphosphorinane (55) only one signal was observed over the entire temperature range (129-300 K) corresponding to the equatorial conformer. Moreover, Pringle and co-authors found that the $\mathrm{Bu}^{\mathrm{t}}$ group in 4-t-butyl-3,5-diphenyl-4-phosphorinanone (56) also occupied an equatorial position. ${ }^{61}$ The strong preference of the $\mathrm{Bu}^{\mathrm{t}}$ group for the equatorial position may be attributed to its large size.

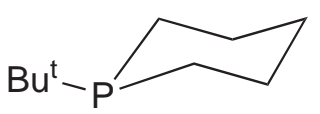

55

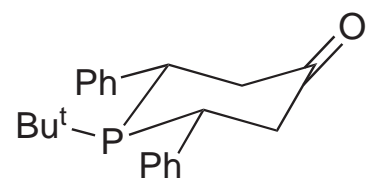

56

As a result of keto-enol tautomerism, phosphorinanone isomer 54 was isolated in the enol form. The IR spectrum showed a broad enolic $\mathrm{OH}$ stretch at $3453 \mathrm{~cm}^{1}$ and a group of bands at 1644, 1610 and $1519 \mathrm{~cm}^{1}$ associated with the carbonyl groups. In the ${ }^{31} \mathrm{P}$ NMR spectrum, compound $\mathbf{5 4}$ had a signal at $6.0 \mathrm{ppm}$. Two non-equivalent methoxy (3.62 and $3.66 \mathrm{ppm})$ and 
dimethylamino (2.91 and $2.95 \mathrm{ppm}$ ) signals were observed in the ${ }^{1} \mathrm{H}$ NMR spectrum indicating asymmetry in isomer 54. The enolic proton resonated at $12.84 \mathrm{ppm}$ and $\mathrm{H}_{3}$ was observed as a doublet at $4.28 \mathrm{ppm}$ with $J_{\mathrm{PH}}$ coupling of $5.9 \mathrm{~Hz}$. Unfortunately, the signals for $\mathrm{H}_{5}$ and $\mathrm{H}_{6}$ overlapped to give a multiplet centred at approximately $3.90 \mathrm{ppm}$ (Figure 2.2). Thus, useful stereochemical information from the magnitude of vicinal and phosphorus couplings for $\mathrm{H}_{5}$ and $\mathrm{H}_{6}$ were instead obtained from a coupled HSQC spectrum. ${ }^{72-75}$

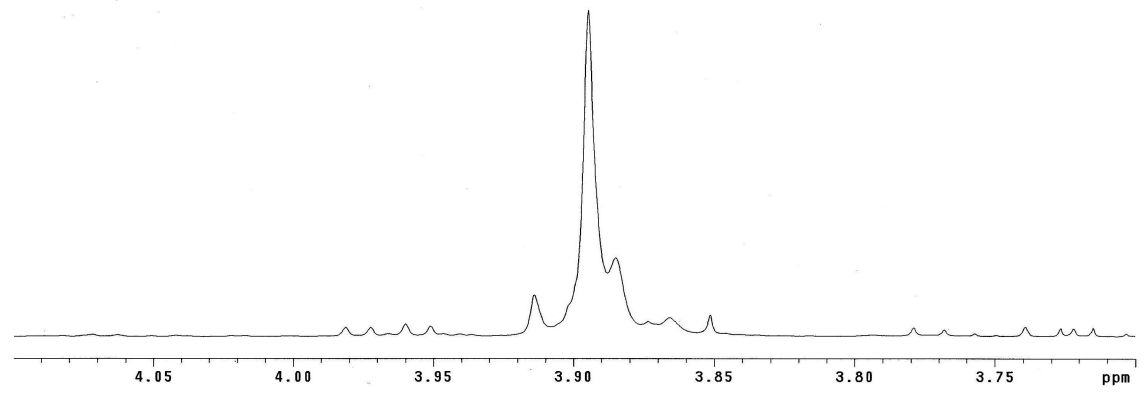

Figure 2.2. ${ }^{1} \mathrm{H}$ NMR spectrum of phosphorinanone isomer 54 shown as an expanded-scale display of the overlapping signal for $\mathrm{H}_{5}$ and $\mathrm{H}_{6}$, $\mathrm{CDCl}_{3}, 600 \mathrm{MHz}$.

A coupled HSQC experiment is performed in the absence of broadband ${ }^{13} \mathrm{C}$ decoupling and with an extended acquisition time as compared with a regular HSQC. Extraction of 1D traces from the coupled HSQC spectrum at the carbon frequency allows the observation of proton multiplets with high resolution nearly equal to that of a conventional proton spectrum. The resolution is further enhanced by the increased acquisition time. The primary doublet splitting is due to the large ${ }^{1} J_{\mathrm{CH}}$ coupling constant as a result of coupling to ${ }^{13} \mathrm{C}$ nuclei. Residual coupling constants can also be measured from the 1D traces as second-order effects caused by strong proton-proton coupling is eliminated. In ${ }^{1} \mathrm{H}$ NMR spectra, complex coupling patterns result from strongly coupled ${ }^{1} \mathrm{H}-{ }^{12} \mathrm{C}-{ }^{12} \mathrm{C}-{ }^{1} \mathrm{H}$ spin systems. In the coupled HSQC experiment these strong couplings are removed and only coupling from ${ }^{1} \mathrm{H}-{ }^{13} \mathrm{C}-{ }^{12} \mathrm{C}-{ }^{1} \mathrm{H}$ 
units are observed. Consequently, undistorted first-order multiplets are restored from which proton-proton and proton-phosphorus coupling constants can be extracted.

The 1D traces (Figure 2.3) from a coupled HSQC spectrum of phosphorinanone isomer 54 showed $\mathrm{H}_{5}$ as a doublet of doublets $\left(J_{\mathrm{HH}} 11.4 \mathrm{~Hz}, J_{\mathrm{PH}} 6.3 \mathrm{~Hz}\right)$ and $\mathrm{H}_{6}$ as a doublet with $J_{\mathrm{HH}}$ of $12.4 \mathrm{~Hz}$, indicating a diaxial arrangement. Nothing can be said about the configuration at $\mathrm{C}_{3}$ because of the isolated position of $\mathrm{H}_{3}$, and also as NOE experiments proved inconclusive. The signals for the eight aromatic protons overlapped to give four resonances in a ratio of $3: 3: 1: 1$. This suggests that one of the dimethylaminophenyl rings is rotating freely to give rise to two signals each integrating for two protons, while the other group is experiencing restricted rotation resulting in four resonances integrating for one proton each. Since the configuration at $\mathrm{C}_{5} / \mathrm{C}_{6}$ is diaxial, the dimethylaminophenyl ring at position 5 is in an equatorial position and would be free to rotate according to a stereomodel of 54. By contrast, the other ring on the enol side of the molecule at position 3 would be restricted in rotation if it is in an axial position and would give rise to four signals in the ${ }^{1} \mathrm{H}$ NMR spectrum. As this was the case, the $\mathrm{H}_{3}$ proton must therefore be in an equatorial position while the dimethylaminophenyl group is axial. Such configuration at $\mathrm{C}_{3}$ is consistent with the observation of two methyl signals for the dimethylaminophenyl groups in phosphorinanone isomer 54. All attempts to grow suitable crystals of compound $\mathbf{5 4}$ for single crystal $X$-ray crystallography failed. A boron adduct was therefore made by reacting 54 with boranedimethyl sulfide in THF. More than one site on $\mathbf{5 4}$ was boronated but the exact structure could not be determined by NMR and all crystallisation attempts were unsuccessful. The NMR data for phosphorinanone isomer 54 are compiled in Tables 2.1 and 2.2 on page 34 .

NMR analysis of a sample containing phosphorinanone isomers 53 and 

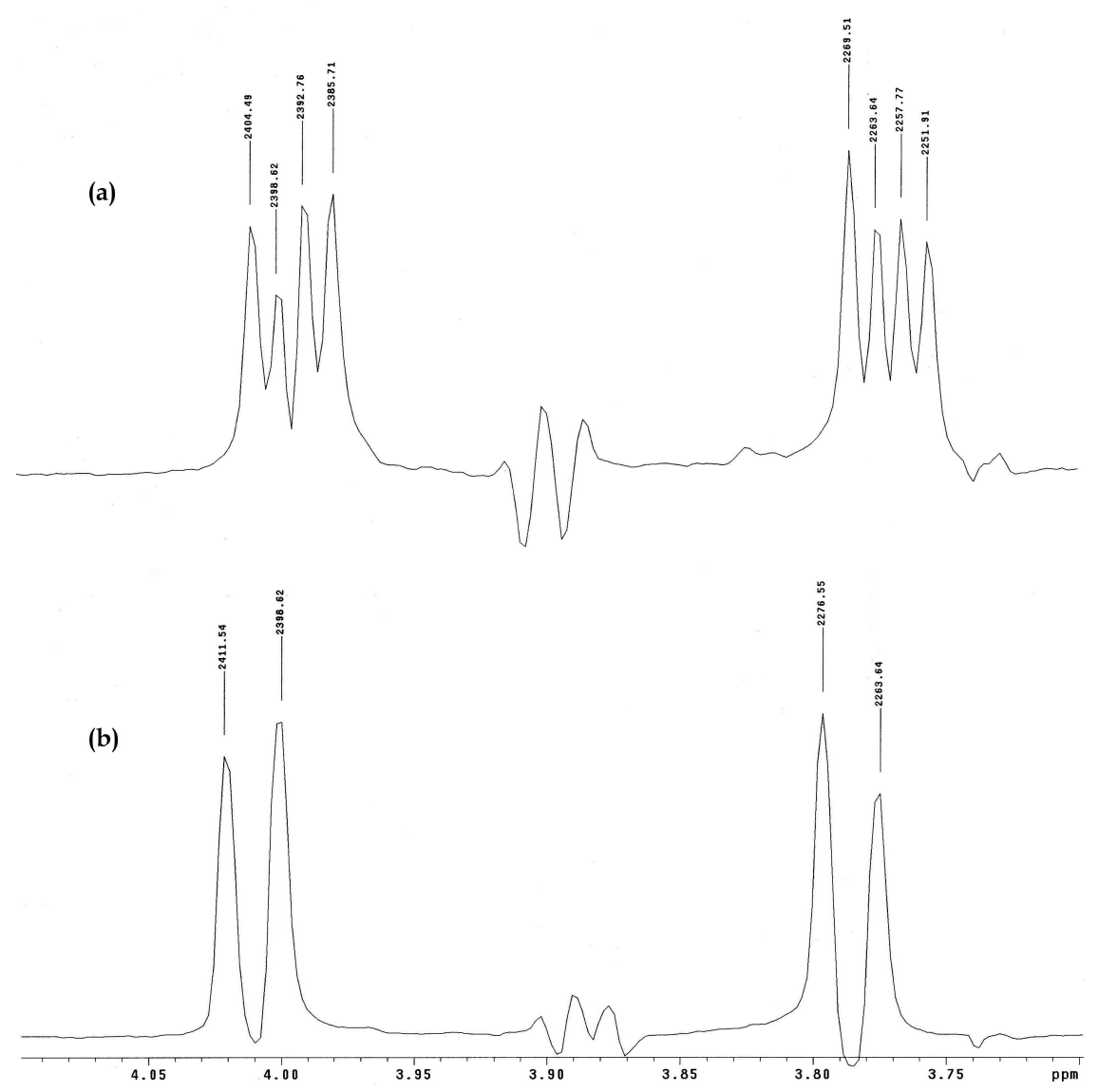

Figure 2.3. Expanded-scale displays of 1D traces from a coupled HSQC spectrum of phosphorinanone isomer $\mathbf{5 4}$ at the frequency of the corresponding carbon atoms for (a) $\mathrm{H}_{5}$ and (b) $\mathrm{H}_{6}, \mathrm{CDCl}_{3}, 600 \mathrm{MHz}$.

54 also showed a complete set of signals corresponding to a second enolic isomer (57) which resonated at $17.5 \mathrm{ppm}$ in the ${ }^{31} \mathrm{P}$ NMR spectrum. The dimethylaminophenyl and the carbomethoxy groups at positions 5 and 6 are both equatorial because a large diaxial coupling constant of $12.7 \mathrm{~Hz}$ was observed between $\mathrm{H}_{5}$ and $\mathrm{H}_{6}$. The $\mathrm{H}_{3}$ proton displayed no phosphorus coupling as it resonated as a singlet at $4.13 \mathrm{ppm}$. Meanwhile, four signals in a ratio of $2: 2: 2: 2$ were observed for the aromatic protons, suggesting free rotation for both of the dimethylaminophenyl rings. To assign a molecular structure to the minor enolic isomer $\mathbf{5 7}$, the configuration at $\mathrm{C}_{3}$ is very important. Since no restricted rotation was observed for the aryl groups, the dimethylaminophenyl group at position 3 
must be equatorial. So far the substituent arrangement in isomer $\mathbf{5 7}$ is the same as isomer 53. Considering that the enol tautomer of $\mathbf{5 3}$ was never observed, for the enolic isomer 57 to be different from 53, the $\mathrm{Bu}^{\mathrm{t}}$ group on phosphorus atom has to be in an axial position even though such arrangement has not been observed before. The ${ }^{1} \mathrm{H}$ and ${ }^{13} \mathrm{C}$ NMR parameters for phosphorinanone isomer 57 are summarised in Tables 2.1 and 2.2 respectively.

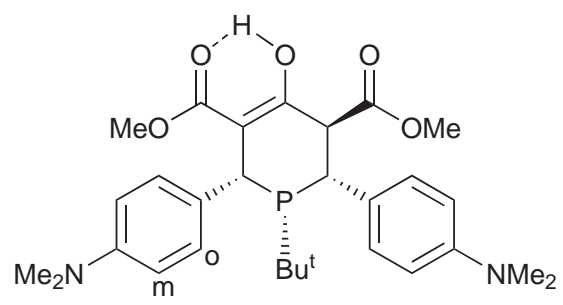

57

Keto-enol tautomerism has also been observed in nitrogen ${ }^{76}$ and sulfur ${ }^{77}$ analogues of the phosphorinanones (Figure 2.4). Galvez et al. ${ }^{76}$ reported a tautomer (58) and a configurational isomer (59) for piperidinone 60, a key intermediate in the synthesis of bispidinones as new $\mathrm{GABA}_{\mathrm{B}}$ receptor antagonists. However, the authors offer no evidence for the equilibrium between piperidinones 58 and 59. Additionally, Chen and co-workers ${ }^{77}$ observed the formation of $\mathbf{6 1}$ from the reaction of the dibenzylideneacetone derivative $\mathbf{3 8}$ with $\mathrm{H}_{2} \mathrm{~S}$ in connection with the synthesis of $4 \mathrm{H}$-thiopyrans. The nitrogen and sulfur enol isomers were isolated and characterised but were not used in any further reactions. 
Table 2.1. ${ }^{1} \mathrm{H}$ NMR data of phosphorinanone isomers 53, 54 and 57.

\begin{tabular}{lccc}
\hline \hline Group & $\mathbf{5 3}$ & $\mathbf{5 4}$ & $\mathbf{5 7}$ \\
\hline $\mathrm{H}_{2}$ & $3.97(\mathrm{dd}, 12.7 \mathrm{~Hz}, 5.4 \mathrm{~Hz})$ & - & - \\
$\mathrm{H}_{3}$ & $3.59(\mathrm{dd}, 12.7 \mathrm{~Hz}, 5.9 \mathrm{~Hz})$ & $3.90(\mathrm{~m})$ & $4.13(\mathrm{~s})$ \\
$\mathrm{H}_{5}$ & $3.59(\mathrm{dd}, 12.7 \mathrm{~Hz}, 5.9 \mathrm{~Hz})$ & $3.90(\mathrm{~m})$ & $3.78(\mathrm{dd}, 12.6 \mathrm{~Hz}, 3.2 \mathrm{~Hz})$ \\
$\mathrm{H}_{6}$ & $3.97(\mathrm{dd}, 12.7 \mathrm{~Hz}, 5.4 \mathrm{~Hz})$ & $4.28(\mathrm{~d}, 5.9 \mathrm{~Hz})$ & $4.42(\mathrm{dd}, 12.6 \mathrm{~Hz}, 1.0 \mathrm{~Hz})$ \\
$\mathrm{OMe}$ & $3.51(\mathrm{~s})$ & $3.62(\mathrm{~s})$ & $3.58(\mathrm{~s})$ \\
& & $3.66(\mathrm{~s})$ & $3.61(\mathrm{~s})$ \\
$\mathrm{NMe}_{2}$ & $2.91(\mathrm{~s})$ & $2.91(\mathrm{br} \mathrm{s})$ & $2.90(\mathrm{~s})$ \\
& & $2.95(\mathrm{br} \mathrm{s})$ & $2.90(\mathrm{~s})$ \\
$\mathrm{Bu}^{\mathrm{t}}$ & $0.63(\mathrm{~d}, 10.7 \mathrm{~Hz})$ & $0.52(\mathrm{~d}, 11.6 \mathrm{~Hz})$ & $0.96(\mathrm{~d}, 11.3 \mathrm{~Hz})$ \\
$\mathrm{OH}$ & - & $12.84(\mathrm{~s})$ & $13.13(\mathrm{~s})$ \\
\hline \hline
\end{tabular}

Spectra obtained in $\mathrm{CDCl}_{3}$. Chemical shifts in ppm. Multiplicity and coupling constants given in parentheses.

Table 2.2. ${ }^{13} \mathrm{C}$ NMR data of phosphorinanone isomers 53, 54 and $\mathbf{5 7}$.

\begin{tabular}{lccc}
\hline \hline Group & $\mathbf{5 3}$ & $\mathbf{5 4}$ & $\mathbf{5 7}$ \\
\hline $\mathrm{C}_{1}$ & $199.4(\mathrm{~d}, 3.4 \mathrm{~Hz})$ & $168.3(\mathrm{~d}, 6.2 \mathrm{~Hz})$ & $169.9(\mathrm{~s})$ \\
$\mathrm{C}_{2}$ & $65.4(\mathrm{~d}, 15.8 \mathrm{~Hz})$ & $103.8(\mathrm{~d}, 9.0 \mathrm{~Hz})$ & $99.9(\mathrm{~d}, 2.8 \mathrm{~Hz})$ \\
$\mathrm{C}_{3}$ & $42.3(\mathrm{~d}, 19.7 \mathrm{~Hz})$ & $35.2(\mathrm{~d}, 24.1 \mathrm{~Hz})$ & $34.5(\mathrm{~d}, 13.5 \mathrm{~Hz})$ \\
$\mathrm{C}_{5}$ & $42.3(\mathrm{~d}, 19.7 \mathrm{~Hz})$ & $36.5(\mathrm{~d}, 19.1 \mathrm{~Hz})$ & $34.3(\mathrm{~d}, 21.3 \mathrm{~Hz})$ \\
$\mathrm{C}_{6}$ & $65.4(\mathrm{~d}, 15.8 \mathrm{~Hz})$ & $57.3(\mathrm{~d}, 17.4 \mathrm{~Hz})$ & $48.1(\mathrm{~d}, 2.0 \mathrm{~Hz})$ \\
$\mathrm{COO}$ & $168.2(\mathrm{~d}, 10.6 \mathrm{~Hz})$ & $172.6(\mathrm{~d}, 13.2 \mathrm{~Hz})$ & $172.6(\mathrm{~d}, 6.7 \mathrm{~Hz})$ \\
& & $172.8(\mathrm{~d}, 6.7 \mathrm{~Hz})$ & $173.1(\mathrm{~s})$ \\
$\mathrm{OMe}$ & $52.1(\mathrm{~s})$ & $52.6(\mathrm{~s})$ & $52.0(\mathrm{~s})$ \\
& & $52.4(\mathrm{~s})$ & $52.0(\mathrm{~s})$ \\
$\mathrm{NMe}_{2}$ & $40.6(\mathrm{~s})$ & $40.7(\mathrm{br} \mathrm{s})$ & $40.0(\mathrm{~s})$ \\
& & $40.8(\mathrm{br} \mathrm{s})$ & $40.0(\mathrm{~s})$ \\
$\mathrm{C}\left(\mathbf{C H}_{3}\right)_{3}$ & $28.7(\mathrm{~d}, 10.1 \mathrm{~Hz})$ & $27.6(\mathrm{~d}, 12.3 \mathrm{~Hz})$ & $29.8(\mathrm{~d}, 13.7 \mathrm{~Hz})$ \\
$\mathbf{C}\left(\mathrm{CH}_{3}\right)_{3}$ & $30.9(\mathrm{~d}, 20.6 \mathrm{~Hz})$ & $30.2(\mathrm{~d}, 21.3 \mathrm{~Hz})$ & $31.7(\mathrm{~d}, 30.9 \mathrm{~Hz})$ \\
\hline \hline
\end{tabular}

Spectra obtained in $\mathrm{CDCl}_{3}$. Chemical shifts in ppm. Multiplicity and coupling constants given in parentheses. 
<smiles>COC(=O)C1=C(C(=O)OC)[C@H](c2ccccc2)N(C)C1c1ccccc1</smiles>

58<smiles>COC(=O)C1C2=C(C(=O)OCO2)C(c2ccccc2)N([R4](=O)c2ccccc2)[C@H]1c1ccccc1</smiles>

59<smiles>C=CC1[C@H](C(=O)OC)C(=O)[C@@H](C(=O)OC)[C@H](c2ccccc2)N1[N+](=O)[O-]</smiles>

60<smiles>COC(=O)C1C2=C(C(OC)OCO2)[C@@H](c2ccccc2)S[C@H]1c1ccccc1</smiles>

61

Figure 2.4. Keto-enol tautomers of piperidinones and thiopyrans.

\section{$2.2 \quad$ PN ligand synthesis}

The four classes of phosphorinanone compounds were reacted with different amines and aldehydes in the Mannich reaction to synthesise bicyclic phosphorusnitrogen ligands. To construct the nitrogen-containing ring, two consecutive Mannich reactions (first inter- and then intramolecularly) are required at the -positions to the central carbonyl group in the phosphorinanone compounds.

\subsubsection{4-Phenylphosphorinanone}

The Mannich reaction of 4-phenylphosphorinanone (42) with formaldehyde in ethanol was attempted with three different amines, namely methylamine, cyclohexylamine and benzylamine (Scheme 2.6). Numerous products were formed as indicated by the number of signals in the ${ }^{31} \mathrm{P}$ NMR spectrum. 
Extensive NMR analyses yielded no useful information on whether PN bicylic compounds were produced in these reactions.

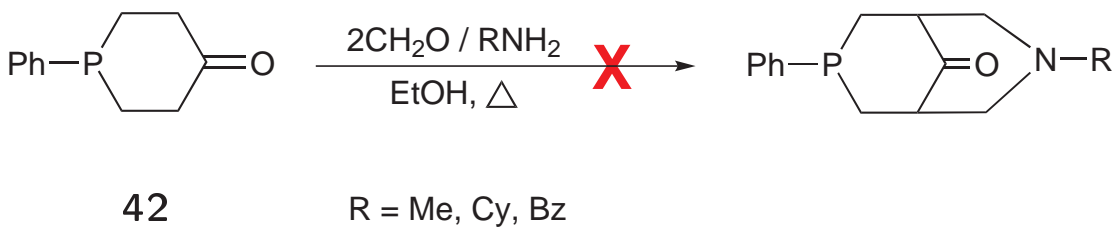

Scheme 2.6

\subsubsection{3,5-Diphenyl phosphorinanones}

Samples containing predominantly the asymmetric phosphorinanone isomer 44 were subjected to typical Mannich reaction conditions using methylamine and formaldehyde in boiling ethanol (Table 2.3). Many products were obtained from the reactions as shown by the plethora of signals in the ${ }^{31} \mathrm{P}$ NMR spectrum. Changing the reactants gave similar results, except for $t$-butylamine which did not react at all, probably due to steric reasons. All efforts were made to purify the products, including the use of column chromatography, and extensive NMR analyses were performed on the mixture of products but no reasonable conclusions could be drawn about the synthesis of bicyclic PN ligands.

\subsubsection{2,6-Dimethyl phosphorinanones}

The synthesis of PN compounds from phosphorinanone isomers $\mathbf{5 0}$ and $\mathbf{5 1}$ was attempted. A summary of all Mannich reaction conditions used are compiled in Table 2.4. No reaction was observed between the phosphorinanones and methylamine and formaldehyde in ethanol for different reaction times. Addition of either acid or base (as the Mannich reaction can be done under acidic or basic conditions) resulted in the isomerisation of the asymmetric isomer 50 into 51. The use of different amines, aldehydes and solvents was also unsuccessful, as was 
Table 2.3. Summary of Mannich reaction conditions of 3,5-diphenyl phosphorinanone isomers 44 and 45 .

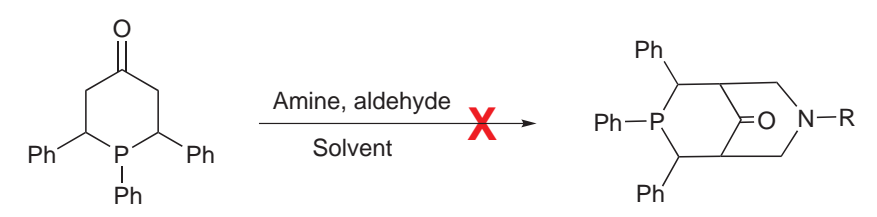

\begin{tabular}{llllll}
\hline Amine & Aldehyde & Solvent & Temp & Time & Result \\
\hline $\mathrm{MeNH}_{2}$ & $\mathrm{CH}_{2} \mathrm{O}$ & $\mathrm{EtOH}$ & reflux & $24 \mathrm{hr}$ & Unidentifiable products \\
$\mathrm{Bu}^{\mathrm{t}} \mathrm{NH}_{2}$ & $\mathrm{CH}_{2} \mathrm{O}$ & $\mathrm{EtOH}$ & reflux & $43 \mathrm{hr}$ & No reaction \\
$\mathrm{PhCH}_{2} \mathrm{NH}_{2}$ & $\mathrm{CH}_{2} \mathrm{O}$ & $\mathrm{EtOH}$ & reflux & $43 \mathrm{hr}$ & Unidentifiable products \\
$\mathrm{CyNH}_{2}$ & $\mathrm{CH}_{2} \mathrm{O}$ & $\mathrm{EtOH}$ & reflux & $24 \mathrm{hr}$ & Unidentifiable products \\
$\mathrm{CH}_{3} \mathrm{CO}_{2} \mathrm{NH}_{4}$ & anisaldehyde & $\mathrm{EtOH}$ & reflux & $24 \mathrm{hr}$ & Unidentifiable products \\
$\mathrm{MeNH}_{2}$ & $\mathrm{CH}_{2} \mathrm{O}$ & $\mathrm{MeCN}$ & reflux & $24 \mathrm{hr}$ & Unidentifiable products \\
$\mathrm{MeNH}_{2}$ & $\mathrm{CH}_{2} \mathrm{O}$ & $\mathrm{MeOH}$ & reflux & $24 \mathrm{hr}$ & Unidentifiable products \\
\hline \hline
\end{tabular}

the attempted reaction under microwave conditions. In view of these results, a double Mannich reaction was perhaps not feasible with this phosphorinanone system. Thus, a single Mannich reaction was attempted with $\mathrm{Me}_{2} \mathrm{NH}$ and its hydrochloride salt but neither produced the desired products.

The outcome from the Mannich reactions of the dimethyl phosphorinanones was surprising as analogous bispidinone compounds with methyl substituents at the -positions to the central carbonyl group have been reported. ${ }^{31,32}$ Such bispidinones were prepared by the Mannich condensation reaction with the aldehyde, ketone and amine components present in the reaction mixture in a 4:1:2 ratio. However the yields were very low, never exceeding 18\%. This suggests that diethyl ketone is not effective as the ketonic substrate in these syntheses. The methyl groups could be deactivating the -positions to the carbonyl group, hence disfavouring a double Mannich reaction. Further support for such a hypothesis came from work published by Omarov and co-workers. ${ }^{78}$ They report the successful condensation of 3,5-diphenylpiperidinone (62) and 2-methyl3,5-diphenylpiperidinone (63) to the corresponding bispidinone compounds, 
Table 2.4. Summary of Mannich reaction conditions of 2,6-dimethyl phosphorinanone isomers $\mathbf{5 0}$ and $\mathbf{5 1 .}$

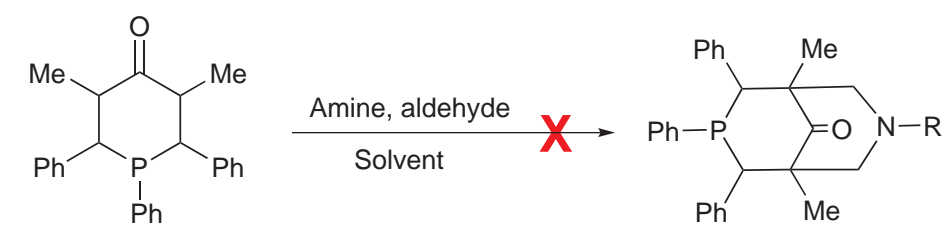

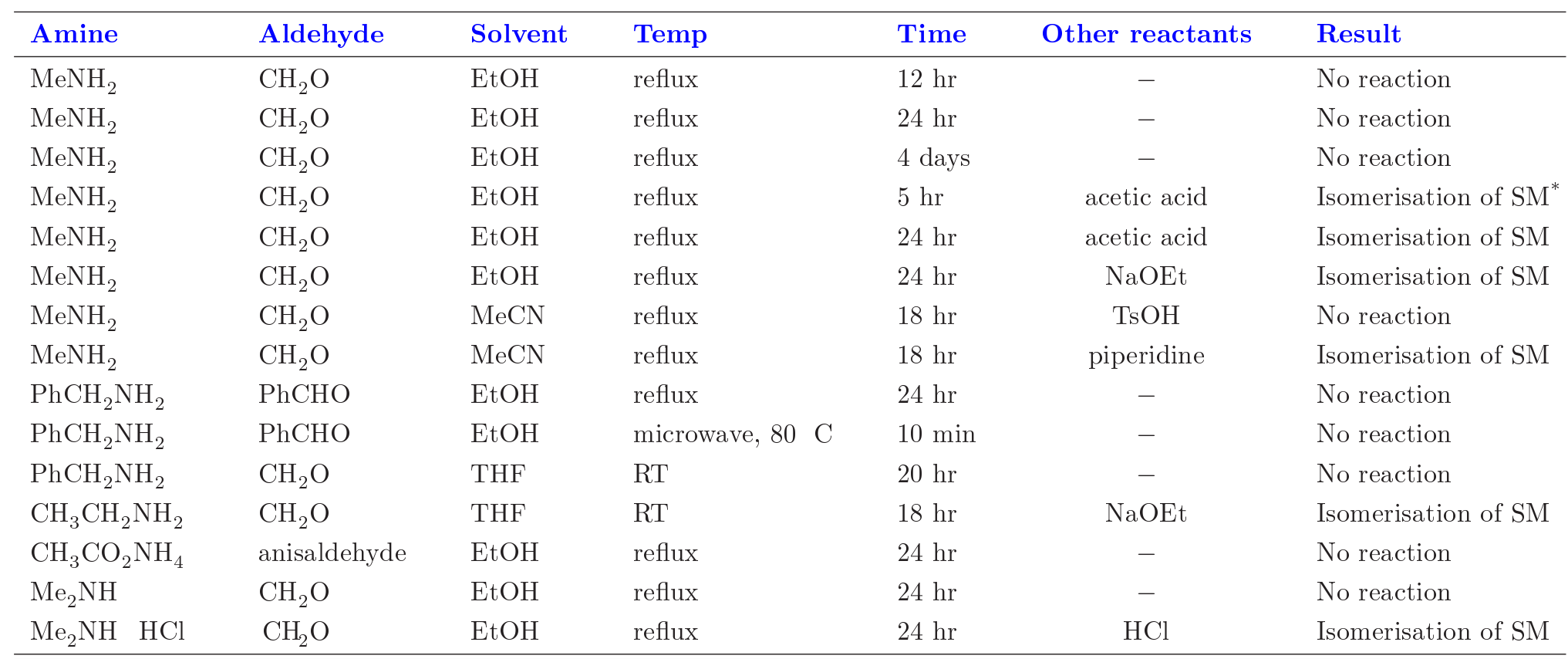

* Starting Material.

$p$-Toluenesulfonic acid. 
although the rate of condensation of $\mathbf{6 3}$ was much slower than $\mathbf{6 2}$, but 2,6dimethyl-3,5-diphenylpiperidinone (64) did not react at all (Scheme 2.7). These observations suggest that a double Mannich reaction using diethyl ketone can be performed if the synthesis is carried out in one pot. However, the Mannich reaction is unsuccessful when 2,6-dimethyl piperidinones are used as the starting materials. As the results from this project have shown, the same is true for phosphorinanone isomers 50 and 51.<smiles>O=C1CC(c2ccccc2)NC(c2ccccc2)C1</smiles><smiles>CCOc1ccccc1</smiles>

62<smiles>CC1C(=O)CC(c2ccccc2)NC1c1ccccc1</smiles><smiles>CCOc1ccccc1</smiles>

63<smiles>CC1C(=O)C(C)C(c2ccccc2)NC1c1ccccc1</smiles><smiles>NC(=O)OCC(=O)OCc1ccccc1</smiles>

$\mathrm{EtOH}$, reflux
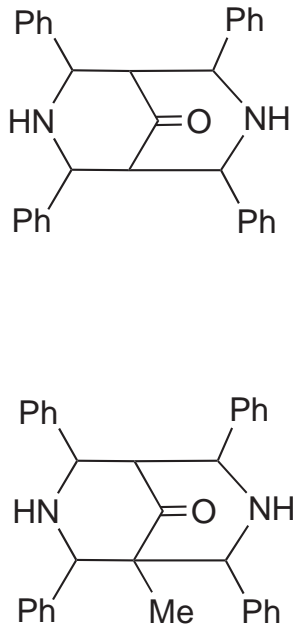

No Reaction

64

\section{Scheme 2.7}

To investigate the degree of reactivity of the -positions to the central carbonyl group in the dimethyl phosphorinanone isomers, a series of small scale exchange experiments were performed using samples containing mainly the symmetrical isomer $\mathbf{5 1}$ to obtain simpler NMR spectra (Table 2.5). Since basic amines are used in Mannich reactions, a $\mathrm{H} / \mathrm{D}$ exchange experiment was carried out in $\mathrm{MeOH}-\mathrm{d}_{4}$ in the presence of diisopropylamine as it has a much 
higher boiling point than methylamine. No deuterium exchange was observed at the -positions. In light of this result, it is not so surprising that a complex double Mannich reaction was never observed with isomers 50 and $\mathbf{5 1 .}$

The H/D exchange was successful when performed in the presence of a strong base such as NaOMe. In the ${ }^{1} \mathrm{H}$ NMR spectrum, the two methyl substituents in phosphorinanone isomer $\mathbf{5 1}$ normally resonate as doublets due to coupling to the -protons, but after the exchange only a singlet at $0.88 \mathrm{ppm}$ was observed. The -protons, which usually appear as a doublet of doublets due to coupling to the -protons as well as phosphorus, now resonated as only a doublet at $2.99 \mathrm{ppm}$.

Following the success of the $\mathrm{H} / \mathrm{D}$ exchange in the presence of $\mathrm{NaOMe}$, a larger electrophile was used. The $\mathrm{H} / \mathrm{Me}$ exchange reactions resulted in the formation of several unidentified products. However, performing a similar experiment in $\mathrm{CDCl}_{3}$ at room temperature without any base produced a phosphonium ion as methylation had occurred on the phosphorus atom. The ${ }^{1} \mathrm{H}$ NMR spectrum of the phosphonium ion showed an extra doublet at $2.62 \mathrm{ppm}\left(J_{\mathrm{PH}} 12.5 \mathrm{~Hz}\right)$, while the ${ }^{31} \mathrm{P}$ NMR spectrum showed that the phosphorus atom in $\mathbf{5 1}$ was very deshielded as its signal shifted from 0.70 to $26.0 \mathrm{ppm}$. Formation of the phosphonium ion indicates that the phosphorus atom is nucleophilic and is competing with the enol form of $\mathbf{5 1}$ for the methyl electrophile. Finally, some exchange experiments were done under acidic conditions. The presence of sulfuric acid also resulted in the formation of many products that were not identified.

\subsubsection{2,6-Diester phosphorinanones}

\section{Mannich reaction of phosphorinanone isomer 53}

The Mannich reaction of phosphorinanone isomer $\mathbf{5 3}$ with methylamine and two equivalents of formaldehyde in ethanol produced a bicyclic phosphorus-nitrogen compound (65) in good yields (Scheme 2.8). The PN compound crystallised out 
Table 2.5. Summary of exchange experiments at the -positions of 2,6-dimethyl phosphorinanone isomer 51.
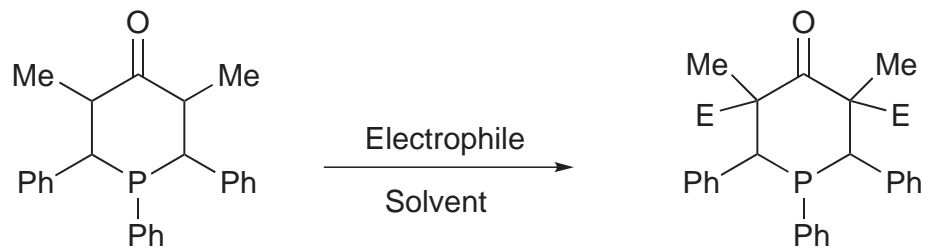

\begin{tabular}{clllcl}
\hline Electrophile & Solvent & Temp & Time & Other reactants & Result \\
\hline $\mathrm{D}$ & $\mathrm{MeOH}-\mathrm{d}_{4}$ & reflux & $15 \mathrm{~min}$ & - & No exchange \\
$\mathrm{D}$ & $\mathrm{MeOH}-\mathrm{d}_{4}$ & reflux & $15 \mathrm{~min}$ & $\left(\mathrm{Me}_{2} \mathrm{CH}\right)_{2} \mathrm{NH}$ & No exchange \\
$\mathrm{D}$ & $\mathrm{MeOH}-\mathrm{d}_{4}$ & reflux & $24 \mathrm{hr}$ & $\left(\mathrm{Me}_{2} \mathrm{CH}\right)_{2} \mathrm{NH}$ & No exchange \\
$\mathrm{D}$ & $\mathrm{MeOH}-\mathrm{d}_{4}$ & reflux & $15 \mathrm{~min}$ & $\mathrm{NaOMe}$ & Exchange at $\alpha$-positions \\
$\mathrm{CH}_{3} / \mathrm{CH}_{3} \mathrm{I}$ & $\mathrm{MeOH}$ & reflux & $30 \mathrm{~min}$ & $\mathrm{NaOMe}$ & Unidentifiable products \\
$\mathrm{CH}_{3} / \mathrm{CH}_{3} \mathrm{I}$ & $\mathrm{MeOH}$ & reflux & $1 \mathrm{hr}$ & $\mathrm{NaOMe}$ & Unidentifiable products \\
$\mathrm{CH}_{3} / \mathrm{CH}_{3} \mathrm{I}$ & $\mathrm{MeOH}$ & reflux & $4 \mathrm{hr}$ & $\mathrm{NaOMe}$ & Unidentifiable products \\
$\mathrm{CH}_{3} / \mathrm{CH}_{3} \mathrm{I}$ & $\mathrm{MeOH}$ & reflux & $24 \mathrm{hr}$ & $\mathrm{NaOMe}_{3}$ & Unidentifiable products \\
$\mathrm{CH}_{3} / \mathrm{CH}_{3} \mathrm{I}$ & $\mathrm{CDCl}$ & $\mathrm{RT}$ & $24 \mathrm{hr}$ & - & Methylation on phosphorus \\
- & $\mathrm{CDCl}$ & $\mathrm{RT}$ & $15 \mathrm{~min}$ & $\mathrm{H}_{2} \mathrm{SO}_{4}(1 \mathrm{drop})$ & Unidentifiable products \\
$\mathrm{D}$ & $\mathrm{MeOH}-\mathrm{d}_{4}$ & reflux & $15 \mathrm{~min}$ & $\mathrm{H}_{2} \mathrm{SO}_{4}(1 \mathrm{drop})$ & Unidentifiable products \\
$\mathrm{D}$ & $\mathrm{MeOH}-\mathrm{d}_{4}$ & reflux & $15 \mathrm{~min}$ & $\mathrm{H}_{2} \mathrm{SO}_{4}(10$ drops $)$ & Unidentifiable products \\
\hline \hline
\end{tabular}


of the reaction mixture as white needles upon cooling and was air stable.

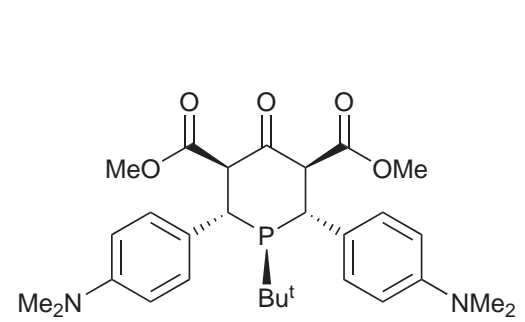

53

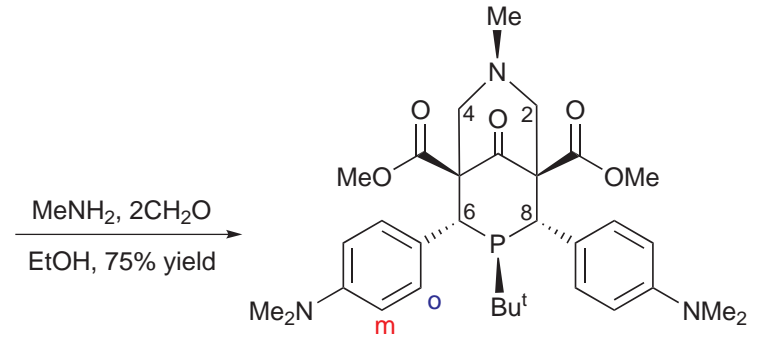

65

\section{Scheme 2.8}

The ${ }^{1} \mathrm{H}$ NMR spectrum of 65 in benzene- $\mathrm{d}_{6}$ showed only half of the signals expected for this PN compound, implying symmetrical positions for the carbomethoxy and dimethylaminophenyl substituents, and for $\mathrm{H} /$ and $\mathrm{H} /$. Four broad doublets between 6 and 9 ppm were observed indicating that the phenyl protons are magnetically inequivlant as a result of restricted rotation about the $\mathrm{C}-\mathrm{C}$ bond. This was confirmed by variable temperature ${ }^{1} \mathrm{H}$ NMR experiments ranging from 20 to $70 \mathrm{C}$ (Figure 2.5). The signals of the metaprotons between 6 and 7 ppm gradually collapsed and coalesced at $60 \mathrm{C}$, whereas the ortho-proton signals required higher temperatures to reach coalescence. The ${ }^{31} \mathrm{P}$ NMR spectrum showed a single peak at $8.4 \mathrm{ppm}$, and the IR spectrum was dominated by two carbonyl stretches at 1712 and $1733 \mathrm{~cm}^{1}$ corresponding to the ketone and ester groups respectively.

Crystals of PN compound $\mathbf{6 5}$ were grown by the slow evaporation of a $\mathrm{C}_{6} \mathrm{D}_{6}$ solution and the $X$-ray crystal structure was determined (Figure 2.6). The solid state crystal structure shows a perfect mirror symmetrical chairchair conformation with the carbomethoxy, dimethylaminophenyl, $\mathrm{Me}$ and $\mathrm{Bu}^{\mathrm{t}}$ substituents in equatorial sites (Figure 2.7(a)). This conformation is favourable as the ligand is set up for metal complexation via both donor atoms to form a stable tricyclic quasi-adamantane structure. The 6,8-dimethylaminophenyl groups are constrained by the bicyclic framework to be in close proximity to 


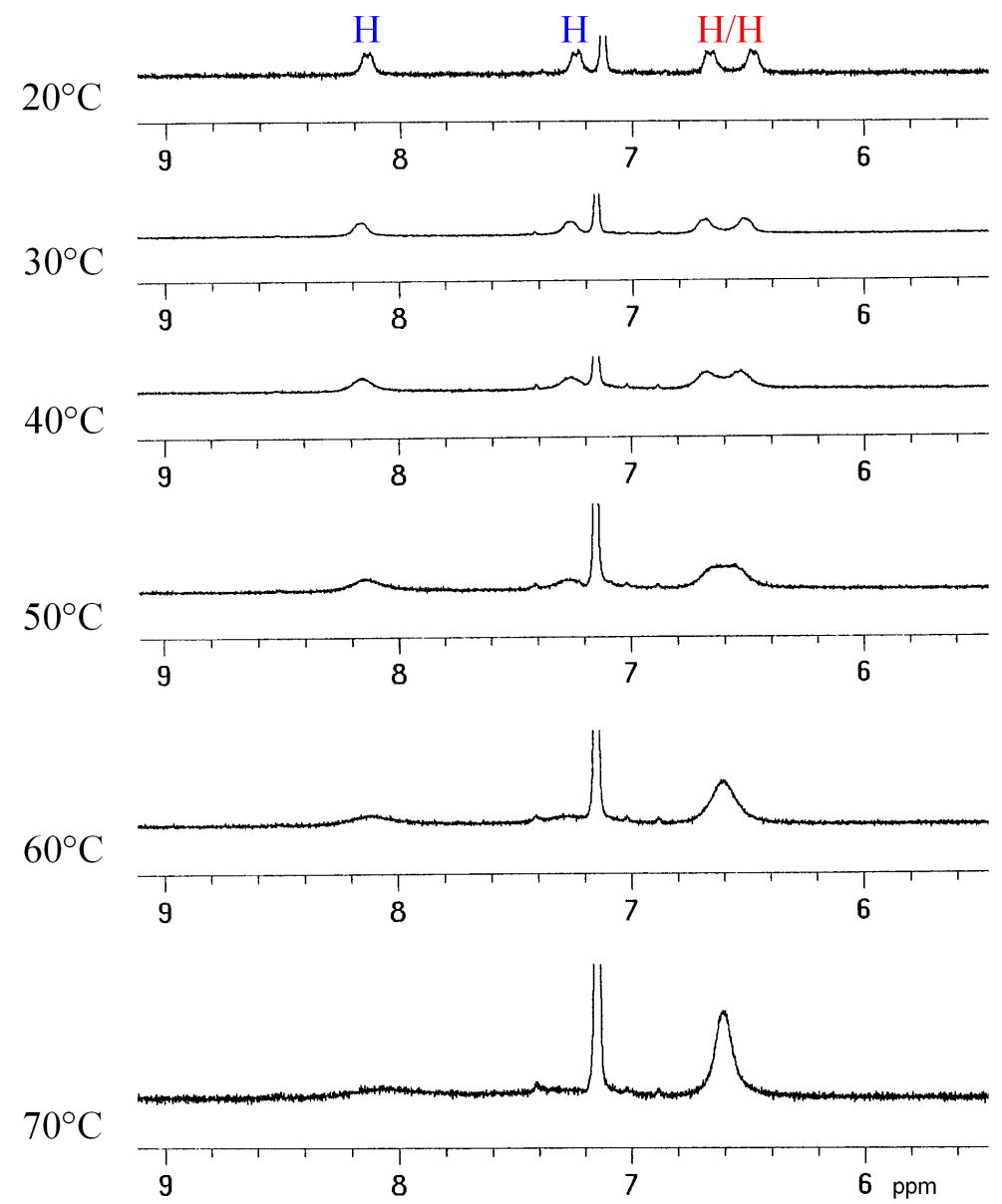

Figure 2.5. Variable temperature ${ }^{1} \mathrm{H}$ NMR spectra of PN compound 65 shown as expanded-scale display of the aromatic region, ortho-protons $(\mathrm{H})$, meta-protons $(\mathrm{H}), \mathrm{C}_{6} \mathrm{D}_{6}, 300 \mathrm{MHz}$.

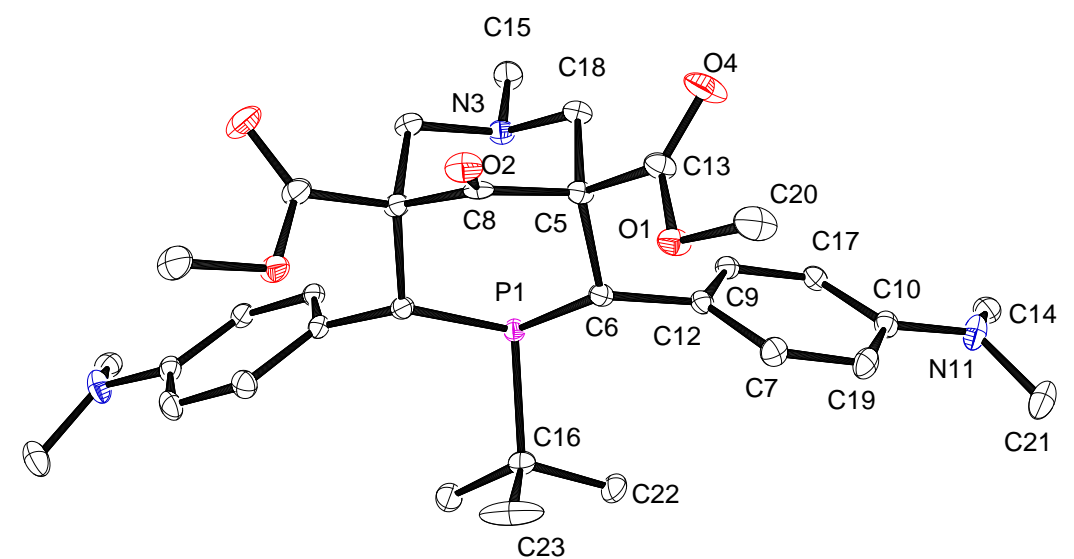

Figure 2.6. ORTEP diagram of PN compound $\mathbf{6 5}$ (30\% thermal ellipsoids). Hydrogen atoms omitted for clarity. 
the metal (Figure 2.7(b)). This could lead to unusual coordination chemistry. Furthermore, the $X$-ray crystal structure also shows the unique out-of-plane protection that would be provided by the dimethylaminophenyl groups for coordinated metals. The crystallographic dimensions of PN compound 65 are very similar to its phenyl analogue $37 .{ }^{48}$ For example, the intramolecular distance between the phosphorus and nitrogen donor atoms is $2.9 \AA$ in both PN compounds. This distance is also the same as the average NN distance in bispidinone compounds. ${ }^{33}$ Some selected bond lengths and angles are given in Table 2.6, and the crystallographic parameters are summarised in Table 2.7.

\section{Mannich reaction of phosphorinanone isomer 54}

The Mannich reaction of the enol phosphorinanone isomer $\mathbf{5 4}$ with formaldehyde and methylamine in ethanol gave highly unexpected results (Scheme 2.9). Removal of ethanol and washing the resulting yellow residue with diethyl ether several times yielded the symmetrical PN compound $\mathbf{6 5}(26 \%)$. The ether wash still contained small amounts of $\mathbf{6 5}$. Taking the ether wash to dryness and washing the residue with hexane successfully separated the other products. The hexane-insoluble solid was identified as a new six-membered phosphorus-nitrogen compound (66) produced in very small yields (13\%) and contaminated with compound 65. Although PN compound 66 is air stable, the use of flash column chromatography for its purification was not successful as it decomposed on the column. It could, however, be further purified by washing several times with small volumes of ethyl acetate which dissolved most of PN compound $\mathbf{6 5}$ along with small amounts of $\mathbf{6 6}$. The hexane wash contained the $E / Z(\mathbf{6 7})$ isomers of 3-(p-dimethylaminophenyl)methyl-2-propenoate (37\%), with the $E$ isomer being dominant.

PN compound 66 was characterised by IR and NMR spectroscopy and mass spectrometry. Elemental analysis could not be performed due to contamination 


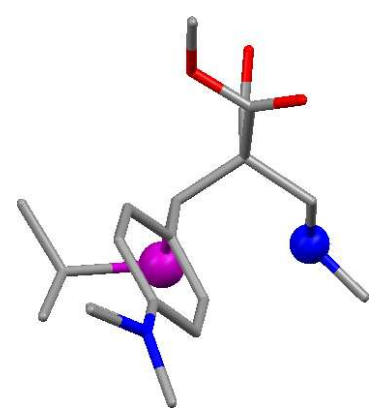

(a)

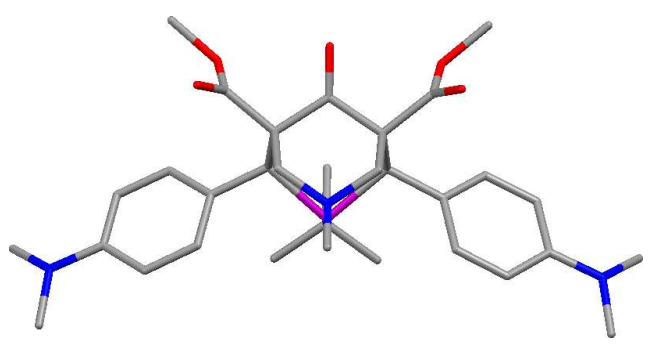

(b)

Figure 2.7. Different views of PN compound 65 as determined by $X$-ray diffraction. The molecule lies on a crystallographic mirror plane through $\mathrm{P}, \mathrm{N}$ and the central carbonyl group.

Table 2.6. Selected bond distances $(\AA)$ and angles ( ) for PN compound $\mathbf{6 5}$.

\begin{tabular}{llll}
\hline \hline \multicolumn{2}{c}{ Bond distances $(\AA)$} & \multicolumn{2}{c}{ Bond angles ( ) } \\
\hline $\mathrm{P} 1-\mathrm{C} 6$ & $1.878(2)$ & $\mathrm{C} 6-\mathrm{P} 1-\mathrm{C} 16$ & $100.8(1)$ \\
$\mathrm{P} 1-\mathrm{C} 16$ & $1.907(2)$ & $\mathrm{C} 5-\mathrm{C} 6-\mathrm{P} 1$ & $114.0(1)$ \\
$\mathrm{C} 6-\mathrm{C} 12$ & $1.513(2)$ & $\mathrm{C} 12-\mathrm{C} 6-\mathrm{P} 1$ & $111.7(1)$ \\
$\mathrm{C} 5-\mathrm{C} 6$ & $1.572(2)$ & $\mathrm{C} 8-\mathrm{C} 5-\mathrm{C} 6$ & $110.9(1)$ \\
$\mathrm{C} 5-\mathrm{C} 8$ & $1.529(2)$ & $\mathrm{C} 8-\mathrm{C} 5-\mathrm{C} 18$ & $105.5(1)$ \\
$\mathrm{C} 5-\mathrm{C} 13$ & $1.533(2)$ & $\mathrm{C} 13-\mathrm{C} 5-\mathrm{C} 18$ & $108.7(1)$ \\
$\mathrm{C} 5-\mathrm{C} 18$ & $1.545(2)$ & $\mathrm{C} 13-\mathrm{C} 5-\mathrm{C} 6$ & $109.7(1)$ \\
$\mathrm{N} 3-\mathrm{C} 15$ & $1.458(3)$ & $\mathrm{N} 3-\mathrm{C} 18-\mathrm{C} 5$ & $109.1(1)$ \\
$\mathrm{N} 3-\mathrm{C} 18$ & $1.456(2)$ & $\mathrm{C} 15-\mathrm{N} 3-\mathrm{C} 18$ & $111.8(1)$ \\
$\mathrm{O} 2-\mathrm{C} 8$ & $1.211(3)$ & $\mathrm{C} 12-\mathrm{C} 6-\mathrm{C} 5$ & $112.0(1)$ \\
\hline \hline
\end{tabular}


Table 2.7. Crystallographic data of PN compound 65 .

\begin{tabular}{|c|c|}
\hline Empirical formula & $\mathrm{C}_{32} \mathrm{H}_{44} \mathrm{~N}_{3} \mathrm{O}_{5} \mathrm{P}$ \\
\hline Formula weight & 581.67 \\
\hline Crystal system & Orthorhombic \\
\hline Space group & Pnma \\
\hline $\mathrm{a} / \AA$ & $12.631(1)$ \\
\hline $\mathrm{b} / \AA$ & $22.509(2)$ \\
\hline $\mathrm{c} / \AA$ & $10.961(1)$ \\
\hline$\alpha==/$ & 90 \\
\hline $\mathrm{V} / \AA^{3}$ & 3116.0 \\
\hline Z & 4 \\
\hline Cell determination reflections & 6817 \\
\hline Cell determination range, $\min -\max /$ & $2.46-25.13$ \\
\hline Temperature/K & $93(2)$ \\
\hline Radiation type & Mo K $\alpha$ \\
\hline Radiation $($ ) $/ \AA$ & 0.71073 \\
\hline Crystal size/ mm & $0.70 \times 0.40 \times 0.20$ \\
\hline $\mathrm{D}_{\text {calc }} / \mathrm{g} \mathrm{m}^{3}$ & 1.240 \\
\hline $\mathrm{F}(000)$ & 1248 \\
\hline $\mathrm{mm}$ & 0.132 \\
\hline $\mathrm{T}_{\max }, \mathrm{T}_{\min }$ & $1.000,0.881$ \\
\hline Reflections collected & $14215, R_{\text {equiv }}=0.0216$ \\
\hline Index range $h$ & $-15-14$ \\
\hline Index range $k$ & $-26-17$ \\
\hline Index range $l$ & $-12-13$ \\
\hline range/ & $2.46-25.17$ \\
\hline Independent reflections & 2868 \\
\hline Reflections $\left[\begin{array}{lll}I & 2 & (I)\end{array}\right]$ & 2497 \\
\hline Restraints/parameters & $0 / 286$ \\
\hline GOF & 0.822 \\
\hline$R \quad\left[\begin{array}{lll}I & 2 & (I)\end{array}\right]$ & 0.038 \\
\hline $\mathrm{w} R 2\left[\begin{array}{lll}I & 2 & (I)\end{array}\right]$ & 0.15 \\
\hline$R \quad$ [all data] & 0.045 \\
\hline $\mathrm{w} R 2$ [all data] & 0.18 \\
\hline
\end{tabular}




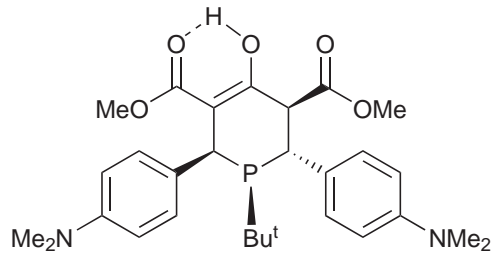

54

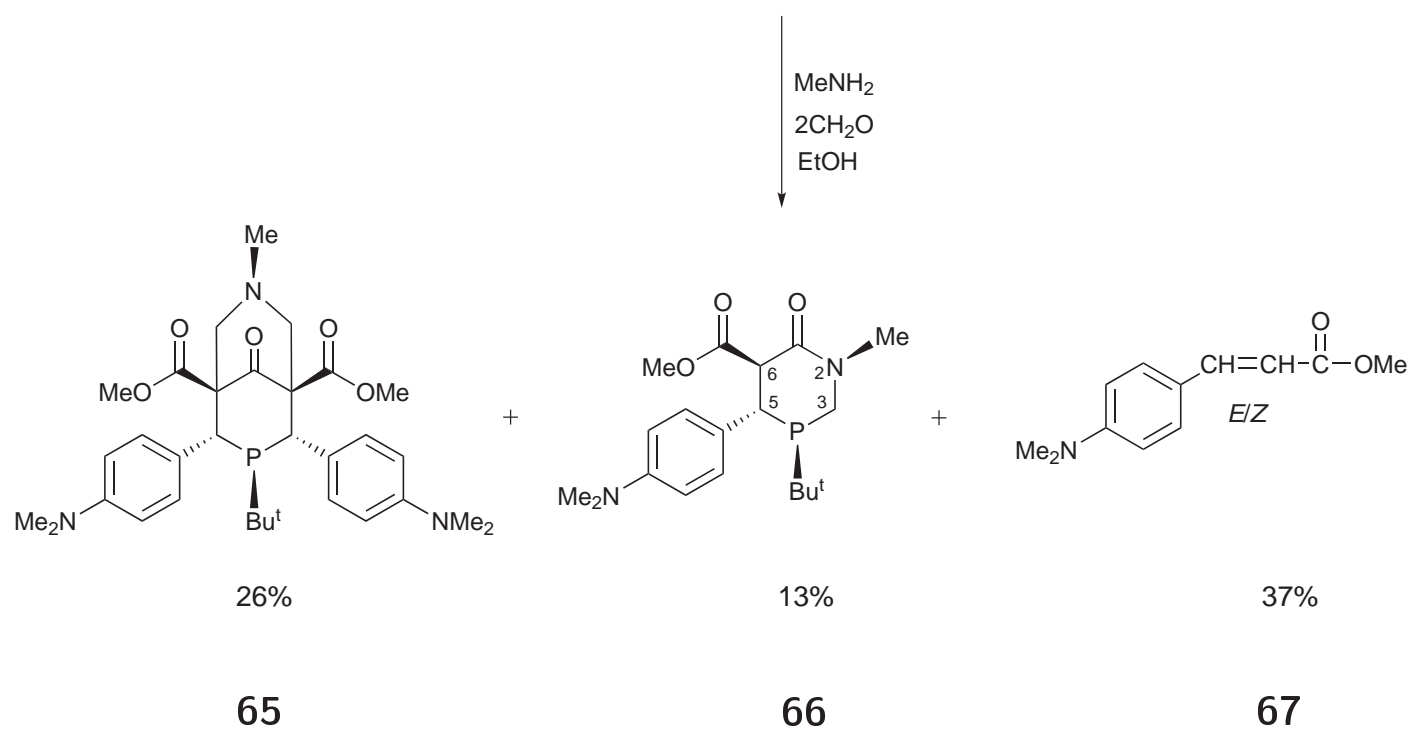

Scheme 2.9

with $\mathbf{6 5}$, but HRESIMS analysis confirmed the molecular formula of compound 66. The IR spectrum of $\mathbf{6 6}$ showed a carbonyl stretch at $1744 \mathrm{~cm}^{1}$ and an amide stretch at $1655 \mathrm{~cm}^{1}$. The phosphorus atom in 66 resonated at $-3.5 \mathrm{ppm}$ in the ${ }^{31} \mathrm{P} \mathrm{NMR}$ spectrum in $\mathrm{CDCl}_{3}$. In the ${ }^{1} \mathrm{H}$ NMR spectrum, the axial and equatorial protons of the $\mathrm{CH}_{2}$ group each appeared as a doublet of doublets at 2.84 and $3.03 \mathrm{ppm}$ with $J_{\mathrm{HH}}$ of $14.5 \mathrm{~Hz}$. The phosphorus coupling constants were vastly different between the two protons; $18.0 \mathrm{~Hz}$ for proton at $3.03 \mathrm{ppm}$ and only $2.6 \mathrm{~Hz}$ for its geminal partner. The protons in positions 5 and 6 were in a diaxial arrangement with a $J_{\mathrm{HH}}$ of $12.8 \mathrm{~Hz}$ indicating that the carbomethoxy and dimethylaminophenyl groups are in equatorial positions. The $t$-butyl group is expected to occupy an equatorial position for reasons discussed in Section 2.1.4. The preferred orientation of the N-methyl substituent should also be equatorial 
since its ${ }^{13} \mathrm{C}$ chemical shift (36.6 ppm) is in agreement with equatorial disposition of N-substituents in piperidinone rings. ${ }^{76}$

The results obtained from the Mannich reaction of phosphorinanone isomer 54 are abstruse. Firstly, the use of an asymmetric phosphorinanone such as isomer 54 in the Mannich reaction was hoped to produce an asymmetric PN compound. As this was not the case, formation of the symmetric PN compound 65 implies that some sort of isomerisation about the stereogenic centres in phosphorinanone $\mathbf{5 4}$ had taken place during the double Mannich reaction. Secondly, formation of compound $\mathbf{6 6}$ suggests that a side reaction was occurring under the Mannich conditions, which had not been observed before. Thirdly, the observation of the $E / Z$ isomers of compound 67 could be the result of the side reaction, or perhaps the result of the complete decomposition of phosphorinanone 54 under such reaction conditions. Consequently, the behaviour of phosphorinanone isomer 54 under the Mannich conditions used is very difficult to understand.

\subsection{Concluding remarks}

The synthesis of bicyclic phosphorus-nitrogen compounds via the Mannich condensation reaction of a phosphorinanone, an amine and two equivalents of an aldehyde proved to be challenging. The nature of the substituents at the -positions to the central carbonyl group in the phosphorinanone compounds had a great effect on the success of the double Mannich reaction. This was demonstrated by the 2,6-diester phosphorinanone system, from which the only PN bicyclic compound was produced. The electron-withdrawing ester groups enhanced the acidic character of the - $\mathrm{CH}$ protons, and also resonance stabilised the enol form of the phosphorinanones. The presence of methyl substituents at the -positions was detrimental to the success of the Mannich reaction, as 
illustrated by the 2,6-dimethyl phosphorinanone system. The lack of reactivity can be attributed to the electron-donating nature of the methyl groups and their inability to stabilise the enol form of the phosphorianones. The remaining 3,5-diphenyl and 4-phenyl phosphorinanone systems had no -substituents, but ascertaining whether the synthesis of any bicyclic PN compounds had been achieved was still difficult. Overall, these results suggest that a combination of steric and electronic factors govern the success of a double Mannich reaction in the different phosphorinanone systems examined in this project.

The newly synthesised bicyclic PN compound 65 adopted a rigid chair-chair conformation both in solution and the solid state. This structural feature presets a bidentate capability and ensures that the nitrogen donor group remains in close proximity to the metal centre in non-chelating situations. The coordination chemistry of the novel PN ligand will be explored with transition metals. 


\section{Chapter 3}

\section{Transition Metal Complexes of Phosphorus-Nitrogen Ligands}

The coordination chemistry of the phosphorus nitrogen ligand 7-t-butyl-1,5di(carbomethoxy)-6,8-bis( $p$-dimethylaminophenyl)-3-methyl-3-aza-7-phosphabicyclo[3.3.1]nonan-9-one (65) was explored extensively through a series of complexation reactions with rhodium, palladium and platinum metal precursors. The PN ligand is capable of chelating to the metal centres by binding through both donor atoms, or it can coordinate via only the phosphorus atom depending on the nature of the metal and the ancillary ligands. All reactions were studied by NMR spectroscopy, and where feasible the $X$-ray crystal structures were determined.

\subsection{Metal(II) complexes}

\section{Platinum methyl compound}

Metal alkyls constitute some of the earliest examples of organometallic complexes. They are of intrinsic importance in catalysis as they represent key intermediates in many catalytic reactions involving hydrocarbons and transition 
metals. $^{79}$

The reaction of the $\mathrm{PN}$ ligand $\mathbf{6 5}$ with $\left[\mathrm{PtMe}_{2}(1,5\right.$-hexadiene $\left.)\right]$ in benzene at room temperature resulted in the quantitative formation of the square planar complex $\left[\mathrm{PtMe}_{2}(\mathbf{6 5})\right](\mathbf{6 8})$ as an off-white solid (Scheme 3.1). Two carbonyl stretches were observed in the IR spectrum at 1743 and $1721 \mathrm{~cm}^{1}$, corresponding to the ketone and ester groups respectively. These values are slightly higher than the corresponding values in the ligand itself.

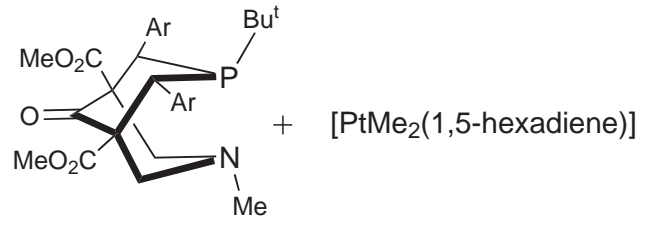

65
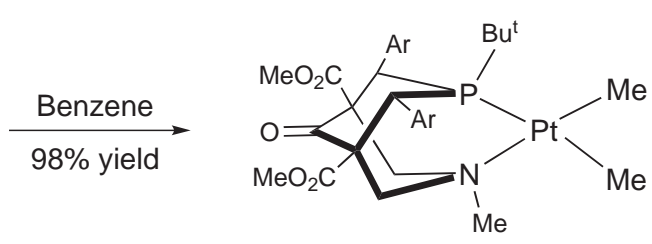

68

\section{Scheme 3.1}

The ${ }^{1} \mathrm{H}$ NMR spectrum of complex 68 showed half the expected signals for the coordinated PN ligand 65, indicating that it has retained its plane of symmetry upon complexation to platinum. Restricted rotation of the aryl rings was still observed as it resulted in four aromatic resonances in the ${ }^{1} \mathrm{H}$ NMR spectrum. This was the case in all the coordination compounds of PN ligand $\mathbf{6 5}$.

The most dramatic change in the ${ }^{1} \mathrm{H}$ NMR spectrum of PN ligand 65 upon complexation was the pronounced downfield shift of one set of the ortho-protons of the dimethylaminophenyl groups. The ortho-protons shifted from $8.17 \mathrm{ppm}$ in the free ligand to $10.32 \mathrm{ppm}$ in complex $\mathbf{6 8}$. This effect was attributed to the close proximity of the ortho-protons to the metal centre. The ortho-protons of the other set were less affected by the metal as they resonated at $7.04 \mathrm{ppm}(c f$. $7.27 \mathrm{ppm}$ in the free ligand). Complex 68 had a ${ }^{31} \mathrm{P}$ signal at $26.6 \mathrm{ppm}$ with a relatively small $J_{\mathrm{PtP}}$ of $1882 \mathrm{~Hz}$, indicating that the phosphorus nucleus is trans to a ligand with a strong trans-influence, i.e. a methyl group.

The NMR signals for the methyl groups were differentiated as a result of 
being trans to the different donor atoms: the methyl group trans to phosphorus resonated as a doublet at $1.38 \mathrm{ppm}\left(J_{\mathrm{PH}} 7.4 \mathrm{~Hz}\right)$ with platinum coupling of $65 \mathrm{~Hz}$, whereas the cis methyl appeared as a doublet at $1.59 \mathrm{ppm}\left(J_{\mathrm{PH}} 6.7 \mathrm{~Hz}\right)$ but with a slightly larger coupling to platinum $\left(J_{\mathrm{PtH}} 92 \mathrm{~Hz}\right)$. The effects of the inherently different donor atoms on the respective trans-positions on the metal were more pronounced in the ${ }^{13} \mathrm{C}$ NMR chemical shifts of the methyl groups: the methyl trans to phosphorus appeared as a doublet at 13.7 ppm with a very large phosphorus coupling constant of $112.6 \mathrm{~Hz}$ and $J_{\mathrm{PtP}}$ of $711 \mathrm{~Hz}$, whereas the methyl group trans to nitrogen was observed at $-23.0 \mathrm{ppm}$ with a small $J_{\mathrm{PC}}$ of $3.8 \mathrm{~Hz}$, but a larger platinum coupling constant of $782 \mathrm{~Hz}$. Therefore, the NMR data strongly suggests that PN ligand $\mathbf{6 5}$ is bonded to platinum via both donor atoms in complex 68 as the two methyl groups are in very distinct chemical environments. This in turn implies that PN ligand 65 has maintained its chairchair conformation upon metal coordination and that no dynamic processes are occurring in solution at room temperature.

\section{Palladium chloro compound}

Halide ligands are ubiquitous in coordination chemistry. Transition metal halide complexes are important both in catalysis and as synthetic precursors for the construction of new molecules. Some halide complexes also have medicinal applications, for example the anti-cancer drug cisplatin $\left(\right.$ cis- $\left.\left[\mathrm{PtCl}_{2}\left(\mathrm{NH}_{3}\right)_{2}\right]\right) \cdot{ }^{80}$

Treatment of $\left[\mathrm{PdCl}_{2}(\mathrm{NCMe})_{2}\right]$ with $\mathrm{PN}$ ligand 65 in dichloromethane afforded the complex $\left[\mathrm{PdCl}_{2}(\mathbf{6 5})\right]$ (69) in good yield (Scheme 3.2). The ${ }^{1} \mathrm{H}$ NMR spectrum of 69 showed half a set of signals for PN ligand 65 indicating a plane of symmetry, with a pronounced downfield shift of one set of the aromatic ortho-protons to $9.70 \mathrm{ppm}$ due to close proximity to the palladium metal centre. The IR spectrum showed two carbonyl stretches at 1744 and $1728 \mathrm{~cm}^{1}$, and the phosphorus atom resonated at $27.0 \mathrm{ppm}$ in the ${ }^{31} \mathrm{P}$ NMR spectrum. 


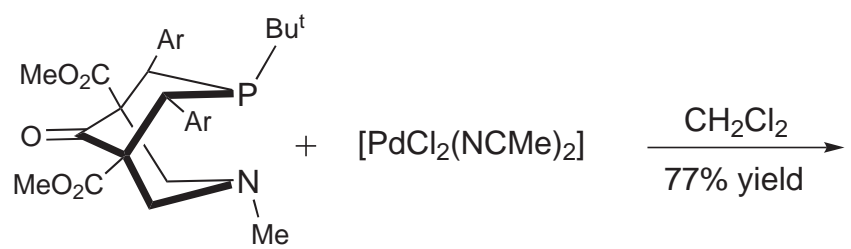

65

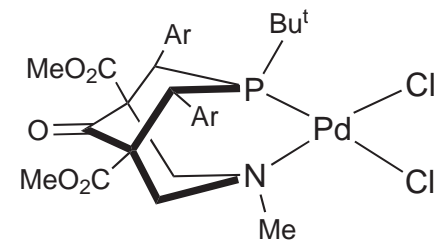

69

\section{Scheme 3.2}

The crystal structure of $\mathbf{6 9}$ was determined from crystals obtained by the slow diffusion of diethyl ether into a dichloromethane-benzene solution (Figure 3.1). Some bond lengths and angles are summarised in Table 3.1 and other crystallographic parameters are compiled in Table 3.2. The structure shows a square planar complex (Figure 3.2) and a perfectly symmetrical PN ligand, which supports the evidence from the ${ }^{1} \mathrm{H}$ NMR spectrum. It also shows the outof-plane protection for the metal centre provided by the dimethylaminophenyl groups. The effect of the different donor atoms on the respective trans-positions on the metal is very evident in the $\mathrm{Pd}-\mathrm{Cl}$ bond lengths. The $\mathrm{Pd}-\mathrm{Cl}$ bond trans to phosphorus $(2.361(3) \AA)$ is comparatively longer than the $\mathrm{Pd}-\mathrm{Cl}$ bond trans to nitrogen $(2.269(3) \AA)$. The degree of ligand rigidity and preorganisation is retained upon complexation to the palladium metal as the distance between the phosphorus and nitrogen donor atoms is $3.0 \AA$, which is very similar to the free ligand ( $c f .2 .9 \AA)$.

In addition to the formation of complex $\mathbf{6 9}$, a minor complex 70 was also observed in solution. Based on peak intensity in the ${ }^{31} \mathrm{P}$ NMR spectrum, the minor complex formed in a 1:3 ratio to complex 69 and exhibited similar NMR features. For example, the ${ }^{31} \mathrm{P}$ NMR signal was observed at $25.2 \mathrm{ppm}$ compared to $27.0 \mathrm{ppm}$ for complex 69. One significant difference between the two complexes was found in the ${ }^{13} \mathrm{C}$ NMR spectrum: no carbonyl signal for $\mathbf{7 0}$ was apparent, and a peak at $94.5 \mathrm{ppm}$ was observed instead. HMBC 


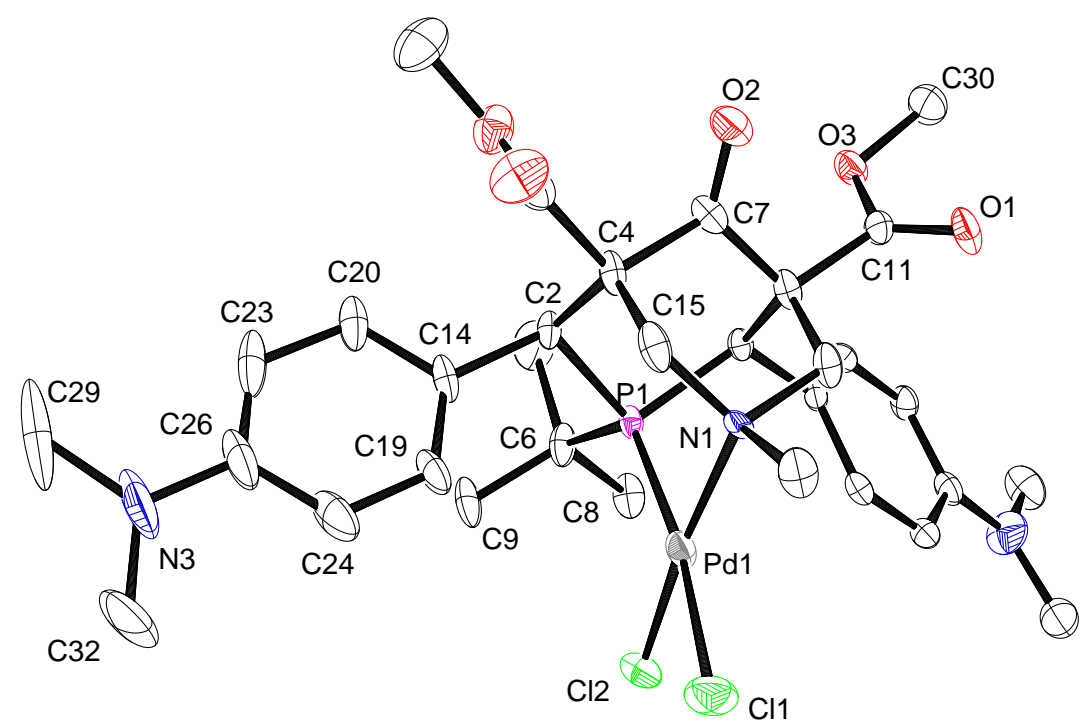

Figure 3.1. ORTEP diagram of $\left[\mathrm{PdCl}_{2}(\mathbf{6 5})\right]$ complex (69) (30\% thermal ellipsoids). Hydrogen atoms omitted for clarity.

Table 3.1. Selected bond distances $(\AA)$ and angles ( ) for complex $\left[\mathrm{PdCl}_{2}(\mathbf{6 5})\right](\mathbf{6 9})$.

\begin{tabular}{lllr}
\hline \hline \multicolumn{2}{c}{ Bond distances $(\AA)$} & \multicolumn{2}{c}{ Bond angles $(~)$} \\
\hline $\mathrm{Pd} 1-\mathrm{Cl} 1$ & $2.361(3)$ & $\mathrm{P} 1-\mathrm{Pd} 1-\mathrm{N} 1$ & $86.1(2)$ \\
$\mathrm{Pd} 1-\mathrm{Cl} 2$ & $2.269(3)$ & $\mathrm{Cl} 1-\mathrm{Pd} 1-\mathrm{Cl} 2$ & $86.3(1)$ \\
$\mathrm{Pd} 1-\mathrm{N} 1$ & $2.142(6)$ & $\mathrm{P} 1-\mathrm{Pd} 1-\mathrm{Cl} 1$ & $171.8(1)$ \\
$\mathrm{Pd} 1-\mathrm{P} 1$ & $2.238(2)$ & $\mathrm{P} 1-\mathrm{Pd} 1-\mathrm{C} 2$ & $93.0(1)$ \\
$\mathrm{P} 1-\mathrm{C} 2$ & $1.853(7)$ & $\mathrm{N} 1-\mathrm{Pd} 1-\mathrm{Cl} 1$ & $95.5(2)$ \\
$\mathrm{N} 1-\mathrm{C} 15$ & $1.48(1)$ & $\mathrm{N} 1-\mathrm{Pd} 1-\mathrm{Cl} 2$ & $173.3(1)$ \\
$\mathrm{C} 15-\mathrm{C} 4$ & $1.52(1)$ & $\mathrm{C} 2-\mathrm{P} 1-\mathrm{C} 2$ & $101.9(3)$ \\
$\mathrm{C} 2-\mathrm{C} 4$ & $1.54(1)$ & $\mathrm{C} 15-\mathrm{N} 1-\mathrm{C} 15$ & $111.2(6)$ \\
$\mathrm{C} 4-\mathrm{C} 7$ & $1.54(1)$ & $\mathrm{C} 4-\mathrm{C} 7-\mathrm{C} 4$ & $112.5(7)$ \\
$\mathrm{C} 7-\mathrm{O} 2$ & $1.18(1)$ & & \\
\hline \hline
\end{tabular}


Table 3.2. Crystallographic data of complex $\left[\mathrm{PdCl}_{2}(65)\right](69)$.

\begin{tabular}{|c|c|}
\hline Empirical formula & $\mathrm{C}_{32} \mathrm{H}_{44} \mathrm{~N}_{3} \mathrm{O}_{5} \mathrm{PCl}_{2} \mathrm{Pd}$ \\
\hline Formula weight & 758.97 \\
\hline Crystal system & Triclinic \\
\hline Space group & $P \overline{1}$ \\
\hline $\mathrm{a} / \AA$ & $10.453(1)$ \\
\hline $\mathrm{b} / \AA$ & $12.746(1)$ \\
\hline $\mathrm{c} / \AA$ & $17.665(2)$ \\
\hline$\alpha /$ & $70.026(3)$ \\
\hline / & $84.257(3)$ \\
\hline / & $70.217(3)$ \\
\hline $\mathrm{V} / \AA^{3}$ & 2081.3 \\
\hline $\mathrm{Z}$ & 2 \\
\hline Cell determination reflections & 7938 \\
\hline Cell determination range, $\min -\max /$ & $2.26-30.49$ \\
\hline Temperature/K & $131(2)$ \\
\hline Radiation type & Mo K $\alpha$ \\
\hline Radiation $($ )/A & 0.71073 \\
\hline Crystal size/ mm & $0.75 \times 0.75 \times 0.28$ \\
\hline $\mathrm{D}_{\text {calc }} / \mathrm{g} \mathrm{m}^{3}$ & 1.211 \\
\hline $\mathrm{F}(000)$ & 784 \\
\hline $\mathrm{mm}$ & 0.65 \\
\hline $\mathrm{T}_{\max }, \mathrm{T}_{\min }$ & $1.000,0.667$ \\
\hline Reflections collected & $14667, R_{\text {equiv }}=0.0334$ \\
\hline Index range $h$ & $-14-14$ \\
\hline Index range $k$ & $-18-14$ \\
\hline Index range $l$ & $-24-24$ \\
\hline range/ & $1.80-30.60$ \\
\hline Independent reflections & 10441 \\
\hline Reflections $\left[\begin{array}{lll}I & 2 & (I)\end{array}\right]$ & 6768 \\
\hline Restraints/parameters & $0 / 407$ \\
\hline GOF & 1.436 \\
\hline$R \quad\left[\begin{array}{lll}I & 2 & (I)\end{array}\right]$ & 0.12 \\
\hline $\mathrm{w} R 2\left[\begin{array}{lll}I & 2 & (I)\end{array}\right]$ & 0.32 \\
\hline$R \quad$ [all data] & 0.18 \\
\hline $\mathrm{w} R 2$ [all data] & 0.35 \\
\hline
\end{tabular}




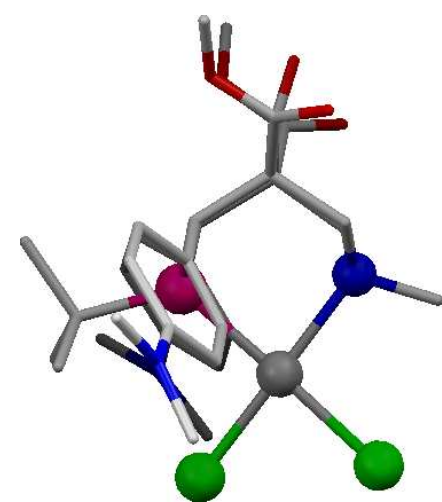

(a)

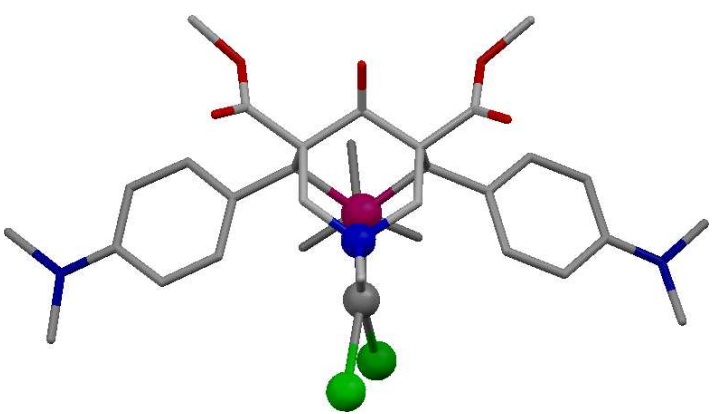

(b)

Figure 3.2. Different views of complex $\left[\mathrm{PdCl}_{2}(65)\right](69)$ as determined by $X$-ray diffraction.

correlations to this carbon atom were observed from two signals in the ${ }^{1} \mathrm{H}$ $\mathrm{NMR}$ spectrum in $\mathrm{CDCl}_{3}$ : from $6.56 \mathrm{ppm}$ (overlapping with the meta-aromatic protons) and a sharp singlet at $6.64 \mathrm{ppm}$. The two ${ }^{1} \mathrm{H}$ NMR signals lacked direct $\mathrm{C}-\mathrm{H}$ correlations in the ${ }^{1} \mathrm{H}-{ }^{13} \mathrm{C}$ HSQC spectrum, indicating that they were bound to a heteroatom. Further HMBC correlations were observed from the new ${ }^{1} \mathrm{H}$ NMR resonances to the quaternary -carbon atom at $57.5 \mathrm{ppm}$. A third HMBC correlation was also observed from the resonance at $6.64 \mathrm{ppm}$ to the ester carbonyl groups at $170.9 \mathrm{ppm}$. These NMR results indicate that the central carbonyl group in ligand $\mathbf{6 5}$ had been hydrated to a geminal diol upon complexation to palladium to produce the hydrated minor complex $\mathbf{7 0}$. The ${ }^{13} \mathrm{C}$ resonance at $94.5 \mathrm{ppm}$ corresponds to the hydrated carbon atom and the two ${ }^{1} \mathrm{H}$ NMR signals at 6.56 and $6.64 \mathrm{ppm}$ are the hydroxylic protons (Figure 3.3). The two $\mathrm{OH}$ groups are expected to be in different chemical environments, and the hydroxylic protons have the possibility of hydrogen bonding to the ester carbonyl groups to form stable six-membered rings. The IR spectrum of complex 70 further supported the presence of the hydroxyl groups as a broad $\mathrm{OH}$ peak was observed at $3423 \mathrm{~cm}^{1}$.

To further confirm the presence of the hydroxyl groups, a drop of $\mathrm{D}_{2} \mathrm{O}$ 


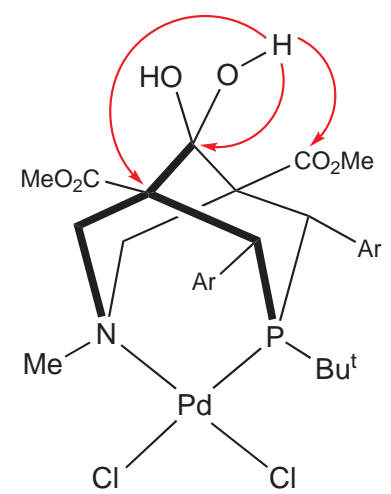

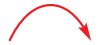

HMBC

Figure 3.3. HMBC correlations for the hydrated analogue of complex $\left[\mathrm{PdCl}_{2}(\mathbf{6 5})\right](\mathbf{7 0})$. Correlations from only the $\mathrm{OH}$ proton at $6.64 \mathrm{ppm}$ are shown for clarity.

was added to a NMR sample containing both the ketone and hydrate forms of $\left[\mathrm{PdCl}_{2}(\mathbf{6 5})\right]$ and the ${ }^{1} \mathrm{H}$ NMR spectrum was recorded (Figure 3.4). The spectrum showed the disappearance of the sharp peak at $6.64 \mathrm{ppm}$, while small changes were noted for the overlapping signals at $6.56 \mathrm{ppm}$. This experiment demonstrated the exchangeability of the two hydroxylic protons with deuterium ions, and hence their disappearance from the ${ }^{1} \mathrm{H}$ NMR spectrum.

Formation of the hydrated complex $\mathbf{7 0}$ was surprising as the reaction and all manipulations were done under an inert atmosphere using freshly distilled solvents. The volume of water required to hydrate one third of $100 \mathrm{mg}$ of $\left[\mathrm{PdCl}_{2}(\mathbf{6 5})\right]$ was calculated to be $0.8 \mu \mathrm{L}$, which equates to $0.013 \%$ in $6 \mathrm{~cm}^{3}$ of $\mathrm{CH}_{2} \mathrm{Cl}_{2}$. Such a small volume of water could still be present in the distilled solvent or on the surface of the glassware being used. The ketone and hydrate complexes were separable in the solid state as the crystal selected for $X$-ray crystallography consisted only of ketone molecules. However, no crystals of the hydrate were isolated.

To study the relationship between the ketone (69) and hydrate (70) forms of $\left[\mathrm{PdCl}_{2}(\mathbf{6 5})\right]$, a NMR experiment was carried out in which water was added to a NMR sample containing both complexes. The 3:1 ketone to hydrate ratio did 


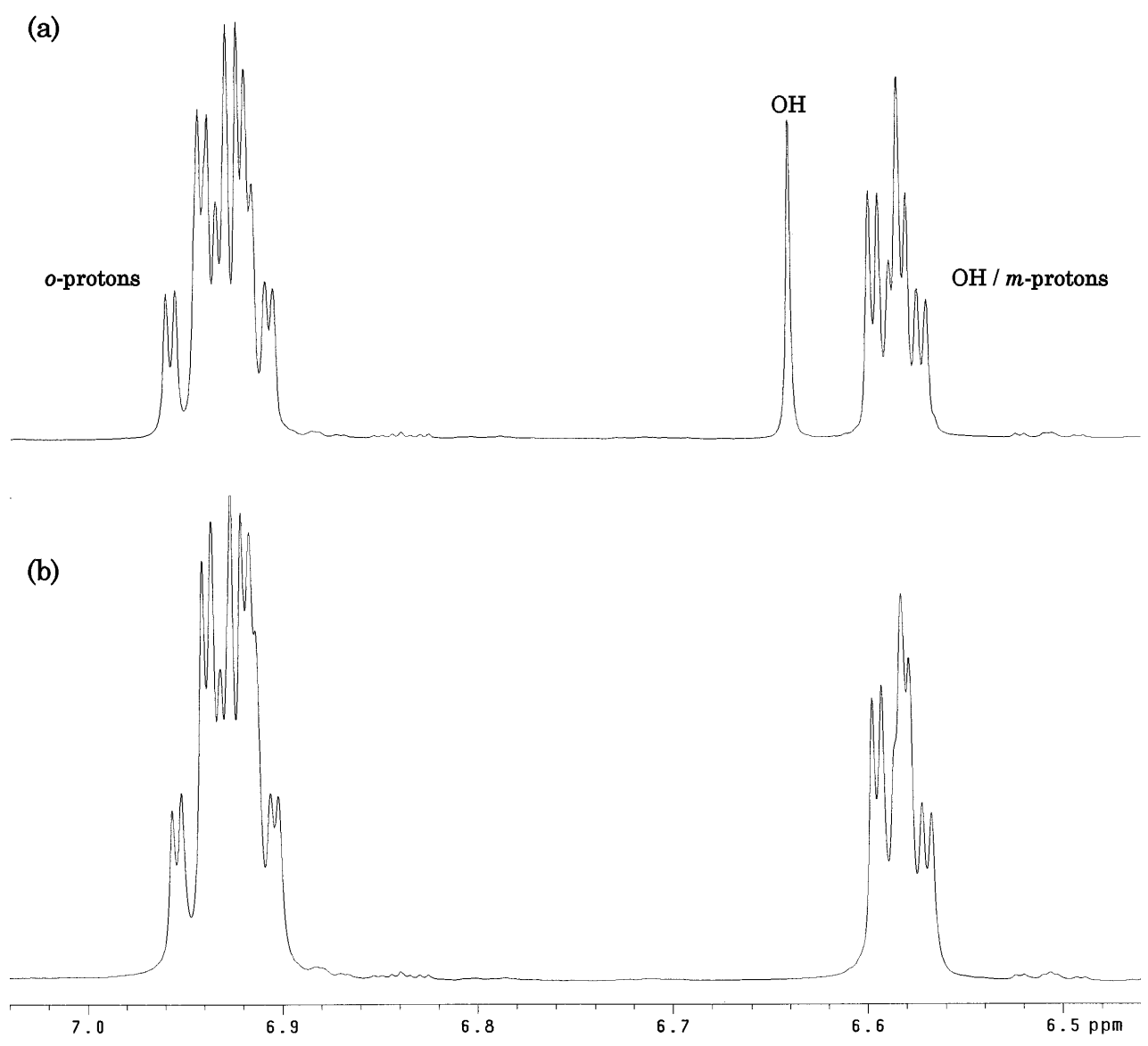

Figure 3.4. ${ }^{1} \mathrm{H}$ NMR spectra of the ketone (69) and hydrate (70) forms of $\left[\mathrm{PdCl}_{2}(\mathbf{6 5})\right]$ complex, shown as expanded-scale displays of the aromatic regions, $\mathrm{CDCl}_{3}, 600 \mathrm{MHz}$ : (a) experimental spectrum; (b) with $\mathrm{D}_{2} \mathrm{O}$.

not change, suggesting that the two complexes are not in equilibrium.

Hydrate formation upon complexation to metal ions is well known in bispidinone coordination chemistry. Numerous examples of palladium, platinum and first-row transition metal complexes containing bispidinone ligands in which the central carbonyl group has been hydrated to the corresponding geminal diol have been reported. ${ }^{31-33}$ In addition, if the complexation reaction is carried out in methanolic solutions then the carbonyl group is converted into a hemiacetal (MeO-C-OH) functionality. ${ }^{81,82}$ Hydration of coordinated bispidinone ligands is generally observed if the complexation reactions are not performed under strictly water-free conditions. Furthermore, hydration only seems to occur for 
bispidinone ligands with ester substituents at the -positions to the carbonyl group. Bispidinone ligands with $\mathrm{Ph}, \mathrm{SPh}$ and Me groups at the -positions form only the keto-complexes. This observation is very apparent from studies by Comba et al., ${ }^{33}$ but is somewhat ambiguous from results published by Black and co-workers. ${ }^{31}$ The latter reported twelve bispidinone complexes, half of which contain varying amounts of water that is treated as water of crystallisation. As no crystal structures or ${ }^{13} \mathrm{C}$ NMR data are given for the complexes in question, the nature of the interaction between water and the bispidinone complexes is difficult to determine.

Since free bispidinone ligands do not undergo voluntary hydration, metal coordination must considerably enhance the reactivity of the carbonyl group. This might involve an increase of the electron deficit at the carbonyl carbon atom via an inductive effect. If this is the case, then the nucleophilic addition of water to the carbonyl carbon atom followed by a series of proton transfers would result in the formation of the geminal diol. ${ }^{63}$ Furthermore, the presence of ester substituents at the -positions to the carbonyl group would further stabilise the $\mathrm{OH}$ groups through hydrogen bonding. Thus, trace amounts of water in the reaction medium or on the surface of glassware could lead to the formation of hydrated complexes. Hydration of the bispidinone ketone group appears to have negligible effect both experimentally and computationally on the geometry and, more importantly, the electronic structure and relative energies of the resultant metal complexes. ${ }^{33,83}$

As no hydration of the central carbonyl group in the free PN ligand 65 has been observed, formation of the hydrated complex 70 could be attributed to similar reasons as for the hydrated bispidinone complexes. Interestingly, complete hydration of bispidinone ligands occurs upon metal complexation, whereas only a third of the PN ligand was hydrated to form complex $\mathbf{7 0 .}$ 


\subsection{Rhodium complexes}

Rhodium containing compounds are important in homogeneous catalysis. Examples of $\mathrm{Rh}(\mathrm{I})$ catalysts include Wilkinson's catalyst, $\left[\mathrm{RhCl}\left(\mathrm{PPh}_{3}\right)_{3}\right]$, for the hydrogenation of unhindered alkenes, and rhodium complexes bearing chiral phosphine ligands for asymmetric hydrogenation reactions. ${ }^{84}$ The coordination chemistry of PN ligand $\mathbf{6 5}$ with $\mathrm{Rh}(\mathrm{I})$ was studied as rhodium has many similarities to platinum and palladium.

The addition of the PN ligand 65 to $[\mathrm{Rh}(\mu-\mathrm{Cl})(\operatorname{cod})]_{2}$ in dichloromethane in a 2:1 ratio at room temperature resulted in no reaction (Scheme 3.3), but abstraction of the chloride ions with $\mathrm{AgSbF}_{6}$ afforded the four-coordinate complex $[\mathrm{Rh}(\operatorname{cod})(\mathbf{6 5})] \mathrm{SbF}_{6}(\mathbf{7 1})$. The ${ }^{31} \mathrm{P}$ NMR spectrum of 71 showed a doublet at $21.9 \mathrm{ppm}$ due to rhodium coupling $\left(J_{\mathrm{RhP}} 149.4 \mathrm{~Hz}\right)$. The PN ligand retained its plane of symmetry upon complexation as evident by the simple ${ }^{1} \mathrm{H}$ NMR spectrum and the downfield shift of one set of the ortho-protons to $9.72 \mathrm{ppm}$. The COD NMR resonances reflected the rigidity of the PN ligand and the asymmetry imposed by the different donor atoms on the metal centre as two sets of $\mathrm{COD}-\mathrm{CH}$ signals were observed. The $\mathrm{CH}$ protons resonated as doublets at $4.54\left(J_{\mathrm{PH}} 2.4 \mathrm{~Hz}\right)$ and $5.68 \mathrm{ppm}\left(J_{\mathrm{PH}} 2.6 \mathrm{~Hz}\right)$, while the respective carbon atoms appeared at $73.5(\mathrm{~d}, J 11.3 \mathrm{~Hz})$ and $105.1 \mathrm{ppm}\left(J_{\mathrm{PC}}+J_{\mathrm{RhC}}\right.$ $14.9 \mathrm{~Hz}$ ). The latter ${ }^{13} \mathrm{C}$ NMR signal at $105.1 \mathrm{ppm}$ was an apparent triplet due to the overlap of two doublets from which the exact magnitude of each coupling constant was difficult to determine, hence the sum of the two coupling constants is reported. Since both phosphorus and rhodium nuclei are NMR active $(I=$ $1 / 2$ ), the couplings exhibited by the $\mathrm{COD}-\mathrm{CH}{ }^{13} \mathrm{C}$ NMR resonances are not distinguishable as they could be due to either nuclide.

The COD NMR data are consistent with 71 being a four-coordinate Rh(I) complex containing a bidentate phosphorus-nitrogen ligand. ${ }^{23}$ Comparison may be made with the PTN ligand $\mathbf{1 0}$ as it has a similar carbon framework 


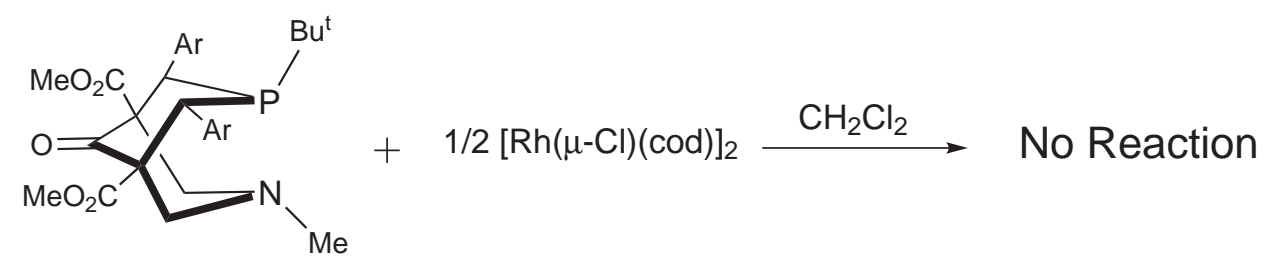

65

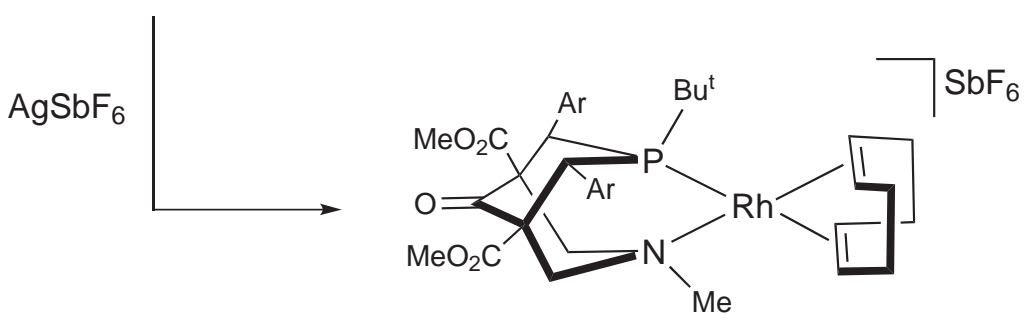

71

Scheme 3.3

to PN ligand 65. PTN forms the complexes $[\mathrm{RhCl}(\operatorname{cod})(\mathrm{PTN})]$ (15) and $[\mathrm{Rh}(\operatorname{cod})(\mathrm{PTN})] \mathrm{BAr}^{\mathrm{F}}(\mathbf{7 2})\left(\mathrm{BAr}^{\mathrm{F}}=\mathrm{B}\left[3,5-\left(\mathrm{CF}_{3}\right)_{2} \mathrm{C}_{6} \mathrm{H}_{3}\right]_{4}\right)($ Scheme 3.4$) .{ }^{23}$ The formation of the monodentate PTN complex $\mathbf{1 5}$ is possible due to the considerably smaller size of the PTN ligand compared with PN ligand 65. As in complex 71, one set of the COD-CH groups in the PTN complex 72 was also shifted upfield to $3.56 \mathrm{ppm}$ ( $\mathrm{c} 71.0 \mathrm{ppm}$ ), while the other group resonated at $5.30 \mathrm{ppm}$ ( c $109.1 \mathrm{ppm}$ ). The upfield chemical shifts in complex 72 were attributed to the ring current generated by the -system of the phenyl substituent on phosphorus resulting in shielding of one of the $\mathrm{COD}-\mathrm{CH}$ groups. However, this explanation cannot be valid for PN complex 71 as there is no phenyl group on the phosphorus donor atom. A more plausible explanation for the disparity in the chemical shifts of the two COD-CH groups is the different trans-influence of the phosphorus and nitrogen donor atoms.

The minor hydrated analogue (73) of complex 71 was also observed in solution. Complex $\mathbf{7 3}$ formed in a 1:3 ratio and had similar NMR data as $\mathbf{7 1}$. For example, a ${ }^{31} \mathrm{P}$ NMR signal was observed at $20.3 \mathrm{ppm}$ with $J_{\mathrm{RhP}}$ of $146.2 \mathrm{~Hz}$. The different COD-CH groups resonated at $4.44\left(J_{\mathrm{PH}} 2.4 \mathrm{~Hz}\right)$ and $5.55 \mathrm{ppm}\left(J_{\mathrm{PH}}\right.$ 


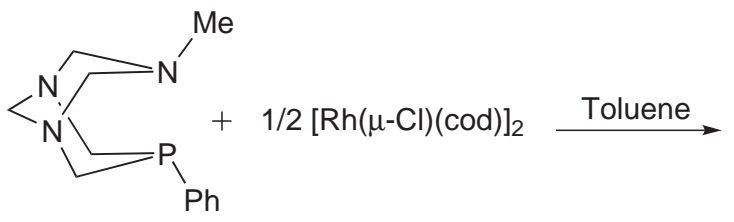

10

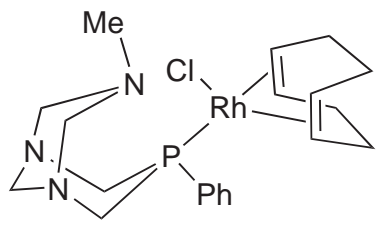

15

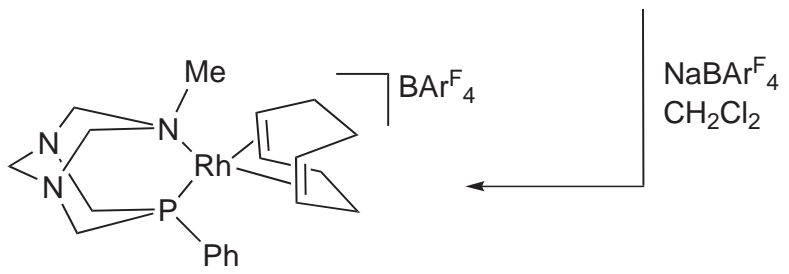

72

Scheme 3.4

$2.8 \mathrm{~Hz}$ ). The respective $\mathrm{COD}-\mathrm{CH}{ }^{13} \mathrm{C} \mathrm{NMR}$ signals were observed at 72.6 and $103.7 \mathrm{ppm}$, and the hydrated carbon atom resonated at $94.5 \mathrm{ppm}$. Hydroxylic protons were observed in the ${ }^{1} \mathrm{H}$ NMR spectrum at 6.38 and $6.42 \mathrm{ppm}$, which also displayed ${ }^{1} \mathrm{H}-{ }^{13} \mathrm{C}$ HMBC correlations to the hydrated carbon atom at $94.5 \mathrm{ppm}$ and the quaternary -carbon atom at $57.4 \mathrm{ppm}$. Finally, an absorption at $3434 \mathrm{~cm}^{1}$ was observed in the IR spectrum consistent with the presence of the $\mathrm{OH}$ groups in complex 73.

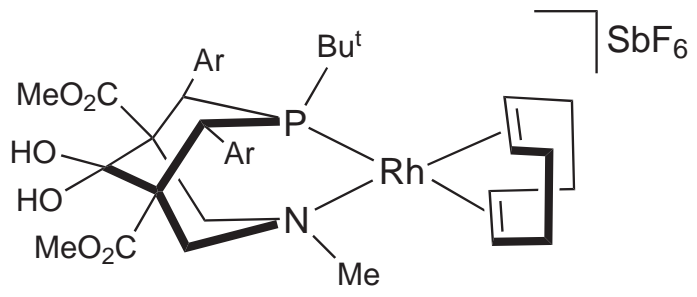




\subsection{Alkene complexes}

Transition metal alkene complexes are the oldest class of organometallic compounds known and they have been extensively studied. The most famous example, Zeise's salt $\left(\mathrm{K}\left[\mathrm{Pt}\left(\eta-\mathrm{C}_{2} \mathrm{H}_{4}\right) \mathrm{Cl}_{3}\right]\right),{ }^{85}$ was first reported in 1830, and is considered the prototype for the classic Dewar-Chatt-Duncanson model for bonding in transition metal alkene complexes. ${ }^{86}$ Metal alkene complexes are used as precursors for the synthesis of new coordination compounds, as well as being important in homogeneous catalysis as they represent key catalytic intermediate species.

\section{Reaction with tris(norborn-2-ene)platinum}

Addition of $\mathrm{PN}$ ligand 65 to a solution of $\left[\mathrm{Pt}(\mathrm{norb})_{3}\right]$ in benzene afforded the 16-electron complex $\left[\mathrm{Pt}\left(\right.\right.$ norb)(65)] (74) (Scheme 3.5) in high yields. The ${ }^{1} \mathrm{H}$ and ${ }^{13} \mathrm{C}$ NMR spectra in $\mathrm{CD}_{2} \mathrm{Cl}_{2}$ were simple, indicating that the $\mathrm{PN}$ ligand is in a symmetrical environment as a result of dynamic behaviour, such as free rotation about the $\mathrm{Pt}-$ alkene bond. In the ${ }^{1} \mathrm{H}$ NMR spectrum, one set of the phenylic ortho-protons gave rise to a distinctive doublet at $9.26 \mathrm{ppm}$, and the norborn-2-ene olefinic protons appeared at $2.08 \mathrm{ppm}$ as a broad singlet with $J_{\mathrm{PtH}}$ of $77 \mathrm{~Hz}$. Surprisingly, the ${ }^{1} \mathrm{H}$ and ${ }^{13} \mathrm{C}$ signals for the NMe group showed coupling to phosphorus as well. The methyl protons appeared as a doublet at $3.71 \mathrm{ppm}, J_{\mathrm{PH}} 1.9 \mathrm{~Hz}$, and the carbon atom was observed at $62.9 \mathrm{ppm}$ with $J_{\mathrm{PC}}$ of $4.5 \mathrm{~Hz}$. This is the only instance in which the NMe group displayed phosphorus coupling and it must reflect the unusual bonding in complex $\mathbf{7 4}$.

The ${ }^{13} \mathrm{C}$ NMR signal for the contact carbon atoms of the coordinated alkene resonated at $46.7 \mathrm{ppm}$ as a doublet, due to phosphorus coupling through the metal centre $\left(J_{\mathrm{PC}} 27.8 \mathrm{~Hz}\right)$, with $J_{\mathrm{PtC}}$ of $469 \mathrm{~Hz}$. A similar coupling pattern was observed for the carbon atom of the non-bridgehead $\mathrm{CH}_{2}$ groups in norborn- 


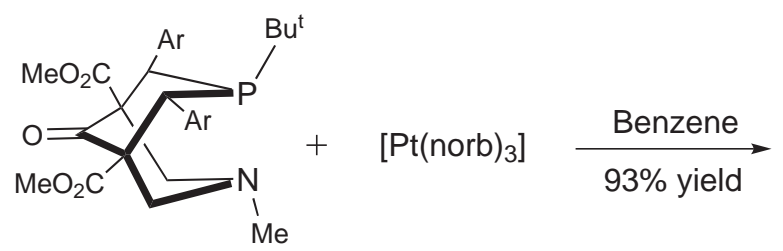

65

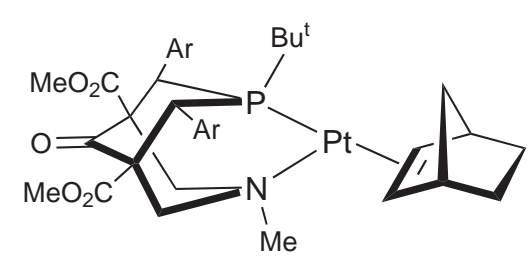

74

\section{Scheme 3.5}

2-ene at $30.2 \mathrm{ppm}$ with $J_{\mathrm{PC}}$ of $5.5 \mathrm{~Hz}$ and $J_{\mathrm{PtC}}$ of $77 \mathrm{~Hz}$. The ${ }^{31} \mathrm{P}$ NMR spectrum of 74 showed a single resonance at $47.5 \mathrm{ppm}$ with ${ }^{195} \mathrm{Pt}$ coupling of $3559 \mathrm{~Hz}$. All attempts at crystallisation failed partly due to complex 74 being very fragile in solution even under an inert atmosphere. As a solid, complex $\mathbf{7 4}$ is air stable but cannot be stored for prolonged periods of time.

\section{Reaction with tris(ethene)platinum}

Treatment of an ethene-saturated solution of $\left[\mathrm{Pt}\left(\mathrm{C}_{2} \mathrm{H}_{4}\right)_{3}\right]$ with $\mathrm{PN}$ ligand $\mathbf{6 5}$ in benzene- $\mathrm{d}_{6}$ immediately formed $\left[\mathrm{Pt}\left(\mathrm{C}_{2} \mathrm{H}_{4}\right)(65)\right]$ complex (75) (Scheme 3.6). After 10 minutes at room temperature, a second ethene complex (76) was observed, which will be discussed in detail in section 3.5. Monitoring the reaction mixture by ${ }^{1} \mathrm{H}$ and ${ }^{31} \mathrm{P}$ NMR showed that the initial ethene complex 75 was slowly converting into $\mathbf{7 6}$, and that the conversion process was complete after one day. Consequently, complex 75 was never isolated for analysis without any conversion occurring. The conversion process between the two ethene complexes ceases at $-10 \mathrm{C}$.

The ${ }^{1} \mathrm{H}$ and ${ }^{31} \mathrm{P}$ NMR spectra of complex 75 recorded at $-10 \mathrm{C}$ were similar to spectra recorded within 10 minutes of reaction at room temperature. Thus, the ${ }^{1} \mathrm{H}$ NMR spectrum at room temperature showed a symmetrical PN ligand with a characteristic downfield shift of one set of the aromatic ortho-protons to $9.78 \mathrm{ppm}$. Only one signal was observed for the ethene protons at $3.22 \mathrm{ppm}$, 


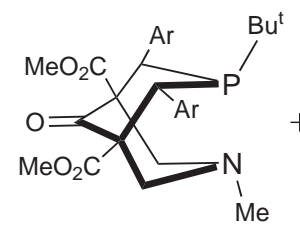

65

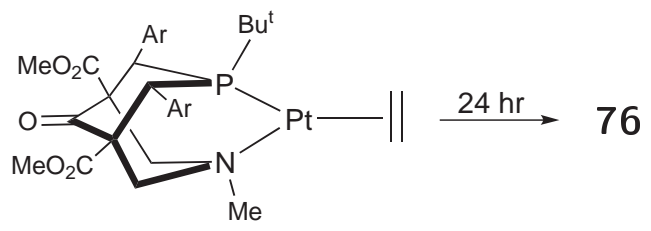

75

Scheme 3.6

which appeared as a doublet $\left(J_{\mathrm{PH}} 1.9 \mathrm{~Hz}, J_{\mathrm{PtH}} 16 \mathrm{~Hz}\right)$ and integrated for four protons. This indicated the presence of only one coordinated ethene unit in complex 75, which is rotating freely about the Pt-alkene bond. ${ }^{A}{ }^{13} \mathrm{C} N M R$ spectrum was also obtained at $-10 \mathrm{C}$ in which the coordinated ethene carbon atoms resonated at $64.7 \mathrm{ppm}$ as a broad singlet with no distinguishable ${ }^{195} \mathrm{Pt}$ satellites due to the weak spectrum. Complex 75 had a ${ }^{31} \mathrm{P}$ NMR signal at $47.5 \mathrm{ppm}$ with platinum coupling of $3727 \mathrm{~Hz}$.

\section{Reaction with $\mathrm{Pd}_{2}(\mathrm{dba})_{3} \mathrm{CHCl}_{3}$}

Reaction of $\mathrm{PN}$ ligand 65 with $\mathrm{Pd}_{2}(\mathrm{dba})_{3} \mathrm{CHCl}_{3}$ in benzene resulted in the formation of the 16-electron complex $[\mathrm{Pd}(\mathrm{dba})(\mathbf{6 5})]$ (77) (Scheme 3.7). The byproduct from this reaction, free dba, could not be completely removed despite all purification efforts. Thus, complex 77 was always contaminated with free dba. The dba complex is remarkably air stable both as a solid and in solution,

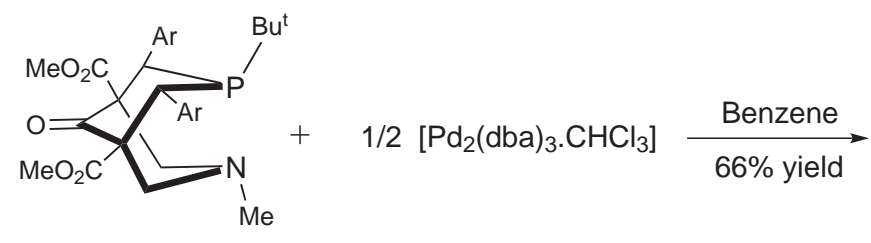

65

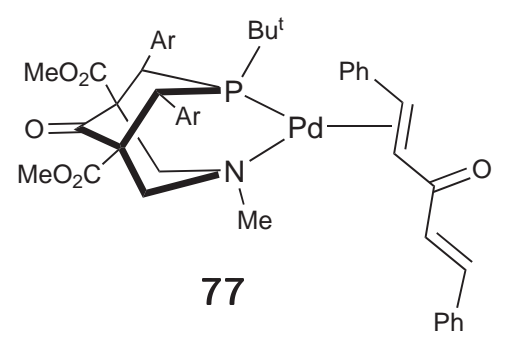

Scheme 3.7 
and is readily soluble in polar solvents but only moderately soluble in benzene and toluene. Complex 77 had a signal in the ${ }^{31} \mathrm{P}$ NMR spectrum at $33.6 \mathrm{ppm}$.

The ${ }^{1} \mathrm{H}$ and ${ }^{13} \mathrm{C}$ NMR spectra (Table 3.3) of complex $[\mathrm{Pd}(\mathrm{dba})(\mathbf{6 5})]$ showed that the coordinated PN ligand had no plane of symmetry. Furthermore, the observation of both coordinated and free alkene signals suggested that the dba ligand was bound to palladium through only one of the double bonds, and that no interchange was occurring between the coordinated and non-coordinated dba double bonds at room temperature on the NMR time scale. This in turn destroyed the symmetrical mirror plane found in metal-bound PN ligand 65.

Table 3.3. NMR data of the olefinic positions of coordinated dba ligand in complex $[\mathrm{Pd}(\mathrm{dba})(\mathbf{6 5})](\mathbf{7 7})$ and free dba.*

\begin{tabular}{|c|c|c|c|c|}
\hline \multirow[b]{2}{*}{$\mathbf{H C}=\mathbf{C H}$} & \multicolumn{2}{|c|}{$\alpha$} & \multicolumn{2}{|l|}{$\beta$} \\
\hline & ${ }^{1} \mathbf{H}$ & ${ }^{13} \mathrm{C}$ & ${ }^{1} \mathbf{H}$ & ${ }^{13} \mathrm{C}$ \\
\hline coordinated & $5.51(\mathrm{~d}, 10.0 \mathrm{H}$ & $59.8(\mathrm{br} \mathrm{s})$ & 4.99 (br s) & $66.9(\mathrm{~m})$ \\
\hline non-coordianted & $7.25(\mathrm{~m})$ & $128.5(\mathrm{~s})$ & $8.12(\mathrm{~d}, 15.6 \mathrm{~Hz})$ & $137.2(\mathrm{~s})$ \\
\hline free dba & $6.88(\mathrm{~d}, 15.9 \mathrm{H}$ & $126.1(\mathrm{~s})$ & $7.80(\mathrm{~d}, 15.9 \mathrm{~Hz})$ & $142.7(\mathrm{~s})$ \\
\hline
\end{tabular}

*Spectra obtained in $\mathrm{C}_{6} \mathrm{D}_{6}$. Chemical shifts in ppm. Multiplicity and coupling constants given in parentheses.

The ${ }^{1} \mathrm{H}$ NMR resonances of the coordinated dba double bond were found at $5.51 \mathrm{ppm}$ for the -proton and $4.99 \mathrm{ppm}$ for the -proton, while those of free dba appeared at 6.88 and 7.80 ppm respectively. The upfield shift of the - and -protons reflects the shielding effect of the palladium metal upon complexation. Conversely, the olefinic protons of the non-coordinated dba double bond were deshielded as their resonances were observed at 7.25 and 8.12 ppm respectively. The effect of metal coordination to only one of the dba double bonds was also evident in the ${ }^{13} \mathrm{C}$ NMR signals. The carbon atoms of the coordinated dba double bond resonated upfield at 59.8 and $66.9 \mathrm{ppm}$, while the other olefinic 
carbon atoms were only affected to a small degree as they appeared at 128.5 and $137.2 \mathrm{ppm}$. The latter ${ }^{13} \mathrm{C}$ NMR signals are similar to the values in free dba (126.1 and $142.7 \mathrm{ppm}$ ). Moreover, the ${ }^{13} \mathrm{C}$ NMR resonance of the dba carbonyl group at 188.8 ppm showed unusual coupling $\left(J_{\mathrm{PC}} 2.2 \mathrm{~Hz}\right)$ to phosphorus through the metal via three bonds.

Two downfield signals at 8.99 and $9.57 \mathrm{ppm}$ were observed for one set of the ortho-protons of the dimethylaminophenyl groups, which also had two nonequivalent methyl singlets at 2.46 and $2.50 \mathrm{ppm}$. In total, eight aromatic proton signals were observed owing to the absence of a symmetry plane in PN ligand 65. Variable temperature ${ }^{1} \mathrm{H}$ and ${ }^{31} \mathrm{P}$ NMR studies were conducted in toluene- $\mathrm{d}_{8}$ from -40 to $80 \mathrm{C}$ to explore any dynamic processes in $\mathbf{7 7}$. No major changes were observed at low temperatures except for some signal broadening. On increasing the temperature, all $\mathrm{PN}{ }^{1} \mathrm{H}$ NMR signals achieved coalescence to give an average spectrum of a symmetric PN ligand at $80 \mathrm{C}$. Higher temperatures were required to observe the coalesced average dba ${ }^{1} \mathrm{H}$ NMR signals as up to $80 \mathrm{C}$ they only broadened until they were indistinguishable from the baseline. The signals of the free dba already present in the solution of 77 were unaffected by the temperature change. The ${ }^{31} \mathrm{P}$ NMR signal of 77 was unaltered over the entire temperature range. These results show that free dba is not involved in any dynamic processes, and that only one isomer of complex $\mathbf{7 7}$ is formed as low temperature NMR spectra showed no new signals. Furthermore, an intramolecular alkene exchange between the coordinated and non-coordinated double bonds of the bound dba ligand in complex 77 occurs at higher temperatures. This exchange, together with rotation about the $\mathrm{Pd}-\mathrm{dba}$ bond, account for the averaged PN NMR signals.

The formation and behaviour of complex $\mathbf{7 7}$ is different from other palladiumdba compounds containing chelating PN ligands. For example, complex 78 containing the ligand $\mathrm{PhPN}$ exhibits one ${ }^{31} \mathrm{P}$ NMR signal at room temperature, 
but two signals are observed at $-13 \mathrm{C}$ indicating that two isomers are formed that are involved in a fast equilibrium at room temperature (Scheme 3.8). ${ }^{87}$ The contrasting behaviour of PN ligand 65 could be due to its large size, which is selectively directing the coordination of dba through one double bond to form one isomer of $[\mathrm{Pd}(\mathrm{dba})(\mathbf{6 5})]$.

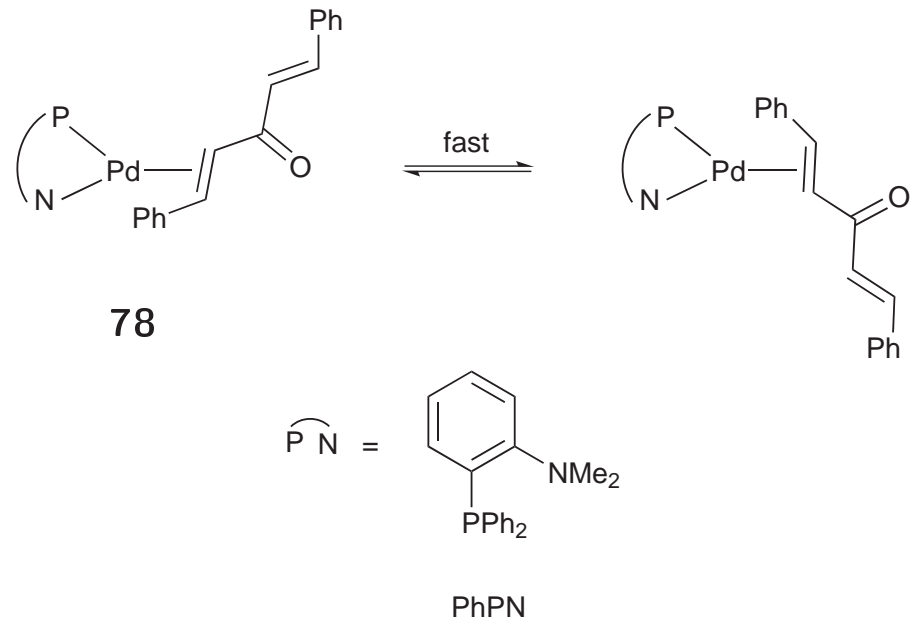

Scheme 3.8

\subsection{Palladium allyl complexes}

Transition metal allyl complexes are intrinsically important in organometallic chemistry and in homogeneous catalysis as they represent key reaction intermediates. ${ }^{88-90}$ The allyl ligand can coordinate to metal centres through $\eta$ or $\eta^{3}$ bonding modes. An asymmetric limit of the $\eta^{3}$ bonding mode has also been described as a $\sigma-$ allyl coordination. ${ }^{89,91}$ The $\eta^{3}$ coordination mode is the most general in Pd-allyl chemistry.

The reaction of $\mathrm{PN}$ ligand $\mathbf{6 5}$ with $\left[\mathrm{Pd}\left(\eta^{3}-\mathrm{C}_{3} \mathrm{H}_{5}\right)(\mu-\mathrm{Cl})\right]_{2}$ in dichloromethane afforded a new allyl chloro $\operatorname{Pd}(\mathrm{II})$ complex (Scheme 3.9). The spectroscopic NMR data collected at $600 \mathrm{MHz}$ at room temperature suggest that an $\eta^{3}$-allyl complex $(\mathbf{7 9})$ is observed in solution, which can be 
formed by the dissociation of the chloride ligand from $\mathbf{8 0}$.

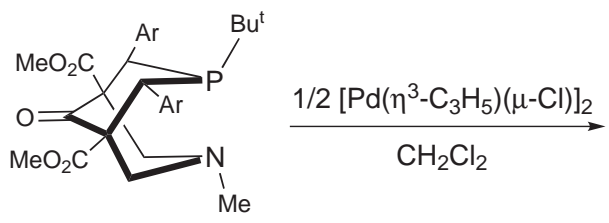

65

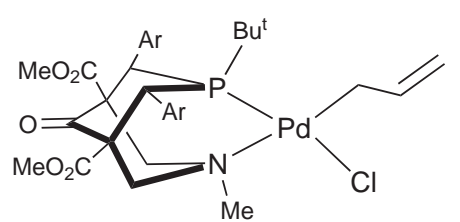

80

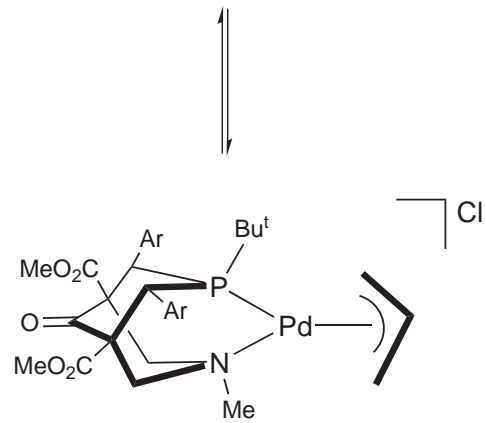

79

\section{Scheme 3.9}

Only four allyl signals were observed in the ${ }^{1} \mathrm{H}$ NMR spectrum. The $\mathrm{CH}_{2}$ group cis to phosphorus resonated at $3.35 \mathrm{ppm}\left(\mathrm{d}, J_{\mathrm{HH}} 9.4 \mathrm{~Hz}\right)$, while two dd were observed for the syn and anti protons of the trans $\mathrm{CH}_{2}$ group at 5.26 and $4.75 \mathrm{ppm}$ respectively. The anti proton exhibited large coupling constants to the central allylic proton $\left(J_{\mathrm{HH}} 14.1 \mathrm{~Hz}\right)$ and to phosphorus $\left(J_{\mathrm{PH}} 9.6 \mathrm{~Hz}\right)$, whereas the syn proton had almost equal couplings $\left(J_{\mathrm{PH}} 7.4\right.$ and $\left.J_{\mathrm{HH}} 7.3 \mathrm{~Hz}\right)$ hence its dd had the appearance of a triplet. A complex multiplet at $6.26 \mathrm{ppm}$ was observed for the central allylic proton.

The appearance of the syn and anti protons of the cis $\mathrm{CH}_{2}$ group as a single resonance is consistent with an $\eta^{3}-\eta$ allyl isomerisation through selective dissociation of the $\mathrm{Pd}-\mathrm{CH}_{2}-\mathrm{CH}$ bond trans to the phosphorus atom. This reflects the larger trans-effect of the $\mathrm{P}$ donor compared to the nitrogen donor atom. The different influences of $\mathrm{P}$ and $\mathrm{N}$ donor atoms were also observed in the ${ }^{13} \mathrm{C}$ NMR chemical shifts. The cis $\mathrm{CH}_{2}$ carbon atom resonated as a doublet 
at $49.5 \mathrm{ppm}\left(J_{\mathrm{PC}} 4.8 \mathrm{~Hz}\right)$, while the trans $\mathrm{CH}_{2}$ carbon atom was observed at $88.1 \mathrm{ppm}\left(J_{\mathrm{PC}} 26.9 \mathrm{~Hz}\right)$. The central allylic carbon atom appeared as a doublet at $122.3 \mathrm{ppm}$ with $J_{\mathrm{PC}}$ of $6.2 \mathrm{~Hz}$.

Looking now at the coordinated PN ligand, the ${ }^{1} \mathrm{H}$ and ${ }^{13} \mathrm{C}$ NMR spectra indicated a symmetrical molecule as only one set of signals was observed. This implies that the $\eta^{3}$-allyl ligand is fluxional at room temperature. In the hope of observing the $\eta$-allyl complex 80, the ${ }^{1} \mathrm{H}$ and ${ }^{13} \mathrm{C}$ NMR spectra were recorded at -80 C. At such temperature no change was observed in the allylic signals suggesting that the fluxional $\eta^{3}$-allyl complex is still the dominant species. In contrast, palladium-allyl complexes containing bidentate oxazoline-based PN ligands exhibit the $\eta^{3}$ bonding mode at low temperatures as indicated by ${ }^{1} \mathrm{H}$ and ${ }^{13} \mathrm{C}$ NMR data. ${ }^{92-95}$ Upon raising the temperature, the chemical shifts progressively move toward those of a static $\eta$-allyl structure, which is always trans to the nitrogen donor atom. For example, at $-96 \mathrm{C}\left(\mathrm{CD}_{2} \mathrm{Cl}_{2}\right)$ the allyl fragment adopts an $\eta^{3}$ bonding mode in complex 81 (Scheme 3.10). ${ }^{93}$ Increasing the temperature results in the formation of complex $\mathbf{8 2}$, in which the allyl ligand is coordinated in an $\eta$ fashion. Moreover, the $X$-ray structure of 82 confirmed the $\eta$-allyl bonding mode and its cis arrangement with the phosphorus atom.

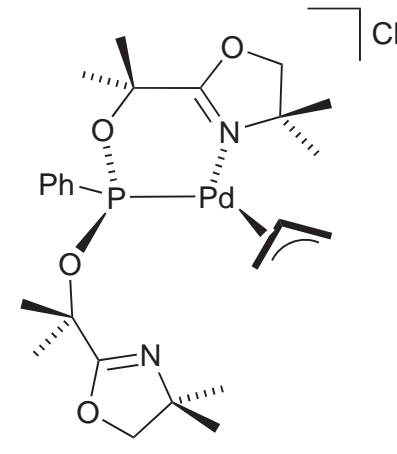

81

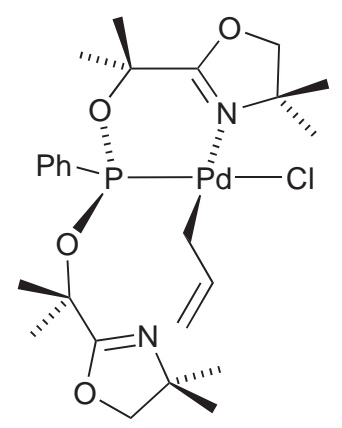

82

Scheme 3.10

The ${ }^{31} \mathrm{P}$ NMR spectrum of the allyl complex showed two signals in a 
3:1 ratio at 38.7 and $39.9 \mathrm{ppm}$ for the ketone (79) and hydrate (83) forms respectively. The hydrated complex had very similar ${ }^{1} \mathrm{H}$ and ${ }^{13} \mathrm{C}$ NMR chemical shifts to the ketone complex with respect to the PN and allyl ligands. For example, a complex multiplet was also observed for the central allylic proton at approximately $5.94 \mathrm{ppm}$. This particular proton is expected to couple to both the cis- and trans- $\mathrm{CH}_{2}$ allylic protons and the phosphorus donor atom. A phosphorus-decoupled ${ }^{1} \mathrm{H}$ NMR spectrum of complexes 79 and 83 showed no change in the coupling pattern of the central allylic proton in both complexes, thus suggesting a lack of coupling between the central allylic proton and the phosphorus atom. To further confirm the absence of phosphorus coupling, the coupling pattern of the central allylic proton in the hydrate analogue $\mathbf{8 3}$ was calculated using the spectral simulation programme gNMR. ${ }^{96}$ The calculated coupling pattern matched exactly the experimental data, hence corroborating the lack of phosphorus coupling (Figure 3.5). Consequently, the coupling pattern of the central allylic proton in complexes $\mathbf{7 9}$ and 83 is a dtd.

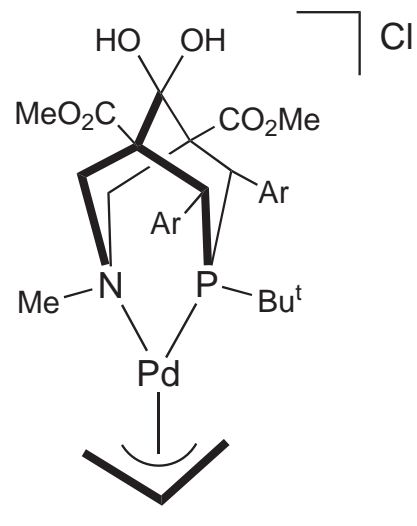

83

The hydrated analogue also had an $\mathrm{OH}$ stretch at $3408 \mathrm{~cm}^{1}$ in the IR spectrum. To obtain more insight into hydrate formation, a few drops of water were added to a sample containing both the ketone and hydrate complexes and the sample was monitored by ${ }^{1} \mathrm{H}$ and ${ }^{31} \mathrm{P}$ NMR over a period of one month. 

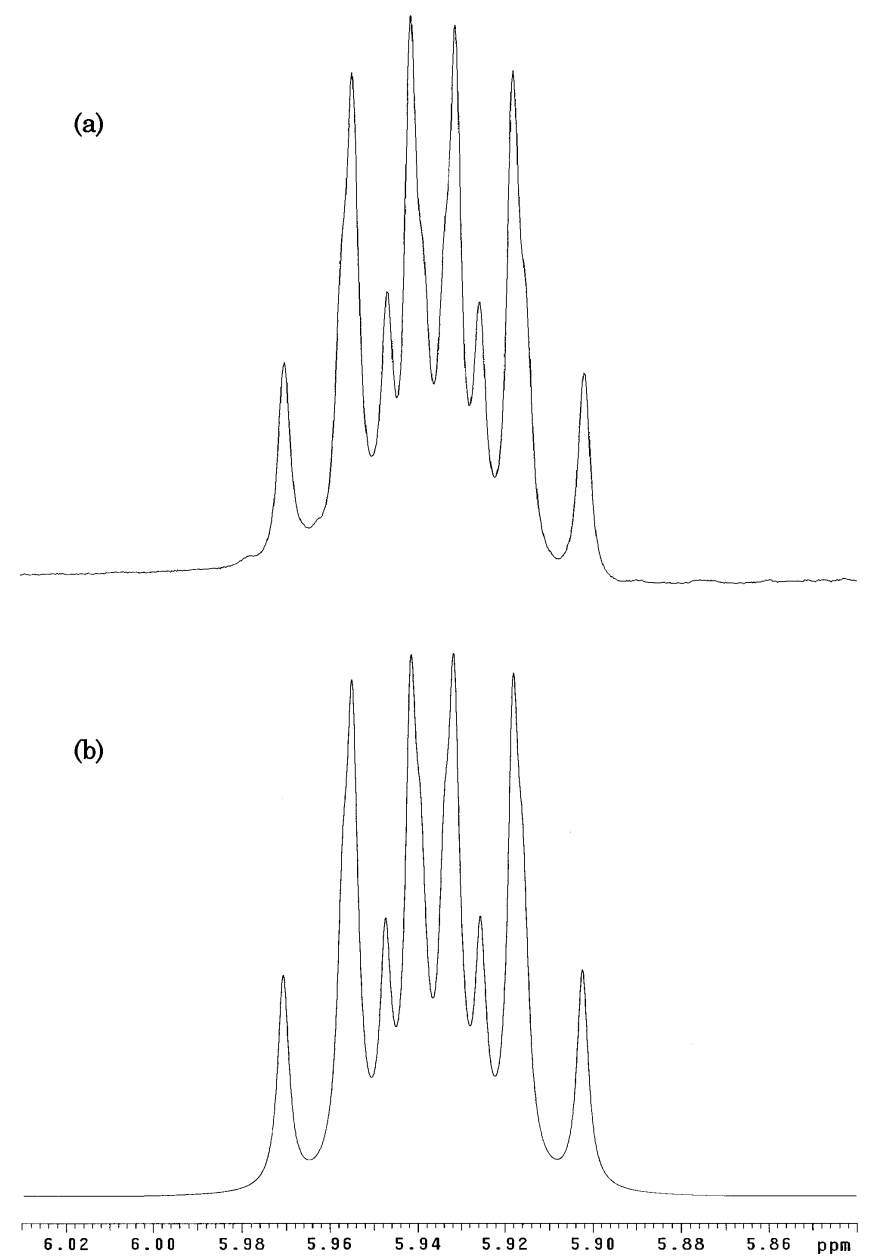

Figure 3.5. ${ }^{1} \mathrm{H}$ NMR spectra of the hydrate form of $\left[\mathrm{Pd}\left(\eta^{3}-\mathrm{C}_{3} \mathrm{H}_{5}\right)(65)\right] \mathrm{Cl}$ complex (83) shown as an expanded-scale display of the central allylic proton signal: (a) experimental spectrum, $\mathrm{CD}_{2} \mathrm{Cl}_{2}, 600 \mathrm{MHz}$; (b) calculated spectrum obtained with gNMR.

The NMR spectra showed no change in the ratio between the two forms of the $\left[\mathrm{Pd}\left(\eta^{3}-\mathrm{C}_{3} \mathrm{H}_{5}\right)(\mathbf{6 5})\right] \mathrm{Cl}$ complex. This suggests that the ketone and hydrate forms are not in equilibrium and that no aqua complex was formed.

In addition, abstraction of the chloride ions from the ketone (79) and hydrate $(\mathbf{8 3})$ forms of $\left[\mathrm{Pd}\left(\eta^{3}-\mathrm{C}_{3} \mathrm{H}_{5}\right)(\mathbf{6 5})\right] \mathrm{Cl}$ using $\mathrm{AgSbF}{ }_{6}$ produced very similar $\eta^{3}$-allyl complexes. The new $\left[\mathrm{Pd}\left(\eta^{3}-\mathrm{C}_{3} \mathrm{H}_{5}\right)(\mathbf{6 5})\right] \mathrm{SbF}_{6}$ complexes also formed in a 3:1 ketone (84) to hydrate (85) ratio. Complexes 84 and $\mathbf{8 5}$ exhibited similar NMR features, which in turn resembled the spectroscopic data for complexes 79 and 83 respectively. For example, the ${ }^{31} \mathrm{P}$ chemical shift for the ketone 
form 84 was observed at $38.8 \mathrm{ppm}$ (cf. $38.7 \mathrm{ppm}$ in complex 79 ), while the ${ }^{31} \mathrm{P}$ NMR signal for the hydrate analogue 85 appeared at 37.7 ppm (cf. 39.9 ppm in complex 83).

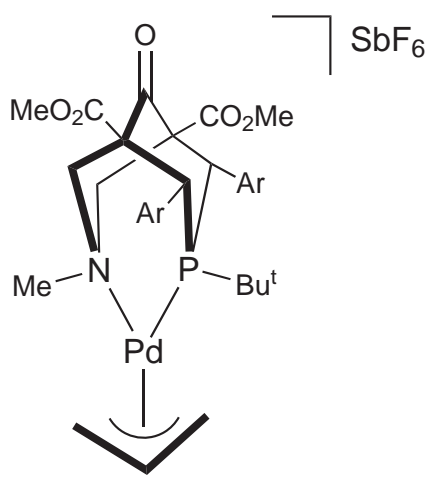

84

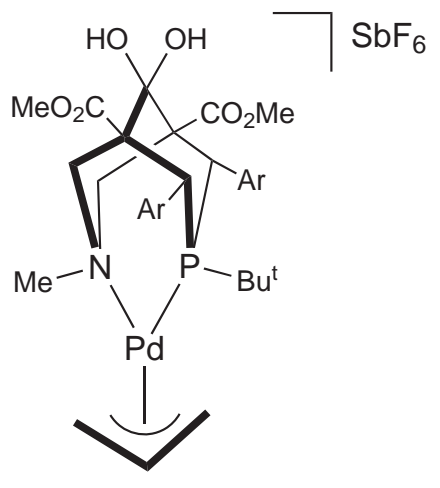

85

\subsection{Metallation reactions}

Cyclometallated compounds describe transition metal complexes in which the ligand has undergone an intramolecular metallation to form a chelate ring containing a metal-carbon $\sigma$-bond.${ }^{97,98}$ Metallation of phenyl-substituted ligands at the ortho-position of the ring is termed ortho-metallation and is very common in coordination complexes. Cyclometallated compounds can undergo a variety of reactions, for example ligand exchange and insertion reactions, and are of interest in organic synthesis.

\section{Ethene complexes}

As discussed previously in section 3.3, the reaction of $\mathrm{PN}$ ligand 65 with tris(ethene)platinum under an ethene atmosphere in benzene- $\mathrm{d}_{6}$ initially produced $\left[\mathrm{Pt}\left(\mathrm{C}_{2} \mathrm{H}_{4}\right)(\mathbf{6 5})\right](\mathbf{7 5})$. After 10 minutes of reaction at room temperature, complex 75 started to convert into a second ethene complex (76). The 
conversion between the two ethene complexes was complete after one day and was accompanied by the formation of ethane, which was observed at $0.78 \mathrm{ppm}$ in the ${ }^{1} \mathrm{H}$ NMR spectrum. The ${ }^{31} \mathrm{P}$ NMR signal for the new complex shifted dramatically from $47.5 \mathrm{ppm}$ in complex 75 to $73.8 \mathrm{ppm}$ with platinum coupling of $3965 \mathrm{~Hz}$. Extensive analysis of the spectroscopic data showed that $\mathbf{7 6}$ was in fact a dimetallated complex in which cyclometallation had occurred at the ortho-positions of both of the dimethylaminophenyl groups (Scheme 3.11). The eliminated ortho-protons were in turn used to hydrogenate some of the dissolved ethene gas to form ethane.

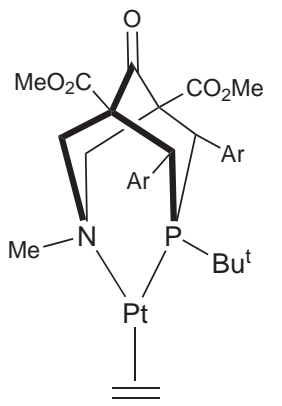

75

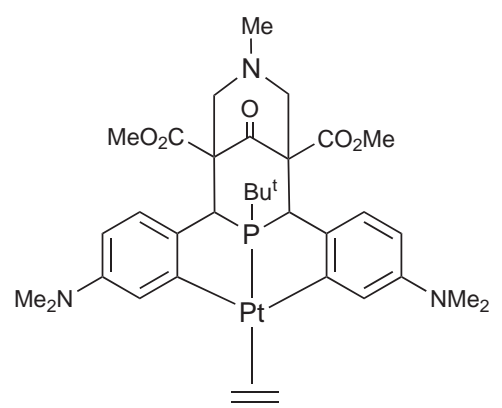

76

Scheme 3.11

The aromatic regions of the ${ }^{1} \mathrm{H}$ NMR spectra show the differences between complexes $\left[\mathrm{Pt}\left(\mathrm{C}_{2} \mathrm{H}_{4}\right)(\mathbf{6 5})\right](\mathbf{7 5})$ and $\left[\mathrm{Pt}\left(\mathrm{C}_{2} \mathrm{H}_{4}\right)(\mathbf{6 5}-2 \mathrm{H})\right]$ (76) very clearly (Figure 3.6). The signal for one set of the ortho-protons at $9.78 \mathrm{ppm}$ disappears in complex 75 as the metal inserts into the aromatic $\mathrm{C}-\mathrm{H}$ bonds. Consequently, the meta-protons at 6.50 and $6.92 \mathrm{ppm}$ now exhibit platinum coupling of 61 and $26 \mathrm{~Hz}$ respectively. The effect of cycloplatination was also felt by the $\mathrm{PCH}$ protons, which are normally found between 3.9 and $4.5 \mathrm{ppm}$, as they shifted downfield to $5.07 \mathrm{ppm}$ and displayed coupling to platinum of $25 \mathrm{~Hz}$. Coordinated ethene protons were observed at $4.02 \mathrm{ppm}$ with $J_{\mathrm{PtH}}$ of $55 \mathrm{~Hz}$, while the olefinic carbon atoms resonated as a singlet at $62.5 \mathrm{ppm}$. Two significant changes were observed in the ${ }^{13} \mathrm{C}$ NMR spectrum of the dimetallated complex: (i) the aromatic 

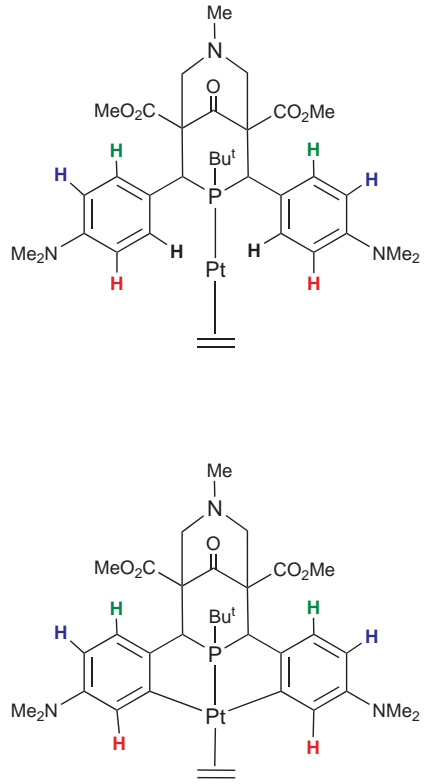

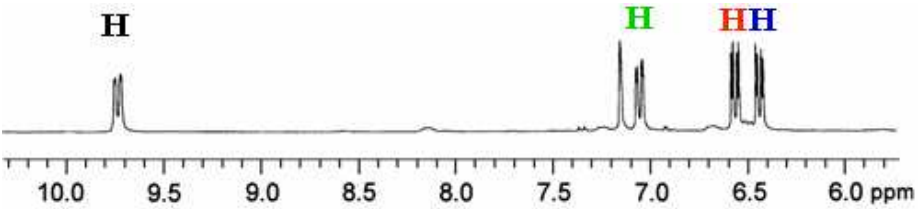

(a)

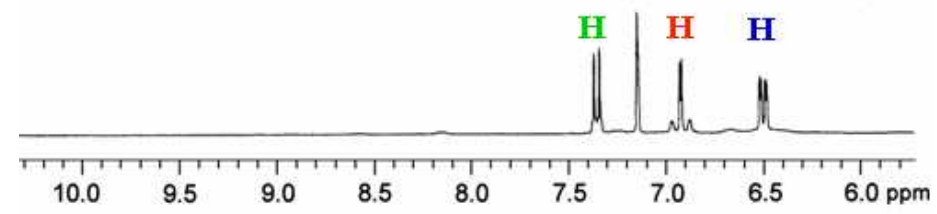

(b)

Figure 3.6. Expanded-scale aromatic regions of the ${ }^{1} \mathrm{H}$ NMR spectra of: (a) $\left[\mathrm{Pt}\left(\mathrm{C}_{2} \mathrm{H}_{4}\right)(65)\right](75)$ and $(\mathrm{b})\left[\mathrm{Pt}\left(\mathrm{C}_{2} \mathrm{H}_{4}\right)(\mathbf{6 5}-2 \mathrm{H})\right](\mathbf{7 6})$. The nitrogen group in complex 75 is not shown to be coordinated for clarity. $300 \mathrm{MHz}, \mathrm{C}_{6} \mathrm{D}_{6}$.

ipso-carbon atoms, which typically resonate between 118 and 120 ppm, were observed at $143.6 \mathrm{ppm}$ as a doublet with a large phosphorus coupling of $18 \mathrm{~Hz}$; (ii) the metallated ortho-carbon atoms were observed at $161.2 \mathrm{ppm}$ as a small doublet $\left(J_{\mathrm{PC}} 2.4 \mathrm{~Hz}\right)$. The spectroscopic data reflect the close proximity of the metal as the proton and carbon atoms are shifted downfield. No platinum coupling was observed in the ${ }^{13} \mathrm{C}$ NMR spectrum due to a weak sample. Large scale synthesis and isolation of complex $\mathbf{7 6}$ was not successful as the complex decomposed into an unidentifiable brown residue.

\section{COD complexes}

In view of the formation of the dimetallated ethene complex $\mathbf{7 6}$, the reaction of PN ligand 65 with bis(cycloocta-1,5-diene)platinum in benzene at room temperature was studied. This reaction was much slower than the reaction of $\left[\mathrm{Pt}\left(\mathrm{C}_{2} \mathrm{H}_{4}\right)_{3}\right]$ with $\mathrm{PN}$ ligand 65. The ${ }^{31} \mathrm{P}$ NMR resonance of the expected 
product $[\mathrm{Pt}(\operatorname{cod})(\mathbf{6 5})](\mathbf{8 6})$ was observed initially at $45.0 \mathrm{ppm}$ with $J_{\mathrm{PtP}}$ of $3621 \mathrm{~Hz}$. Subsequently, a new ${ }^{31} \mathrm{P}$ NMR signal appeared at $70.4 \mathrm{ppm}$ with a slightly larger platinum coupling of $3787 \mathrm{~Hz}$ as 86 converted into a new (87) COD complex (Scheme 3.12). After a period of one day at room temperature, the reaction mixture contained predominately complex 87 and trace amounts of 86. The isolation and characterisation of the initial COD complex 86 was not possible.

The phosphorus chemical shift of the second COD complex 87 is similar to the dimetallated ethene complex 76 (73.8 ppm). This suggests that complex 87 also contains a metallated PN ligand. Detailed analysis of the NMR spectra revealed that cyclometallation had occurred at the ortho-position of only one of the dimethylaminophenyl groups, and that the COD ligand had undergone major changes. The NMR data showed that the COD ligand was bonded to platinum via a $1-3-\eta$-allyl system to form a $\mathrm{C}_{8} \mathrm{H}_{13}$ fragment.

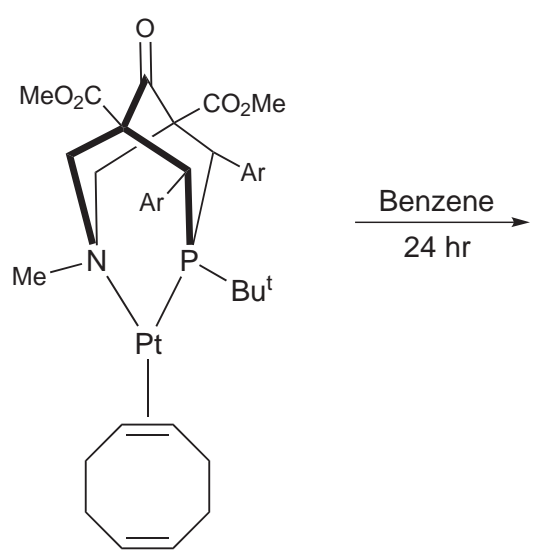

86

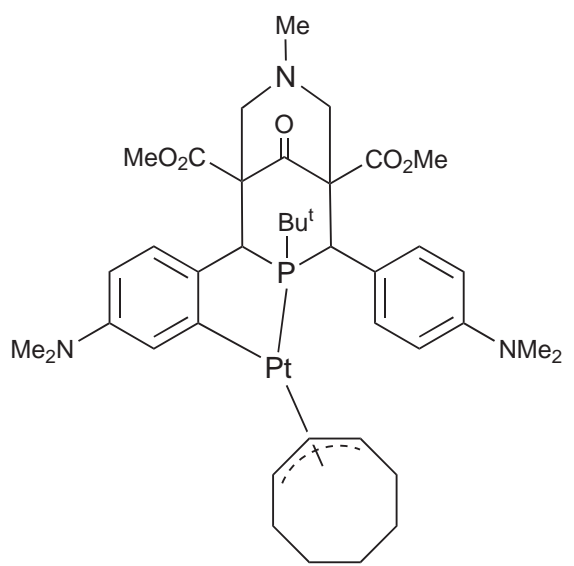

87

Scheme 3.12

Due to the asymmetric binding of the PN ligand in complex 87 , two sets of NMR signals were observed. Three signals were observed for the metallated aryl ring protons at $6.66,7.34$ and $8.28 \mathrm{ppm}$, whereas only two signals were noted 
for the other dimethylaminophenyl ring: a sharp doublet integrating for two meta-protons at $6.52 \mathrm{ppm}$ and a very broad peak at $7.50 \mathrm{ppm}$, which sharpened into a doublet upon increasing the temperature to $40 \mathrm{C}$, representing the orthoprotons. This was quite an unusual observation as the aromatic groups normally exhibit restricted rotation, resulting in four distinct proton environments at room temperature. Upon lowering the temperature to $-30 \mathrm{C}$ and recording the ${ }^{1} \mathrm{H}$ NMR spectrum in toluene- $d_{8}$ four signals were observed. This implies that at room temperature, the signals for the meta-protons had already coalesced but the ortho-protons had only collapsed and needed higher temperatures to achieve coalescence. Furthermore, the averaging of the signals at room temperature must be a consequence of the asymmetric binding mode of PN ligand 65 to platinum, which presumably shifts the five-membered metallacycle slightly to one side allowing the non-metallated ring to rotate freely.

Broad peaks were also observed in the ${ }^{13} \mathrm{C}$ NMR spectrum for the orthoand meta-carbon atoms of the free dimethylaminophenyl ring, while the other ring showed evidence of metallation. The metallated carbon atom appeared as a small doublet $\left(J_{\mathrm{PC}} 1.9 \mathrm{~Hz}\right)$ at $157.6 \mathrm{ppm}$ with a very large platinum coupling of $1188 \mathrm{~Hz}$. All the other carbon atoms displayed platinum couplings ranging from 55 to $75 \mathrm{~Hz}$, except for the para-carbon atom with respect to the metallated position.

Looking at the $\mathrm{C}_{8} \mathrm{H}_{13}$ ligand, three allyl signals were observed at 3.75, 4.29 and $5.08 \mathrm{ppm}$ and five $\mathrm{CH}_{2}$ groups were identified. This suggests that the $\mathrm{C}_{8} \mathrm{H}_{13}$ ligand is asymmetrically bound to the metal. The ${ }^{13} \mathrm{C}$ NMR spectrum supported this observation as the terminal carbon atoms were found to be inequivalent, giving rise to signals at 65.1 and $73.0 \mathrm{ppm}$, while the central allylic carbon atom was observed at $107.3 \mathrm{ppm}$. Moreover, the carbon atom at $65.1 \mathrm{ppm}$ exhibited large phosphorus $(49.6 \mathrm{~Hz})$ and platinum (237 Hz) couplings, implying that it is in a transoid position to phosphorus. The above observations could also 
suggest that the $\sigma, \quad$-bonding model is more appropriate than the $1-3-\eta$-allyl description as a consequence of the larger trans-influence of the metallated carbon donor atom as compared with phosphorus.

\subsection{Protonation reactions}

The presence of a transition metal in an alkyl complex imparts properties to the alkyl group that are unprecedented in normal organic chemistry. As a result, the normally relatively inert $\mathrm{C}-\mathrm{H}$ bonds of an appended ligand can form significant interactions with the metal centre. Agostic interactions describe the coordination of an alkyl ligand to a metal in an $\eta$ fashion, which involves the simultaneous bonding of a hydrogen atom to both a carbon and a metal atom. ${ }^{99-101}$ Such interactions are of prime significance in organometallic chemistry and catalysis as they feature heavily in catalytic intermediates.

The comparative reactions of ethene and COD platinum precursors with PN ligand 65 showed that the close proximity of the dimethylamionphenyl substituents to the metal had led to cycloplatination, and that depending on the nature and size of the other ligands, one or both of the aromatic rings were metallated. The same reactions were therefore studied with the addition of strong protic acids.

The fluorocarbon acids $\mathrm{CH}_{2}\left(\mathrm{SO}_{2} \mathrm{CF}_{3}\right)_{2}$ and $\mathrm{CHPh}\left(\mathrm{SO}_{2} \mathrm{CF}_{3}\right)_{2}$ were chosen for the protonation studies. They were reported by Koshar and Mitsch ${ }^{102}$ in 1973, and have since been used in the protonation reactions of organometallic complexes. ${ }^{103-106}$ These acids were selected because they possess a combination of unique properties. They are strong non-oxidising acids as the $\mathrm{p} K_{\mathrm{a}}$ of bis(trifluoromethylsulfonyl)methane was estimated to be about -1. Both acids are crystalline solids and can be handled easily in the air as they are not hygroscopic. They are soluble in apolar, non-donor solvents such as 
dichloromethane and toluene, and their conjugate bases are essentially noncoordinating.

\section{COD complexes}

In the reaction of $\left[\mathrm{Pt}(\mathrm{cod})_{2}\right]$ with $\mathrm{PN}$ ligand 65 and $\mathrm{CH}_{2}\left(\mathrm{SO}_{2} \mathrm{CF}_{3}\right)_{2}$ in dichloromethane, an anionic complex (88) containing a $1-\sigma, 4-5-\eta-\mathrm{C}_{8} \mathrm{H}_{13}$ ligand was obtained as an air-stable white solid. Examination of the NMR spectra showed that no metallation of $\mathbf{6 5}$ had occurred as protonation probably involved direct attack on the COD ligand in precursor 86. Complex 88 had a ${ }^{31} \mathrm{P}$ NMR signal at $18.1 \mathrm{ppm}$ with platinum coupling of $4304 \mathrm{~Hz}$. Two sets of NMR signals for the coordinated PN ligand $\mathbf{6 5}$ were observed due to the binding mode of the $\mathrm{C}_{8} \mathrm{H}_{13}$ ligand. The $\eta$-bonded olefinic protons resonated at 6.38 and $6.45 \mathrm{ppm}$, and the corresponding carbon atoms were observed at 113.3 and $110.2 \mathrm{ppm}$ as doublets ( $J_{\mathrm{PC}} 10.8$ and $8.7 \mathrm{~Hz}$ respectively). An upfield signal at $18.0 \mathrm{ppm}$ with $J_{\mathrm{PtC}} 601 \mathrm{~Hz}$ was assigned to the carbon-platinum $\sigma$ bond, and its proton was located at $3.08 \mathrm{ppm}$. The above data are in accordance with other complexes containing an identical $\mathrm{C}_{8} \mathrm{H}_{13}$ ligand. ${ }^{107}$ Moreover, the noncoordinated anion $\mathrm{CH}\left(\mathrm{SO}_{2} \mathrm{CF}_{3}\right)_{2}$ was observed at $-81.0 \mathrm{ppm}$ in the ${ }^{19} \mathrm{~F}$ NMR spectrum. In addition, the hydrated analogue of complex 88 was also observed. The hydrated complex formed in a 1:3 ratio to the ketone form and had a ${ }^{31} \mathrm{P}$ NMR signal at $16.1 \mathrm{ppm}\left(J_{\mathrm{PtP}} 4220 \mathrm{~Hz}\right)$.

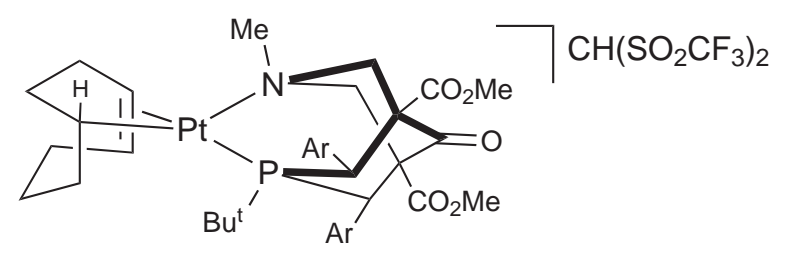

88

Furthermore, the $1-\sigma, 4-5-\eta-\mathrm{C}_{8} \mathrm{H}_{13}$ ligand in complex 88 rearranged slowly 
over time into a $1-3-\eta-\mathrm{C}_{8} \mathrm{H}_{13}$ fragment to give complex 89. The ${ }^{31} \mathrm{P} \mathrm{NMR}$ signal for the new complex was observed at $30.7 \mathrm{ppm}\left(J_{\mathrm{PtP}} 4010 \mathrm{~Hz}\right)$, and its hydrated analogue (90) at $28.4 \mathrm{ppm}\left(J_{\mathrm{PtP}} 3928 \mathrm{~Hz}\right)$.

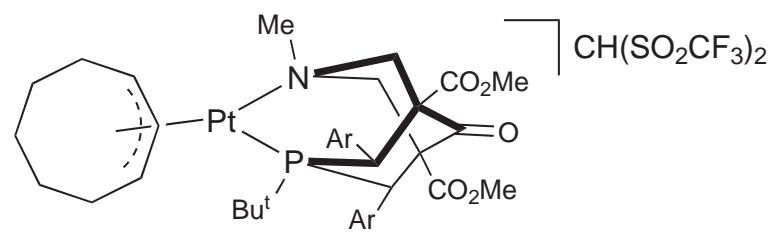

89

The $\mathrm{C}_{8} \mathrm{H}_{13}$ ligand in complex 89 is static at room temperature as the spectroscopic data showed three allylic and five $\mathrm{CH}_{2}$ signals. This resulted in an asymmetric PN ligand. The central allylic proton resonated at $5.85 \mathrm{ppm}$ as a triplet $\left(J_{\mathrm{HH}} 8.4 \mathrm{~Hz}\right)$ with platinum coupling of $64 \mathrm{~Hz}$, while the other $\mathrm{CH}$ protons appeared at 5.55 and $4.20 \mathrm{ppm}$. Their ${ }^{13} \mathrm{C}$ chemical shifts reflected the asymmetry of the platinum-bonded allyl system: the central and one of the terminal $\mathrm{CH}$ carbon atoms exhibited double bond character as they resonated at 109.6 and 91.9 ppm respectively, whereas the other $\mathrm{CH}$ group was found upfield at $49.4 \mathrm{ppm}$ with large coupling to platinum $(270 \mathrm{~Hz})$. In view of the above observations, the bonding mode of the $\mathrm{C}_{8} \mathrm{H}_{13}$ ligand in complex 89 is closer to a $\sigma, \quad$ interaction, and is similar to the $\mathrm{C}_{8} \mathrm{H}_{13}$ ligand in complex 87 .

\section{Ethene complexes}

Protonation studies of the ethene system proved to be much more challenging. Five products were obtained from the reaction of $\left[\mathrm{Pt}\left(\mathrm{C}_{2} \mathrm{H}_{4}\right)_{3}\right]$ with PN ligand 65 and $\mathrm{CH}_{2}\left(\mathrm{SO}_{2} \mathrm{CF}_{3}\right)_{2}$ in benzene. The protonation precursor $\left[\mathrm{Pt}\left(\mathrm{C}_{2} \mathrm{H}_{4}\right)(\mathbf{6 5})\right]$ (75) could not be made first and then added to the acid as it converted to the dimetallated ethene complex $\mathbf{7 6}$.

Three of the products were identified from the ${ }^{31} \mathrm{P}$ NMR signals $(10.0,21.5$ and $24.3 \mathrm{ppm}$ ) as being derived from the PN ligand alone as their ${ }^{31} \mathrm{P}$ resonances 
lacked platinum coupling and were all observed in a control experiment between the PN ligand and acid only. The structure of one of these species (91), the compound with p $21.5 \mathrm{ppm}$, was elucidated by NMR spectroscopy. Analysis revealed that compound $\mathbf{9 1}$ is a protonated form of PN ligand $\mathbf{6 5}$, and that the protonation was at the phosphorus atom as a doublet of triplets was observed at $8.42 \mathrm{ppm}$ with $J_{\mathrm{PH}} 563 \mathrm{~Hz}$ and $J_{\mathrm{HH}} 10.7 \mathrm{~Hz}$ in the ${ }^{1} \mathrm{H}$ NMR spectrum. The formation of compound $\mathbf{9 1}$ suggests that the reaction of the acid with PN ligand 65 is much faster than either the formation of $\left[\mathrm{Pt}\left(\mathrm{C}_{2} \mathrm{H}_{4}\right)(65)\right]$ and/or its reaction with the acid. Unfortunately, the structures of the other two compounds could not be determined.

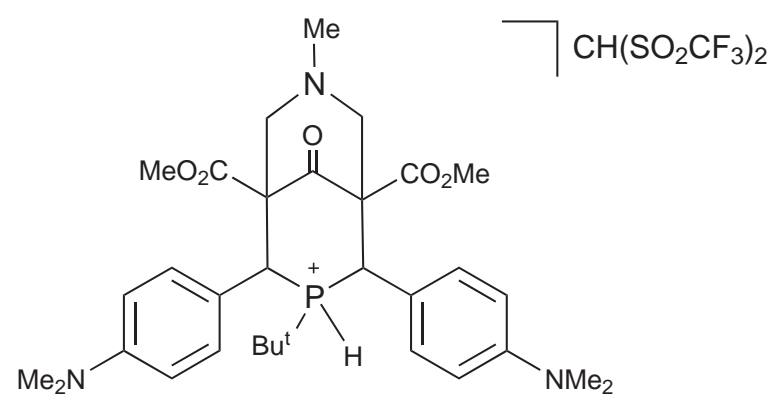

91

Most of the fourth product (92) crystallised out of solution as air-stable long fine colourless needles. The complex had a ${ }^{31} \mathrm{P}$ NMR signal at $33.4 \mathrm{ppm}$ with $J_{\mathrm{PtP}} 3768 \mathrm{~Hz}$. An IR stretch at $2250 \mathrm{~cm}^{1}$ and an upfield signal at $-20.26 \mathrm{ppm}$ with $J_{\mathrm{PtH}} 1285 \mathrm{~Hz}$ in the ${ }^{1} \mathrm{H}$ NMR spectrum confirmed the existence of a hydride ligand. The magnitude of the platinum coupling places the hydride trans to the nitrogen donor atom rather than phosphorus as the latter would result in a smaller platinum coupling due to its larger trans-influence. Analysis of the spectroscopic data showed no coordinated ethene-type signals. This was puzzling as to what ligand was occupying the fourth coordination site on the metal. The nature of the fourth ligand in complex 92 was elucidated from two NMR signals: a doublet at $5.37 \mathrm{ppm}\left(J_{\mathrm{PH}} 6.4 \mathrm{~Hz}\right)$ with platinum coupling of $64 \mathrm{~Hz}$ observed 
in the ${ }^{1} \mathrm{H}$ NMR spectrum, which was attached to a carbon atom at $67.6 \mathrm{ppm}$, which also resonated as a doublet with very large phosphorus $(65.9 \mathrm{~Hz})$ and platinum $(469 \mathrm{~Hz})$ couplings. These NMR chemical shifts are consistent with a $\mathrm{CH}\left(\mathrm{SO}_{2} \mathrm{CF}_{3}\right)_{2}$ ligand covalently bonded to platinum, as observed for, cis- and trans- $\left[\mathrm{PtH}\left\{\mathrm{HC}\left(\mathrm{SO}_{2} \mathrm{CF}_{3}\right)_{2}\right\}\left(\mathrm{Ph}_{3} \mathrm{P}\right)_{2}\right]$ complexes. ${ }^{104}$ This was further supported by a signal at $-74.9 \mathrm{ppm}$ with platinum coupling of $24 \mathrm{~Hz}$ in the ${ }^{19} \mathrm{~F}$ NMR spectrum which is indicative of a coordinated $\mathrm{CH}\left(\mathrm{SO}_{2} \mathrm{CF}_{3}\right)_{2}$ group, as the free anion resonates at $-81.0 \mathrm{ppm}$ with no ${ }^{195} \mathrm{Pt}$ coupling.

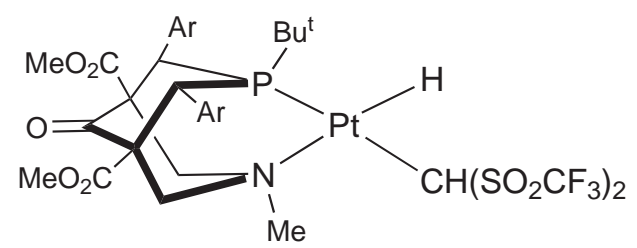

92

To prevent the formation of complex 92, i.e. coordination of the anion $\left[\mathrm{CH}\left(\mathrm{SO}_{2} \mathrm{CF}_{3}\right)_{2}\right]$ to the metal, the bulky phenyl analogue $\left[\mathrm{CHPh}\left(\mathrm{SO}_{2} \mathrm{CF}_{3}\right)_{2}\right]$ was used. Indeed, no product similar to complex $\mathbf{9 2}$ containing a metal-bound $\mathrm{CPh}\left(\mathrm{SO}_{2} \mathrm{CF}_{3}\right)_{2}$ group was observed. However, multiple products were also formed in this reaction, including compounds derived from the PN ligand only.

The final product $(\mathbf{9 3})$ from the protonation reaction of the ethene system had a ${ }^{31} \mathrm{P}$ NMR signal at $11.3 \mathrm{ppm}$ with a very large ${ }^{195} \mathrm{Pt}$ coupling of $5424 \mathrm{~Hz}$. This was the lowest observed ${ }^{31} \mathrm{P}$ NMR chemical shift for a transition metal complex containing PN ligand 65. The ${ }^{1} \mathrm{H}$ NMR spectrum showed a triplet at $1.22 \mathrm{ppm}\left(J_{\mathrm{HH}} 7.5 \mathrm{~Hz}\right)$ and a quartet at $1.91 \mathrm{ppm}\left(J_{\mathrm{HH}} 6.7 \mathrm{~Hz}\right)$ in a $3: 2$ ratio. Based on the NMR data, 93 could either be a 14-electron 3-coordinate complex containing an ethyl ligand, or alternatively an agostic complex with a three-centre, two-electron Pt-H-C ( -agostic) interaction (Figure 3.7). The triplet resonance represents the $\mathrm{CH}_{3}$ group of the 14-electron complex, or the 
agostic and $\mathrm{C}$ protons which are interchanging at room temperature. The quartet signal corresponds to the $\mathrm{CH}_{2}$ unit. The magnitude of the $\mathrm{Pt}-\mathrm{P}$ coupling constant is appropriate for both of the proposed chemical structures of complex 93. The $\mathrm{CH}\left(\mathrm{SO}_{2} \mathrm{CF}_{3}\right)_{2}$ group is not coordinated to the metal as a signal at $-81.0 \mathrm{ppm}$ was observed in the ${ }^{19} \mathrm{~F}$ NMR spectrum. The ${ }^{13} \mathrm{C}$ chemical shifts of the ethyl ligand could not be obtained from the NMR spectra recorded at room temperature. Variable-temperature NMR studies on complex 93 revealed no useful information about the $\mathrm{C}_{2} \mathrm{H}_{5}$ moiety.
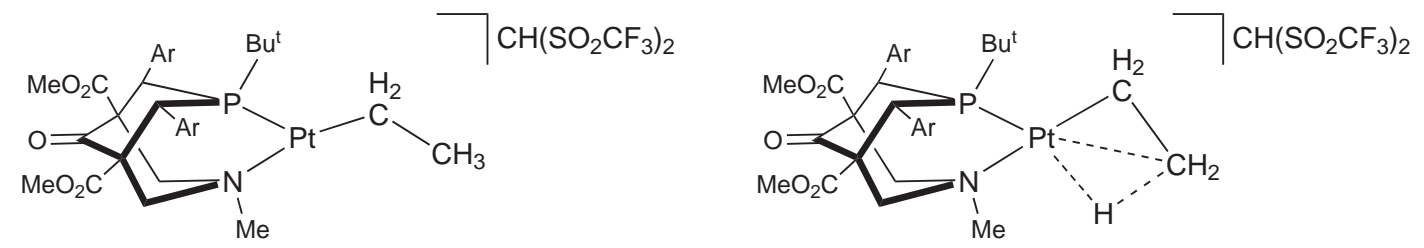

Figure 3.7. Possible structures of complex 93

The agostic form of complex $\mathbf{9 3}$ is the expected product from the protonation reaction of complex $\left[\mathrm{Pt}\left(\mathrm{C}_{2} \mathrm{H}_{4}\right)_{2}(\mathbf{6 5})\right]$ (75). Previous work has shown that ethyl agostic complexes are in equilibrium with the alkene/hydride forms and that several factors influence the position of the equilibrium, such as the nature of the complex and the ancillary ligands present. ${ }^{99,108,109}$ The ethyl agostic moiety in platinum complexes containing bis-phosphine ligands show facile scrambling of all five protons and both carbon atoms such that sharp averaged signals are observed in the NMR spectra at room temperature. ${ }^{108}$ These observations are attributed to rapid intramolecular rearrangement processes involving both the alkyl form, for which methyl rotation is rapid, and the alkene/hydride form, in which ethene rotation is facile (Scheme 3.13). In contrast, cobalt complexes of the type $\left[\mathrm{Co}\left(\eta-\mathrm{C}_{5} \mathrm{Me}_{5}\right) \mathrm{Et}\left(\mathrm{PR}_{3}\right)\right]$ show one ${ }^{1} \mathrm{H}$ NMR signal for the agostic methyl protons and two resonances for the methylene protons at room temperature. ${ }^{110}$ Thus, the agostic form of complex 93 resembles the cobalt complexes as two distinct ${ }^{1} \mathrm{H}$ NMR signals were observed at 1.22 and $1.91 \mathrm{ppm}$ 
for the ethyl group.

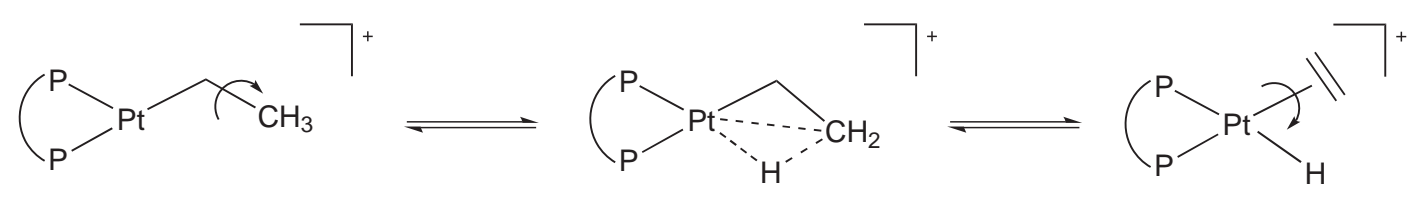

Scheme 3.13

The alkene-hydride form of $\mathbf{9 3}$ was not observed at room temperature, but it could well be the precursor to complex 92 by simple substitution of the coordinated ethene molecule with the anion $\mathrm{CH}\left(\mathrm{SO}_{2} \mathrm{CF}_{3}\right)_{2}$. Due to the numerous products formed, accurate elemental analytical data could not be obtained for complex 93 but its molecular weight was confirmed by mass spectrometry.

\section{Norbornene complexes}

The protonation reaction of $[\mathrm{Pt}($ norb $) 65](\mathbf{7 4})$ with $\mathrm{CH}_{2}\left(\mathrm{SO}_{2} \mathrm{CF}_{3}\right)_{2}$ acid was also studied. This reaction produced only two products. The minor product was identified as $\left[\mathrm{PtH}\left(\mathrm{CH}\left(\mathrm{SO}_{2} \mathrm{CF}_{3}\right)_{2}\right)(\mathbf{6 5})\right](\mathbf{9 2})$, suggesting that the $\left[\mathrm{CH}\left(\mathrm{SO}_{2} \mathrm{CF}_{3}\right)_{2}\right]$ anion has the propensity to coordinate to platinum in such reactions. The major product had a very similar ${ }^{31} \mathrm{P}$ signal to 92 at $34.8 \mathrm{ppm}$ (cf. $35.5 \mathrm{ppm}$, $\left.J_{\mathrm{PtP}} 3724\right)$ but with very large platinum coupling of $6013 \mathrm{~Hz}$, which indicates that the phosphorus atom is trans to a weakly bound ligand such as an agostic $\mathrm{C}-\mathrm{H}$ bond. A broad doublet of doublets signal in the ${ }^{1} \mathrm{H}$ NMR spectrum at -1.02 ppm supported this observation, as it corresponded to the agostic proton being coupled to phosphorus $\left(J_{\mathrm{PH}} 50.3 \mathrm{~Hz}\right)$ and its geminal partner $\left(J_{\mathrm{HH}} 13.6 \mathrm{~Hz}\right)$. However, no platinum-proton coupling was observed. Since this protonation reaction produced the desired agostic norbornyl complex in high yields, the reaction was repeated with $\mathrm{CHPh}\left(\mathrm{SO}_{2} \mathrm{CF}_{3}\right)_{2}$ to completely eliminate the formation of $\mathbf{9 2}$. This indeed was the case and the agostic complex $\mathbf{9 4}$ was 
obtained in $71 \%$ yield, of which $10 \%$ was in the hydrated form $(\mathbf{9 5})$. The ${ }^{31} \mathrm{P}$ NMR chemical shift of complex $\mathbf{9 4}$ was slightly different due to the different acid and was observed at $33.8 \mathrm{ppm}\left(J_{\mathrm{PtP}} 6008 \mathrm{~Hz}\right)$, while the ${ }^{31} \mathrm{P}$ NMR signal for the hydrate analogue resonated at $31.6 \mathrm{ppm}\left(J_{\mathrm{PtP}} 5886 \mathrm{~Hz}\right)$.

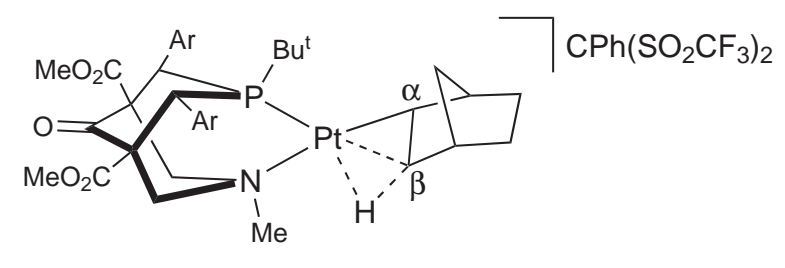

94

The inward diffusion of diethyl ether into a dichloromethane solution yielded crystals suitable for single crystal $X$-ray diffraction. The particular crystal that was examined contained a molecule each of the ketone (94) and hydrate (95) forms of $\left[\mathrm{Pt}\left(\eta-\mathrm{C}_{7} \mathrm{H}_{11}\right)(\mathbf{6 5})\right] \mathrm{CPh}\left(\mathrm{SO}_{2} \mathrm{CF}_{3}\right)_{2}$ in the asymmetric unit (Figure 3.8). A summary of the crystallographic data are compiled in Table 3.4.

Looking at the ketone form 94, the solid-state structure of $\left[\operatorname{Pt}\left(\eta-\mathrm{C}_{7} \mathrm{H}_{11}\right)(\mathbf{6 5})\right]$ shows that the norbornyl ligand is bound via both a $\sigma$-bond to the -carbon and a -agostic interaction. Consequently, the carbon atom C33 is within the normal $\sigma$-bond distance to platinum $(2.02(1) \AA)$, whereas C34 is more remote $(2.37(1) \AA)$ due to its bonding mode and the strong trans-influence of phosphorus, but is still close enough to interact with the metal (Table 3.5). The agostic proton was located directly (Pt-H1 2.05, C34-H1 $1.16 \AA$ ) and lies in the coordination plane defined by Pt, P1 and N1. The rigidity of the coordinated PN ligand in both the ketone and hydrate forms of $\left[\operatorname{Pt}\left(\eta-\mathrm{C}_{7} \mathrm{H}_{11}\right)(\mathbf{6 5})\right]$ is reflected in the distance between the phosphorus and nitrogen donor atoms as it is $3.0 \AA$, which is very similar to the free ligand ( $c f$. $2.9 \AA$ ) and the same as in the dichloro-complex 69. In addition, in both the ketone and hydrate $X$-ray crystal structures, the agostic interaction is trans 


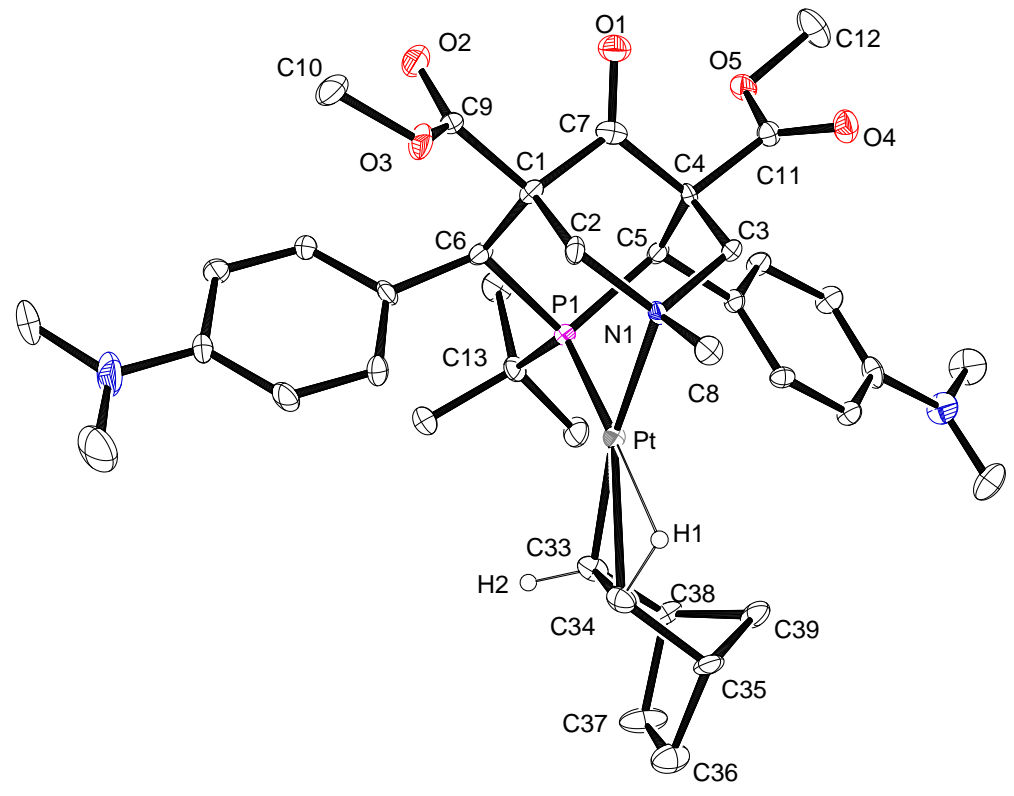

(a)

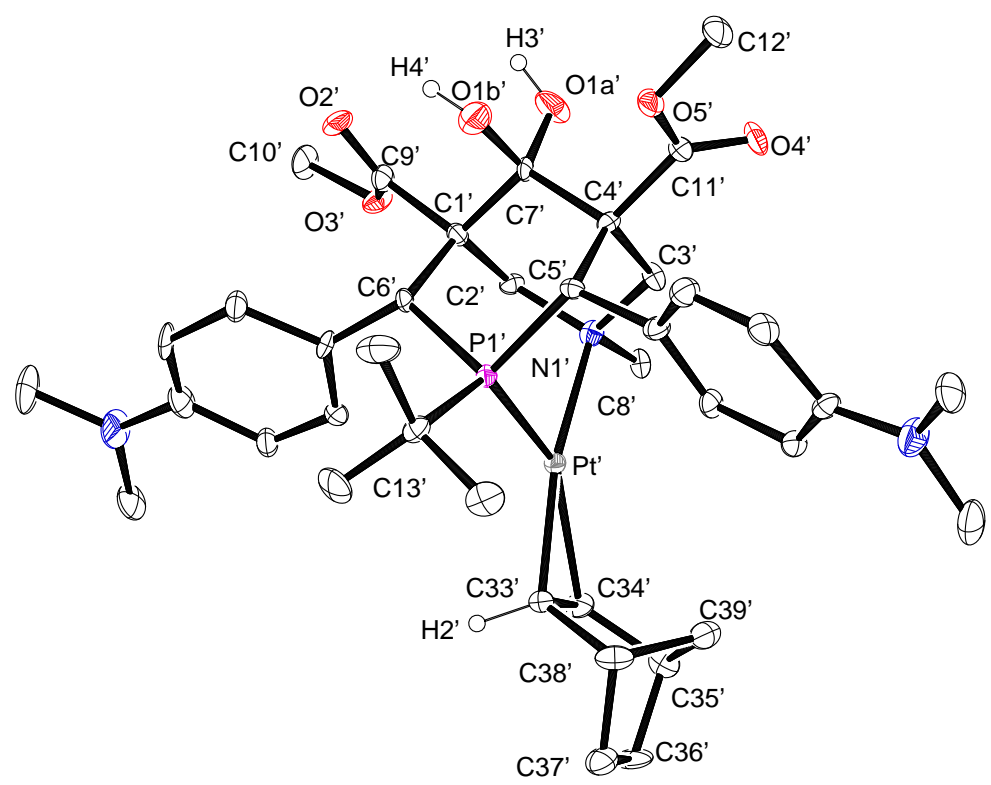

(b)

Figure 3.8. ORTEP diagrams of $\left[\mathrm{Pt}\left(\eta-\mathrm{C}_{7} \mathrm{H}_{11}\right)(\mathbf{6 5})\right]$ : (a) ketone form 94 and (b) hydrate form $\mathbf{9 5}$ (30\% thermal ellipsoids). Most hydrogen atoms and the $\mathrm{CPh}\left(\mathrm{SO}_{2} \mathrm{CF}_{3}\right)_{2}$ anions are omitted for clarity. 
Table 3.4. Crystallographic data of norbornyl agostic complexes 94 and $\mathbf{9 5 .}$

\begin{tabular}{|c|c|}
\hline Empirical formula & $\mathrm{C}_{96} \mathrm{H}_{122} \mathrm{~N}_{6} \mathrm{O}_{19} \mathrm{P}_{2} \mathrm{~S}_{4} \mathrm{~F}_{12} \mathrm{Pt}_{2}{ }^{*}$ \\
\hline Formula weight & 1227.17 \\
\hline Crystal system & Triclinic \\
\hline Space group & $P 1$ \\
\hline $\mathrm{a} / \AA$ & $13.313(1)$ \\
\hline $\mathrm{b} / \AA$ & $14.961(1)$ \\
\hline $\mathrm{c} / \AA$ & $16.193(1)$ \\
\hline$\alpha /$ & $91.528(2)$ \\
\hline / & $97.270(2)$ \\
\hline / & $114.749(2)$ \\
\hline $\mathrm{V} / \AA^{3}$ & 2894.0 \\
\hline $\mathrm{Z}$ & 2 \\
\hline Cell determination reflections & 9822 \\
\hline Cell determination range, $\min -\max /$ & $2.28-30.89$ \\
\hline Temperature/K & $119(2)$ \\
\hline Radiation type & Mo K $\alpha$ \\
\hline Radiation ( )/§ & 0.71073 \\
\hline Crystal size/ mm & $0.46 \times 0.41 \times 0.38$ \\
\hline $\mathrm{D}_{\text {calc }} / \mathrm{g} \mathrm{m}^{3}$ & 1.408 \\
\hline $\mathrm{F}(000)$ & 1240 \\
\hline $\mathrm{mm}$ & 2.59 \\
\hline $\mathrm{T}_{\max }, \mathrm{T}_{\min }$ & $0.747,0.585$ \\
\hline Reflections collected & $88313, R_{\text {equiv }}=0.0393$ \\
\hline Index range $h$ & $-20-21$ \\
\hline Index range $k$ & $-22-23$ \\
\hline Index range $l$ & $-25-24$ \\
\hline range/ & $2.55-35.21$ \\
\hline Independent reflections & 40129 \\
\hline Reflections $\left[\begin{array}{lll}I & 2 & (I)\end{array}\right]$ & 33422 \\
\hline Restraints/parameters & $3 / 1296$ \\
\hline GOF & 1.054 \\
\hline$R \quad\left[\begin{array}{lll}I & 2 & (I)\end{array}\right]$ & 0.047 \\
\hline $\mathrm{w} R 2\left[\begin{array}{lll}I & 2 & (I)\end{array}\right]$ & 0.13 \\
\hline$R \quad$ [all data] & 0.060 \\
\hline $\mathrm{w} R 2$ [all data] & 0.14 \\
\hline
\end{tabular}

*Combined formulae of ketone and hydrate molecules. 
Table 3.5. Selected interatomic distances $(\AA)$ and interbond angles ( ) for the ketone (94) and hydrate (95) forms of $\left[\mathrm{Pt}\left(\eta-\mathrm{C}_{7} \mathrm{H}_{11}\right)(\mathbf{6 5})\right]$.

\begin{tabular}{|c|c|c|c|c|c|}
\hline \multicolumn{3}{|c|}{ Bond distances $(\AA)$} & \multicolumn{3}{|c|}{ Bond angles ( ) } \\
\hline & 94 & 95 & & 94 & 95 \\
\hline $\mathrm{Pt}-\mathrm{P} 1$ & $2.197(3)$ & $2.197(3)$ & $\mathrm{P} 1-\mathrm{Pt}-\mathrm{N} 1$ & $86.1(2)$ & $85.3(2)$ \\
\hline $\mathrm{Pt}-\mathrm{N} 1$ & $2.18(1)$ & $2.20(1)$ & $\mathrm{C} 33-\mathrm{Pt}-\mathrm{C} 34$ & $40.1(3)$ & $39.3(4)$ \\
\hline $\mathrm{Pt}-\mathrm{C} 33$ & $2.02(1)$ & $2.04(1)$ & $\mathrm{P} 1-\mathrm{Pt}-\mathrm{C} 33$ & $111.2(2)$ & $111.2(3)$ \\
\hline $\mathrm{Pt}-\mathrm{C} 34$ & $2.37(1)$ & $2.36(1)$ & $\mathrm{P} 1-\mathrm{Pt}-\mathrm{C} 34$ & $150.2(2)$ & $149.6(2)$ \\
\hline C33-C34 & $1.54(1)$ & $1.50(1)$ & $\mathrm{N} 1-\mathrm{Pt}-\mathrm{C} 33$ & $162.6(3)$ & $163.3(3)$ \\
\hline $\mathrm{Pt}-\mathrm{H} 1$ & 2.05 & * & $\mathrm{N} 1-\mathrm{Pt}-\mathrm{C} 34$ & $122.7(2)$ & $124.3(3)$ \\
\hline C34-H1 & 1.16 & $*$ & $\mathrm{Pt}-\mathrm{C} 34-\mathrm{H} 1$ & 59.6 & * \\
\hline $\mathrm{C} 33-\mathrm{H} 2$ & 0.98 & 0.98 & $\mathrm{Pt}-\mathrm{H} 1-\mathrm{C} 34$ & 91.2 & * \\
\hline $\mathrm{C} 7-\mathrm{O} 1$ & $1.19(1)$ & - & $\mathrm{C} 34-\mathrm{Pt}-\mathrm{H} 1$ & 29.3 & * \\
\hline $\mathrm{C} 7-\mathrm{O} 1 \mathrm{a}$ & - & $1.29(1)$ & $\mathrm{P} 1-\mathrm{Pt}-\mathrm{H} 1$ & 178.4 & * \\
\hline $\mathrm{C} 7-\mathrm{O} 1 \mathrm{~b}$ & - & $1.47(1)$ & $\mathrm{N} 1-\mathrm{Pt}-\mathrm{H} 1$ & 94.1 & * \\
\hline C34-C35 & $1.52(1)$ & $1.50(1)$ & $\mathrm{Pt}-\mathrm{P} 1-\mathrm{C} 5$ & $110.1(3)$ & 109.7(3) \\
\hline C35-C36 & $1.56(1)$ & $1.49(1)$ & $\mathrm{Pt}-\mathrm{N} 1-\mathrm{C} 2$ & $113.9(5)$ & $112.2(6)$ \\
\hline C36-C37 & $1.53(2)$ & $1.58(2)$ & $\mathrm{C} 5-\mathrm{P} 1-\mathrm{C} 6$ & $99.6(4)$ & $101.8(4)$ \\
\hline C37-C38 & $1.57(2)$ & $1.51(1)$ & $\mathrm{C} 2-\mathrm{N} 1-\mathrm{C} 3$ & $108.9(7)$ & $112.8(7)$ \\
\hline C33-C38 & $1.52(1)$ & $1.54(2)$ & $\mathrm{C} 1-\mathrm{C} 7-\mathrm{C} 4$ & $110.4(7)$ & $113.1(7)$ \\
\hline C38-C39 & $1.55(2)$ & $1.53(2)$ & $\mathrm{Pt}-\mathrm{C} 33-\mathrm{C} 34$ & $82.4(5)$ & $81.7(5)$ \\
\hline \multirow[t]{3}{*}{ C35-C39 } & $1.51(1)$ & $1.53(2)$ & $\mathrm{Pt}-\mathrm{C} 34-\mathrm{C} 33$ & $57.4(5)$ & $59.0(4)$ \\
\hline & & & C33-C34-C35 & $103.4(8)$ & $105.0(8)$ \\
\hline & & & $\mathrm{C} 34-\mathrm{C} 33-\mathrm{C} 38$ & 103.7(8) & $102.6(9)$ \\
\hline
\end{tabular}

*Not observed.

to the phosphorus donor atom. This could be a consequence of the stronger trans-influence of the phosphorus atom, which places the strong $\sigma$-bond trans to the nitrogen donor atom. This situation is very similar to the PN palladiumallyl systems in which the $\eta$-allyl ligand is always trans to nitrogen, while the chloride ion is trans to phosphorus making it labile and able to form the corresponding $\eta^{3}$-allyl complexes (Section 3.4).

The crystallographic dimensions of the ketone $\mathbf{9 4}$ and hydrate $\mathbf{9 5}$ forms of $\left[\mathrm{Pt}\left(\eta-\mathrm{C}_{7} \mathrm{H}_{11}\right)(65)\right] \mathrm{CPh}\left(\mathrm{SO}_{2} \mathrm{CF}_{3}\right)_{2}$ are very similar as shown in Table 3.5, suggesting that the hydrate form is chemically equivalent to the dominant ketone form (Figure 3.9). The agostic hydrogen atom could not be located in the hydrate 
form but both of the $\mathrm{OH}$ hydrogens were found. The hydroxylic $\mathrm{H} 4$ proton was found to be hydrogen bonded to the ester carbonyl oxygen $\mathrm{O} 2$, whereas no such interaction was possible for $\mathrm{H} 3$. The $\mathrm{C}-\mathrm{O}$ bond lengths however were found to be anomalous: the $\mathrm{C} 7$-O1a bond was very short (1.29(1) $\AA$ ) for a C-O single bond and almost like a $\mathrm{C}=\mathrm{O}$ double bond, while the $\mathrm{C} 7-\mathrm{O} 1 \mathrm{~b}$ bond was significantly longer $(1.47(1) \AA)$. These bond distances are also different from other metal complexes containing hydrated bispidinone ligands, in which the average $\mathrm{C}-\mathrm{O}$ bond lengths were 1.394 and $1.404 \AA .{ }^{33}$ The anomaly suggests that the crystallographic position of the $\mathrm{C} 7$ carbon atom is not entirely correct in complex 95, and that it could be due to some crystallographic artifact. Nonetheless, the $\mathrm{C}-\mathrm{O}$ bond distances should be compared with other metal complexes containing similar hydrated PN ligands when they become available to obtain a more general idea about such complexes and how they differ from their bispidinone counterparts.

Furthermore, the crystallographic parameters of the norbornyl ligand in 94 were compared (Table 3.6) with $\left[\mathrm{Pt}\left(\mathrm{C}_{7} \mathrm{H}_{11}\right)(\mathrm{L}-\mathrm{L})\right] \mathrm{BF}_{4} \quad$ (96), $\left[\mathrm{L}-\mathrm{L}=\mathrm{Bu}_{2}^{\mathrm{t}} \mathrm{P}\left(\mathrm{CH}_{2}\right)_{2} \mathrm{PBu}_{2}^{\mathrm{t}}\right]$, reported by Spencer and co-workers. ${ }^{111}$ Although the parameters are similar, they do indicate that the agostic interaction in $\mathbf{9 4}$ is weaker. This was concluded from longer $\mathrm{Pt}-\mathrm{C}$ and $\mathrm{Pt}-\mathrm{H}$ bond lengths (2.37(1) and $2.05 \AA$ respectively), which in turn resulted in appreciably shorter Pt-P1 and $\mathrm{C}-\mathrm{H}$ bond distances $(2.197(3)$ and $1.16 \AA$ respectively). As a consequence, the norbornyl carbon atoms bonded to the metal are now more $\mathrm{sp}^{3}$ in character than $\mathrm{sp}$, as in complex $\mathbf{9 6}$, as the $\mathrm{C}-\mathrm{C}$ bond is much longer (1.54(1) $\AA, c f .1 .480(6) \AA)$. The weaker agostic interaction in complex 94 was further supported by the very large $J_{\mathrm{PtP}}$ coupling constant of $6013 \mathrm{~Hz}$, which is appreciably larger than $4909 \mathrm{~Hz}$ in complex $\mathbf{9 6 .}$

Wholly consistent with the solid-state structure, the solution NMR data of the agostic complex 94 showed that the norbornyl ligand is bound to the 


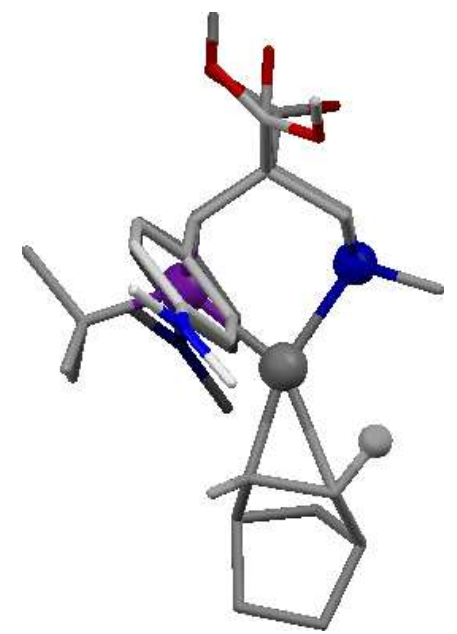

(a)

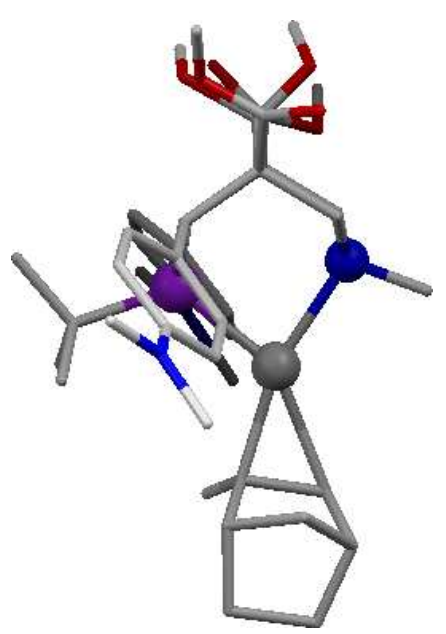

(b)

Figure 3.9. Crystallographic views of (a) ketone form (94) and (b) hydrate form $(\mathbf{9 5})$ of the norbornyl agostic complex $\left[\mathrm{Pt}\left(\eta-\mathrm{C}_{7} \mathrm{H}_{11}\right)(\mathbf{6 5})\right]$.

Table 3.6. Comparison between the agostic bond distances $(\AA)$ in complexes 94 and 96.

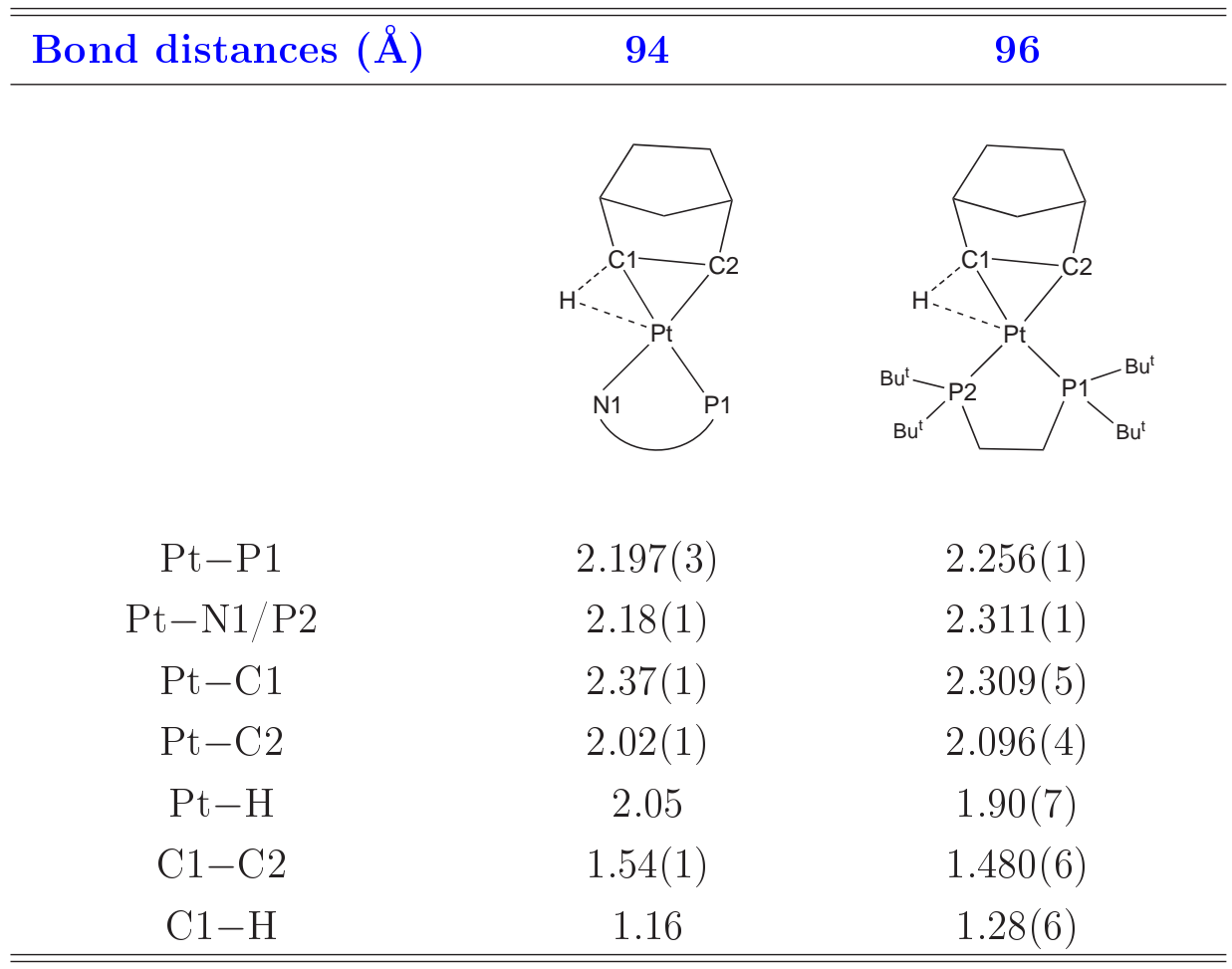


metal through both $\sigma$-alkyl and -agostic interactions. The -carbon and its proton were located at 38.7 and 3.12 ppm respectively, whereas the -carbon resonated at $26.3 \mathrm{ppm}$ and the non-agostic proton at $1.37 \mathrm{ppm}$. The presence of such an agostic bond would be expected to manifest itself in a substantially diminished ${ }^{1} J_{\mathrm{CH}}$ coupling constant for the agostic hydrogen atom, due to the reduced $\mathrm{C}-\mathrm{H}$ bond order in the two-electron, three-centre $\mathrm{C}-\mathrm{H}-\mathrm{M}$ bond. ${ }^{99}$ This was indeed the case as the -carbon atom showed proton couplings of 70 and $173 \mathrm{~Hz}$. Although only six, rather than seven, ${ }^{13} \mathrm{C}$ NMR resonances were noted for the agostic norbornyl ligand as the signals for the $\mathrm{CH}_{2}$ groups overlapped, the NMR data showed that the agostic complex $\mathbf{9 4}$ did not undergo any dynamic behaviour at room temperature. This is in contrast with complex 96, in which the agostic hydrogen is rapidly transferred to the metal to give an intermediate alkene-hydride species for which rotation about the metal-alkene bond is facile (Scheme 3.14). This results in a time-averaged NMR spectrum for the agostic norbornyl ligand such that only four carbon environments are discerned.

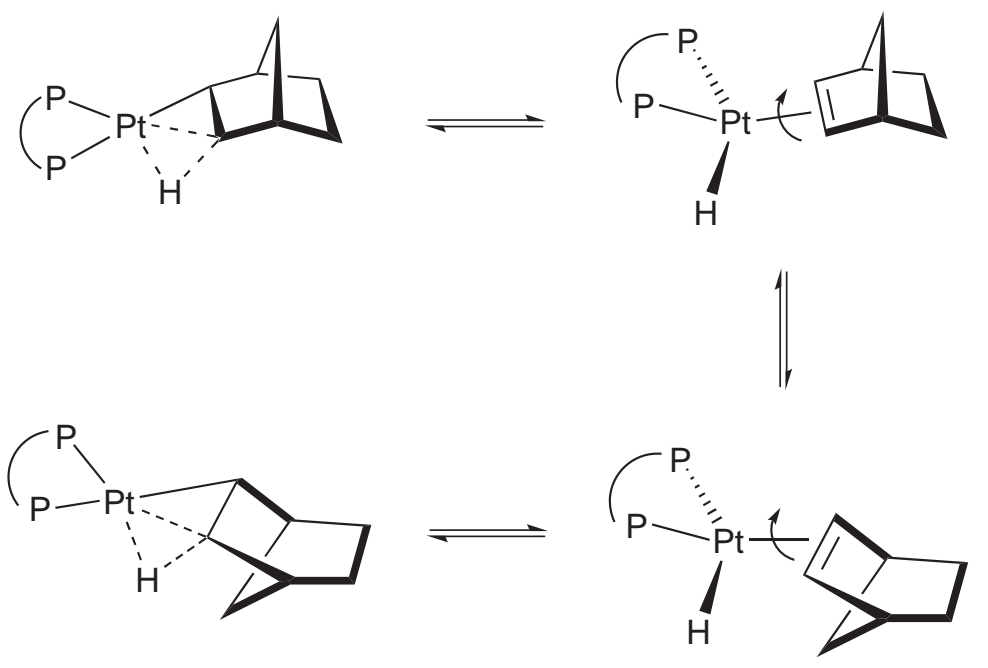

Scheme 3.14

Due to the asymmetric nature of the agostic interaction of the $\mathrm{C}_{7} \mathrm{H}_{11}$ ligand, two sets of NMR signals were observed for the coordinated PN ligand as its symmetry plane was destroyed. In general, the ketone and hydrated analogues 
exhibited similar NMR features except for the presence of a hydrated carbon atom at $94.1 \mathrm{ppm}$. The counterion $\mathrm{CPh}\left(\mathrm{SO}_{2} \mathrm{CF}_{3}\right)_{2}$ had a signal at $-78.6 \mathrm{ppm}$ in the ${ }^{19} \mathrm{~F}$ NMR spectrum indicating that it is a free anion. Finally, complex 94 represents the first example of an agostic norbornyl interaction stabilised by a phosphorus-nitrogen ligand.

\subsection{Hydroxo-bridged platinum complexes}

Dinuclear platinum complexes represent an important class of compounds because of their potential in homogeneous catalysis and for the synthesis of mixed ligand mononuclear platinum complexes. ${ }^{112}$ For example, bis-hydroxobridged dimers of platinum promote the Baeyer-Villiger (BV) oxidation of cyclic and acyclic ketones in the presence of $\mathrm{H}_{2} \mathrm{O}_{2}$ to give esters and lactones respectively. ${ }^{113,114}$ For these reasons, understanding the structure and properties of dimeric platinum complexes is important.

In view of the formation of the dimetallated complex $\left[\mathrm{Pt}\left(\mathrm{C}_{2} \mathrm{H}_{4}\right)(\mathbf{6 5})\right](\mathbf{7 6})$ from the reaction of tris(ethene)platinum with PN ligand 65, its hydrogenation reaction was studied. The reaction was studied on a NMR scale in benzene- $\mathrm{d}_{6}$ and monitored by both ${ }^{1} \mathrm{H}$ and ${ }^{31} \mathrm{P}$ NMR. The pale yellow solution of $\mathbf{7 6}$ darkened over time and a fine black suspension formed. The reaction was rather slow as the signals for the dimetallated complex gradually decreased and then disappeared after a period of 20 days at room temperature. The expected products from the hydrogenation reaction of $\mathbf{7 6}$ were $\left[\mathrm{PtH}_{2}(\mathbf{6 5})\right](\mathbf{9 7})$ and ethane (Scheme 3.15), but the ${ }^{1} \mathrm{H}$ and ${ }^{31} \mathrm{P}$ NMR spectra clearly showed that 97 had not been formed. No signal corresponding to ethane or ethene was observed in the ${ }^{1} \mathrm{H}$ NMR spectrum under the experimental conditions used.

The ${ }^{31} \mathrm{P}$ NMR spectrum showed two peaks in about $1: 1$ ratio at 47.8 and $49.9 \mathrm{ppm}$, both with very similar couplings to platinum of 4874 and $4851 \mathrm{~Hz}$ 


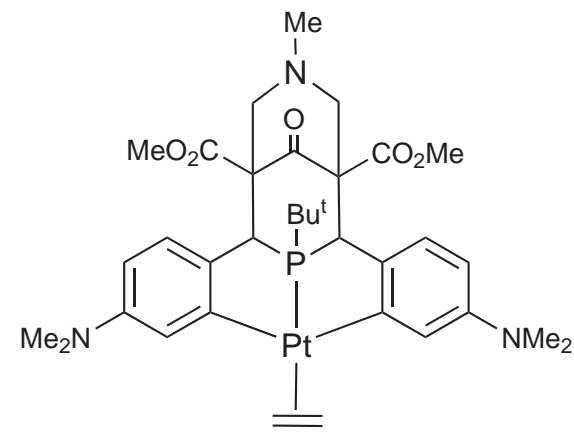

76

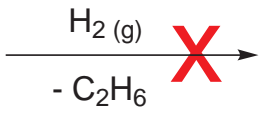

97

\section{Scheme 3.15}

respectively. Two doublets integrating for one proton each were observed in the ${ }^{1} \mathrm{H}$ NMR spectrum at $-0.62\left(J_{\mathrm{PH}} 3.1 \mathrm{~Hz}\right)$ and $0.06 \mathrm{ppm}\left(J_{\mathrm{PH}} 1.9 \mathrm{~Hz}\right)$. The phosphorus couplings were confirmed by a phosphorus-decoupled ${ }^{1} \mathrm{H}$ NMR spectrum in which the two doublets resonated as singlets. Moreover, the two protons were not attached to carbon atoms as they were absent from the HSQC spectrum. Even though these signals resonate at unique chemical shifts typical for hydrogen atoms interacting closely with a metal, they are not likely to correspond to $\mathrm{Pt}-\mathrm{H}$ because such hydride resonances would be expected at very high field with large platinum coupling. Interestingly, HMBC correlations were observed from the hydride-like signals at -0.62 and $0.06 \mathrm{ppm}$ to carbon atoms at 138.3 and $138.2 \mathrm{ppm}$ respectively.

Extensive analyses of the 2D NMR spectra revealed that two very similar compounds had been formed in which the PN ligand was asymmetric. Two $\mathrm{C}=\mathrm{O}{ }^{13} \mathrm{C}$ NMR signals were observed at 205.3 and $205.9 \mathrm{ppm}$ indicating that both compounds were in the ketone form, thus eliminating the formation of a hydrated analogue. In both compounds, the NMR data showed that something unusual had happened to one of the dimethylaminophenyl groups as only one ortho- and two meta-protons were located along with their corresponding carbon atoms. The other ortho- $\mathrm{CH}$ group remained elusive. Beside the two hydride- 
like peaks and the two ${ }^{13} \mathrm{C}$ signals at 138.2 and $138.3 \mathrm{ppm}$, every resonance in the ${ }^{1} \mathrm{H}$ and ${ }^{13} \mathrm{C}$ spectra had been accounted for as belonging to the coordinated PN ligand 65. If the dimethylaminophenyl group was ortho-metallated, then the metallated carbon atom would be expected to resonate downfield above $155 \mathrm{ppm}$ in the ${ }^{13} \mathrm{C}$ NMR spectrum as in complexes 76 and 87. As no such ${ }^{13} \mathrm{C}$ NMR signals were observed, the nature of the other ligand(s) on the metal remained ambiguous. Furthermore, no platinum coupling was observed in either the ${ }^{1} \mathrm{H}$ or the ${ }^{13} \mathrm{C}$ NMR spectra.

The same two compounds were also obtained from the reaction of $\left[\mathrm{Pt}\left(\mathrm{Ph}_{2} \mathrm{C}_{2}\right)_{2}\right]$ and $\left[\mathrm{Pt}\left(\mathrm{C}_{2} \mathrm{H}_{5}\right)_{2}(\operatorname{cod})\right]$ with $\mathrm{PN}$ ligand 65. These observations suggest that the formation of these two similar compounds is independent of the other ligands on platinum metal. To shed some light on the identity of the other ligands, two NMR experiments were performed with oxygen gas and water. The reaction of complex 76 with water resulted in no change at all, whereas the reaction with oxygen produced some other unidentifiable products.

The NMR scale hydrogenation reaction was scaled up many times using Schlenk techniques but most of the product decomposed to give a dark brown residue. Finally, the reaction was repeated in a Fischer-Porter vessel to try and minimise the decomposition. This experimental set-up was indeed a success as enough material for crystallisation was produced, although some brown residue was deposited at the bottom of the reaction vial. The slow diffusion of diethyl ether into a benzene solution of the two compounds at $5 \mathrm{C}$ yielded small and large yellow cubic crystals and some pale brown amorphous solid. Samples of each type of solid were analysed by ${ }^{1} \mathrm{H}$ and ${ }^{31} \mathrm{P}$ NMR: the large crystals contained the complex with the proton signal at $0.06 \mathrm{ppm}$ and the ${ }^{31} \mathrm{P}$ resonance at $47.8 \mathrm{ppm}$; the small crystals were mainly of the other complex which had a ${ }^{31} \mathrm{P}$ signal at $49.9 \mathrm{ppm}$; and finally the brown residue was a mixture of the latter complex plus some unidentifiable organic compounds. These results suggested 
that the two complexes had crystallised separately to give different crystals and that one of them did not crystallise well under these conditions. No further analyses were done on the small crystals due to their limited quantity, but a complete analysis including $X$-ray diffraction was performed on the large crystals.

The $X$-ray crystal structure obtained from a single large crystal showed that the mysterious complex (98) was a platinum dimer bridged by hydroxyl groups (Scheme 3.16). The PN ligand is bonded through the phosphorus donor atom and a carbon atom from the dimethylaminophenyl ring in which ortho-metallation had occurred (Figure 3.10). The solid-state structure of $\left[\mathrm{Pt}_{2}(\mu-\mathrm{OH})_{2}(65-\mathrm{H})_{2}\right]$ clearly shows that the nitrogen donor atom is not bonded to platinum. The dimer has a $C_{2}$ symmetry axis at the midpoint of the two

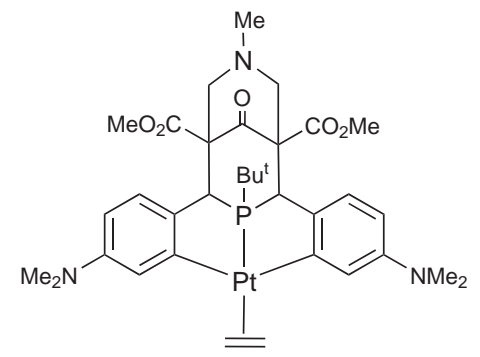

76

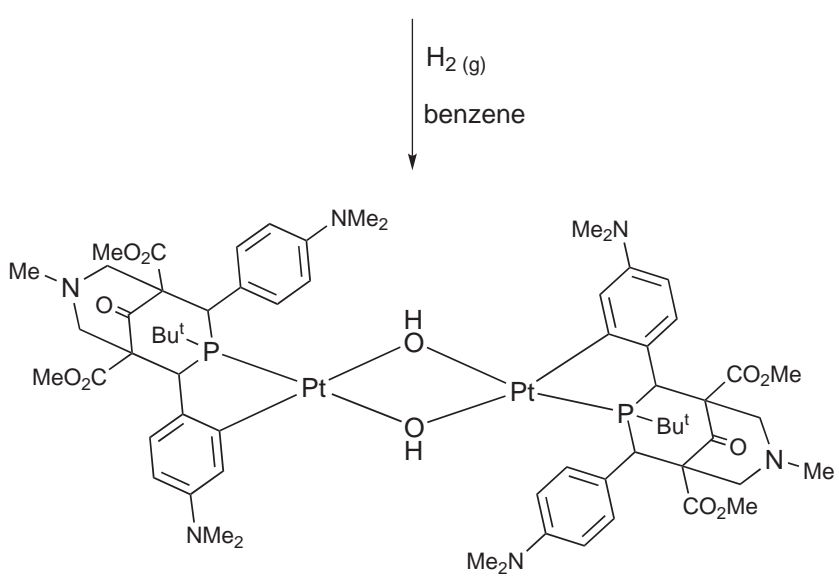

98

Scheme 3.16 
platinum atoms. A summary of crystallographic parameters of complex $\mathbf{9 8}$ are given in Table 3.7, and some selected bond distances and angles are given in Table 3.8.

The NMR data of complex $\mathbf{9 8}$ is in accordance with the $X$-ray crystal structure. Due to the asymmetric binding of PN ligand 65, all its proton and carbon atoms resonated in different chemical environments. The unique ${ }^{1} \mathrm{H}$ NMR resonance at $0.06 \mathrm{ppm}$ is probably due to the bridging hydroxylic hydrogen atoms, which also had a HMBC correlation to the unassigned carbon atom at $138.2 \mathrm{ppm}$. This suggests that the latter ${ }^{13} \mathrm{C}$ NMR signal corresponds to the $\mathrm{Pt}-\mathrm{C}$ carbon atom in the metallated dimethylaminophenyl ring, which is more shielded than the metallated carbon atoms in complexes $\mathbf{7 6}$ and 87 ( $c f .161 .2$ and $157.6 \mathrm{ppm}$ respectively). The absence of any observable coupling to platinum could be due to peak overlap. Moreover, a sharp $\mathrm{OH}$ stretch was observed in the IR spectrum at $3564 \mathrm{~cm}^{1}$ confirming the presence of the bridging hydroxyl groups.

The coordination sphere around each metal atom is square planar, and the dihedral angle between the two $\mathrm{O} 1-\mathrm{C} 13-\mathrm{P} 1-\mathrm{O} 1$ planes is 21 . This results in a slightly bent structure according to the possible molecular conformation reported by Aullón et al. for binuclear complexes with monosubstituted bridges. ${ }^{115}$ The hydroxylic hydrogens at the bridging atoms were found $(\mathrm{O}-\mathrm{H} 0.72 \AA)$ but their positions could not be refined. Their relative orientation to the coordination core in complex 98 was exo to give a bent, exo (be) structure (Figure 3.11). Such orientation is probably the result of the lone pair of electrons on the bridging oxygen atoms occupying more space than the bonding $\mathrm{O}-\mathrm{H}$ electron pair. There is no interaction between the two bridging oxygen atoms as the distance between them is $2.56 \AA$. The $\mathrm{O} 1-\mathrm{Pt} 1-\mathrm{O} 1$ angle is $75.4(2)$, while the Pt1-O1-Pt1 angle is $100.6(2)$.

Although the nitrogen donor atom is not coordinated to platinum metal 


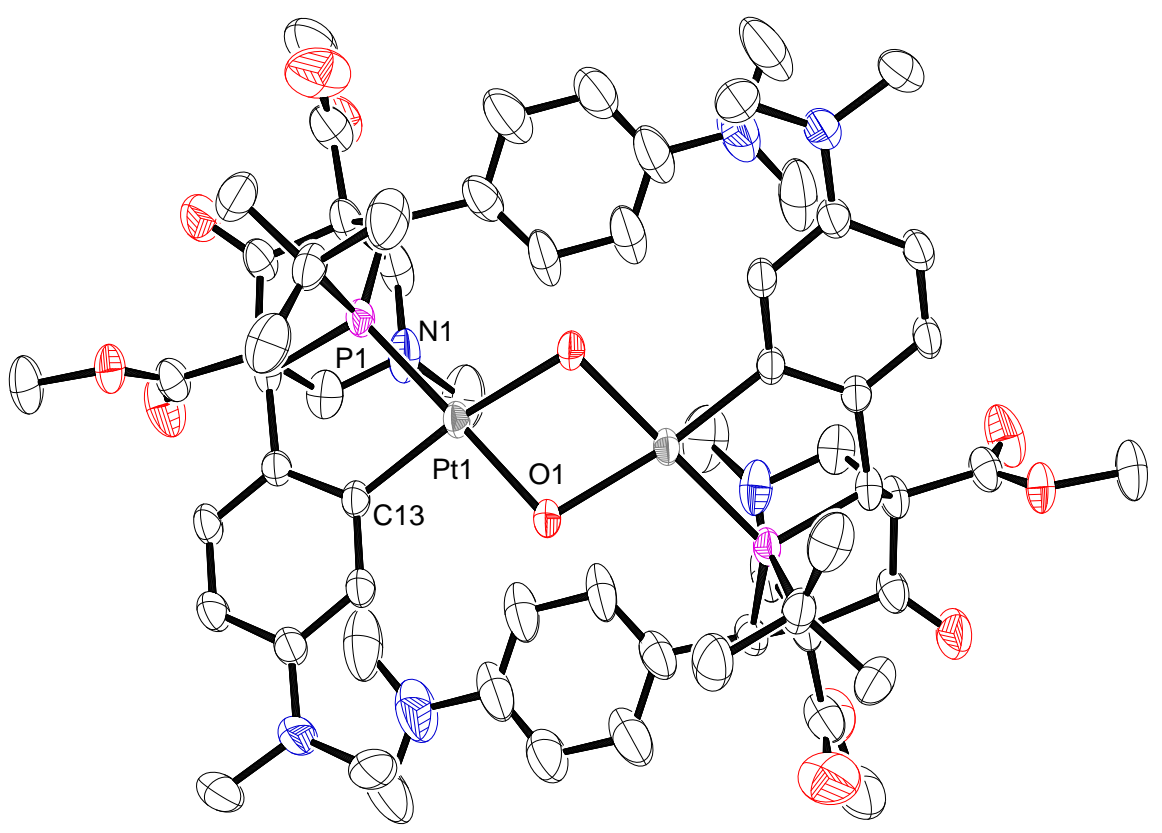

(a)

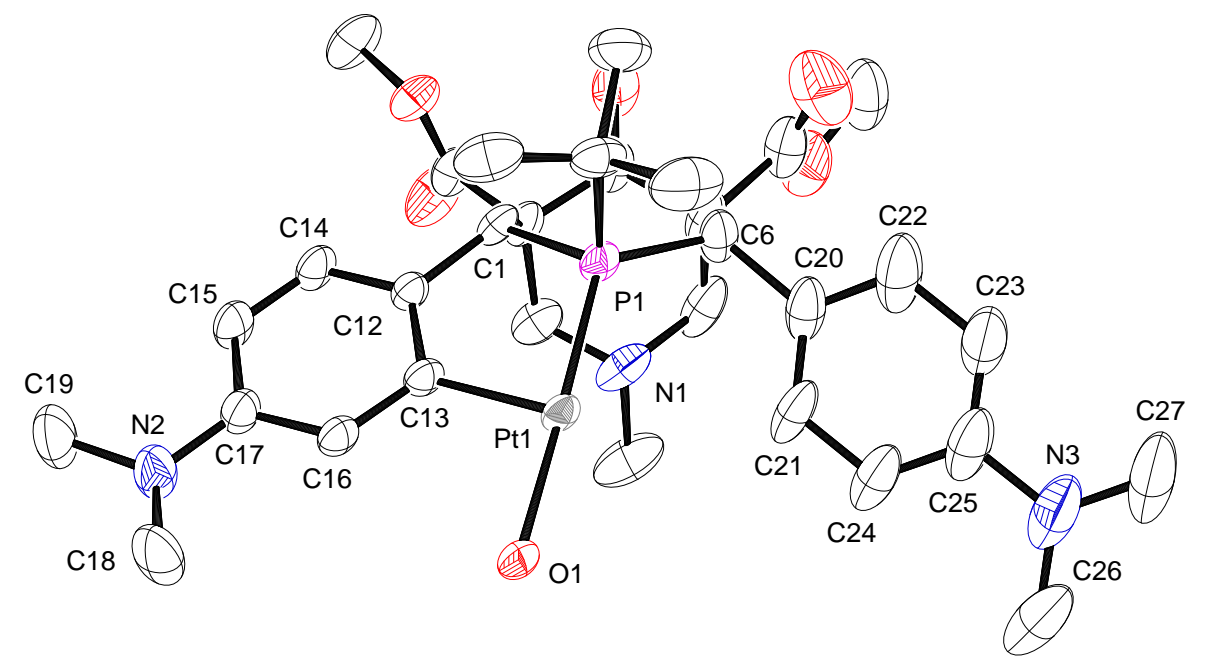

(b)

Figure 3.10. ORTEP diagrams of hydroxo-bridged platinum complex (98): (a) complete dimer (b) half dimer (30\% thermal ellipsoids). Hydrogen atoms omitted for clarity. 
Table 3.7. Crystallographic data of hydroxo-bridged platinum complex 98.

\begin{tabular}{|c|c|}
\hline Empirical formula & $\mathrm{C}_{64} \mathrm{H}_{88} \mathrm{~N}_{6} \mathrm{O}_{12} \mathrm{P}_{2} \mathrm{Pt}_{2}$ \\
\hline Formula weight & 1553.52 \\
\hline Crystal system & Monoclinic \\
\hline Space group & $C 2 / c$ \\
\hline $\mathrm{a} / \AA$ & $15.356(1)$ \\
\hline $\mathrm{b} / \AA$ & $16.572(1)$ \\
\hline $\mathrm{c} / \AA$ & $27.816(2)$ \\
\hline$\alpha /$ & 90 \\
\hline / & $105.768(5)$ \\
\hline / & 90 \\
\hline $\mathrm{V} / \AA^{3}$ & 6812.8 \\
\hline Z & 8 \\
\hline Cell determination reflections & 9952 \\
\hline $\begin{array}{l}\text { Cell determination range, } \min -\max / \\
\text { Temperature } / \mathrm{K}\end{array}$ & $\begin{array}{l}2.46-23.20 \\
296(2)\end{array}$ \\
\hline Radiation type & Mo K $\alpha$ \\
\hline Radiation $($ ) $/ \AA$ & 0.71073 \\
\hline Crystal size/ mm & $0.41 \times 0.35 \times 0.32$ \\
\hline $\mathrm{D}_{\text {calc }} / \mathrm{g} \mathrm{m}^{3}$ & 1.515 \\
\hline $\mathrm{F}(000)$ & 3120 \\
\hline $\mathrm{mm}$ & 4.21 \\
\hline $\mathrm{T}_{\max }, \mathrm{T}_{\min }$ & $0.746,0.572$ \\
\hline Reflections collected & $82218, R_{\text {equiv }}=0.0670$ \\
\hline Index range $h$ & $-21-21$ \\
\hline Index range $k$ & $-22-23$ \\
\hline Index range $l$ & $-38-39$ \\
\hline range/ & $2.57-30.17$ \\
\hline Independent reflections & 10011 \\
\hline Reflections $\left[\begin{array}{lll}I & 2 & (I)\end{array}\right]$ & 6441 \\
\hline Restraints/parameters & $0 / 402$ \\
\hline GOF & 1.076 \\
\hline$R \quad\left[\begin{array}{lll}I & 2 & (I)\end{array}\right]$ & 0.057 \\
\hline $\mathrm{w} R 2\left[\begin{array}{lll}I & 2 & (I)\end{array}\right]$ & 0.12 \\
\hline$R$ [all data] & 0.10 \\
\hline w $R 2$ [all data] & 0.14 \\
\hline
\end{tabular}


Table 3.8. Selected bond distances $(\AA)$ and angles ( ) for hydroxo-bridged platinum complex 98.

\begin{tabular}{lllr}
\hline \hline \multicolumn{2}{c}{ Bond distances $(\AA)$} & \multicolumn{2}{c}{ Bond angles $(~)$} \\
\hline Pt1-P1 & $2.179(2)$ & Pt1-O1-Pt1 & $100.6(2)$ \\
Pt1-C13 & $1.999(7)$ & O1-Pt1-O1 & $75.4(2)$ \\
Pt1-O1 & $2.074(5)$ & P1-Pt1-C13 & $83.2(2)$ \\
Pt1-O1 & $2.110(5)$ & Pt1-P1-C1 & $107.1(3)$ \\
Pt1-Pt1 & $3.221(1)$ & P1-C1-C12 & $104.6(4)$ \\
P1-C1 & $1.86(1)$ & C1-C12-C13 & $119.5(6)$ \\
P1-C6 & $1.87(1)$ & C12-C13-Pt1 & $122.3(6)$ \\
$\mathrm{C} 1-\mathrm{C} 12$ & $1.52(1)$ & O1-Pt1-C13 & $96.3(3)$ \\
$\mathrm{C} 12-\mathrm{C} 13$ & $1.41(1)$ & O1-Pt1-P1 & $104.8(2)$ \\
\hline \hline
\end{tabular}

in complex 98, the bound PN ligand still maintains its rigid chair-chair conformation. The distance between the phosphorus and nitrogen donor atoms is slightly longer as expected at $3.2 \AA$ ( $c f .3 .0 \AA$ in complexes containing a coordinated nitrogen donor atom). In contrast, the $\mathrm{Pt}-\mathrm{N}$ distance is very long at $3.8 \AA$. This is longer than in complex $[\mathrm{AuCl}(\mathbf{3 7})](\mathbf{4 1})(3.1 \AA)$ in which the nitrogen atom was also not bound to the metal. ${ }^{62}$ This could be due to the different metal atoms used and the fact that complex $\mathbf{9 8}$ contains a cyclometallated dimethylaminophenyl group. Interestingly, the cyclometallation did not have a significant impact on the bond distances within the phenyl ring as they are similar to the bond lengths of the other non-metallated aryl group.

The stronger trans-influence of the carbon donor atom is clearly reflected

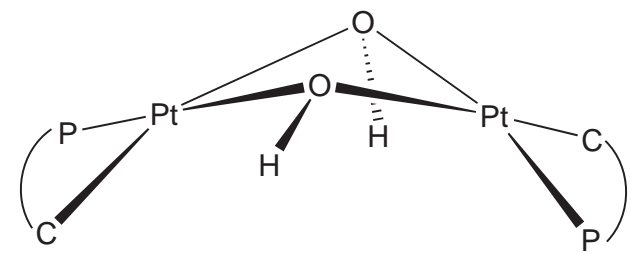

be

Figure 3.11. Molecular conformation of the coordination core in hydroxo-bridged platinum complex $\mathbf{9 8}$ 
in the respective trans $\mathrm{Pt}-\mathrm{O}$ bond being longer $(2.110(5) \AA)$ than the other Pt-O bond trans to phosphorus $(2.074(5) \AA)$. Both bond distances fall within the expected range of $\mathrm{Pt}-\mathrm{O}$ bonds in hydroxo-bridged platinum complexes. ${ }^{116}$ The two platinum atoms in the dimer are not bonded as the distance between them is $3.221 \AA .{ }^{117}$ This explains the lack of a second smaller platinum coupling in the ${ }^{31} \mathrm{P}$ NMR spectrum as the effect of the second platinum atom was not felt by the coordinated phosphorus as the two platinum atoms were too far apart.

All the crystallographic parameters of complex 98 agree very well with other similar bis-hydroxo-bridged dimers of platinum(II) as shown by a search performed on 37 structures in the Cambridge Crystallographic Database. Most complexes were planar with a square planar geometry around each platinum atom, and only five complexes showed a slight bend between the two metal coordination planes. Examples of such dimers are 99 and 100, which contain phosphorus and carbon ligands. ${ }^{118,119}$ Both complexes have $C_{2}$ symmetry and a similar trans-influence was observed for the $\mathrm{Pt}-\mathrm{O}$ bonds due to the different donor atoms.

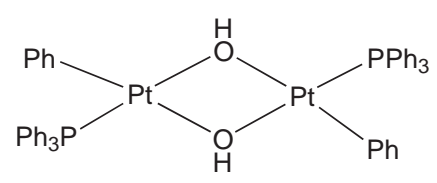

99

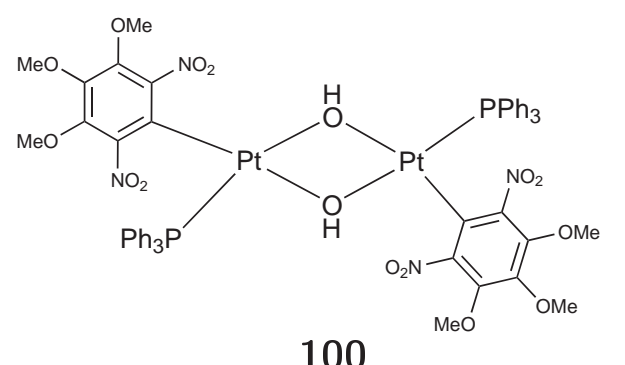

100

The formation of the platinum dimer 98 was probably the consequence of adding one molecule of adventitious water to the dimetallated ethene platinum complex 76 to form a highly reactive 14-electron species (Scheme 3.17). This intermediate in turn dimerised to form the hydroxo-bridged complex. The presence of the hydrogen gas is necessary for the formation of complex $\mathbf{9 8}$ presumably to hydrogenate the complexed ethene ligand to release it. 


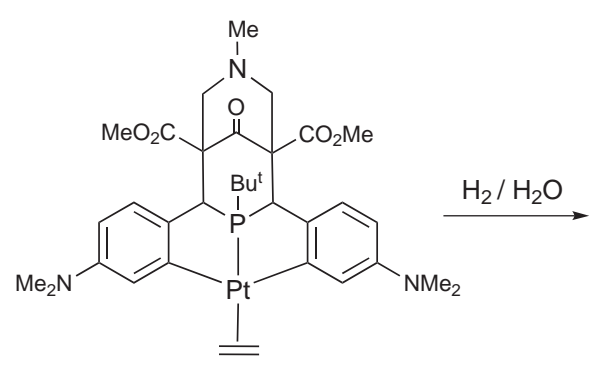

76

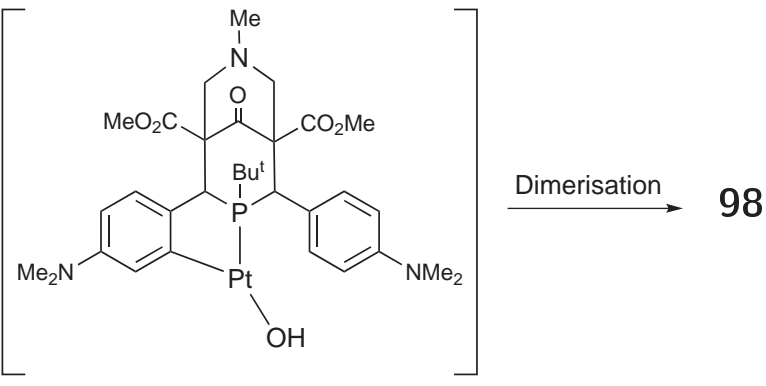

14-electron species

\section{Scheme 3.17}

During the dimerisation process there are two orientations in which the 14electron reactive intermediates can combine together: if a double $\mathrm{OH}$ bridge is formed between two $\mathrm{P}-\mathrm{C}$ fragments where one unit had rotated by $180 \mathrm{C}$, complex 98 is formed; however, a new configurational isomer can be produced if no rotation occurs. This could explain the observation of a similar complex to dimer 98 under all the reaction conditions used. The second dimer (101) was observed at $49.9 \mathrm{ppm}$ in the ${ }^{31} \mathrm{P}$ NMR, and it crystallised as small yellow crystals from the benzene-diethyl ether mixture. Although complex 101 possesses a vertical symmetry plane across the bridging atoms, the two $\mathrm{OH}$ hydrogen atoms should still be different and would be expected to give two $\mathrm{OH}$ resonances in the ${ }^{1} \mathrm{H}$ NMR spectrum. Since only one signal was observed at $-0.62 \mathrm{ppm}$, perhaps the two hydroxylic protons are exchanging rapidly on the NMR time scale.

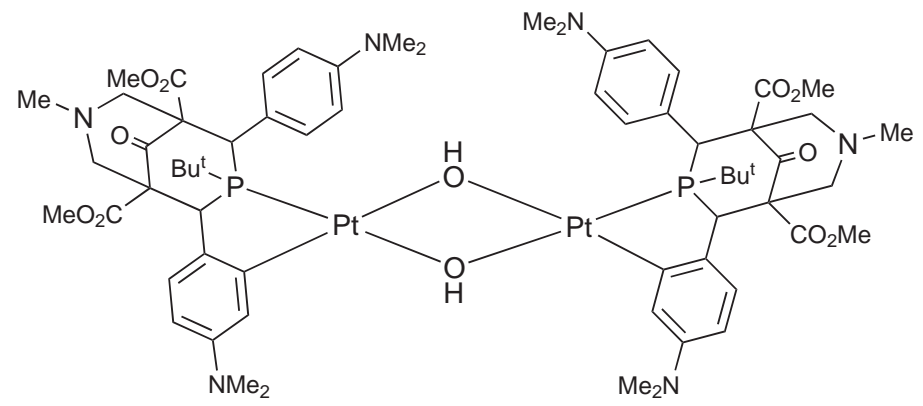

101 


\subsection{Bis(phosphorus-nitrogen) ligand complexes}

Reactions of PN ligand $\mathbf{6 5}$ with three platinum precursors in a 2:1 ligand to metal ratio were carried out in an attempt to prepare bis(PN)metal complexes. The ligand was reacted with $\left[\mathrm{Pt}(\text { norb })_{3}\right],\left[\mathrm{Pt}(\mathrm{cod})_{2}\right]$ and $\left[\mathrm{Pt}\left(\mathrm{Ph}_{2} \mathrm{C}_{2}\right)_{2}\right]$ metal precursors in $\mathrm{C}_{6} \mathrm{D}_{6}$ on a NMR scale at room temperature. The products from all three reactions were the same as the products obtained from the respective 1:1 ligand to metal syntheses, i.e. [Pt(norb)(65)] (74) (Section 3.3), $\left[\mathrm{Pt}\left(1-3-\eta-\mathrm{C}_{8} \mathrm{H}_{13}\right)(\mathbf{6 5}-\mathrm{H})\right]$ (87) (Section 3.5) and trans- and cis- $\left[\mathrm{Pt}_{2}(\mu-\mathrm{OH})_{2}(\mathbf{6 5}-\mathrm{H})_{2}\right](\mathbf{9 8}, \mathbf{1 0 1})$ (Section 3.7). Such results suggest that PN ligand 65 is too bulky to form 2:1 complexes in which the ligand is coordinated through both donor atoms, or via only the phosphorus atom in a monodentate fashion. In contrast, the similar but considerably smaller PTN ligand 10 can act as either a mono- or bidentate PN ligand and form 2:1 ligand to metal complexes. $^{23,24}$

\subsection{Ligand hydration}

The formation of hydrated complexes was an intriguing characteristic of the coordination chemistry of PN ligand 65. In such complexes, the central carbonyl group at position 9 was hydrated to form a geminal diol. Interestingly, hydration of the PN ligand only occurred upon metal complexation, despite the use of dry solvents and inert atmosphere, and was only observed for complexes prepared in $\mathrm{CDCl}_{3}, \mathrm{CD}_{2} \mathrm{Cl}_{2}$ and $\mathrm{CH}_{2} \mathrm{Cl}_{2}$. No hydration occurred for complexes synthesised in benzene, toluene or their respective deuterated analogues. These observations suggest that the hydration of the central carbonyl group in complexed PN ligand 65 could be due to the presence of the metal and the acidic character of the chlorinated solvents. The precise effect of metal coordination is not well understood as the hydration is taking place at a site remote from the 
reaction centre. The oxidation state of the metal could be a contributing factor considering that all hydrated complexes contain M(I) or M(II) metals.

Furthermore, hydrated analogues generally formed in a 1:3 ratio to the ketone forms of the PN metal complexes. The ketone and hydrate forms are not in equilibrium, as might be expected, because their relative ratios remained unchanged regardless of how much water was added to the product mixtures. The hydrated analogues appear to have similar chemical characteristics to their ketone counterparts both in solution and the solid state.

\subsection{Coordination chemistry of PN ligand 66}

Despite the small quantity of PN ligand $\mathbf{6 6}$ isolated and the fact that it was only about $80 \%$ pure as it was contaminated with PN ligand 65 and 3-(4-dimethylaminophenyl)methyl-2-propenoate $\mathbf{6 7}$, some preliminary complexation studies were conducted. A NMR scale experiment was performed with $\left[\mathrm{PtMe}_{2}(1,5\right.$-hexadiene $\left.)\right]$ in a 2:1 ratio in benzene- $\mathrm{d}_{6}$ at room temperature. PN ligand 66 cannot act as a bidentate ligand because the angle between the phosphorus and nitrogen donor atoms is too small. The expected product from the reaction was cis- $\left[\mathrm{PtMe}_{2}(\mathbf{6 6})_{2}\right]$ (102), but the ${ }^{31} \mathrm{P}$ NMR spectrum clearly showed that complex 102 had not been formed.

The ${ }^{31} \mathrm{P}$ NMR spectrum showed an AB pattern with a $28.1 \mathrm{ppm}, J\left(\mathrm{PtP}_{\mathrm{A}}\right)$ $3066 \mathrm{~Hz}$ and ${ }_{\mathrm{B}} 59.4 \mathrm{ppm}, J\left(\mathrm{PtP}_{\mathrm{B}}\right) 3204 \mathrm{~Hz}$ and $J\left(\mathrm{P}_{\mathrm{A}} \mathrm{P}_{\mathrm{B}}\right) 429 \mathrm{~Hz}$. This is consistent with the formation of a trans complex in which cyclometallation has occurred on one of the coordinated phosphine ligands. The signal at $28.1 \mathrm{ppm}$ is assigned to the monodentate phosphine and the low-field ${ }^{31} \mathrm{P}$ chemical shift at $59.4 \mathrm{ppm}$ corresponds to the internally metallated phosphine. ${ }^{120}$ Moreover, methane was observed at $0.14 \mathrm{ppm}$ in the ${ }^{1} \mathrm{H}$ NMR spectrum indicating the hydrogenolysis of one of the coordinated methyl groups. The ${ }^{1} \mathrm{H}$ NMR spectrum 
also showed a triplet at $-0.17 \mathrm{ppm}\left(J_{\mathrm{PH}} 5.5, J_{\mathrm{PtH}} 49 \mathrm{~Hz}\right)$ corresponding to the other methyl group bonded to platinum which is coupling to two phosphorus atoms. Two doublets at $0.80\left(J_{\mathrm{PH}} 13.8 \mathrm{~Hz}\right)$ and $1.25 \mathrm{ppm}\left(J_{\mathrm{PH}} 13.3 \mathrm{~Hz}\right)$ were also observed due to the non-equivalent $t$-butyl groups. The doublet at $0.80 \mathrm{ppm}$ was slightly broader possibly due to coupling with the other phosphorus nucleus.

Potential cyclometallated complexes of ligand $\mathbf{6 6}$ are shown in Figure 3.12. These include metallation at the methylene (103) or the methine (104) carbons on either side of the phosphorus atom to form 3-membered rings, or metallation at an ortho-position of the dimethylaminophenyl ring (105) or on the N-methyl substituent (106) to produce 5-membered metallacycles. A 4-membered ring can also be formed through metallation at the activated -position to the ketone (107). Internal metallation on a methyl group of the $t$-butyl substituent can be ruled out as two $t$-butyl doublets were observed in the ${ }^{1} \mathrm{H}$ NMR spectrum.

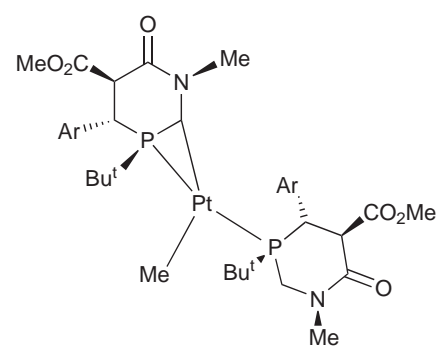

103

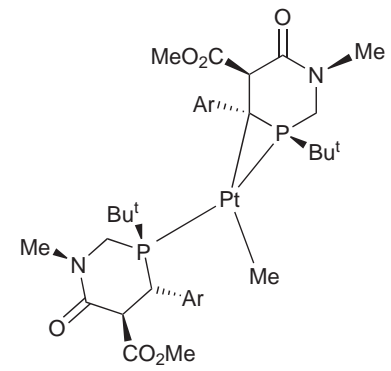

104

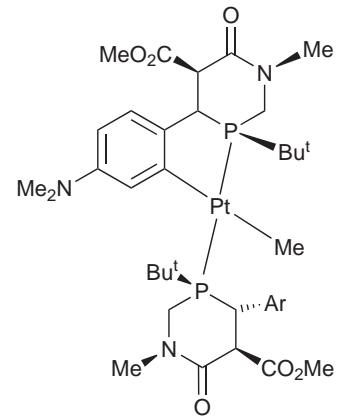

105

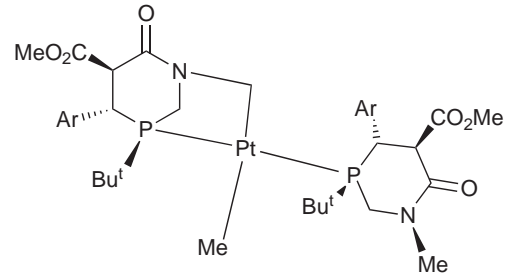

106

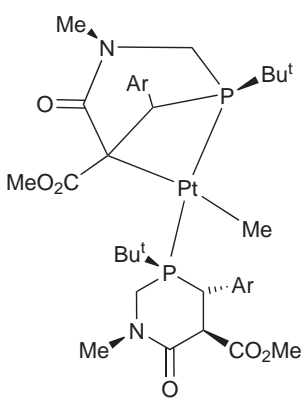

107

Figure 3.12. Possible metallaphosphabicyclic complexes of PN ligand 66. 
To determine exactly the cycloplatination position in ligand $\mathbf{6 6}$, NMR spectra were recorded on a $500 \mathrm{MHz}$ NMR instrument. However, these revealed that the metallated complex had decomposed at room temperature within hours of its formation. For this reason, the NMR scale experiment was repeated in toluene- $\mathrm{d}_{8}$ so that NMR spectra could be recorded at $-20 \mathrm{C}$ to avoid decomposition. Cooling the reaction mixture down to $-20 \mathrm{C}$ in a $300 \mathrm{MHz}$ NMR instrument straight after combining the reactants together at room temperature ceased the cyclometallation reaction of ligand $\mathbf{6 6}$ and allowed the observation of the intermediate cis-dimethyl complex 102 in the ${ }^{31} \mathrm{P}$ NMR spectrum at $33.9 \mathrm{ppm}$ with $J_{\mathrm{PtP}}$ of $1830 \mathrm{~Hz}$ (Scheme 3.18). As PN ligand 66 is chiral, it is possible to form the meso and rac diastereoisomers of 102. However, the observation of one signal in the ${ }^{31} \mathrm{P}$ NMR spectrum indicates the dominance of only one species.

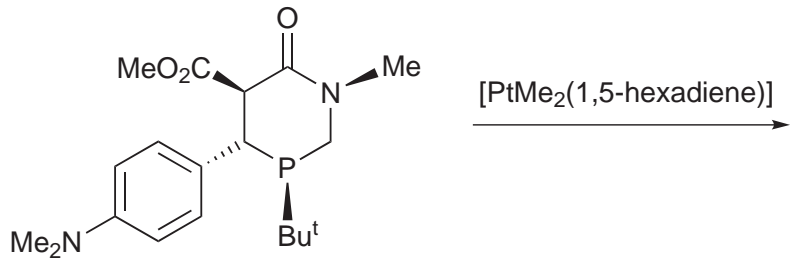

66

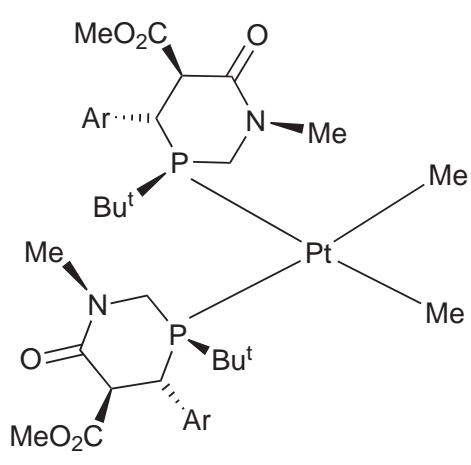

102

\section{Scheme 3.18}

Small quantities of the cyclometallated complex were also present indicating that the cycloplatination reaction is very facile at room temperature. NMR analysis of the spectra recorded at $-20 \mathrm{C}$ to characterise complex 102 and possibly also the trans-complex proved to be inconclusive. The spectra acquired were of low resolution and broad due to short acquisition time and low acquisition temperature, and they were further complicated by peaks due to compounds $\mathbf{6 5}$ and 67. Consequently, the NMR spectra were recorded at room temperature on a $600 \mathrm{MHz}$ NMR instrument which should produce high resolution spectra 
over short periods of time before much decomposition had taken place. After an extensive examination of the highly complex spectra, no definite conclusions could be made about the metallation position of ligand 66. However, some other useful NMR data were obtained, for example the ${ }^{13} \mathrm{C}$ chemical shift for the methyl group was at $-21.0 \mathrm{ppm}$.

Although the NMR data were not conclusive about the metallation position of the coordinated ligand $\mathbf{6 6}$, the ${ }^{31} \mathrm{P}$ chemical shift $(59.4 \mathrm{ppm})$ of the metallated ligand could give some insight into the ring size being formed. Looking at the possible metallated complexes in Figure 3.12, compounds 103 and 104 both have 3-membered rings and compound 107 has a 4-membered ring after cyclometallation. The ${ }^{31} \mathrm{P}$ NMR chemical shifts of phosphine ligands become very shielded upon formation of 3- and 4-membered metallacycles. ${ }^{120}$ For example, a similar phosphine ligand (108) resonates at $17.1 \mathrm{ppm}$ in the ${ }^{31} \mathrm{P}$ NMR spectrum (Scheme 3.19). ${ }^{61}$ Upon its reaction with $\left[\mathrm{PtCl}_{2}(\mathrm{cod})\right]$, a [3.1.1]metallaphosphabicyclic product (109) is formed in which the phosphorus atom in the 4-membered ring has a ${ }^{31} \mathrm{P}$ NMR signal at $-13.0 \mathrm{ppm}$. Therefore, complexes 103, 104 and 107 can be ruled out as the ${ }^{31} \mathrm{P}$ chemical shift of the metallated ligand 66 was very deshielded as compared to the free ligand ( $c f$. $-3.5 \mathrm{ppm})$.

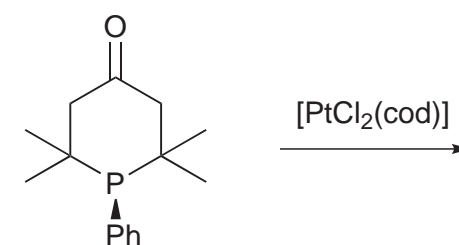

108

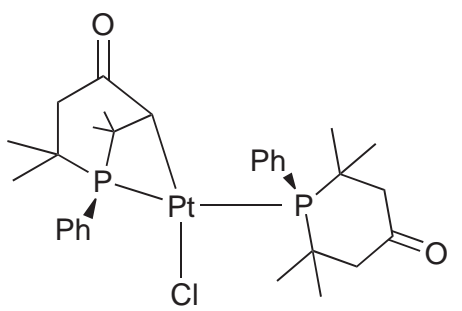

109

Scheme 3.19

The ${ }^{31} \mathrm{P}$ NMR resonances of phosphine ligands tend to become deshielded when metallation results in a 5 -membered ring. ${ }^{120}$ Since the ${ }^{31} \mathrm{P}$ NMR chemical 
shift of the metallated ligand is at $59.4 \mathrm{ppm}$, it is therefore more consistent with the formation of a 5-membered ring as in complexes 105 and 106. Of these two, complex 105 represents the most likely structure as ortho-metallation at the dimethylaminophenyl group has been observed in the coordination chemistry of PN ligand 65. Nevertheless, further experimental studies are required to determine the exact structure of the trans-metallated complex as well as to explore the coordination chemistry of PN ligand 66 .

\subsection{Concluding remarks}

The coordination chemistry of bicyclic PN ligand 65 was explored extensively with rhodium, palladium and platinum. Generally, the ligand coordinated via both the phosphorus and nitrogen donor atoms, to form stable and well defined metal complexes. This showed that the degree of ligand preorganisation was transferred to the resulting metal complexes. Coordination compounds containing 2:1 ligand to metal ratio were never observed, possibly due to the large size of PN ligand 65. Moreover, the ligand favoured bidentate binding as no metal complexes containing monodentate PN ligands were confirmed. The effect of the different donor atoms on the respective trans-positions on the metal was clearly evident both in solution and the solid state structures.

Complexation of PN ligand 65 to a metal was generally characterised by a large downfield shift of the dimethylaminophenyl ortho-protons in the ${ }^{1} \mathrm{H}$ NMR spectrum. This was attributed to the close proximity of the aryl groups (which were constrained by the ligand backbone) to the metal. In extreme cases, ortho-metallation was observed with platinum insertion into one or both of the dimethylaminophenyl rings. In such metallated complexes, the nitrogen donor group was not bound to the metal. Instead, the PN ligand coordinated through the phosphorus and the metallated ortho-carbon atoms. Moreover, 
further reaction of some metallated compounds led to the formation of new complexes.

Another feature of the coordination chemistry of PN ligand $\mathbf{6 5}$ was hydration of the central carbonyl group into a geminal diol upon metal complexation. Hydrated analogues were only observed for M(I) and M(II) complexes prepared in chlorinated solvents. The relative ratio between the ketone and hydrate forms remained constant at 3:1 regardless of the amount of water present in solution. This suggests that the ketone and hydrate forms are not in equilibrium. The precise factors controlling the hydration of the remote carbonyl group are not well understood.

In addition, protonation studies using the fluorocarbon acid $\mathrm{CH}_{2}\left(\mathrm{SO}_{2} \mathrm{CF}_{3}\right)_{2}$ revealed that the $\mathrm{CH}\left(\mathrm{SO}_{2} \mathrm{CF}_{3}\right)_{2}$ anion has the propensity to coordinate to the metal centre in platinum complexes containing PN ligand 65, even though it is often considered to be a non-coordinating species.

Overall, the coordination chemistry of PN ligand $\mathbf{6 5}$ has revealed that the combination of the bicyclic framework, the phosphorus and nitrogen donor atoms, the dimethylaminophenyl groups and the central ketone functionality gives this ligand interesting chemical properties. A total of 24 complexes were prepared and fully characterised by spectroscopic methods in solution and, where possible, by $X$-ray diffraction in the solid state. Among these coordination compounds are hydroxo-bridged dimers containing a metallated PN ligand and the first examples of agostic ethyl and norbornyl complexes stabilised by a phosphorus-nitrogen ligand. The PN metal complexes also featured different coordination modes of the nitrogen donor atom, which were studied by ${ }^{15} \mathrm{~N}$ NMR spectroscopy and will be further discussed in Chapter 4. 


\section{Chapter 4}

\section{Nitrogen NMR Spectroscopy of Transition Metal Complexes}

The importance of nitrogen in all branches of chemistry makes nitrogen nuclear magnetic resonance an attractive means of gaining insight into bonding and the nature of interactions in molecules. Inversely detected ${ }^{15} \mathrm{~N}$ NMR experiments at the natural abundance level of the ${ }^{15} \mathrm{~N}$ nuclide were used to measure the ${ }^{15} \mathrm{~N}$ chemical shifts of PN ligand $\mathbf{6 5}$ and its various metal complexes. The results provided valuable information about the coordination behaviour of the ligand nitrogen arm in the PN metal complexes.

\subsection{Nitrogen NMR spectroscopy}

The utilisation of ${ }^{15} \mathrm{~N}$ NMR as a structural probe is highly desirable as nitrogen-containing compounds are ubiquitous in chemistry. ${ }^{121,122}$ It represents a powerful technique to study the molecular structures and electronic properties of molecules. This branch of molecular spectroscopy is experimentally more difficult than the NMR of other commonly occurring elements such as hydrogen, carbon, phosphorus and fluorine for several reasons: (1) both $\mathrm{N}$ and $\mathrm{N}$ isotopes have low gyromagnetic ratios resulting in low sensitivity; (2) the more 
abundant $(99.6 \%)$ but quadrupolar $(I=1) \quad \mathrm{N}$ nuclide yields very broad NMR signals; (3) the other isotopic form, $\quad \mathrm{N}$, has no quadrupole moment $(I=1 / 2)$ but is only $0.37 \%$ abundant. Therefore, the NMR spectroscopy of the N nucleus is preferred but its direct detection at natural abundance is very difficult. Commonly, samples enriched with ${ }^{15} \mathrm{~N}$ are used, but these can be costly and time consuming to prepare.

The development of inversely-detected NMR experiments, the use of powerful superconducting magnets and major advances in probe design have made it possible to overcome the difficulties associated with N NMR. In this study, ${ }^{15} \mathrm{~N}$ chemical shifts were obtained from ${ }^{1} \mathrm{H}-{ }^{15} \mathrm{~N}$ Heteronuclear Multiple Bond Correlation (HMBC) experiments ${ }^{123}$ since the PN ligand 65 has no direct $\mathrm{N}-\mathrm{H}$ bonds. The ${ }^{15} \mathrm{~N}$ NMR data were recorded on a $600 \mathrm{MHz}$ NMR spectrometer and were referenced to nitromethane for which the $\mathrm{N}$ chemical shift is taken to be zero. Thus, resonances observed upfield of nitromethane are assigned negative chemical shifts, while downfield signals are assigned positive values. For $\mathrm{N}$, the range of chemical shifts for organic compounds spans ca $900 \mathrm{ppm},{ }^{121}$ while the range for transition metal complexes containing nitrogen ligands extends over 1500 ppm. ${ }^{122}$ This is significantly larger than the ranges for ${ }^{1} \mathrm{H}$ and ${ }^{13} \mathrm{C}$ nuclei.

\section{$4.2{ }^{15} \mathrm{~N}$ NMR of PN compounds}

Two different ${ }^{15} \mathrm{~N}$ chemical shifts were observed for PN compound $\mathbf{6 5}$, at -337 and $-353 \mathrm{ppm}$. The HMBC correlations that determined the ${ }^{15} \mathrm{~N}$ chemical shifts are shown in Figure 4.1. Correlations from the methyl groups and the meta-protons established the ${ }^{15} \mathrm{~N}$ chemical shift of the nitrogen atom in the dimethylaminophenyl group, while correlations from the methylene protons and the methyl substituent established the signal for the nitrogen arm in PN compound 65 . 


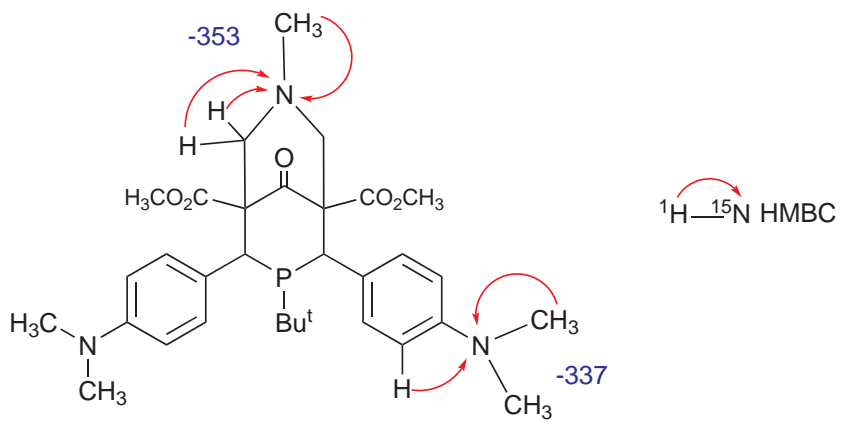

Figure 4.1. ${ }^{1} \mathrm{H}-{ }^{15} \mathrm{~N}$ HMBC correlations for PN compound 65.

The negative sign of the signals imply that the nitrogen atoms in $\mathbf{6 5}$ are more shielded than in nitromethane, and that the nitrogen arm is in turn more shielded than the $\mathrm{NMe}_{2}$ groups. The NMe resonance is in the expected range for compounds with the same bicyclic framework, for example bispidinone compounds (Figure 4.2). ${ }^{124}$ The nitrogen groups in the bispidinone compounds are deshielded due to the electron-withdrawing substituents. The ${ }^{15} \mathrm{~N}$ chemical shifts of PN compound 66 were also measured. The $\mathrm{NMe}_{2}$ group resonated at the same chemical shift of -337 ppm, but the NMe group was observed at $-279 \mathrm{ppm}$. Due to the limited quantity of $\mathbf{6 6}$ isolated and the short life of its platinum complexes, this compound was not investigated further by ${ }^{15} \mathrm{~N}$ NMR.

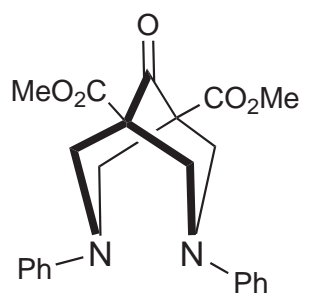

$-323$

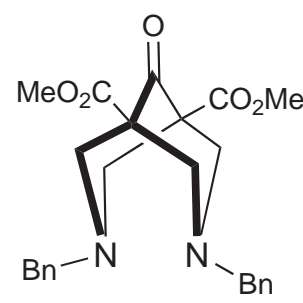

$-337$

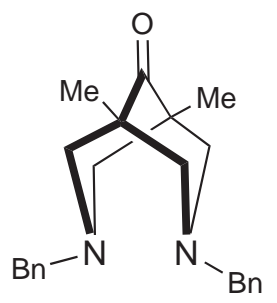

$-334$

Figure 4.2. ${ }^{15} \mathrm{~N}$ NMR chemical shifts of bispidinone compounds. 


\section{$4.3 \quad{ }^{15} \mathrm{~N}$ NMR of metal complexes}

Nitrogen NMR spectroscopy is a sensitive structural probe to detect changes upon coordination of nitrogen-containing ligands to metal ions. ${ }^{15} \mathrm{~N}$ NMR data reported for coordinated nitrogen ligands in transition metal complexes are rare, ${ }^{121,122,125-127}$ and to our knowledge no such data have been reported for metal complexes containing PN ligands. Since the nitrogen arm in PN ligands has the potential to be hemilabile, ${ }^{15} \mathrm{~N}$ NMR can be particularly useful in studying its coordination mode in metal complexes.

The ${ }^{15} \mathrm{~N}$ chemical shifts of almost all metal complexes containing PN ligand 65 were obtained and are summarised in Table 4.1. The ${ }^{15} \mathrm{~N}$ chemical shifts will be influenced by many factors including the nature of the metal and its oxidation state, the bonding mode of the PN ligand itself and finally the nature of the coligands. The ${ }^{15} \mathrm{~N}$ chemical shift of the dimethylamino $\left(\mathrm{NMe}_{2}\right)$ group in all metal complexes studied does not reflect major changes upon ligand complexation as expected since it is far from the reaction site. As for the NMe group, there appears to be no straightforward correlation between the ${ }^{15} \mathrm{~N}$ chemical shifts and the nitrogen binding mode of the PN ligand in the metal complexes. Therefore, the ${ }^{15} \mathrm{~N}$ NMR data has to be interpreted carefully with the aid of chemical understanding of the individual structures and the information obtained from $X$-ray crystallography, even though the solution structure may not necessarily be reflected in the solid state.

The largest differences in the ${ }^{15} \mathrm{~N}$ chemical shifts of the NMe group in PN ligand 65 were observed for complexes $\left[\mathrm{PtMe}_{2}(\mathrm{PN})\right](-377 \mathrm{ppm}),\left[\mathrm{PdCl}_{2}(\mathrm{PN})\right]$ $(-377 \mathrm{ppm})$, and $\left[\mathrm{Rh}\left(\mathrm{C}_{8} \mathrm{H}_{12}\right)(\mathrm{PN})\right] \mathrm{SbF}_{6}(-372 \mathrm{ppm})$ as the nitrogen group became very shielded. The bidentate coordination of the $\mathrm{PN}$ ligand in $\left[\mathrm{PdCl}_{2}(\mathrm{PN})\right]$ was confirmed by its $X$-ray crystal structure, and from the NMR data for complex $\left[\mathrm{Rh}\left(\mathrm{C}_{8} \mathrm{H}_{12}\right)(\mathrm{PN})\right] \mathrm{SbF}_{6}$. In $\left[\mathrm{PtMe}_{2}(\mathrm{PN})\right]$, as well as the differences in the NMR data for the two methyl ligands, ${ }^{1} \mathrm{H}-{ }^{15} \mathrm{~N}$ HMBC correlations from both 
Table 4.1. ${ }^{15} \mathrm{~N}$ NMR chemical shifts of PN compound 65 and metal complexes thereof, $600 \mathrm{MHz}$, referenced to $\mathrm{CH}_{3} \mathrm{NO}_{2}$.

\begin{tabular}{|c|c|c|c|c|}
\hline Compound & $\#$ & Solvent & $\mathrm{N} \mathrm{NMe}_{2}$ & N NMe \\
\hline $\mathrm{PN}$ & 65 & $\mathrm{C}_{6} \mathrm{D}_{6}$ & -337 & -353 \\
\hline$\left[\mathrm{PtMe}_{2}(\mathrm{PN})\right]$ & 68 & $\mathrm{C}_{6} \mathrm{D}_{6}$ & -335 & -377 \\
\hline$[\mathrm{Pt}($ norb $)(\mathrm{PN})]$ & 74 & $\mathrm{CD}_{2} \mathrm{Cl}_{2}$ & -336 & -362 \\
\hline$\left[\mathrm{Pt}\left(\mathrm{C}_{2} \mathrm{H}_{4}\right)(\mathrm{PN})\right]$ & 75 & $\mathrm{C}_{6} \mathrm{D}_{6}$ & -336 & -363 \\
\hline$\left[\mathrm{Pt}\left(\mathrm{C}_{2} \mathrm{H}_{4}\right)(\mathrm{PN}-2 \mathrm{H})\right]$ & 76 & $\mathrm{C}_{6} \mathrm{D}_{6}$ & -336 & -362 \\
\hline$\left[\mathrm{Pt}\left(1-3--\mathrm{C}_{8} \mathrm{H}_{13}\right)(\mathrm{PN}-\mathrm{H})\right]$ & 87 & $\mathrm{C}_{6} \mathrm{D}_{6}$ & $\begin{array}{l}-336 \\
-339\end{array}$ & -354 \\
\hline$\left[\mathrm{Pt}\left(1-, 4-5--\mathrm{C}_{8} \mathrm{H}_{13}\right)(\mathrm{PN})\right] \mathrm{CH}\left(\mathrm{SO}_{2} \mathrm{CF}_{3}\right)_{2}$ & 88 & $\mathrm{CDCl}_{3}$ & -331 & -356 \\
\hline$\left[\mathrm{Pt}\left(1-3--\mathrm{C}_{8} \mathrm{H}_{13}\right)(\mathrm{PN})\right] \mathrm{CH}\left(\mathrm{SO}_{2} \mathrm{CF}_{3}\right)_{2}$ & 89 & $\mathrm{CDCl}_{3}$ & -331 & -369 \\
\hline$\left[\mathrm{PtH}\left\{\mathrm{CH}\left(\mathrm{SO}_{2} \mathrm{CF}_{3}\right)_{2}\right\}(\mathrm{PN})\right]$ & 92 & $\mathrm{CD}_{2} \mathrm{Cl}_{2}$ & -332 & -367 \\
\hline$\left[\mathrm{Pt}\left(\mathrm{C}_{7} \mathrm{H}_{11}\right)(\mathrm{PN})\right] \mathrm{CPh}\left(\mathrm{SO}_{2} \mathrm{CF}_{3}\right)_{2}$ & 94 & $\mathrm{CD}_{2} \mathrm{Cl}_{2}$ & -332 & -355 \\
\hline trans- $\left[\mathrm{Pt}_{2}(-\mathrm{OH})_{2}(\mathrm{PN}-\mathrm{H})_{2}\right]$ & 98 & $\mathrm{C}_{6} \mathrm{D}_{6}$ & -333 & -355 \\
\hline$c i s-\left[\mathrm{Pt}_{2}(-\mathrm{OH})_{2}(\mathrm{PN}-\mathrm{H})_{2}\right]$ & 101 & $\mathrm{C}_{6} \mathrm{D}_{6}$ & -339 & -354 \\
\hline$\left[\mathrm{PdCl}_{2}(\mathrm{PN})\right]$ & 69 & $\mathrm{CD}_{2} \mathrm{Cl}_{2}$ & -331 & -377 \\
\hline$[\mathrm{Pd}(\mathrm{dba})(\mathrm{PN})]$ & 77 & $\mathrm{C}_{6} \mathrm{D}_{6}$ & -335 & -359 \\
\hline$\left[\mathrm{Pd}\left({ }^{3}-\mathrm{C}_{3} \mathrm{H}_{5}\right)(\mathrm{PN})\right] \mathrm{Cl}$ & 79 & $\mathrm{CD}_{2} \mathrm{Cl}_{2}$ & -331 & -369 \\
\hline$\left[\mathrm{Pd}\left({ }^{3}-\mathrm{C}_{3} \mathrm{H}_{5}\right)(\mathrm{PN})\right] \mathrm{SbF}_{6}$ & 84 & $\mathrm{CD}_{2} \mathrm{Cl}_{2}$ & -332 & -363 \\
\hline$\left[\mathrm{Rh}\left(\mathrm{C}_{8} \mathrm{H}_{12}\right)(\mathrm{PN})\right] \mathrm{SbF}_{6}$ & 71 & $\mathrm{CDCl}_{3}$ & -331 & -372 \\
\hline
\end{tabular}

of the methyl groups to the metal-bound nitrogen donor atom were observed (Figure 4.3). These observations confirmed the bonding between the platinum metal and the nitrogen atom.

Similarly, the nitrogen donor atom in complex $\left[\mathrm{PtH}\left\{\mathrm{CH}\left(\mathrm{SO}_{2} \mathrm{CF}_{3}\right)_{2}\right\}(\mathrm{PN})\right]$ resonated at -367 ppm, and an HMBC correlation was observed from the hydride ligand to the nitrogen atom. This is consistent with the other NMR data, which indicated that both donor atoms in PN ligand 65 were bonded to platinum.

Although the ${ }^{15} \mathrm{~N}$ chemical shift of the norbornyl agostic complex 94 at $-355 \mathrm{ppm}$ is very similar to the free ligand $(-353 \mathrm{ppm})$, the nitrogen donor atom is definitely bonded to platinum as shown by the $X$-ray crystal structure. In 

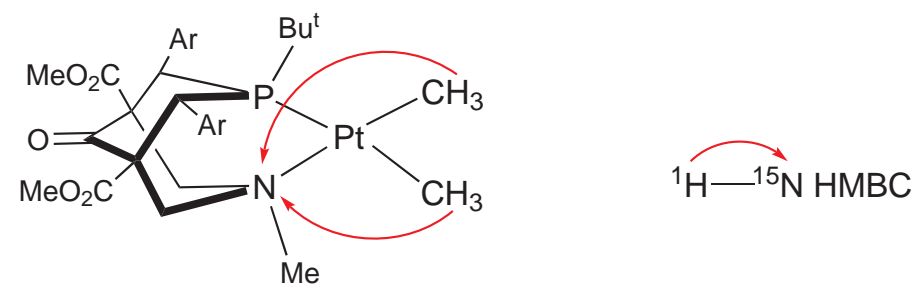

Figure 4.3. ${ }^{1} \mathrm{H}-{ }^{15} \mathrm{~N}$ HMBC correlations for $\left[\mathrm{PtMe}_{2}(\mathrm{PN})\right]$ complex.

this instance, the change in the chemical environment around the nitrogen group was not reflected by the ${ }^{15} \mathrm{~N}$ NMR signal. In contrast, the ${ }^{15} \mathrm{~N}$ chemical shift of the PN ligand in the trans hydroxo-bridged platinum complex 98 at -355 ppm certainly demonstrated that the nitrogen donor atom was not coordinated to the metal as was shown by the solid state structure. Moreover, the same assumption can be made for the cis platinum dimer 101, in which the NMe group resonated at $-354 \mathrm{ppm}$. These results clearly show that many factors influence the ${ }^{15} \mathrm{~N}$ chemical shifts of the coordinated PN ligand.

The ${ }^{15} \mathrm{~N}$ chemical shifts of the alkene complexes were not very informative as to the binding mode of the nitrogen arm in PN ligand 65. Complexes $[\mathrm{Pt}($ norb $)(\mathrm{PN})]$ and $\left[\mathrm{Pt}\left(\mathrm{C}_{2} \mathrm{H}_{4}\right)(\mathrm{PN})\right]$ had very similar ${ }^{15} \mathrm{~N}$ NMR signals at -362 and -363 ppm respectively, while the nitrogen donor atom in $[\mathrm{Pd}(\mathrm{dba})(\mathrm{PN})]$ complex resonated at $-359 \mathrm{ppm}$. These chemical shifts are only slightly different from the free ligand and no ${ }^{1} \mathrm{H}-{ }^{15} \mathrm{~N}$ HMBC correlations were observed, thus making these results difficult to interpret. However, as the metal centres are in the zero oxidation state, the expected chemical structures of these complexes require the coordination of the nitrogen donor atom to give 16-electron complexes. Without nitrogen binding, electron deficient complexes would form, which might be expected to be too reactive to observe and isolate. In contrast, despite the similarity of the ${ }^{15} \mathrm{~N}$ chemical shift of the second ethene complex $\left[\mathrm{Pt}\left(\mathrm{C}_{2} \mathrm{H}_{4}\right)(\mathrm{PN}-2 \mathrm{H})\right]$ at $-362 \mathrm{ppm}$, the NMe group is unlikely to be coordinated to the metal because the PN ligand is doubly metallated. This would place the 
nitrogen donor atom out of bonding distance to the metal as was the case for the hydroxo-bridged complex trans- $\left[\mathrm{Pt}_{2}(\mu-\mathrm{OH})_{2}(\mathrm{PN}-\mathrm{H})_{2}\right]$, in which the $\mathrm{Pt}-\mathrm{N}$ distance was $3.8 \AA$.

The above conclusion about ligand metallation could also apply to complex $\left[\mathrm{Pt}\left(1-3-\eta-\mathrm{C}_{8} \mathrm{H}_{13}\right)(\mathrm{PN}-\mathrm{H})\right]$ in which the $\mathrm{PN}$ ligand was singly metallated. In the other two COD complexes $\left[\mathrm{Pt}\left(1-\sigma, 4-5-\eta-\mathrm{C}_{8} \mathrm{H}_{13}\right)(\mathrm{PN})\right] \mathrm{CH}\left(\mathrm{SO}_{2} \mathrm{CF}_{3}\right)_{2}$ and $\left[\mathrm{Pt}\left(1-3-\eta-\mathrm{C}_{8} \mathrm{H}_{13}\right)(\mathrm{PN})\right] \mathrm{CH}\left(\mathrm{SO}_{2} \mathrm{CF}_{3}\right)_{2}$, and the allyl complexes $\left[\mathrm{Pd}\left(\eta^{3}-\mathrm{C}_{3} \mathrm{H}_{5}\right)(\mathrm{PN})\right] \mathrm{Cl}$ and $\left[\mathrm{Pd}\left(\eta^{3}-\mathrm{C}_{3} \mathrm{H}_{5}\right)(\mathrm{PN})\right] \mathrm{SbF}_{6}$, the nitrogen group is expected to coordinate to form stable 16-electron complexes. Moreover, the NMR data for each complex were consistent with the proposed structures involving bidentate binding by the PN ligand.

\subsection{Concluding remarks}

The ${ }^{15} \mathrm{~N}$ chemical shifts obtained from ${ }^{1} \mathrm{H}-{ }^{15} \mathrm{~N}$ HMBC NMR spectra were analysed extensively in an effort to determine the binding mode of the nitrogen donor atom in $\mathrm{PN}$ ligand $\mathbf{6 5}$ in various transition metal complexes. The NMR data showed no obvious correlation between the ${ }^{15} \mathrm{~N}$ chemical shifts and the coordination mode of the nitrogen group. Thus, structural information obtained from other NMR data and $X$-ray crystallography was utilised to propose chemical structures in which the nitrogen donor atom was coordinated to the metal centres in some cases and non-coordinated in other instances. 


\section{Chapter 5}

\section{Conclusion}

Phosphorus-nitrogen (PN) compounds represent an important class of ligands in coordination chemistry. These ligands combine the individual characteristics of the donor atoms to display an interesting mode of coordination to metal centres. Such ligands can also be hemilabile as the weakly bound nitrogen group plays the role of an intramolecular solvent molecule assuring the stability of the metal complexes in catalytic reactions.

In this study, the synthesis of phosphorus-nitrogen ligands based on a bicyclo[3.3.1]nonan-9-one backbone was attempted via the Mannich reaction using four different classes of phosphorinanone compounds. Reaction of the symmetric 2,6-diester phosphorinanone isomer $\mathbf{5 3}$ with methylamine and formaldehyde produced the bicyclic PN compound $\mathbf{6 5}$ in $75 \%$ yield. In contrast, many products were obtained from the Mannich reaction of the asymmetric isomer 54. These included PN compound 65 but in low yield (26\%), a new sixmembered compound containing phosphorus and nitrogen atoms $(\mathbf{6 6})$ and the $E / Z$ isomers of 3 -(p-dimethylaminophenyl)methyl-2-propenoate (67). These results were surprising and difficult to interpret.

The Mannich reaction of the 2,6-dimethyl phosphorinanones $\mathbf{5 0}$ and $\mathbf{5 1}$ was not successful possibly due to the decreased acidity of the -protons caused by 
the electron-donating methyl substituents at these positions. The remaining 3,5diphenyl $(\mathbf{4 4}, \mathbf{4 5})$ and 4-phenyl (42) phosphorinanones had no -substituents, yet the products obtained from their respective Mannich reactions could not be identified. Therefore, it was difficult to determine if the Mannich reaction was successful in these two cases.

PN ligand 65 adopted a chair-chair conformation both in solution and the solid state ensuring a preset bidentate capability. The coordination chemistry of PN ligand 65 was comprehensively explored with rhodium, palladium and platinum metals. A range of complexes were synthesised in which the ligand was coordinated via both the phosphorus and nitrogen donor atoms. The contrasting trans-influence of the phosphorus and nitrogen donor atoms were clearly exhibited by the ligands in the respective trans-positions on the metal. For example, in complex $\left[\mathrm{PdCl}_{2}(\mathbf{6 5})\right](69)$, the $\mathrm{Pd}-\mathrm{Cl}$ bond trans to phosphorus was longer than the cis bond as determined from the $X$-ray crystal structure.

Cyclometallated platinum complexes were also observed. Depending on the nature of the complex, metallation occurred at the ortho-position of one or both of the dimethylaminophenyl groups. In such complexes, the nitrogen donor atom was not coordinated as the PN ligand was bound through the phosphorus atom and the ortho-carbon atom in the aryl rings only. This ligand binding mode was confirmed by $X$-ray crystallography for the hydroxo-bridged platinum complex trans- $\left[\mathrm{Pt}_{2}(\mu-\mathrm{OH})_{2}(\mathbf{6 5}-\mathrm{H})_{2}\right](\mathbf{9 8})$.

Protonation of the alkene complexes $\left[\mathrm{Pt}\left(\mathrm{C}_{2} \mathrm{H}_{4}\right)(\mathbf{6 5})\right](\mathbf{7 5})$ and $[\mathrm{Pt}($ norb) $(\mathbf{6 5})]$ (74) with the fluorocarbon acid $\mathrm{CH}_{2}\left(\mathrm{CF}_{3} \mathrm{SO}_{2}\right)_{2}$ resulted in the formation of the hydride complex $\left[\mathrm{PtH}\left\{\mathrm{CH}\left(\mathrm{SO}_{2} \mathrm{CF}_{3}\right)_{2}\right\}(\mathbf{6 5})\right]$ (92), in which the anion was coordinated to the metal. The use of the sterically bulky analogue $\mathrm{CHPh}\left(\mathrm{CF}_{3} \mathrm{SO}_{2}\right)_{2}$ eliminated the formation of such hydride complexes, and produced the respective ethyl (93) and norbornyl (94) agostic complexes. The agostic interaction in complex 94 was confirmed by $X$-ray crystallography, and 
this compound represents the first example of an agostic complex containing a phosphorus-nitrogen ligand.

Hydration of the central carbonyl group in PN ligand 65 to a geminal diol upon metal complexation was also observed. This was partially attributed to the acidic character of the solvents used and the high oxidation state of the metal. Hydrated complexes possessed similar chemical properties to their ketone counterparts.

The coordination mode of the nitrogen donor atom in coordinated PN ligand 65 was studied by ${ }^{15} \mathrm{~N}$ NMR. Inversely-detected ${ }^{1} \mathrm{H}-{ }^{15} \mathrm{~N}$ HMBC experiments were used to measure the ${ }^{15} \mathrm{~N}$ NMR chemical shifts of the PN ligand and its various metal complexes. The NMR data showed no direct correlation between the ${ }^{15} \mathrm{~N}$ chemical shift and the binding mode of the nitrogen group.

In summary, incorporating phosphorus and nitrogen donor atoms in the bicyclo[3.3.1]nonan-9-one framework gave rise to a highly rigid and preorganised bicyclic PN ligand. The structure of the free ligand matched closely the ligand conformation in the PN metal complexes. The ligand framework constrained the dimethylaminophenyl substituents causing them to be in close proximity to the metal centres. This sometimes led to the formation of cyclometallated platinum complexes under mild conditions, in which the nitrogen donor group was not coordinated.

As part of future work, the catalytic activity of the different PN metal complexes should be evaluated through a series of catalytic reactions. Such studies would shed light on the catalytic potential of such complexes, and also on the hemilability of the nitrogen donor group. The possibility of synthesising chiral PN ligands containing the bicyclic framework is also feasible. Metal complexes of such ligands could potentially be used in asymmetric catalysis. 


\section{Chapter 6}

\section{Experimental}

\section{General procedures}

All reactions and manipulation of products and reagents were carried out under an inert nitrogen atmosphere using standard Schlenk line techniques unless otherwise stated. Analytical grade reagents and high purity solvents were degassed and purged with nitrogen before use, except for diethyl ether and tetrahydrofuran which were dried by refluxing over sodium/benzophenone ketyl. NMR spectra were recorded using a Varian Unity Inova $300\left(300 \mathrm{MHz}\right.$ for ${ }^{1} \mathrm{H}$, $75 \mathrm{MHz}$ for ${ }^{13} \mathrm{C}, 121 \mathrm{MHz}$ for ${ }^{31} \mathrm{P}$ and $282 \mathrm{MHz}$ for ${ }^{19} \mathrm{~F}$ ), a Varian Unity Inova $500\left(500 \mathrm{MHz}\right.$ for ${ }^{1} \mathrm{H}$ and $125 \mathrm{MHz}$ for $\left.{ }^{13} \mathrm{C}\right)$, or a Varian DirectDrive $600\left(600 \mathrm{MHz}\right.$ for ${ }^{1} \mathrm{H}, 150 \mathrm{MHz}$ for ${ }^{13} \mathrm{C}$ and $60 \mathrm{MHz}$ for $\left.{ }^{15} \mathrm{~N}\right)$ spectrometers. The $600 \mathrm{MHz}$ instrument was equipped with a Varian inverse-detected tripleresonance $\mathrm{HCN}$ cold probe operating at $25 \mathrm{~K}$. All direct-detected ${ }^{1} \mathrm{H}$ and ${ }^{13} \mathrm{C}$ chemical shifts were referenced to the residual solvent peak. ${ }^{128}$ Indirectlydetected ${ }^{15} \mathrm{~N}$ chemical shifts were referenced to the unified TMS scale with $\Xi$ ratio of 10.136767, and an uncertainty of 2 ppm. ${ }^{129}$ NMR samples were prepared under an inert nitrogen atmosphere unless otherwise stated using $\mathrm{C}_{6} \mathrm{D}_{6}, \mathrm{CDCl}_{3}$, $\mathrm{CD}_{2} \mathrm{Cl}_{2}$ and toluene- $\mathrm{d}_{8}$. All NMR solvents were degassed before use. Variable 
temperature NMR was carried out in toluene- $\mathrm{d}_{8}$ or $\mathrm{CD}_{2} \mathrm{Cl}_{2}$ using Varian Unity Inova $300 \mathrm{MHz}$ NMR spectrometer. Infrared spectra were recorded with a PerkinElmer Spectrum One FT-IR spectrophotometer using pressed KBr discs. Microanalyses were performed by The Campbell Microanalytical Laboratory at Otago University. Melting points were recorded on a Gallenkamp Melting Point Apparatus under vacuum unless otherwise stated. Single crystal $X$-ray diffraction data were recorded by the $X$-ray Crystallography Laboratory at the University of Canterbury. Electrospray ionisation mass spectra were either recorded on a PE Biosystem Mariner 5158 TOF mass spectrometer at Victoria University, or performed by the GlycoSyn QC laboratory at Industrial Research Limited using a Waters Q-TOF Premier Tandem mass spectrometer. Calculated ${ }^{1} \mathrm{H}$ NMR spectra were obtained from gNMR spectral simulation programme, version 5.0.6.0 written by P. H. M. Budzelaar, IvorySoft 2006.

\section{Crystallography}

Diffraction data* (see Tables 2.7, 3.2, 3.4, 3.7 for details) were collected using Bruker CCD diffractometers with Mo K radiation $(0.71073 \AA$ ) from fine-focus sealed tubes with graphite monochromators, using phi and omega scans. Multiscan absorption corrections were applied. The structures were solved by direct methods and full-matrix least squares refinement, with anisotropic thermal parameters for all non-H atoms. ${ }^{130}$ Hydrogen atoms are in calculated positions and refined using a riding model with sHeLXL defaults. The agostic hydrogen atom in $\mathrm{Pt}-\mathrm{H}-\mathrm{C}$ interaction was located and its position refined, and all relevant bond distances and angles were calculated using Mercury, version 1.4.2. Molecular drawings were made using ORTEP3. ${ }^{131}$

\footnotetext{
*Bruker SMART (Version 5.054), SADABS (Version 2.03), and SAINT (Version 6.02A), Bruker AXS Inc., Madison, Wisconsin, USA, 1997.

G. M. Sheldrick, SHELX-97. Programmes for the Solution and Refinement of Crystal Structures, 1997.
} 


\section{2,4 - Di(carbomethoxy) - 1,5 - bis ( $p$ - dimethylaminophenyl $)$ - penta-1,4-dien-3-one (38)}

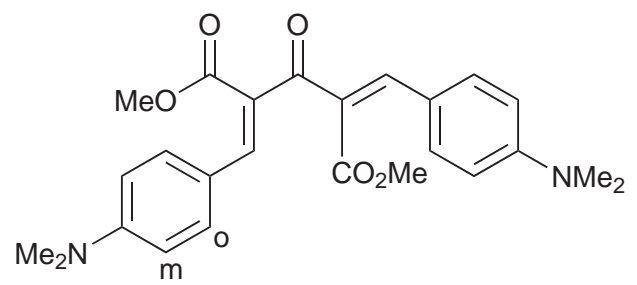

Dimethyl 1,3-acetonedicarboxylate (3.5 g, $0.02 \mathrm{~mol})$, p-dimethylaminobenzaldehyde $(6.0 \mathrm{~g}, 0.04 \mathrm{~mol})$, piperidine $\left(0.45 \mathrm{~cm}^{3}, 4.6 \mathrm{mmol}\right)$ and glacial acetic acid $\left(0.30 \mathrm{~cm}^{3}, 5.2 \mathrm{mmol}\right)$ were combined in benzene $\left(60 \mathrm{~cm}^{3}\right)$ in a $250 \mathrm{~cm}^{3}$ round bottom flask in the air. The flask was equipped with a Dean-Stark trap to measure the volume of water being eliminated during the course of the reaction. The trap was in turn equipped with a condenser, and the reaction mixture was heated under reflux for 1 day. About $0.7 \mathrm{~cm}^{3}$ of water were collected in the Dean-Stark trap indicating that the reaction was complete. The solvent was removed in vacuo to yield a dark red oil. The oil was washed with petroleum ether several times then taken up in benzene. The mixture was stirred at room temperature for several hours during which yellow crystalline solid precipitated out as the oil slowly dissolved. The solid was filtered, washed with benzene and dried in the air (7.5 g, 86\%); mp 124.5-124.8 C (from benzene); (Found: C, 69.2; $\mathrm{H}, 6.5 ; \mathrm{N}, 6.4 . \mathrm{C}_{25} \mathrm{H}_{28} \mathrm{~N}_{2} \mathrm{O}_{5}$ requires $\left.\mathrm{C}, 68.8 ; \mathrm{H}, 6.5 ; \mathrm{N}, 6.4 \%\right) ; \max (\mathrm{KBr}) / \mathrm{cm}^{1}$ $1732,1719,1701,1693,1572,1526,1373,1189$ and 1158; н $\left(300 \mathrm{MHz} ; \mathrm{C}_{6} \mathrm{D}_{6}\right.$; $\left.\mathrm{Me}_{4} \mathrm{Si}\right) 2.18\left(6 \mathrm{H}, \mathrm{s}, \mathrm{NMe}_{2}\right), 2.19$ (6 H, s, $\left.\mathrm{NMe}_{2}\right), 3.43$ (3 H, s, OMe), 3.69 (3 H, $\mathrm{s}, \mathrm{OMe}), 6.12\left(2 \mathrm{H}, \mathrm{d}, J_{\mathrm{HH}} 9.0, m-\mathrm{H}\right), 6.23\left(2 \mathrm{H}, \mathrm{d}, J_{\mathrm{HH}} 9.0, m-\mathrm{H}\right), 7.31(2 \mathrm{H}$, $\left.\mathrm{d}, J_{\mathrm{HH}} 9.0, o-\mathrm{H}\right), 7.62\left(2 \mathrm{H}, \mathrm{d}, J_{\mathrm{HH}} 9.0, o-\mathrm{H}\right), 7.88(1 \mathrm{H}, \mathrm{s}, \mathrm{CH}=\mathrm{CH})$ and 8.32 $(1 \mathrm{H}, \mathrm{s}, \mathrm{CH}=\mathrm{CH}) ; \quad$ c $\left(75 \mathrm{MHz} ; \mathrm{C}_{6} \mathrm{D}_{6} ; \mathrm{Me}_{4} \mathrm{Si}\right) 39.15\left(2 \mathrm{C}, \mathrm{s}, \mathrm{NMe}_{2}\right), 39.17$ (2 C, s, $\left.\mathrm{NMe}_{2}\right), 51.8(1 \mathrm{C}, \mathrm{s}, \mathrm{OMe}), 52.0(1 \mathrm{C}, \mathrm{s}, \mathrm{OMe}), 111.8\left(1 \mathrm{C}, \mathrm{s}, m-\mathrm{C}_{6} \mathrm{H}_{4}\right)$, $112.1\left(1 \mathrm{C}, \mathrm{s}, m_{-}-\mathrm{C}_{6} \mathrm{H}_{4}\right), 120.9\left(2 \mathrm{C}, \mathrm{s}, \mathrm{C}_{6} \mathrm{H}_{4}\right), 121.2\left(2 \mathrm{C}, \mathrm{s}, \mathrm{C}_{6} \mathrm{H}_{4}\right), 132.5(2 \mathrm{C}, \mathrm{s}$, 
$\left.o-\mathrm{C}_{6} \mathrm{H}_{4}\right), 133.2\left(2 \mathrm{C}, \mathrm{s}, o-\mathrm{C}_{6} \mathrm{H}_{4}\right), 143.7\left(1 \mathrm{C}, \mathrm{s}, p-\mathrm{C}_{6} \mathrm{H}_{4}\right), 143.9\left(1 \mathrm{C}, \mathrm{s}, p-\mathrm{C}_{6} \mathrm{H}_{4}\right)$, 166.5 (1 C, s, COO), 169.3 (1 C, s, COO) and 193.8 (1 C, s, CO); m/z (ESI) $459.1000\left([\mathrm{M}+\mathrm{Na}]^{+} \cdot \mathrm{C}_{25} \mathrm{H}_{28} \mathrm{~N}_{2} \mathrm{O}_{5} \mathrm{Na}\right.$ requires 459.1896).

\section{2,4-Dimethyl-1,5-diphenyl-1,4-pentadien-3-one (46)}

Compound 46 was made by a literature method, ${ }^{68}$ in which two side products $\left(47^{69}\right.$ and 48$)$ were produced.

\section{Compound 48:}

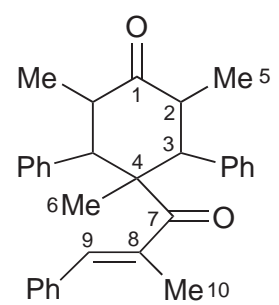

н $\left(600 \mathrm{MHz} ; \mathrm{CDCl}_{3} ; \mathrm{Me}_{4} \mathrm{Si}\right) 0.90(3 \mathrm{H}, \mathrm{s}, \mathrm{Me}-10), 0.91$ (3 H, d, J $\left.\mathrm{HH}_{\mathrm{H}} 6.5, \mathrm{Me}-5\right)$, $1.68(3 \mathrm{H}, \mathrm{s}, \mathrm{Me}-6), 3.10\left(2 \mathrm{H}, \mathrm{dq}, J_{\mathrm{HH}} 13.0,6.5, \mathrm{CH}-2\right), 3.53\left(2 \mathrm{H}, \mathrm{d}, J_{\mathrm{HH}} 13.4\right.$, CH-3), 4.32 (1 H, br s, CH-9), $6.72\left(2 \mathrm{H}, \mathrm{d}, J_{\mathrm{HH}} 7.3, \mathrm{Ph}\right)$ and 7.09-7.45 (13 H, m, Ph); с (150 MHz; CDCl $\left.; \mathrm{Me}_{4} \mathrm{Si}\right) 12.8$ (1 C, s, Me-6), 13.0 (2 C, s, Me-5), 13.9 (1 C, s, Me-10), 44.3 (2 C, s, CH-2), 58.8 (1 C, s, C4), 59.3 (2 C, s, CH-3), 127.1 (1 C, s, Ph), 127.3 (1 C, s, Ph), 128.0 (1 C, s, CH-9), 128.1 (1 C, s, Ph), 129.0 (2 C, s, Ph), 135.7 (1 C, s, Ph), 138.2 (1 C, s, C8), 138.6 (2 C, s, Ph), 211.5 (1 C, s, CO-1) and 213.0 (1 C, s, CO-7). 


\section{4 - $t$ - Butyl - 2,6 - di(carbomethoxy) - 3,5 - bis ( $p$ - dimethyl - aminophenyl)-4-phosphacyclohexanone $(53,54,57)$}

Dibenzylideneacetone derivative 38 (3.6 g, $8.2 \mathrm{mmol})$ was dissolved in pyridine $\left(30 \mathrm{~cm}^{3}\right)$. To the solution, $t$-butylphosphine $(1.1 \mathrm{~g}, 12.3 \mathrm{mmol})$ was quickly added. The reaction mixture was stirred at room temperature for 1 day in a closed vessel to prevent $\mathrm{Bu}^{\mathrm{t}} \mathrm{PH}_{2}$ from escaping. Over time a white solid precipitated out. The solid was filtered in the air, washed with diethyl ether then dried in vacuo to give the first batch of phosphorinanone isomer 53. The filtrate was reduced to dryness in vacuo to give a yellow foam. Washing the foam with diethyl ether yielded a second batch of compound $\mathbf{5 3}$ as a white solid.

The diethyl ether wash was reduced to dryness in vacuo and the yellow solid was recrystallised from hot methanol in the air to produce white crystalline fine needles of 54. The yield can be increased by several cycles of crystallisations of the filtrates from hot methanol. Sometimes residual 53 co-crystallised with $\mathbf{5 4}$ as off-white balls, which could be physically separated from the needles. The final mother liquor contained small amounts of 53, 54, 57 and several other isomers as shown by ${ }^{1} \mathrm{H}$ and ${ }^{31} \mathrm{P}$ NMR spectra. It was impractical to separate the remaining isomers any further.

\section{Compound 53:}

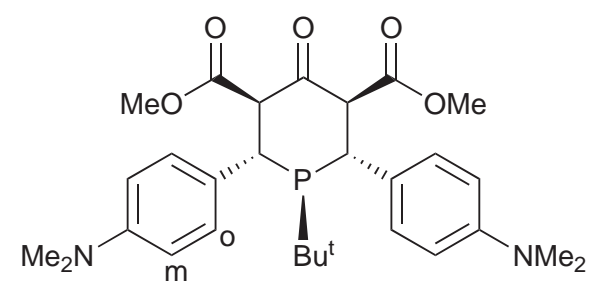

(2.4 g, 55\%); decomposition at $200 \mathrm{C}$ (from pyridine); (Found: C, 66.2; H, 7.7;

$\mathrm{N}$, 5.4. $\mathrm{C}_{29} \mathrm{H}_{39} \mathrm{~N}_{2} \mathrm{O}_{5} \mathrm{P}$ requires C, 66.1; H, 7.5; N, 5.3\%); $\max (\mathrm{KBr}) / \mathrm{cm}^{1} 1755$, $1707,1610,1520 ;$ н $\left(500 \mathrm{MHz} ; \mathrm{CDCl}_{3} ; \mathrm{Me}_{4} \mathrm{Si}\right) 0.63\left(9 \mathrm{H}, \mathrm{d}, J_{\mathrm{PH}} 10.7, \mathrm{Bu}^{\mathrm{t}}\right)$, 
$2.91\left(12 \mathrm{H}, \mathrm{s}, \mathrm{NMe}_{2}\right), 3.51$ (6 H, s, OMe), 3.59 (2 H, dd, $J_{\mathrm{PH}} 12.7, J_{\mathrm{HH}} 5.9$, $\mathrm{PCH}), 3.97\left(2 \mathrm{H}, \mathrm{dd}, J_{\mathrm{PH}} 12.7, J_{\mathrm{HH}} 5.4, \mathrm{PCCH}\right), 6.62\left(4 \mathrm{H}, \mathrm{d}, J_{\mathrm{HH}} 8.5, m-\mathrm{H}\right)$ and $7.21\left(4 \mathrm{H}, \mathrm{d}, J_{\mathrm{HH}} 8.5, o-\mathrm{H}\right) ; \mathrm{c}\left(125 \mathrm{MHz} ; \mathrm{CDCl}_{3} ; \mathrm{Me}_{4} \mathrm{Si}\right) 28.7$ (3 C, d, $\left.J_{\mathrm{PC}} 10.1, \mathrm{CMe}_{3}\right), 30.9\left(1 \mathrm{C}, \mathrm{d}, J_{\mathrm{PC}} 20.6, \mathrm{CMe}_{3}\right), 40.6\left(4 \mathrm{C}, \mathrm{s}, \mathrm{NMe}_{2}\right), 42.3$ (2 C, d, J $\left.J_{\mathrm{PC}} 19.7, \mathrm{PCH}\right), 52.1$ (2 C, s, OMe), 65.4 (2 C, d, $\left.J_{\mathrm{PC}} 16.1, \mathrm{PCCH}\right)$, $112.7\left(4 \mathrm{C}, \mathrm{s}, m-\mathrm{C}_{6} \mathrm{H}_{4}\right), 127.7\left(2 \mathrm{C}, \mathrm{d}, J_{\mathrm{PC}} 8.2, \mathrm{C}_{6} \mathrm{H}_{4}\right), 129.9\left(4 \mathrm{C}, \mathrm{d}, J_{\mathrm{PC}} 8.2\right.$, $\left.o-\mathrm{C}_{6} \mathrm{H}_{4}\right), 149.6\left(2 \mathrm{C}, \mathrm{s}, p-\mathrm{C}_{6} \mathrm{H}_{4}\right), 168.2\left(2 \mathrm{C}\right.$, d, $\left.J_{\mathrm{PC}} 10.6, \mathrm{COO}\right)$ and 199.4 (1 $\left.\mathrm{C}, \mathrm{d}, J_{\mathrm{PC}} 3.4, \mathrm{CO}\right) ; \quad$ P $\left(121 \mathrm{MHz} ; \mathrm{CDCl}_{3} ; \mathrm{H}_{3} \mathrm{PO}_{4}\right) 13.0(1 \mathrm{P}, \mathrm{s}) ; \mathrm{m} / z$ (ESI) $527.2661\left([\mathrm{M}+\mathrm{H}]^{+} \cdot \mathrm{C}_{29} \mathrm{H}_{40} \mathrm{~N}_{2} \mathrm{O}_{5} \mathrm{P}\right.$ requires 527.2675), $264(100 \%)$.

\section{Compound 54:}

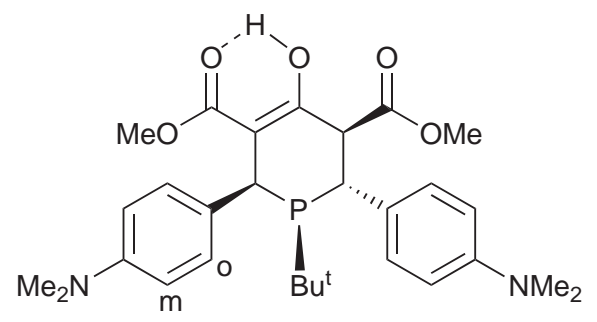

(0.64 g, 15\%); decomposition at $170 \mathrm{C}$ (from methanol); (Found: C, 66.3; H, 7.6; N, 5.4. $\mathrm{C}_{29} \mathrm{H}_{39} \mathrm{~N}_{2} \mathrm{O}_{5} \mathrm{P}$ requires C, 66.1; H, 7.5; N, 5.3\%); $\max (\mathrm{KBr}) / \mathrm{cm}^{1}$ $3453,1735,1644,1610,1519 ;$ н $\left(600 \mathrm{MHz} ; \mathrm{CDCl}_{3} ; \mathrm{Me}_{4} \mathrm{Si}\right) 0.52\left(9 \mathrm{H}, \mathrm{d}, J_{\mathrm{PH}}\right.$ 11.6, $\left.\mathrm{Bu}^{\mathrm{t}}\right), 2.91\left(6 \mathrm{H}\right.$, br s, $\left.\mathrm{NMe}_{2}\right), 2.95\left(6 \mathrm{H}\right.$, br s, $\left.\mathrm{NMe}_{2}\right), 3.62(3 \mathrm{H}, \mathrm{s}, \mathrm{OMe})$, $3.66(3 \mathrm{H}, \mathrm{s}, \mathrm{OMe}), 3.90(2 \mathrm{H}, \mathrm{m}, \mathrm{PCH} / \mathrm{PCCH}), 4.28\left(1 \mathrm{H}, \mathrm{d}, J_{\mathrm{PH}} 5.9, \mathrm{PCH}\right)$, $6.51\left(1 \mathrm{H}\right.$, br s, $\left.m-\mathrm{C}_{6} \mathrm{H}_{4}\right), 6.74\left(3 \mathrm{H}\right.$, br s, $\left.m-\mathrm{C}_{6} \mathrm{H}_{4}\right), 6.91\left(1 \mathrm{H}\right.$, br s, $\left.o-\mathrm{C}_{6} \mathrm{H}_{4}\right), 7.40$ $\left(3 \mathrm{H}\right.$, br s, o- $\left.\mathrm{C}_{6} \mathrm{H}_{4}\right)$ and $12.84(1 \mathrm{H}, \mathrm{s}, \mathrm{OH}) ; \mathrm{c}\left(150 \mathrm{MHz} ; \mathrm{CDCl}_{3} ; \mathrm{Me}_{4} \mathrm{Si}\right) 27.6(3$ C, d, $\left.J_{\mathrm{PC}} 12.3, \mathrm{CMe}_{3}\right), 30.2\left(1 \mathrm{C}, \mathrm{d}, J_{\mathrm{PC}} 21.3, \mathrm{CMe}_{3}\right), 35.2\left(1 \mathrm{C}, \mathrm{d}, J_{\mathrm{PC}} 24.1\right.$, $\mathrm{PCH}), 36.5$ (1 C, d, J $\left.J_{\mathrm{PC}} 19.1, \mathrm{PCH}\right), 40.7$ (2 C, br s, $\mathrm{NMe}_{2}$ ), 40.8 (2 C, br s, $\left.\mathrm{NMe}_{2}\right), 52.4$ (1 C, s, OMe), 52.6 (1 C, s, OMe), 57.3 (1 C, d, $\left.J_{\mathrm{PC}} 17.4, \mathrm{PCCH}\right)$, $103.8\left(1 \mathrm{C}, \mathrm{d}, J_{\mathrm{PC}} 9.0, \mathrm{C} \mathrm{COH}\right), 112.0\left(1 \mathrm{C}\right.$, br s, $\left.m-\mathrm{C}_{6} \mathrm{H}_{4}\right), 112.5$ (1 C, br s, $\left.m-\mathrm{C}_{6} \mathrm{H}_{4}\right), 113.7\left(2 \mathrm{C}\right.$, br s, $\left.m-\mathrm{C}_{6} \mathrm{H}_{4}\right), 127.1$ (1 C, br s, $\left.\mathrm{C}_{6} \mathrm{H}_{4}\right), 128.5$ (1 C, br s, 
$\left.\mathrm{C}_{6} \mathrm{H}_{4}\right), 128.9\left(1 \mathrm{C}\right.$, br s, o- $\left.\mathrm{C}_{6} \mathrm{H}_{4}\right), 130.6$ (3 C, br s, o- $\left.\mathrm{C}_{6} \mathrm{H}_{4}\right), 149.1$ (1 C, br s, $\left.p-\mathrm{C}_{6} \mathrm{H}_{4}\right), 149.7\left(1 \mathrm{C}\right.$, br s, $\left.p-\mathrm{C}_{6} \mathrm{H}_{4}\right), 168.3\left(1 \mathrm{C}\right.$, d, J $\left.J_{\mathrm{PC}} 6.2, \mathrm{C} \mathrm{COH}\right), 172.6$ (1 $\left.\mathrm{C}, \mathrm{d}, J_{\mathrm{PC}} 13.2, \mathrm{COO}\right)$ and $172.8\left(1 \mathrm{C}, \mathrm{d}, J_{\mathrm{PC}} 6.7, \mathrm{COO}\right) ;$ P $\left(121 \mathrm{MHz} ; \mathrm{CDCl}_{3}\right.$; $\left.\mathrm{H}_{3} \mathrm{PO}_{4}\right) 6.0(1 \mathrm{P}, \mathrm{s}) ; m / z$ (ESI) $527.2677\left([\mathrm{M}+\mathrm{H}]^{+} \cdot \mathrm{C}_{29} \mathrm{H}_{40} \mathrm{~N}_{2} \mathrm{O}_{5} \mathrm{P}\right.$ requires $527.2675)$.

\section{Compound 57:}

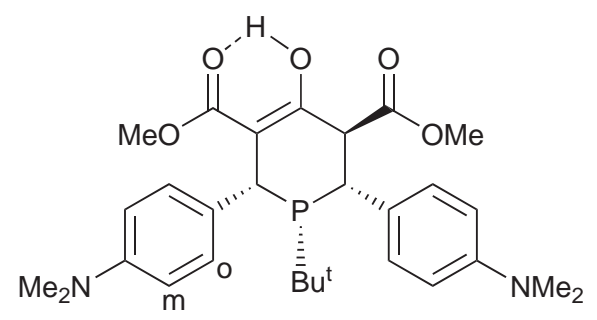

This phosphorinanone isomer was not isolated, $\mathrm{H}\left(600 \mathrm{MHz} ; \mathrm{CDCl}_{3} ; \mathrm{Me}_{4} \mathrm{Si}\right.$ ) $0.96\left(9 \mathrm{H}, \mathrm{d}, J_{\mathrm{PH}} 11.3, \mathrm{Bu}^{\mathrm{t}}\right), 2.90\left(12 \mathrm{H}, \mathrm{s}, \mathrm{NMe}_{2}\right), 3.58$ (3 H, s, OMe), 3.61 (3 H, s, OMe), $3.78\left(1 \mathrm{H}, \mathrm{dd}, J_{\mathrm{HH}} 12.6, J_{\mathrm{PH}} 3.2, \mathrm{PCH}\right), 4.13(1 \mathrm{H}, \mathrm{s}, \mathrm{PCH}), 4.42$ $\left(1 \mathrm{H}, \mathrm{dd}, J_{\mathrm{HH}} 12.6, J_{\mathrm{PH}} 1.0, \mathrm{PCCH}\right) 6.57\left(2 \mathrm{H}, \mathrm{d}, J_{\mathrm{HH}} 8.8, m-\mathrm{C}_{6} \mathrm{H}_{4}\right), 6.72(2 \mathrm{H}$, m, $\left.m-\mathrm{C}_{6} \mathrm{H}_{4}\right), 7.13\left(2 \mathrm{H}, \mathrm{d}, J_{\mathrm{HH}} 8.7, o-\mathrm{C}_{6} \mathrm{H}_{4}\right), 7.24\left(2 \mathrm{H}, \mathrm{m}, o-\mathrm{C}_{6} \mathrm{H}_{4}\right)$ and 13.13 $(1 \mathrm{H}, \mathrm{s}, \mathrm{OH}) ; \quad$ C $\left(150 \mathrm{MHz} ; \mathrm{CDCl}_{3} ; \mathrm{Me}_{4} \mathrm{Si}\right) 29.8$ (3 C, d, J $\left.J_{\mathrm{PC}} 13.7, \mathrm{CMe}_{3}\right), 31.7$ $\left(1 \mathrm{C}, \mathrm{d}, J_{\mathrm{PC}} 30.9, \mathrm{CMe}_{3}\right), 34.3\left(1 \mathrm{C}, \mathrm{d}, J_{\mathrm{PC}} 21.3, \mathrm{PCH}\right), 34.5\left(1 \mathrm{C}, \mathrm{d}, J_{\mathrm{PC}} 13.5\right.$, PCH), 40.0 (4 C, s, $\mathrm{NMe}_{2}$ ), 52.0 (2 C, s, OMe), 48.1 (1 C, d, J $\left.J_{\mathrm{PC}} 2.0, \mathrm{PCCH}\right)$, $99.9\left(1 \mathrm{C}, \mathrm{d}, J_{\mathrm{PC}} 2.8, \mathrm{C} \mathrm{COH}\right), 112.0\left(4 \mathrm{C}, \mathrm{s}, m-\mathrm{C}_{6} \mathrm{H}_{4}\right), 126.0\left(1 \mathrm{C}, \mathrm{d}, J_{\mathrm{PC}} 6.7\right.$, $\left.\mathrm{C}_{6} \mathrm{H}_{4}\right), 130.8\left(1 \mathrm{C}, \mathrm{d}, J_{\mathrm{PC}} 11.8, \mathrm{C}_{6} \mathrm{H}_{4}\right), 128.4\left(2 \mathrm{C}, \mathrm{d}, J_{\mathrm{PC}} 5.9, o-\mathrm{C}_{6} \mathrm{H}_{4}\right), 128.7(2$ $\left.\mathrm{C}, \mathrm{d}, J_{\mathrm{PC}} 5.9, o-\mathrm{C}_{6} \mathrm{H}_{4}\right), 148.7\left(2 \mathrm{C}, \mathrm{m}, p-\mathrm{C}_{6} \mathrm{H}_{4}\right), 169.9(1 \mathrm{C}, \mathrm{s}, \mathrm{C} \quad \mathrm{COH}), 172.6$ $\left(1 \mathrm{C}, \mathrm{d}, J_{\mathrm{PC}} 6.7, \mathrm{COO}\right)$ and $173.1(1 \mathrm{C}, \mathrm{s}, \mathrm{COO}) ; \mathrm{P}\left(121 \mathrm{MHz} ; \mathrm{CDCl}_{3} ; \mathrm{H}_{3} \mathrm{PO}_{4}\right)$ $17.5(1 \mathrm{P}, \mathrm{s})$. 


\section{General procedure for the Mannich reaction of 4- phenylphosphorinanone (42)}

4-Phenylphosphorinanone ${ }^{65} 42(0.10 \mathrm{~g}, 0.52 \mathrm{mmol})$, methylamine $\left(0.05 \mathrm{~cm}^{3}\right.$, $0.52 \mathrm{mmol})$ and formaldehyde $\left(0.08 \mathrm{~cm}^{3}, 1.0 \mathrm{mmol}\right)$ were combined in absolute ethanol $\left(10 \mathrm{~cm}^{3}\right)$. The reaction mixture was heated under reflux for $24 \mathrm{hr}$. Removal of solvent in vacuo gave a pale yellow solid, which could not be identified.

\section{General procedure for the Mannich reaction of phosphori- nanone isomers 44 and 45}

A mixture of phosphorinanone isomers ${ }^{58,60,61} 44$ and 45 (0.10 g, $\left.0.29 \mathrm{mmol}\right)$, methylamine $\left(0.03 \mathrm{~cm}^{3}, 0.29 \mathrm{mmol}\right)$ and formaldehyde $\left(0.04 \mathrm{~cm}^{3}, 0.58 \mathrm{mmol}\right)$ were combined in absolute ethanol $\left(10 \mathrm{~cm}^{3}\right)$. The reaction mixture was heated under reflux for the required length of time. Removal of solvent in vacuo gave a pale yellow oil, which could not be identified.

\section{General procedure for the Mannich reaction of phosphori- nanone isomers 50 and 51}

A mixture of phosphorinanone isomers ${ }^{59,60} \mathbf{5 0}$ and 51 (0.10 g, $\left.0.27 \mathrm{mmol}\right)$, methylamine $\left(0.02 \mathrm{~cm}^{3}, 0.27 \mathrm{mmol}\right)$ and formaldehyde $\left(0.04 \mathrm{~cm}^{3}, 0.54 \mathrm{mmol}\right)$ were combined in absolute ethanol $\left(10 \mathrm{~cm}^{3}\right)$. The reaction mixture was heated under reflux for the required length of time. Upon cooling down to room temperature, the phosphorinanones crystallised out of the reaction mixture as white needles. These were filtered in the air, washed with cold ethanol and dried in vacuo then re-used in subsequent attempts. 


\section{General procedure for the exchange reactions of phospho- rinanone isomer 51}

Phosphorinanone isomer 51 (0.005 g, $0.01 \mathrm{mmol}$ ) and NaOMe (0.001 g, $0.03 \mathrm{mmol}$ ) were combined in $\mathrm{MeOH}-\mathrm{d}_{4}$. The reaction mixture was heated under reflux for 15 min. White solid precipitated out as the mixture cooled down to room temperature. The solvent was decanted and the solid dried in vacuo.

\section{7 - $t$ - Butyl - 1,5 - di(carbomethoxy) - 6,8 - bis ( $p$ - dimethyl - aminophenyl) - 3 - methyl - 3 - aza - 7 - phosphabicyclo[3.3.1] - nonan-9-one (65)}

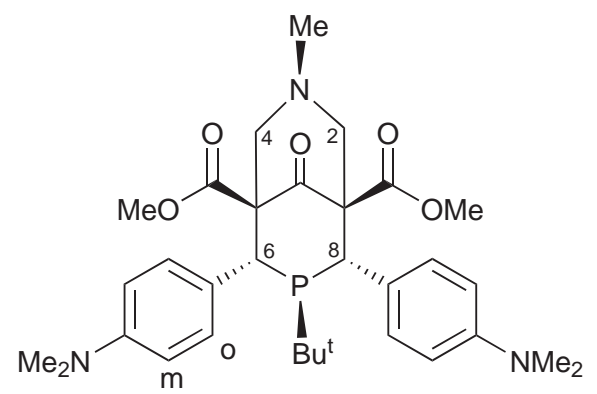

Phosphorinanone isomer 53 (1.7 g, $3.2 \mathrm{mmol})$, methylamine $\left(0.30 \mathrm{~cm}^{3}, 3.2 \mathrm{mmol}\right)$ and formaldehyde $\left(0.51 \mathrm{~cm}^{3}, 6.3 \mathrm{mmol}\right)$ were combined in absolute ethanol $\left(30 \mathrm{~cm}^{3}\right)$. The reaction mixture was heated under reflux for 1 day. Colourless needles crystallised out of the yellow reaction mixture as it cooled down to room temperature. The needles were filtered in the air, washed with cold ethanol and dried in vacuo (1.83 g, 75\%); decomposition at $200 \mathrm{C}$ (from ethanol); (Found: C, 65.7; H, 7.6; N, 7.0. $\mathrm{C}_{32} \mathrm{H}_{44} \mathrm{~N}_{3} \mathrm{O}_{5} \mathrm{P}$ requires $\mathrm{C}, 66.1 ; \mathrm{H}, 7.6 ; \mathrm{N}$, $7.2 \%) ; \quad \max (\mathrm{KBr}) / \mathrm{cm}^{1} 1733,1712,1612,1521,1360,1264 ; \quad$ н $\left(300 \mathrm{MHz} ; \mathrm{C}_{6} \mathrm{D}_{6}\right.$; $\left.\mathrm{Me}_{4} \mathrm{Si}\right) 0.86\left(9 \mathrm{H}, \mathrm{d}, J_{\mathrm{PH}} 9.8, \mathrm{Bu}^{\mathrm{t}}\right), 2.30(3 \mathrm{H}, \mathrm{s}, \mathrm{NMe}), 2.48\left(12 \mathrm{H}, \mathrm{s}, \mathrm{NMe}_{2}\right)$, $2.91\left(2 \mathrm{H}, \mathrm{d}, J_{\mathrm{HH}} 12.0, \mathrm{CH}_{2}\right), 3.44(6 \mathrm{H}, \mathrm{s}, \mathrm{OMe}), 3.56\left(2 \mathrm{H}, \mathrm{d}, J_{\mathrm{HH}} 12.5, \mathrm{CH}_{2}\right)$, $4.44\left(2 \mathrm{H}, \mathrm{d}, J_{\mathrm{PH}} 5.4, \mathrm{PCH}\right), 6.32\left(2 \mathrm{H}\right.$, br d, $\left.J_{\mathrm{HH}} 7.8, m-\mathrm{H}\right), 6.69(2 \mathrm{H}, \mathrm{br}$ d, 
$\left.J_{\mathrm{HH}} 6.7, m-\mathrm{H}\right), 7.27\left(2 \mathrm{H}, \mathrm{br} \mathrm{d}, J_{\mathrm{HH}} 8.1, o-\mathrm{H}\right)$ and $8.17\left(2 \mathrm{H}, \mathrm{br} \mathrm{d}, J_{\mathrm{HH}} 8.6\right.$, $o-\mathrm{H}) ; \quad$ с $\left(75 \mathrm{MHz} ; \mathrm{C}_{6} \mathrm{D}_{6} ; \mathrm{Me}_{4} \mathrm{Si}\right) 28.1$ (3 C, d, J $\left.J_{\mathrm{PC}} 13.4, \mathrm{CMe}_{3}\right), 31.4(1 \mathrm{C}$, d, $\left.J_{\mathrm{PC}} 27.5, \mathrm{CMe}_{3}\right), 39.9\left(4 \mathrm{C}, \mathrm{s}, \mathrm{NMe}_{2}\right), 43.0$ (2 C, d, $\left.J_{\mathrm{PC}} 28.4, \mathrm{PCH}\right), 44.1$ $(1 \mathrm{C}, \mathrm{s}, \mathrm{NMe}), 51.6(2 \mathrm{C}, \mathrm{s}, \mathrm{OMe}), 60.7\left(2 \mathrm{C}, \mathrm{s}, \mathrm{CH}_{2}\right), 65.8\left(2 \mathrm{C}, \mathrm{d}, J_{\mathrm{PC}} 1.4\right.$, PCHC), $112.2\left(2 \mathrm{C}\right.$, br s, $\left.m-\mathrm{C}_{6} \mathrm{H}_{4}\right), 112.4\left(2 \mathrm{C}\right.$, br d, $\left.J_{\mathrm{PC}} 1.3, m-\mathrm{C}_{6} \mathrm{H}_{4}\right), 132.1$ $\left(2 \mathrm{C}\right.$, br d, $\left.J_{\mathrm{PC}} 3.4, \mathrm{C}_{6} \mathrm{H}_{4}\right), 133.1\left(2 \mathrm{C}\right.$, br d, J $\left.J_{\mathrm{PC}} 1.8, o_{-} \mathrm{C}_{6} \mathrm{H}_{4}\right), 133.4(2 \mathrm{C}, \mathrm{br}$ $\left.\mathrm{d}, J_{\mathrm{PC}} 2.0, o-\mathrm{C}_{6} \mathrm{H}_{4}\right), 149.7\left(2 \mathrm{C}, \mathrm{d}, J_{\mathrm{PC}} 1.7, p-\mathrm{C}_{6} \mathrm{H}_{4}\right), 169.7\left(2 \mathrm{C}, \mathrm{d}, J_{\mathrm{PC}} 2.2\right.$, $\mathrm{COO})$ and $205.2\left(1 \mathrm{C}, \mathrm{d}, J_{\mathrm{PC}} 2.5, \mathrm{CO}\right) ; \mathrm{p}\left(121 \mathrm{MHz} ; \mathrm{C}_{6} \mathrm{D}_{6} ; \mathrm{H}_{3} \mathrm{PO}_{4}\right) 8.4(1 \mathrm{P}$, $\mathrm{s}) ; \quad \mathrm{N}\left(60 \mathrm{MHz} ; \mathrm{C}_{6} \mathrm{D}_{6} ; \mathrm{MeNO}_{2}\right)-337\left(2 \mathrm{~N}, \mathrm{NMe}_{2}\right)$ and $-353(1 \mathrm{~N}, \mathrm{NMe}) ; \mathrm{m} / z$ (ESI) $582.3086\left([\mathrm{M}+\mathrm{H}]^{+} \cdot \mathrm{C}_{32} \mathrm{H}_{45} \mathrm{~N}_{3} \mathrm{O}_{5} \mathrm{P}\right.$ requires 582.3096).

\section{Mannich reaction of phosphorinanone isomer 54}

Phosphorinanone isomer $54(1.0 \mathrm{~g}, 1.9 \mathrm{mmol})$, methylamine $\left(0.16 \mathrm{~cm}^{3}, 1.9 \mathrm{mmol}\right)$ and formaldehyde $\left(0.28 \mathrm{~cm}^{3}, 3.8 \mathrm{mmol}\right)$ were combined in absolute ethanol $\left(100 \mathrm{~cm}^{3}\right)$. The reaction mixture was heated under reflux for 1 day. Big colourless crystals of $\mathbf{6 5}$ crystallised out of the yellow reaction mixture as it cooled down to room temperature. The crystals were filtered, washed with ethanol and dried in the air. All solvent was removed from the filtrate to give a yellow solid. Washing the solid with ethanol removed most of the yellow colouration to leave behind $\mathbf{6 5}$ as a white solid. Taking the filtrate to dryness again and washing the resulting yellow solid with diethyl ether gave another batch of compound 65 bringing the total yield to $0.29 \mathrm{~g}, 26 \%$. The yields calculated from this reaction are based on the number of moles of phosphorinanone $\mathbf{5 4}$.

The diethyl ether filtrate was taken to dryness and the resulting yellow residue was washed with hexane. This successfully separated the other products from this reaction. The hexane-insoluble white solid was identified as PN ligand 66 but the solid was contaminated with compound 65. The white solid can be further purified by washing with small volumes of ethyl acetate to give up to 
90\% pure sample of compound 66 (0.09 g, 13\%). The hexane wash contained the $E / Z$ isomers of compound 67 (0.27 g, 37\%, E/Z 9:1).

\section{4-t-Butyl-6-carbomethoxy-5-( $p$-dimethylaminophenyl)-2-methyl-2-} aza-4-phosphacyclohexanone (66):

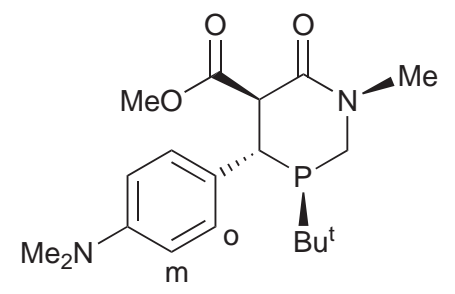

Correct melting point and elemental analytical data could not be obtained because of contamination with compound 65. $\max (\mathrm{KBr}) / \mathrm{cm}^{1} 1744,1655$, 1612, 1520, 1351, 1164; н $\left(500 \mathrm{MHz} ; \mathrm{C}_{6} \mathrm{D}_{6} ; \mathrm{Me}_{4} \mathrm{Si}\right) 0.79\left(9 \mathrm{H}, \mathrm{d}, J_{\mathrm{PH}} 11.5\right.$, $\left.\mathrm{Bu}^{\mathrm{t}}\right), 2.45\left(6 \mathrm{H}, \mathrm{s}, \mathrm{NMe}_{2}\right), 2.68(3 \mathrm{H}, \mathrm{s}, \mathrm{NMe}), 2.84\left(1 \mathrm{H}, \mathrm{dd}, J_{\mathrm{HH}} 14.5, J_{\mathrm{PH}} 2.6\right.$, $\left.\mathrm{CH}_{2}\right), 3.03\left(1 \mathrm{H}, \mathrm{dd}, J_{\mathrm{PH}} 18.0, J_{\mathrm{HH}} 14.5, \mathrm{CH}_{2}\right), 3.32(3 \mathrm{H}, \mathrm{s}, \mathrm{OMe}), 3.67(1 \mathrm{H}$, dd, $\left.J_{\mathrm{HH}} 12.8, J_{\mathrm{PH}} 7.2, \mathrm{PCH}\right), 3.90\left(1 \mathrm{H}, \mathrm{dd}, J_{\mathrm{HH}} 12.8, J_{\mathrm{PH}} 5.3, \mathrm{PCCH}\right), 6.55$ $\left(2 \mathrm{H}, \mathrm{d}, J_{\mathrm{HH}} 8.8, m-\mathrm{H}\right)$ and $7.32\left(2 \mathrm{H}, \mathrm{d}, J_{\mathrm{HH}} 8.8, o-\mathrm{H}\right) ; \mathrm{C}\left(150 \mathrm{MHz} ; \mathrm{C}_{6} \mathrm{D}_{6}\right.$; $\left.\mathrm{Me}_{4} \mathrm{Si}\right) 27.4\left(3 \mathrm{C}, \mathrm{d}, J_{\mathrm{PC}} 13.0, \mathrm{CMe}_{3}\right), 29.2$ (1 C, d, $\left.J_{\mathrm{PC}} 18.7, \mathrm{CMe}_{3}\right), 36.6$ (1 C, s, NMe), 39.2 (1 C, d, J $\left.J_{\mathrm{PC}} 17.3, \mathrm{PCH}\right), 40.0\left(2 \mathrm{C}, \mathrm{s}, \mathrm{NMe}_{2}\right), 43.3$ (1 C, d, J $\mathrm{PC}$ 27.8, $\mathrm{CH}_{2}$ ), 51.7 (1 C, s, OMe), 57.6 (1 C, d, J $J_{\mathrm{PC}}$ 8.6, PCHC), 112.9 (2 C, s, $\left.m-\mathrm{C}_{6} \mathrm{H}_{4}\right), 129.0\left(1 \mathrm{C}, \mathrm{d}, J_{\mathrm{PC}} 13.4, \mathrm{C}_{6} \mathrm{H}_{4}\right), 130.0\left(2 \mathrm{C}, \mathrm{d}, J_{\mathrm{PC}} 8.6, o-\mathrm{C}_{6} \mathrm{H}_{4}\right), 149.5$ $\left(1 \mathrm{C}, \mathrm{d}, J_{\mathrm{PC}} 1.9, p-\mathrm{C}_{6} \mathrm{H}_{4}\right), 167.6(1 \mathrm{C}, \mathrm{s}, \mathrm{CO})$ and 169.7 (1 C, d, J $\left.J_{\mathrm{PC}} 9.1, \mathrm{COO}\right)$; P $\left(121 \mathrm{MHz} ; \mathrm{C}_{6} \mathrm{D}_{6} ; \mathrm{H}_{3} \mathrm{PO}_{4}\right)-3.5(1 \mathrm{P}, \mathrm{s}) ; \mathrm{N}\left(60 \mathrm{MHz} ; \mathrm{C}_{6} \mathrm{D}_{6} ; \mathrm{MeNO}_{2}\right)-337(1$ $\left.\mathrm{N}, \mathrm{NMe}_{2}\right)$ and $-279(1 \mathrm{~N}, \mathrm{NMe}) ; m / z(\mathrm{ESI}) 365.1997\left([\mathrm{M}+\mathrm{H}]^{+} \cdot \mathrm{C}_{19} \mathrm{H}_{30} \mathrm{~N}_{2} \mathrm{O}_{3} \mathrm{P}\right.$ requires 365.1994). 
Compound $67-E$ isomer:

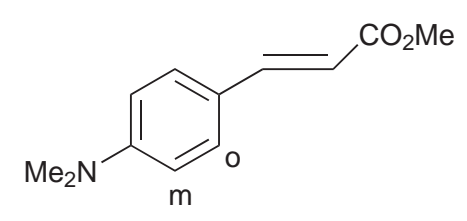

н $\left(500 \mathrm{MHz} ; \mathrm{C}_{6} \mathrm{D}_{6} ; \mathrm{Me}_{4} \mathrm{Si}\right) 2.34\left(6 \mathrm{H}, \mathrm{s}, \mathrm{NMe}_{2}\right), 3.54(3 \mathrm{H}, \mathrm{s}, \mathrm{OMe}), 6.28(2 \mathrm{H}$, $\left.\mathrm{d}, J_{\mathrm{HH}} 8.9, m-\mathrm{H}\right), 6.48\left(1 \mathrm{H}, \mathrm{d}, J_{\mathrm{HH}} 15.9,-\mathrm{H}\right), 7.22\left(2 \mathrm{H}, \mathrm{d}, J_{\mathrm{HH}} 8.9, o-\mathrm{H}\right)$ and $7.99\left(1 \mathrm{H}, \mathrm{d}, J_{\mathrm{HH}} 15.9,-\mathrm{H}\right) ; \quad$ C $\left(150 \mathrm{MHz} ; \mathrm{C}_{6} \mathrm{D}_{6} ; \mathrm{Me}_{4} \mathrm{Si}\right) 39.5\left(2 \mathrm{C}, \mathrm{s}, \mathrm{NMe}_{2}\right)$, 50.9 (1 C, s, OMe), 112.1 (2 C, s, m- $\left.\mathrm{C}_{6} \mathrm{H}_{4}\right), 113.0$ (1 C, s, -C), 122.9 (1 C, s, $\left.\mathrm{C}_{6} \mathrm{H}_{4}\right), 129.9\left(2 \mathrm{C}, \mathrm{s}, o-\mathrm{C}_{6} \mathrm{H}_{4}\right), 145.5(1 \mathrm{C}, \mathrm{s},-\mathrm{C}) 151.8\left(1 \mathrm{C}, \mathrm{s}, p-\mathrm{C}_{6} \mathrm{H}_{4}\right)$ and 167.8 (1 C, s, COO).

Compound $67-Z$ isomer:

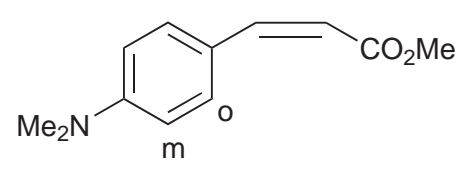

н $\left(300 \mathrm{MHz} ; \mathrm{C}_{6} \mathrm{D}_{6} ; \mathrm{Me}_{4} \mathrm{Si}\right) 2.36\left(6 \mathrm{H}, \mathrm{s}, \mathrm{NMe}_{2}\right), 3.44$ (3 H, s, OMe), $5.81(1 \mathrm{H}$, $\left.\mathrm{d}, J_{\mathrm{HH}} 13.0,-\mathrm{H}\right), 6.44\left(2 \mathrm{H}, \mathrm{d}, J_{\mathrm{HH}} 9.1, m-\mathrm{H}\right), 6.61\left(1 \mathrm{H}, \mathrm{d}, J_{\mathrm{HH}} 13.0,-\mathrm{H}\right)$ and $8.11\left(2 \mathrm{H}, \mathrm{d}, J_{\mathrm{HH}} 8.8, o-\mathrm{H}\right)$. 


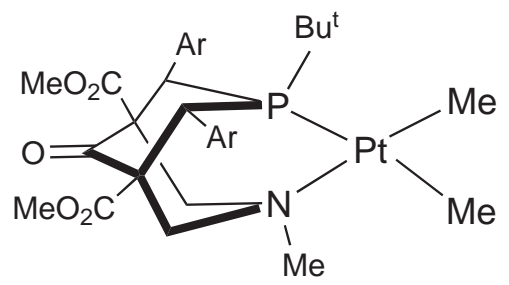

PN ligand 65 (0.1 g, $0.17 \mathrm{mmol})$ and $\left[\mathrm{PtMe}_{2}(1,5\right.$-hexadiene $\left.)\right](0.05 \mathrm{~g}, 0.17 \mathrm{mmol})$ were combined in benzene $\left(5 \mathrm{~cm}^{3}\right)$. The colourless reaction mixture was heated at $50 \mathrm{C}$ for 3 days. Removal of solvent in vacuo gave complex $\mathbf{6 8}$ as an off-white solid (0.14 g, 98\%) decomposition at $130 \mathrm{C}$ (from benzene); (Found: C, 50.5; H, 6.5; N, 5.3. $\mathrm{C}_{34} \mathrm{H}_{50} \mathrm{~N}_{3} \mathrm{O}_{5} \mathrm{PPt}$ requires C, 50.6; H, 6.3; N, 5.2\%); $\max (\mathrm{KBr}) / \mathrm{cm}^{1}$ $1743,1721,1610,1519,1355,1259 ;$ н $\left(300 \mathrm{MHz} ; \mathrm{C}_{6} \mathrm{D}_{6} ; \mathrm{Me}_{4} \mathrm{Si}\right) 0.75$ (9 H, d, $\left.J_{\mathrm{PH}} 12.7, \mathrm{Bu}^{\mathrm{t}}\right), 1.38\left(3 \mathrm{H}, \mathrm{d}, J_{\mathrm{PH}} 7.4, J_{\mathrm{PtH}} 65\right.$, trans-Me $), 1.59\left(3 \mathrm{H}, \mathrm{d}, J_{\mathrm{PH}}\right.$ 6.7, $J_{\mathrm{PtH}} 92$, cis-Me), 2.54 (3 H, br s, NMe), $2.93\left(12 \mathrm{H}, \mathrm{s}, \mathrm{NMe}_{2}\right), 2.94(2 \mathrm{H}, \mathrm{d}$, $\left.J_{\mathrm{HH}} 13.4, \mathrm{CH}_{2}\right), 3.38(6 \mathrm{H}, \mathrm{s}, \mathrm{OMe}), 4.22\left(2 \mathrm{H}, \mathrm{d}, J_{\mathrm{HH}} 13.9, \mathrm{CH}_{2}\right), 4.36(2 \mathrm{H}, \mathrm{d}$, $\left.J_{\mathrm{PH}} 11.2, \mathrm{PCH}\right), 6.43\left(2 \mathrm{H}, \mathrm{dd}, J_{\mathrm{HH}} 8.5, J_{\mathrm{HH}} 2.9, m-\mathrm{H}\right), 6.63\left(2 \mathrm{H}, \mathrm{dd}, J_{\mathrm{HH}} 8.8\right.$, $\left.J_{\mathrm{HH}} 2.7, m-\mathrm{H}\right), 7.04\left(2 \mathrm{H}, \mathrm{dd}, J_{\mathrm{HH}} 8.5, J_{\mathrm{HH}} 2.0, o-\mathrm{H}\right)$ and $10.32\left(2 \mathrm{H}, \mathrm{dd}, J_{\mathrm{HH}}\right.$ $\left.8.8, J_{\mathrm{HH}} 2.0, o-\mathrm{H}\right) ; \quad \mathrm{C}_{(}\left(75 \mathrm{MHz} ; \mathrm{C}_{6} \mathrm{D}_{6} ; \mathrm{Me}_{4} \mathrm{Si}\right)-23.0\left(1 \mathrm{C}, \mathrm{d}, J_{\mathrm{PC}} 3.8, J_{\mathrm{PtC}} 782\right.$, cis-Me), 13.7 (1 C, d, J $J_{\mathrm{PC}} 112.6, J_{\mathrm{PtC}} 711$, trans-Me), 27.7 (3 C, d, J $J_{\mathrm{PC}} 2.3$, $\mathrm{CMe}_{3}$ ), 33.5 (1 C, d, $\left.J_{\mathrm{PC}} 12.2, \mathrm{CMe}_{3}\right), 39.6\left(4 \mathrm{C}, \mathrm{s}, \mathrm{NMe}_{2}\right), 42.6\left(2 \mathrm{C}, \mathrm{d}, J_{\mathrm{PC}}\right.$ 11.4, PCH), 51.7 (2 C, s, OMe), 57.2 (1 C, s, NMe), 64.4 (2 C, br s, $\mathrm{CH}_{2}$ ), 65.0 $\left(2 \mathrm{C}, \mathrm{d}, J_{\mathrm{PC}} 3.6, \mathrm{PCHC}\right), 111.7\left(2 \mathrm{C}, \mathrm{s}, m-\mathrm{C}_{6} \mathrm{H}_{4}\right), 112.4\left(2 \mathrm{C}, \mathrm{s}, m-\mathrm{C}_{6} \mathrm{H}_{4}\right), 122.5$ $\left(2 \mathrm{C}, \mathrm{d}, J_{\mathrm{PC}} 3.1, \mathrm{C}_{6} \mathrm{H}_{4}\right), 132.9\left(2 \mathrm{C}, \mathrm{d}, J_{\mathrm{PC}} 5.2, o-\mathrm{C}_{6} \mathrm{H}_{4}\right), 133.5\left(2 \mathrm{C}, \mathrm{d}, J_{\mathrm{PC}}\right.$ 6.2, o- $\left.\mathrm{C}_{6} \mathrm{H}_{4}\right), 150.1\left(2 \mathrm{C}, \mathrm{s}, p-\mathrm{C}_{6} \mathrm{H}_{4}\right), 168.2\left(2 \mathrm{C}, \mathrm{d}, J_{\mathrm{PC}} 8.5, \mathrm{COO}\right)$ and 203.0 $\left(1 \mathrm{C}, \mathrm{d}, J_{\mathrm{PC}} 1.6, \mathrm{CO}\right) ; \quad$ P $\left(121 \mathrm{MHz} ; \mathrm{C}_{6} \mathrm{D}_{6} ; \mathrm{H}_{3} \mathrm{PO}_{4}\right) 26.6\left(1 \mathrm{P}, \mathrm{s}, J_{\mathrm{PtP}} 1882\right)$; ${ }_{\mathrm{N}}\left(60 \mathrm{MHz} ; \mathrm{C}_{6} \mathrm{D}_{6} ; \mathrm{MeNO}_{2}\right)-335\left(2 \mathrm{~N}, \mathrm{NMe}_{2}\right)$ and $-377(1 \mathrm{~N}, \mathrm{NMe}) ; m / z(\mathrm{ESI})$ $791.2896\left([\mathrm{PtMe}(\mathbf{6 5})]^{+} . \mathrm{C}_{33} \mathrm{H}_{47} \mathrm{~N}_{3} \mathrm{O}_{5}\right.$ PPt requires 791.2901). 


\section{cis-[PdCl $2(65)](69$ and 70$)$}

PN ligand $65(0.1 \mathrm{~g}, 0.17 \mathrm{mmol})$ and $\left[\mathrm{PdCl}_{2}(\mathrm{NCMe})_{2}\right](0.04 \mathrm{~g}, 0.17 \mathrm{mmol})$ were dissolved in dichloromethane $\left(6 \mathrm{~cm}^{3}\right)$. The yellow solution was stirred at room temperature for 3 days. Removal of solvent in vacuo gave the ketone (69) and hydrate $(\mathbf{7 0})$ forms of the title compound in a 3:1 ratio as a pale yellow solid (0.1 g, 77\%). X-ray quality crystals were obtained by the slow diffusion of diethyl ether into a dicholormethane-benzene mixture; (Found: C, 51.0; H, 5.8; $\mathrm{N}$, 4.8. $\mathrm{C}_{32} \mathrm{H}_{44} \mathrm{~N}_{3} \mathrm{O}_{5} \mathrm{PCl}_{2} \mathrm{Pd}$ requires C, 50.6; H, 5.8; N, 5.5\%); $\max (\mathrm{KBr}) / \mathrm{cm}^{1}$ 3423, 1744, 1728, 1608, 1520, 1257; m/z (ESI) $740.1848\left(\left[\mathrm{PdCl}(65)+\mathrm{H}_{2} \mathrm{O}\right]^{+}\right.$. $\mathrm{C}_{32} \mathrm{H}_{46} \mathrm{~N}_{3} \mathrm{O}_{6} \mathrm{PClPd}$ requires 740.1848 ).

\section{Compound 69:}

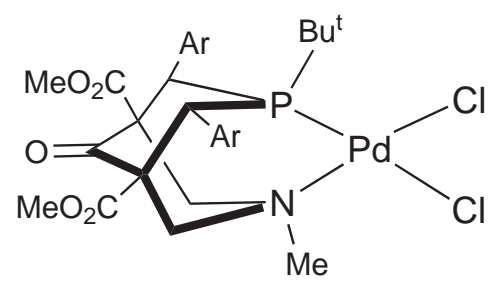

н $\left(600 \mathrm{MHz} ; \mathrm{CD}_{2} \mathrm{Cl}_{2} ; \mathrm{Me}_{4} \mathrm{Si}\right) 0.93\left(9 \mathrm{H}\right.$, br s, Bu $\left.{ }^{\mathrm{t}}\right), 2.89\left(2 \mathrm{H}, \mathrm{d}, J_{\mathrm{HH}}\right.$ 14.1, $\left.\mathrm{CH}_{2}\right), 2.96\left(12 \mathrm{H}, \mathrm{s}, \mathrm{NMe}_{2}\right), 3.42$ (3 H, s, NMe), 3.66 (6 H, s, OMe), $3.89(2 \mathrm{H}$, d, $\left.J_{\mathrm{PH}} 16.2, \mathrm{PCH}\right), 4.12\left(2 \mathrm{H}, \mathrm{d}, J_{\mathrm{HH}} 14.6, \mathrm{CH}_{2}\right), 6.56(2 \mathrm{H}, \mathrm{m}, m-\mathrm{H}), 6.93(4 \mathrm{H}$, $\mathrm{m}, \mathrm{m} / \mathrm{o}-\mathrm{H})$ and $9.70\left(2 \mathrm{H}, \mathrm{dd}, J_{\mathrm{HH}} 8.7, J_{\mathrm{HH}} 1.3, o-\mathrm{H}\right) ;{ }_{\mathrm{C}}\left(150 \mathrm{MHz} ; \mathrm{CD}_{2} \mathrm{Cl}_{2}\right.$; $\left.\mathrm{Me}_{4} \mathrm{Si}\right) 28.2\left(3 \mathrm{C}, \mathrm{s}, \mathrm{CMe}_{\mathbf{3}}\right), 38.6$ (1 C, d, $\left.J_{\mathrm{PC}} 21.0, \mathrm{CMe}_{3}\right), 40.2\left(4 \mathrm{C}, \mathrm{s}, \mathrm{NMe}_{2}\right)$, $41.2\left(2 \mathrm{C}, \mathrm{d}, J_{\mathrm{PC}} 16.9, \mathrm{PCH}\right), 53.0$ (2 C, s, OMe), $61.2(1 \mathrm{C}, \mathrm{s}, \mathrm{NMe}), 63.6$ (2 C, d, $\left.J_{\mathrm{PC}} 2.3, \mathrm{PCHC}\right), 64.1\left(2 \mathrm{C}, \mathrm{d}, J_{\mathrm{PC}} 3.9, \mathrm{CH}_{2}\right), 112.3\left(2 \mathrm{C}, \mathrm{s}, m-\mathrm{C}_{6} \mathrm{H}_{4}\right)$, $113.1\left(2 \mathrm{C}, \mathrm{s}, m-\mathrm{C}_{6} \mathrm{H}_{4}\right), 117.3\left(2 \mathrm{C}, \mathrm{s}, \mathrm{C}_{6} \mathrm{H}_{4}\right), 131.9\left(2 \mathrm{C}, \mathrm{d}, J_{\mathrm{PC}}\right.$ 7.0, o- $\left.\mathrm{C}_{6} \mathrm{H}_{4}\right)$, $132.6\left(2 \mathrm{C}, \mathrm{d}, J_{\mathrm{PC}} 6.0, o_{-} \mathrm{C}_{6} \mathrm{H}_{4}\right), 150.7\left(2 \mathrm{C}, \mathrm{s}, p-\mathrm{C}_{6} \mathrm{H}_{4}\right), 166.3\left(2 \mathrm{C}, \mathrm{d}, J_{\mathrm{PC}}\right.$ 9.9, COO) and 199.4 (1 C, s, CO); $\mathrm{P}\left(121 \mathrm{MHz} ; \mathrm{CD}_{2} \mathrm{Cl}_{2} ; \mathrm{H}_{3} \mathrm{PO}_{4}\right) 27.0$ (1 P, s); N (60 MHz; $\left.\mathrm{CD}_{2} \mathrm{Cl}_{2} ; \mathrm{MeNO}_{2}\right)-331\left(2 \mathrm{~N}, \mathrm{NMe}_{2}\right)$ and -377 (1 N, NMe). 


\section{Compound 70:}

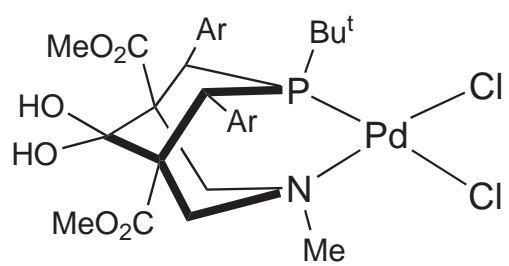

н $\left(600 \mathrm{MHz} ; \mathrm{CD}_{2} \mathrm{Cl}_{2} ; \mathrm{Me}_{4} \mathrm{Si}\right) 0.93\left(9 \mathrm{H}\right.$, br s, Bu $\left.{ }^{\mathrm{t}}\right), 2.77\left(2 \mathrm{H}, \mathrm{d}, J_{\mathrm{HH}}\right.$ 13.4, $\left.\mathrm{CH}_{2}\right), 2.95\left(12 \mathrm{H}, \mathrm{s}, \mathrm{NMe}_{2}\right), 3.35(3 \mathrm{H}, \mathrm{s}, \mathrm{NMe}), 3.44$ (6 H, s, OMe), $3.79(2$ $\left.\mathrm{H}, \mathrm{d}, J_{\mathrm{HH}} 14.4, \mathrm{CH}_{2}\right), 4.04\left(2 \mathrm{H}, \mathrm{d}, J_{\mathrm{PH}} 17.0, \mathrm{PCH}\right), 6.56(3 \mathrm{H}, \mathrm{m}, m-\mathrm{H}, \mathrm{OH})$, $6.64(1 \mathrm{H}, \mathrm{s}, \mathrm{OH}), 6.93(4 \mathrm{H}, \mathrm{m}, \mathrm{m} / \mathrm{o}-\mathrm{H})$ and $9.78\left(2 \mathrm{H}, \mathrm{dd}, J_{\mathrm{HH}} 8.8, J_{\mathrm{HH}} 1.1\right.$, o-H); $\quad$ C $\left(150 \mathrm{MHz} ; \mathrm{CD}_{2} \mathrm{Cl}_{2} ; \mathrm{Me}_{4} \mathrm{Si}\right) 28.3\left(3 \mathrm{C}, \mathrm{s}, \mathrm{CMe}_{\mathbf{3}}\right), 38.2\left(1 \mathrm{C}, \mathrm{d}, J_{\mathrm{PC}} 22.8\right.$, $\mathrm{CMe}_{3}$ ), 39.1 (2 C, d, J $\left.J_{\mathrm{PC}} 17.1, \mathrm{PCH}\right), 40.3$ (4 C, s, NMe ${ }_{2}$ ), 53.1 (2 C, s, OMe), $57.7\left(2 \mathrm{C}, \mathrm{d}, J_{\mathrm{PC}} 2.6, \mathrm{PCHC}\right), 58.2\left(2 \mathrm{C}, \mathrm{d}, J_{\mathrm{PC}} 3.9, \mathrm{CH}_{2}\right), 61.4(1 \mathrm{C}, \mathrm{s}, \mathrm{NMe})$, $94.5\left(1 \mathrm{C}, \mathrm{s}, \mathrm{C}(\mathrm{OH})_{2}\right), 112.2\left(2 \mathrm{C}, \mathrm{s}, m-\mathrm{C}_{6} \mathrm{H}_{4}\right), 113.3\left(2 \mathrm{C}, \mathrm{s}, m-\mathrm{C}_{6} \mathrm{H}_{4}\right), 119.1(2$ C, s, $\left.\mathrm{C}_{6} \mathrm{H}_{4}\right), 132.0\left(2 \mathrm{C}, \mathrm{d}, J_{\mathrm{PC}} 7.0, o-\mathrm{C}_{6} \mathrm{H}_{4}\right), 132.4\left(2 \mathrm{C}, \mathrm{d}, J_{\mathrm{PC}} 6.7, o-\mathrm{C}_{6} \mathrm{H}_{4}\right)$, $150.4\left(2 \mathrm{C}, \mathrm{s}, p-\mathrm{C}_{6} \mathrm{H}_{4}\right)$ and $170.9\left(2 \mathrm{C}, \mathrm{d}, J_{\mathrm{PC}} 11.3, \mathrm{COO}\right) ;$ р $\left(121 \mathrm{MHz} ; \mathrm{CD}_{2} \mathrm{Cl}_{2}\right.$; $\left.\mathrm{H}_{3} \mathrm{PO}_{4}\right) 25.2(1 \mathrm{P}, \mathrm{s}) ; \mathrm{N}\left(60 \mathrm{MHz} ; \mathrm{CD}_{2} \mathrm{Cl}_{2} ; \mathrm{MeNO}_{2}\right)-331\left(2 \mathrm{~N}, \mathrm{NMe}_{2}\right)$ and -379 $(1 \mathrm{~N}, \mathrm{NMe})$.

\section{$[\mathrm{Rh}(\operatorname{cod})(65)] \mathrm{SbF}_{6}(71$ and 73$)$}

PN ligand $65(0.12 \mathrm{~g}, 0.20 \mathrm{mmol}),[\mathrm{Rh}(\mathrm{cod}) \mathrm{Cl}]_{2}(0.05 \mathrm{~g}, 0.10 \mathrm{mmol})$ and $\mathrm{AgSbF}_{6}(0.07 \mathrm{~g}, 0.20 \mathrm{mmol})$ were combined in dichloromethane $\left(5 \mathrm{~cm}^{3}\right)$. The yellow reaction mixture was stirred for $1 \mathrm{hr}$ at room temperature and then was filtered and centrifuged to remove $\mathrm{AgCl}$. The yellow filtrate was stirred at room temperature for 1 week, after which hexane was added to precipitate the ketone (71) and hydrate $(\mathbf{7 3})$ forms of the title compound in a 3:1 ratio as a yellow solid. The solid was filtered in the air, washed with hexane and dried in vacuo (0.09 g, 91\%) (Found: C, 46.9; H, 5.6; N , 4.1. $\mathrm{C}_{40} \mathrm{H}_{56} \mathrm{~F}_{6} \mathrm{~N}_{3} \mathrm{O}_{5} \mathrm{PRhSb}$ requires $\mathrm{C}$, 
46.7; H, 5.5; N, 4.1\%); $\max (\mathrm{KBr}) / \mathrm{cm}^{1} 3434,1741,1609,1520,1259,658 ; \mathrm{m} / \mathrm{z}$ (ESI) $792.3022\left([\mathrm{M}]^{+} . \mathrm{C}_{40} \mathrm{H}_{56} \mathrm{~N}_{3} \mathrm{O}_{5} \mathrm{PRh}\right.$ requires 792.3012).

\section{Compound 71:}

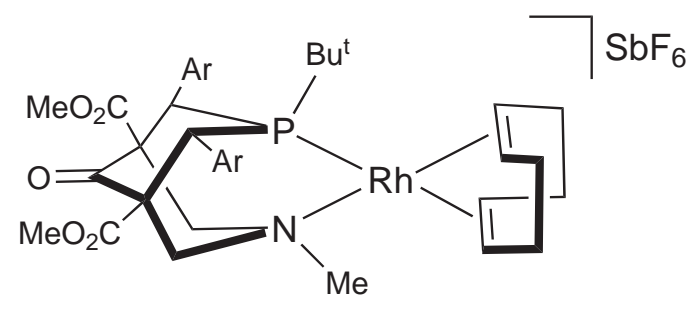

н $\left(600 \mathrm{MHz} ; \mathrm{CDCl}_{3} ; \mathrm{Me}_{4} \mathrm{Si}\right) 0.74\left(9 \mathrm{H}, \mathrm{d}, J_{\mathrm{PH}} 13.7, \mathrm{Bu}^{\mathrm{t}}\right), 2.17(4 \mathrm{H}, \mathrm{m}$, $\left.\mathrm{COD}-\mathrm{CH}_{2}\right), 2.59\left(2 \mathrm{H}, \mathrm{m}, \mathrm{COD}-\mathrm{CH}_{2}\right), 2.80\left(2 \mathrm{H}, \mathrm{m}, \mathrm{COD}-\mathrm{CH}_{2}\right), 2.84(3$ $\mathrm{H}, \mathrm{s}, \mathrm{NMe}), 2.86\left(2 \mathrm{H}, \mathrm{d}, J_{\mathrm{HH}} 14.3, \mathrm{CH}_{2}\right), 3.01\left(12 \mathrm{H}, \mathrm{s}, \mathrm{NMe}_{2}\right), 3.63(6 \mathrm{H}, \mathrm{s}$, OMe), $4.03\left(2 \mathrm{H}, \mathrm{d}, J_{\mathrm{HH}} 14.5, \mathrm{CH}_{2}\right), 4.08\left(2 \mathrm{H}, \mathrm{d}, J_{\mathrm{PH}} 14.3, \mathrm{PCH}\right), 4.54(2 \mathrm{H}$, $\left.\mathrm{d}, J_{\mathrm{PH}} 2.4, \mathrm{COD}-\mathrm{CH}_{\mathrm{X}}\right), 5.68\left(2 \mathrm{H}, \mathrm{d}, J_{\mathrm{PH}} 2.6, \mathrm{COD}^{-\mathrm{CH}_{\mathrm{Y}}}\right), 6.65(2 \mathrm{H}, \mathrm{m}, m-\mathrm{H})$, $6.96(4 \mathrm{H}, \mathrm{m}, \mathrm{m} / \mathrm{o}-\mathrm{H})$ and $9.72\left(2 \mathrm{H}, \mathrm{d}, J_{\mathrm{HH}} 8.6, o-\mathrm{H}\right) ; \mathrm{C}\left(150 \mathrm{MHz} ; \mathrm{CDCl}_{3}\right.$; $\left.\mathrm{Me}_{4} \mathrm{Si}\right) 28.9\left(5 \mathrm{C}, \mathrm{m}, \mathrm{CMe}_{3}, \mathrm{COD}-\mathrm{CH}_{2}\right), 32.2\left(2 \mathrm{C}, \mathrm{d}, J_{\mathrm{PC}} 2.8, \mathrm{COD}-\mathrm{CH}_{2}\right.$ ), $36.9\left(1 \mathrm{C}, \mathrm{d}, J_{\mathrm{PC}} 14.8, \mathrm{CMe}_{3}\right), 40.3\left(4 \mathrm{C}, \mathrm{s}, \mathrm{NMe}_{2}\right), 43.1$ (2 C, d, J $J_{\mathrm{PC}} 13.8$, $\mathrm{PCH}), 52.98$ (2 C, s, OMe), 55.5 (1 C, s, NMe), 63.2 (2 C, d, J $\mathrm{PC}_{3.4}$ PCHC), $64.6\left(2 \mathrm{C}, \mathrm{d}, J_{\mathrm{PC}} 2.3, \mathrm{CH}_{2}\right), 73.5\left(2 \mathrm{C}, \mathrm{d}, J\right.$ 11.3, $\left.\mathrm{COD}-\mathrm{CH}_{\mathrm{X}}\right), 105.1(2 \mathrm{C}, \mathrm{dd}$, $\left.J_{\mathrm{PC}}+J_{\mathrm{RhC}} 14.9, \mathrm{COD}-\mathrm{CH}_{\mathrm{Y}}\right), 111.5\left(2 \mathrm{C}, \mathrm{s}, m-\mathrm{C}_{6} \mathrm{H}_{4}\right), 112.8\left(2 \mathrm{C}, \mathrm{s}, m-\mathrm{C}_{6} \mathrm{H}_{4}\right)$, $118.7\left(2 \mathrm{C}, \mathrm{s}, \mathrm{C}_{6} \mathrm{H}_{4}\right), 132.5\left(2 \mathrm{C}, \mathrm{d}, J_{\mathrm{PC}} 7.6, o-\mathrm{C}_{6} \mathrm{H}_{4}\right), 133.1\left(2 \mathrm{C}, \mathrm{d}, J_{\mathrm{PC}}\right.$ 5.3, $\left.o-\mathrm{C}_{6} \mathrm{H}_{4}\right), 150.7\left(2 \mathrm{C}, \mathrm{s}, p-\mathrm{C}_{6} \mathrm{H}_{4}\right), 166.6\left(2 \mathrm{C}, \mathrm{d}, J_{\mathrm{PC}} 9.5, \mathrm{COO}\right)$ and 200.0 (1 C, s, CO); р (121 MHz; $\left.\mathrm{CDCl}_{3} ; \mathrm{H}_{3} \mathrm{PO}_{4}\right) 21.9$ (1 P, d, J RhP 149.4); N (60 MHz; $\left.\mathrm{CDCl}_{3} ; \mathrm{MeNO}_{2}\right)-331\left(2 \mathrm{~N}, \mathrm{NMe}_{2}\right)$ and $-372(1 \mathrm{~N}, \mathrm{NMe})$. 


\section{Compound 73:}

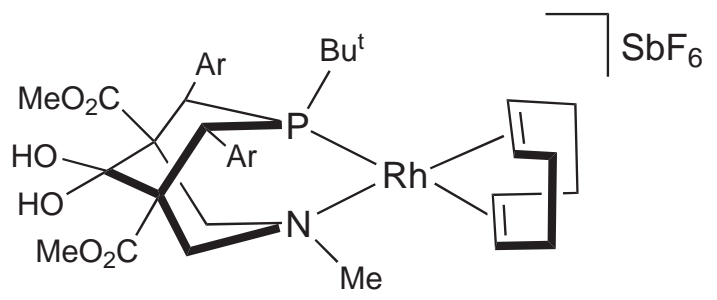

н $\left(600 \mathrm{MHz} ; \mathrm{CDCl}_{3} ; \mathrm{Me}_{4} \mathrm{Si}\right) 0.73\left(9 \mathrm{H}, \mathrm{d}, J_{\mathrm{PH}} 12.9, \mathrm{Bu}^{\mathrm{t}}\right), 2.17(4 \mathrm{H}, \mathrm{m}$, COD- $\left.\mathrm{CH}_{2}\right), 2.59\left(2 \mathrm{H}, \mathrm{m}, \mathrm{COD}-\mathrm{CH}_{2}\right), 2.79\left(5 \mathrm{H}, \mathrm{m}, \mathrm{CH}_{2}, \mathrm{NMe}\right), 2.80(2$ H, m, COD-CH ${ }_{2}$ ), 3.00 (12 H, s, $\mathrm{NMe}_{2}$ ), 3.43 (6 H, s, OMe), 3.67 (2 H, d, J $J_{\mathrm{HH}}$ 14.1, $\left.\mathrm{CH}_{2}\right), 4.29\left(2 \mathrm{H}, \mathrm{d}, J_{\mathrm{PH}} 15.3, \mathrm{PCH}\right), 4.44\left(2 \mathrm{H}, \mathrm{d}, J_{\mathrm{PH}} 2.4, \mathrm{COD}-\mathrm{CH}_{\mathrm{X}}\right)$, $5.55\left(2 \mathrm{H}, \mathrm{d}, J_{\mathrm{PH}} 2.8, \mathrm{COD}-\mathrm{CH}_{\mathrm{Y}}\right), 6.65(2 \mathrm{H}, \mathrm{m}, m-\mathrm{H}), 6.96(4 \mathrm{H}, \mathrm{m}, m / o-\mathrm{H})$ and $9.75\left(2 \mathrm{H}, \mathrm{d}, J_{\mathrm{HH}} 8.5, o-\mathrm{H}\right)$; $\mathrm{C}\left(150 \mathrm{MHz} ; \mathrm{CDCl}_{3} ; \mathrm{Me}_{4} \mathrm{Si}\right) 27.3$ (3 C, br s, $\left.\mathrm{CMe}_{3}\right), 28.9\left(2 \mathrm{C}, \mathrm{m}, \mathrm{COD}-\mathrm{CH}_{2}\right), 32.2\left(2 \mathrm{C}, \mathrm{d}, J_{\mathrm{PC}} 2.8, \mathrm{COD}-\mathrm{CH}_{2}\right), 35.3$ $\left(1 \mathrm{C}, \mathrm{d}, J_{\mathrm{PC}} 4.7, \mathrm{CMe}_{3}\right), 40.5\left(4 \mathrm{C}, \mathrm{s}, \mathrm{NMe}_{2}\right), 41.4\left(2 \mathrm{C}, \mathrm{d}, J_{\mathrm{PC}} 13.8, \mathrm{PCH}\right)$, 53.03 (2 C, s, OMe), 55.7 (1 C, s, NMe), 57.4 (2 C, d, J $\left.J_{\mathrm{PC}} 3.4, \mathrm{PCHC}\right), 58.7$ $\left(2 \mathrm{C}, \mathrm{s}, \mathrm{CH}_{2}\right), 72.6(2 \mathrm{C}, \mathrm{d}, J$ 10.6, COD-CHX $), 94.5\left(1 \mathrm{C}, \mathrm{s}, \mathrm{C}(\mathrm{OH})_{2}\right), 103.7$ $\left(2 \mathrm{C}, \mathrm{dd}, J_{\mathrm{PC}}+J_{\mathrm{RhC}}\right.$ 14.5, COD-CHY $), 111.7\left(2 \mathrm{C}, \mathrm{s}, m-\mathrm{C}_{6} \mathrm{H}_{4}\right), 113.0(2 \mathrm{C}, \mathrm{s}$, $\left.m-\mathrm{C}_{6} \mathrm{H}_{4}\right), 120.7\left(2 \mathrm{C}\right.$, br s, $\left.\mathrm{C}_{6} \mathrm{H}_{4}\right), 132.7\left(2 \mathrm{C}, \mathrm{d}, J_{\mathrm{PC}} 7.5, o-\mathrm{C}_{6} \mathrm{H}_{4}\right), 132.8(2 \mathrm{C}$, $\left.\mathrm{d}, J_{\mathrm{PC}} 5.8, o-\mathrm{C}_{6} \mathrm{H}_{4}\right), 150.3\left(2 \mathrm{C}, \mathrm{s}, p-\mathrm{C}_{6} \mathrm{H}_{4}\right)$ and $170.8\left(2 \mathrm{C}, \mathrm{d}, J_{\mathrm{PC}} 10.7, \mathrm{COO}\right)$; P (121 MHz; $\left.\mathrm{CDCl}_{3} ; \mathrm{H}_{3} \mathrm{PO}_{4}\right) 20.3$ (1 P, d, J RhP 146.2). 


\section{[Pt(norb)(65)] (74)}

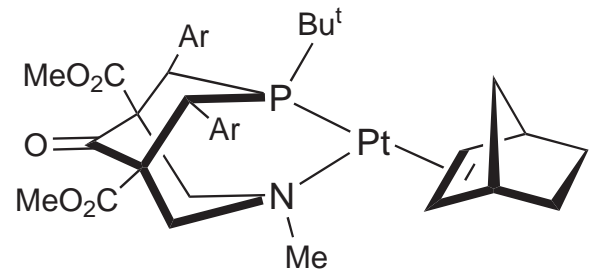

PN ligand 65 (0.10 g, $0.17 \mathrm{mmol})$ and $\left[\mathrm{Pt}(\text { norb })_{3}\right](0.08 \mathrm{~g}, 0.17 \mathrm{mmol})$ were combined in benzene $\left(6 \mathrm{~cm}^{3}\right)$. The yellow reaction mixture was stirred for 1 week at room temperature. Removal of solvent in vacuo gave an off-white solid (0.14 g, 93\%) (Found: C, 53.9; H, 6.2; N, 4.5. $\mathrm{C}_{39} \mathrm{H}_{54} \mathrm{~N}_{3} \mathrm{O}_{5}$ PPt requires $\mathrm{C}$, $53.8 ; \mathrm{H}, 6.3 ; \mathrm{N}, 4.8 \%) ; \quad \max (\mathrm{KBr}) / \mathrm{cm}^{1} 1742,1720,1610,1518,1445,1254$; н $\left(600 \mathrm{MHz} ; \mathrm{CD}_{2} \mathrm{Cl}_{2} ; \mathrm{Me}_{4} \mathrm{Si}\right) 0.51\left(1 \mathrm{H}, \mathrm{d}, J_{\mathrm{HH}} 8.1\right.$, norb-bridge $\left.\mathrm{CH}_{2}\right), 0.58$ $\left(9 \mathrm{H}, \mathrm{d}, J_{\mathrm{PH}} 13.7, \mathrm{Bu}^{\mathrm{t}}\right), 1.14\left(2 \mathrm{H}, \mathrm{d}, J_{\mathrm{HH}} 5.0\right.$, norb $\left.\mathrm{CH}_{2}\right), 1.56\left(2 \mathrm{H}, \mathrm{d}, J_{\mathrm{HH}}\right.$ 7.7, norb $\left.\mathrm{CH}_{2}\right), 1.82\left(1 \mathrm{H}, \mathrm{d}, J_{\mathrm{HH}} 7.9\right.$, norb-bridge $\left.\mathrm{CH}_{2}\right), 2.08\left(2 \mathrm{H}\right.$, br s, $J_{\mathrm{PtH}}$ 77, norb $\mathrm{C}=\mathrm{CH}), 2.57(2 \mathrm{H}$, br s, norb $\mathrm{CH}), 2.92\left(2 \mathrm{H}, \mathrm{m}, \mathrm{CH}_{2}\right), 2.92(12 \mathrm{H}$, s, $\left.\mathrm{NMe}_{2}\right), 3.58(6 \mathrm{H}, \mathrm{s}, \mathrm{OMe}), 3.71\left(3 \mathrm{H}, \mathrm{d}, J_{\mathrm{PH}} 1.9, \mathrm{NMe}\right), 4.05\left(2 \mathrm{H}, \mathrm{d}, J_{\mathrm{HH}}\right.$ 13.7, $\left.\mathrm{CH}_{2}\right), 4.14\left(2 \mathrm{H}, \mathrm{d}, J_{\mathrm{PH}} 9.8, \mathrm{PCH}\right), 6.58(4 \mathrm{H}, \mathrm{m}, m-\mathrm{H}), 6.92(2 \mathrm{H}, \mathrm{m}, o-\mathrm{H})$ and $9.26\left(2 \mathrm{H}, \mathrm{d}, J_{\mathrm{HH}} 8.3, o-\mathrm{H}\right) ; \mathrm{c}\left(150 \mathrm{MHz} ; \mathrm{CD}_{2} \mathrm{Cl}_{2} ; \mathrm{Me}_{4} \mathrm{Si}\right) 26.3(3 \mathrm{C}, \mathrm{d}$, $\left.J_{\mathrm{PC}} 6.7, \mathrm{CMe}_{3}\right), 30.2\left(2 \mathrm{C}, \mathrm{d}, J_{\mathrm{PC}} 5.5, J_{\mathrm{PtC}} 77\right.$, norb $\left.\mathrm{CH}_{2}\right), 32.0\left(1 \mathrm{C}, \mathrm{d}, J_{\mathrm{PC}}\right.$ 10.7, $\mathrm{CMe}_{3}$ ), 40.0 (4 C, s, $\mathrm{NMe}_{2}$ ), $41.8\left(1 \mathrm{C}, \mathrm{s}\right.$, norb-bridge $\left.\mathrm{CH}_{2}\right), 43.1(2 \mathrm{C}, \mathrm{s}$, norb $\mathrm{CH}), 43.6$ (2 C, d, $\left.J_{\mathrm{PC}} 7.3, \mathrm{PCH}\right), 46.7$ (2 C, d, $J_{\mathrm{PC}} 27.8, J_{\mathrm{PtC}} 469$, norb $\mathrm{C}=\mathrm{C}), 51.8(2 \mathrm{C}, \mathrm{s}, \mathrm{OMe}), 62.9\left(1 \mathrm{C}, \mathrm{d}, J_{\mathrm{PC}} 4.5, \mathrm{NMe}\right), 63.9\left(2 \mathrm{C}, \mathrm{s}, \mathrm{CH}_{2}\right)$, $65.2\left(2 \mathrm{C}, \mathrm{d}, J_{\mathrm{PC}} 3.9, \mathrm{PCHC}\right), 111.1\left(2 \mathrm{C}, \mathrm{s}, m-\mathrm{C}_{6} \mathrm{H}_{4}\right), 111.5\left(2 \mathrm{C}, \mathrm{s}, m-\mathrm{C}_{6} \mathrm{H}_{4}\right)$, $122.7\left(2 \mathrm{C}, \mathrm{d}, J_{\mathrm{PC}} 4.2, \mathrm{C}_{6} \mathrm{H}_{4}\right), 132.2\left(2 \mathrm{C}, \mathrm{d}, J_{\mathrm{PC}} 4.5, o-\mathrm{C}_{6} \mathrm{H}_{4}\right), 132.9(2 \mathrm{C}, \mathrm{d}$, $\left.J_{\mathrm{PC}} 7.0, o-\mathrm{C}_{6} \mathrm{H}_{4}\right), 149.8\left(2 \mathrm{C}, \mathrm{s}, p-\mathrm{C}_{6} \mathrm{H}_{4}\right), 168.4\left(2 \mathrm{C}, \mathrm{d}, J_{\mathrm{PC}} 8.4, \mathrm{COO}\right)$ and $203.2\left(1 \mathrm{C}, \mathrm{d}, J_{\mathrm{PC}} 2.0, \mathrm{CO}\right) ; \quad$ P $\left(121 \mathrm{MHz} ; \mathrm{CD}_{2} \mathrm{Cl}_{2} ; \mathrm{H}_{3} \mathrm{PO}_{4}\right) 47.5\left(1 \mathrm{P}, \mathrm{s}, J_{\mathrm{PtP}}\right.$ 3559); $\mathrm{N}\left(60 \mathrm{MHz} ; \mathrm{CD}_{2} \mathrm{Cl}_{2} ; \mathrm{MeNO}_{2}\right)-336\left(2 \mathrm{~N}, \mathrm{NMe}_{2}\right)$ and -362 (1 N, NMe); $m / z(\mathrm{ESI}) 871.3917\left(\left[[\mathrm{M}+\mathrm{H}]^{+}\right] . \mathrm{C}_{39} \mathrm{H}_{55} \mathrm{~N}_{3} \mathrm{O}_{5}\right.$ PPt requires 871.3527). 


\section{$\left[\mathrm{Pt}\left(\mathrm{C}_{2} \mathrm{H}_{4}\right)(65)\right](75)$}

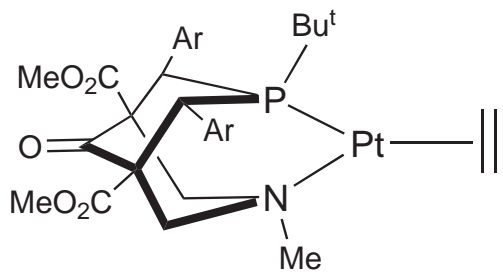

PN ligand $65(0.02 \mathrm{~g}, 0.034 \mathrm{mmol})$ and $\left[\mathrm{Pt}\left(\mathrm{C}_{2} \mathrm{H}_{4}\right)_{3}\right](0.01 \mathrm{~g}, 0.034 \mathrm{mmol})$ were dissolved in either benzene- $\mathrm{d}_{6}$ or toluene- $\mathrm{d}_{8}\left(0.5 \mathrm{~cm}^{3}\right)$ in a NMR tube at room temperature under an ethylene atmosphere. Complex $\mathbf{7 5}$ formed immediately, but it converted into complex $\mathbf{7 6}$ within 1 day at room temperature. н $\left(300 \mathrm{MHz} ; \mathrm{C}_{6} \mathrm{D}_{6} ; \mathrm{Me}_{4} \mathrm{Si}\right) 0.69\left(9 \mathrm{H}, \mathrm{d}, J_{\mathrm{PH}} 13.8, \mathrm{Bu}^{\mathrm{t}}\right), 2.39\left(12 \mathrm{H}, \mathrm{s}, \mathrm{NMe}_{2}\right)$, $2.61\left(3 \mathrm{H}\right.$, br s, NMe), $3.03\left(2 \mathrm{H}, \mathrm{d}, J_{\mathrm{HH}} 14.3, \mathrm{CH}_{2}\right), 3.22\left(4 \mathrm{H}, \mathrm{d}, J_{\mathrm{HH}} 1.9\right.$, $\left.J_{\mathrm{PtH}} 16, \mathrm{C}_{2} \mathrm{H}_{4}\right), 3.39(6 \mathrm{H}, \mathrm{s}, \mathrm{OMe}), 4.30\left(2 \mathrm{H}, \mathrm{d}, J_{\mathrm{HH}} 13.7, \mathrm{CH}_{2}\right), 4.41(2 \mathrm{H}, \mathrm{d}$, $\left.J_{\mathrm{PH}} 10.7, \mathrm{PCH}\right), 6.43\left(2 \mathrm{H}, \mathrm{dd}, J_{\mathrm{HH}} 8.5,2.8, m-\mathrm{H}\right), 6.56\left(2 \mathrm{H}, \mathrm{dd}, J_{\mathrm{HH}} 8.8,2.8\right.$, $m-\mathrm{H}), 7.06\left(2 \mathrm{H}, \mathrm{dd}, J_{\mathrm{HH}} 8.5,2.2, o-\mathrm{H}\right)$ and $9.74\left(2 \mathrm{H}, \mathrm{dd}, J_{\mathrm{HH}} 8.8,1.7, o-\mathrm{H}\right)$; C $\left(75 \mathrm{MHz}\right.$; toluene- $\left.\mathrm{d}_{8} ; \mathrm{Me}_{4} \mathrm{Si},-10 \mathrm{C}\right) 27.2$ (3 C, br s, CMe 3 ), 32.6 (1 C, d, $\left.J_{\mathrm{PC}} 11.4, \mathrm{CMe}_{3}\right), 40.0\left(4 \mathrm{C}, \mathrm{s}, \mathrm{NMe}_{2}\right), 44.4\left(2 \mathrm{C}, \mathrm{d}, J_{\mathrm{PC}} 8.6, \mathrm{PCH}\right), 48.3(1 \mathrm{C}, \mathrm{s}$, NMe), 52.0 (2 C, s, OMe), $60.0\left(2 \mathrm{C}, \mathrm{s}, \mathrm{CH}_{2}\right), 64.7$ (2 C, br s, $\left.\mathrm{C}_{2} \mathrm{H}_{4}\right), 66.0(2 \mathrm{C}$, $\left.\mathrm{d}, J_{\mathrm{PC}} 3.6, \mathrm{PCHC}\right), 111.8\left(2 \mathrm{C}, \mathrm{br} \mathrm{s}, m-\mathrm{C}_{6} \mathrm{H}_{4}\right), 112.3\left(2 \mathrm{C}\right.$, br s, $\left.m-\mathrm{C}_{6} \mathrm{H}_{4}\right), 123.4$ $\left(2 \mathrm{C}, \mathrm{d}, J_{\mathrm{PC}} 4.1, \mathrm{C}_{6} \mathrm{H}_{4}\right), 133.0\left(2 \mathrm{C}\right.$, br s, o- $\left.\mathrm{C}_{6} \mathrm{H}_{4}\right), 134.0$ (2 C, br s, o- $\mathrm{C}_{6} \mathrm{H}_{4}$ ), $150.1\left(2 \mathrm{C}, \mathrm{s}, p-\mathrm{C}_{6} \mathrm{H}_{4}\right), 168.7\left(2 \mathrm{C}, \mathrm{d}, J_{\mathrm{PC}} 8.6, \mathrm{COO}\right)$ and $203.2\left(1 \mathrm{C}, \mathrm{d}, J_{\mathrm{PC}}\right.$ $1.3, \mathrm{CO}) ; \quad$ P $\left(121 \mathrm{MHz} ; \mathrm{C}_{6} \mathrm{D}_{6} ; \mathrm{H}_{3} \mathrm{PO}_{4}\right) 47.5$ (1 P, s, J $\left.J_{\mathrm{PtP}} 3727\right) ; \quad$ N $(60 \mathrm{MHz}$; $\left.\mathrm{C}_{6} \mathrm{D}_{6} ; \mathrm{MeNO}_{2}\right)-336\left(2 \mathrm{~N}, \mathrm{NMe}_{2}\right)$ and $-363(1 \mathrm{~N}, \mathrm{NMe})$. 


\section{$\left[\mathrm{Pt}\left(\mathrm{C}_{2} \mathrm{H}_{4}\right)(65-2 \mathrm{H})\right](76)$}

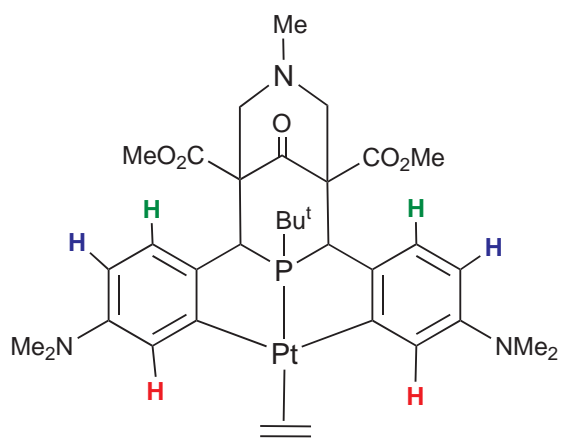

The title compound was obtained from complex 75. H $\left(300 \mathrm{MHz} ; \mathrm{C}_{6} \mathrm{D}_{6} ; \mathrm{Me}_{4} \mathrm{Si}\right)$ $0.85\left(9 \mathrm{H}, \mathrm{d}, J_{\mathrm{PH}} 15.1, \mathrm{Bu}^{\mathrm{t}}\right), 2.10(3 \mathrm{H}, \mathrm{s}, \mathrm{NMe}), 2.70\left(14 \mathrm{H}, \mathrm{m}, \mathrm{NMe}_{2}\right.$ and $\left.\mathrm{CH}_{2}\right)$, $3.01\left(2 \mathrm{H}, \mathrm{d}, J_{\mathrm{HH}} 11.7, \mathrm{CH}_{2}\right), 3.41(6 \mathrm{H}, \mathrm{s}, \mathrm{OMe}), 4.02\left(4 \mathrm{H}, \mathrm{d}, J_{\mathrm{HH}} 3.2, J_{\mathrm{PtH}}\right.$ $\left.55, \mathrm{C}_{2} \mathrm{H}_{4}\right), 5.07\left(2 \mathrm{H}, \mathrm{d}, J_{\mathrm{PH}} 11.5, J_{\mathrm{PtH}} 25, \mathrm{PCH}\right), 6.50\left(2 \mathrm{H}, \mathrm{dd}, J_{\mathrm{HH}} 8.3,2.7\right.$, $\left.J_{\mathrm{PtH}} 61, m-\mathrm{H}\right), 6.92\left(2 \mathrm{H}, \mathrm{d}, J_{\mathrm{HH}} 2.7, J_{\mathrm{PtH}} 26, m-\mathrm{H}\right)$ and $7.34\left(2 \mathrm{H}, \mathrm{d}, J_{\mathrm{HH}} 8.3\right.$, o-H); $\mathrm{C}\left(75 \mathrm{MHz} ; \mathrm{C}_{6} \mathrm{D}_{6} ; \mathrm{Me}_{4} \mathrm{Si}\right) 26.0\left(3 \mathrm{C}, \mathrm{d}, J_{\mathrm{PC}} 3.8, \mathrm{CMe}_{3}\right), 31.5$ (1 C, s, $\left.\mathrm{CMe}_{3}\right), 40.5$ (4 C, s, $\mathrm{NMe}_{2}$ ), 48.4 (2 C, d, J $\left.\mathrm{PC}_{2} 24.0, \mathrm{PCH}\right), 51.7$ (1 C, s, NMe), $52.5(2 \mathrm{C}, \mathrm{s}, \mathrm{OMe}), 59.3\left(2 \mathrm{C}, \mathrm{s}, \mathrm{CH}_{2}\right), 62.5\left(2 \mathrm{C}, \mathrm{s}, \mathrm{C}_{2} \mathrm{H}_{4}\right), 63.1\left(2 \mathrm{C}, \mathrm{d}, J_{\mathrm{PC}}\right.$ 16.0, PCHC), $110.2\left(2 \mathrm{C}, \mathrm{s}, m-\mathrm{C}_{6} \mathrm{H}_{4}\right), 117.2\left(2 \mathrm{C}, \mathrm{s}, m-\mathrm{C}_{6} \mathrm{H}_{4}\right), 125.8(2 \mathrm{C}, \mathrm{d}$, $\left.J_{\mathrm{PC}} 16.4, o-\mathrm{C}_{6} \mathrm{H}_{4}\right), 143.6\left(2 \mathrm{C}, \mathrm{d}, J_{\mathrm{PC}} 18.3, \mathrm{C}_{6} \mathrm{H}_{4}\right), 149.4\left(2 \mathrm{C}, \mathrm{s}, p-\mathrm{C}_{6} \mathrm{H}_{4}\right), 161.2$ $\left(2 \mathrm{C}, \mathrm{d}, J_{\mathrm{PC}} 2.4, \mathrm{Pt}-\mathrm{C}\right), 169.0\left(2 \mathrm{C}, \mathrm{d}, J_{\mathrm{PC}} 8.9, \mathrm{COO}\right)$ and 203.9 (1 C, d, J $J_{\mathrm{PC}}$ 7.0, CO); $\quad$ P $\left(121 \mathrm{MHz} ; \mathrm{C}_{6} \mathrm{D}_{6} ; \mathrm{H}_{3} \mathrm{PO}_{4}\right) 73.5\left(1 \mathrm{P}, \mathrm{s}, J_{\mathrm{PtP}} 3965\right) ; \quad \mathrm{N}(60 \mathrm{MHz}$; $\left.\mathrm{C}_{6} \mathrm{D}_{6} ; \mathrm{MeNO}_{2}\right)-336\left(2 \mathrm{~N}, \mathrm{NMe}_{2}\right)$ and $-362(1 \mathrm{~N}, \mathrm{NMe})$. 


\section{$[\operatorname{Pd}(\mathrm{dba})(65)](77)$}

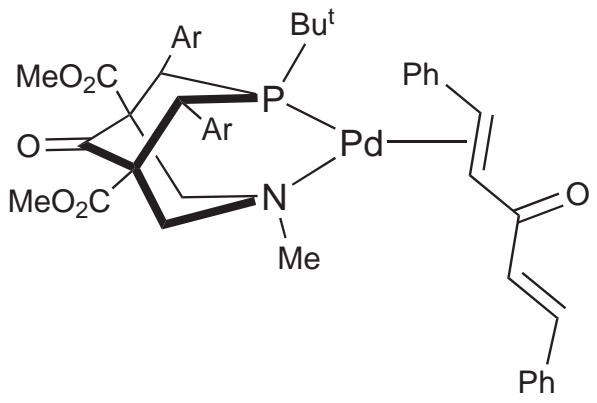

PN ligand $65(0.10 \mathrm{~g}, 0.17 \mathrm{mmol})$ and $\left[\mathrm{Pd}_{2}(\mathrm{dba})_{3} \mathrm{CHCl}_{3}\right](0.09 \mathrm{~g}, 0.09 \mathrm{mmol})$ were combined in benzene $\left(3 \mathrm{~cm}^{3}\right)$. The dark red reaction mixture was stirred for $40 \mathrm{hr}$ at room temperature. Gradually the colour changed to yellow as free dba was released into solution and some fine solid formed. Removal of solvent in vacuo and subsequent washings with hexane in the air removed much of the free dba to give a pale yellow solid $(0.10 \mathrm{~g}, 66 \%)$; accurate elemental analytical data could not be obtained due to contamination with free dba; $\max (\mathrm{KBr}) / \mathrm{cm}^{1}$ $1740,1651,1615,1519,1448,1339,1258 ;$ н $\left(300 \mathrm{MHz} ; \mathrm{C}_{6} \mathrm{D}_{6} ; \mathrm{Me}_{4} \mathrm{Si}\right) 0.44(9$ $\left.\mathrm{H}, \mathrm{d}, J_{\mathrm{PH}} 13.7, \mathrm{Bu}^{\mathrm{t}}\right), 2.46\left(6 \mathrm{H}, \mathrm{s}, \mathrm{NMe}_{2}\right), 2.50\left(6 \mathrm{H}, \mathrm{s}, \mathrm{NMe}_{2}\right), 2.70(2 \mathrm{H}, \mathrm{m}$, $\left.\mathrm{CH}_{2}\right), 3.78$ (3 H, s, NMe), 3.29 (3 H, s, OMe), 3.36 (3 H, s, OMe), 4.02 (2 H, m, $\left.\mathrm{CH}_{2}\right), 4.15\left(1 \mathrm{H}, \mathrm{d}, J_{\mathrm{PH}} 11.0, \mathrm{PCH}\right), 4.25\left(1 \mathrm{H}, \mathrm{d}, J_{\mathrm{PH}} 11.5, \mathrm{PCH}\right), 4.99(1 \mathrm{H}$, br s, coord dba $\mathrm{HC}=\mathrm{CH}), 5.51\left(1 \mathrm{H}, \mathrm{d}, J_{\mathrm{HH}} 10.0\right.$, coord dba $\left.\mathrm{HC}=\mathrm{CH}\right), 6.31$ $\left(1 \mathrm{H}, \mathrm{dd}, J_{\mathrm{HH}} 8.2,1.8, m-\mathrm{H}\right), 6.47\left(1 \mathrm{H}, \mathrm{dd}, J_{\mathrm{HH}} 8.2,2.1, m-\mathrm{H}\right), 6.80(1 \mathrm{H}, \mathrm{m}$, $m-\mathrm{H}), 6.87\left(1 \mathrm{H}, \mathrm{d}, J_{\mathrm{HH}} 8.9, o-\mathrm{H}\right), 7.01(1 \mathrm{H}, \mathrm{m}, o-\mathrm{H}), 7.03(10 \mathrm{H}, \mathrm{m}, \mathrm{dba}-\mathrm{Ph})$, $7.25(1 \mathrm{H}, \mathrm{m}, m-\mathrm{H}), 7.25(1 \mathrm{H}, \mathrm{m}$, non-coord dba $\mathrm{HC}=\mathrm{CH}), 8.12\left(1 \mathrm{H}, \mathrm{d}, J_{\mathrm{HH}}\right.$ 15.6, non-coord dba $\mathrm{HC}=\mathrm{CH}), 8.99\left(1 \mathrm{H}, \mathrm{d}, J_{\mathrm{HH}} 7.8, o-\mathrm{H}\right)$ and $9.57(1 \mathrm{H}, \mathrm{d}$, $\left.J_{\mathrm{HH}} 8.1, o-\mathrm{H}\right), \quad$ С $\left(75 \mathrm{MHz} ; \mathrm{C}_{6} \mathrm{D}_{6} ; \mathrm{Me}_{4} \mathrm{Si}\right) 26.9\left(3 \mathrm{C}, \mathrm{d}, J_{\mathrm{PC}} 6.9, \mathrm{CMe}_{\mathbf{3}}\right), 32.9(1$ C, s, $\mathrm{CMe}_{3}$ ), 39.8 (4 C, s, $\mathrm{NMe}_{2}$ ), 43.6 (1 C, br s, PCH), 44.1 (1 C, br s, PCH), 51.7 (2 C, s, OMe), 57.5 (1 C, s, NMe), 59.8 (1 C, br s, coord dba C=C ), 64.2 (1 C, br s, $\mathrm{CH}_{2}$ ), 64.4 (1 C, br s, $\mathrm{CH}_{2}$ ), 65.2 (1 C, br s, PCHC), 65.3 (1 C, br 
s, PCHC), $66.9\left(1 \mathrm{C}, \mathrm{m}\right.$, coord dba C=C ), $111.9\left(2 \mathrm{C}, \mathrm{s}, m-\mathrm{C}_{6} \mathrm{H}_{4}\right), 113.0(1 \mathrm{C}$, s, $\left.m-\mathrm{C}_{6} \mathrm{H}_{4}\right), 113.3\left(1 \mathrm{C}, \mathrm{s}, m-\mathrm{C}_{6} \mathrm{H}_{4}\right), 122.7$ ( $1 \mathrm{C}$, br s, $\left.\mathrm{C}_{6} \mathrm{H}_{4}\right), 122.9(1 \mathrm{C}$, br s, $\mathrm{C}_{6} \mathrm{H}_{4}$ ), 128.0 (12 C, m, dba-Ph), 128.5 (1 C, s, non-coord dba $\mathrm{C}=\mathrm{C}$ ), 132.4 (1 C, br s, o- $\left.\mathrm{C}_{6} \mathrm{H}_{4}\right), 132.9\left(2 \mathrm{C}, \mathrm{m}, o-\mathrm{C}_{6} \mathrm{H}_{4}\right), 133.8\left(1 \mathrm{C}, \mathrm{m}, o-\mathrm{C}_{6} \mathrm{H}_{4}\right), 137.2(1 \mathrm{C}$, s, non-coord dba C=C ), $149.9\left(1 \mathrm{C}, \mathrm{s}, p-\mathrm{C}_{6} \mathrm{H}_{4}\right), 150.4\left(1 \mathrm{C}, \mathrm{s}, p-\mathrm{C}_{6} \mathrm{H}_{4}\right), 167.8$ (1 C, br s, COO), 168.1 (1 C, br s, COO), 188.8 (1 C, d, J JC 2.2, dba-CO) and $202.4\left(1 \mathrm{C}, \mathrm{d}, J_{\mathrm{PC}} 1.8, \mathrm{CO}\right)$; $\mathrm{P}\left(121 \mathrm{MHz} ; \mathrm{C}_{6} \mathrm{D}_{6} ; \mathrm{H}_{3} \mathrm{PO}_{4}\right) 33.6(1 \mathrm{P}, \mathrm{s})$; N $\left(60 \mathrm{MHz} ; \mathrm{C}_{6} \mathrm{D}_{6} ; \mathrm{MeNO}_{2}\right)-335\left(1 \mathrm{~N}, \mathrm{NMe}_{2}\right),-336\left(1 \mathrm{~N}, \mathrm{NMe}_{2}\right)$ and $-359(1$ $\mathrm{N}, \mathrm{NMe}) ; m / z($ ESI $) 686.1985\left([\mathrm{Pd}(65)-\mathrm{dba}-\mathrm{H}]^{+} \cdot \mathrm{C}_{32} \mathrm{H}_{43} \mathrm{~N}_{3} \mathrm{O}_{5} \mathrm{PPd}\right.$ requires $686.1975)$.

\section{$\left[\mathrm{Pd}\left(\eta^{3}-\mathrm{C}_{3} \mathrm{H}_{5}\right)(65)\right] \mathrm{Cl}(79$ and 83$)$}

$\mathrm{PN}$ ligand $65(0.16 \mathrm{~g}, 0.27 \mathrm{mmol})$ and $\left[\mathrm{Pd}\left(\eta^{3}-\mathrm{C}_{3} \mathrm{H}_{5}\right)(\mu-\mathrm{Cl})\right]_{2}(0.05 \mathrm{~g}$, $0.14 \mathrm{mmol})$ were combined in dichloromethane $\left(5 \mathrm{~cm}^{3}\right)$. The pale green reaction mixture was stirred for 1 day at room temperature. The solvent was removed in vacuo and the residue was washed with hexane in the air and dried in vacuo to give the ketone (79) and hydrate (83) forms of the title compound in a 3:1 ratio as a white solid (0.15 g, 74\%) (Found: C, 50.8; H, 6.4; N, 5.0. $\mathrm{C}_{35} \mathrm{H}_{49} \mathrm{~N}_{3} \mathrm{O}_{5} \mathrm{PClPd}+\mathrm{CH}_{2} \mathrm{Cl}_{2}$ requires $\mathrm{C}, 50.9 ; \mathrm{H}, 6.1 ; \mathrm{N}, 5.0 \%$ ); $\max (\mathrm{KBr}) / \mathrm{cm}^{1} 3408,1728,1609,1519,1257 ; \mathrm{m} / z(\mathrm{ESI}) 728.2464\left([\mathrm{M}-\mathrm{Cl}]^{+}\right.$. $\mathrm{C}_{35} \mathrm{H}_{49} \mathrm{~N}_{3} \mathrm{O}_{5} \mathrm{PPd}$ requires 728.2444). 


\section{Compound 79:}

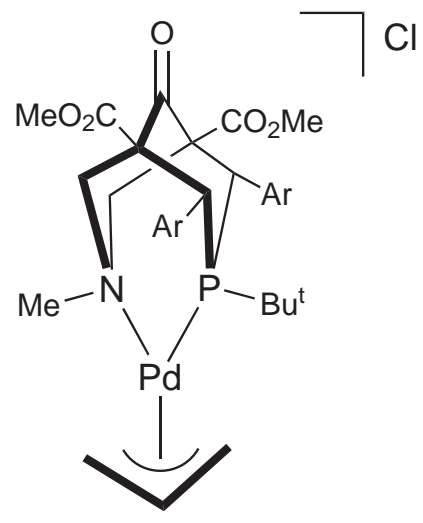

н $\left(600 \mathrm{MHz} ; \mathrm{CD}_{2} \mathrm{Cl}_{2} ; \mathrm{Me}_{4} \mathrm{Si}\right) 0.70\left(9 \mathrm{H}, \mathrm{d}, J_{\mathrm{PH}} 15.4, \mathrm{Bu}^{\mathrm{t}}\right), 2.96\left(12 \mathrm{H}, \mathrm{s}, \mathrm{NMe}_{2}\right)$, $3.06\left(2 \mathrm{H}, \mathrm{d}, J_{\mathrm{HH}} 14.5, \mathrm{CH}_{2}\right), 3.35\left(2 \mathrm{H}, \mathrm{d}, J_{\mathrm{HH}}\right.$ 9.4, allylic $\mathrm{CH}_{2}$ cis to P), 3.65 (6 H, s, OMe), 3.68 (3 H, s, NMe), 4.18 (4 H, m, $\mathrm{CH}_{2}$ and $\left.\mathrm{PCH}\right), 4.75$ (1 H, dd, $J_{\mathrm{HH}} 14.1, J_{\mathrm{PH}} 9.6$, anti allylic $\mathrm{CH}_{2}$ trans to $\left.\mathrm{P}\right), 5.26\left(1 \mathrm{H}\right.$, dd, $J_{\mathrm{PH}} 7.4, J_{\mathrm{HH}} 7.3$, syn allylic $\mathrm{CH}_{2}$ trans to $\left.\mathrm{P}\right), 6.26\left(1 \mathrm{H}\right.$, dtd, $J_{\mathrm{HH}} 14.1,9.4,7.3$, allylic $\left.\mathrm{CH}\right), 6.64$ $(2 \mathrm{H}, \mathrm{m}, m-\mathrm{H}), 6.81\left(2 \mathrm{H}, \mathrm{dd}, J_{\mathrm{HH}} 8.9,2.7, m\right), 6.98\left(2 \mathrm{H}, \mathrm{dd}, J_{\mathrm{HH}} 8.8,2.2, o\right.$ ) and $8.13\left(2 \mathrm{H}\right.$, dd, $\left.J_{\mathrm{HH}} 8.7,1.7, o\right) ; \mathrm{C}\left(150 \mathrm{MHz} ; \mathrm{CD}_{2} \mathrm{Cl}_{2} ; \mathrm{Me}_{4} \mathrm{Si}\right) 26.78(3 \mathrm{C}$, d, $\left.J_{\mathrm{PC}} 27.4, \mathrm{CMe}_{\mathbf{3}}\right), 33.9\left(1 \mathrm{C}, \mathrm{d}, J_{\mathrm{PC}} 14.5, \mathrm{CMe}_{3}\right), 39.80\left(4 \mathrm{C}, \mathrm{s}, \mathrm{NMe}_{2}\right), 42.3$ $\left(2 \mathrm{C}, \mathrm{d}, J_{\mathrm{PC}} 13.8, \mathrm{PCH}\right), 49.5\left(1 \mathrm{C}, \mathrm{d}, J_{\mathrm{PC}} 4.8\right.$, allylic $\mathrm{CH}_{2}$ cis to $\left.\mathrm{P}\right), 52.6(2 \mathrm{C}$, s, OMe), 63.1 (1 C, s, NMe), 64.2 (4 C, m, PCHC and $\mathrm{CH}_{2}$ ), 88.1 (1 C, d, J 26.9, allylic $\mathrm{CH}_{2}$ trans to P), $111.4\left(2 \mathrm{C}, \mathrm{s}, m-\mathrm{C}_{6} \mathrm{H}_{4}\right), 112.3\left(2 \mathrm{C}, \mathrm{s}, m-\mathrm{C}_{6} \mathrm{H}_{4}\right)$, $118.4\left(2 \mathrm{C}, \mathrm{d}, J_{\mathrm{PC}} 2.0, \mathrm{C}_{6} \mathrm{H}_{4}\right), 122.3\left(1 \mathrm{C}, \mathrm{d}, J_{\mathrm{PC}} 6.2\right.$, allylic $\left.\mathrm{CH}\right), 130.8(2 \mathrm{C}, \mathrm{d}$, $\left.J_{\mathrm{PC}} 8.4, o-\mathrm{C}_{6} \mathrm{H}_{4}\right), 132.6\left(2 \mathrm{C}, \mathrm{d}, J_{\mathrm{PC}} 5.3, o-\mathrm{C}_{6} \mathrm{H}_{4}\right), 150.6\left(2 \mathrm{C}, \mathrm{s}, p-\mathrm{C}_{6} \mathrm{H}_{4}\right), 166.5$ $\left(2 \mathrm{C}, \mathrm{d}, J_{\mathrm{PC}} 9.8, \mathrm{COO}\right)$ and $199.4(1 \mathrm{C}, \mathrm{s}, \mathrm{CO}) ; \mathrm{P}\left(121 \mathrm{MHz} ; \mathrm{CDCl}_{3} ; \mathrm{H}_{3} \mathrm{PO}_{4}\right)$ $38.7(1 \mathrm{P}, \mathrm{s}) ; \mathrm{N}\left(60 \mathrm{MHz} ; \mathrm{CD}_{2} \mathrm{Cl}_{2} ; \mathrm{MeNO}_{2}\right)-331\left(2 \mathrm{~N}, \mathrm{NMe}_{2}\right)$ and $-363(1 \mathrm{~N}$, $\mathrm{NMe})$.

Tentatively assigned by comparison to the theoretical gNMR spectrum (see Figure 3.5). 


\section{Compound 83:}

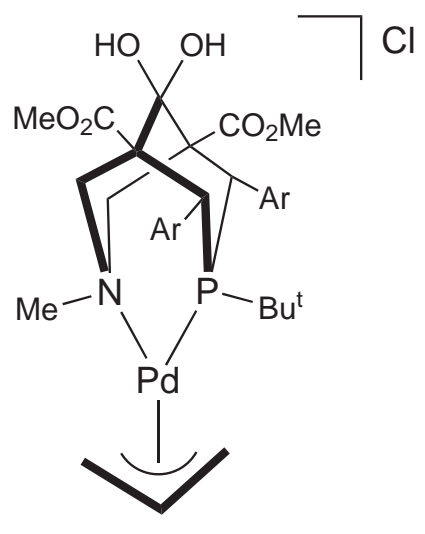

н (600 MHz; $\left.\mathrm{CD}_{2} \mathrm{Cl}_{2} ; \mathrm{Me}_{4} \mathrm{Si}\right) 0.70\left(9 \mathrm{H}, \mathrm{d}, J_{\mathrm{PH}} 15.4, \mathrm{Bu}^{\mathrm{t}}\right), 2.94\left(12 \mathrm{H}, \mathrm{s}, \mathrm{NMe}_{2}\right)$, $3.13\left(4 \mathrm{H}, \mathrm{m}, \mathrm{CH}_{2}\right.$ and allylic $\mathrm{CH}_{2}$ cis to $\left.\mathrm{P}\right), 3.49(3 \mathrm{H}, \mathrm{s}, \mathrm{NMe}), 3.57$ (2 H, d, $\left.J_{\mathrm{HH}} 12.4, \mathrm{CH}_{2}\right), 3.57$ (6 H, s, OMe), $4.26\left(1 \mathrm{H}, \mathrm{dd}, J_{\mathrm{HH}} 14.2, J_{\mathrm{PH}} 9.4\right.$, anti allylic $\mathrm{CH}_{2}$ trans to $\left.\mathrm{P}\right), 4.54\left(2 \mathrm{H}, \mathrm{d}, J_{\mathrm{PH}} 16.5, \mathrm{PCH}\right), 4.82\left(1 \mathrm{H}, \mathrm{dd}, J_{\mathrm{HH}} 7.5\right.$, $J_{\mathrm{PH}}$ 7.0, syn allylic $\mathrm{CH}_{2}$ trans to $\left.\mathrm{P}\right), 5.94\left(1 \mathrm{H}\right.$, dtd, $J_{\mathrm{HH}} 14.2,9.4,7.5$, allylic $\mathrm{CH}), 6.64(4 \mathrm{H}, \mathrm{m}, m-\mathrm{H}), 7.05\left(2 \mathrm{H}, \mathrm{d}, J_{\mathrm{HH}} 8.6, o\right)$ and $7.98\left(2 \mathrm{H}, \mathrm{d}, J_{\mathrm{HH}} 8.2\right.$, o); $\quad$ C $\left(150 \mathrm{MHz} ; \mathrm{CD}_{2} \mathrm{Cl}_{2} ; \mathrm{Me}_{4} \mathrm{Si}\right) 26.75$ (3 C, d, J $\left.J_{\mathrm{PC}} 27.7, \mathrm{CMe}_{3}\right), 33.5$ (1 C, d, $\left.J_{\mathrm{PC}} 16.9, \mathrm{CMe}_{3}\right), 39.7\left(2 \mathrm{C}, \mathrm{d}, J_{\mathrm{PC}} 14.3, \mathrm{PCH}\right), 39.84\left(4 \mathrm{C}, \mathrm{s}, \mathrm{NMe}_{2}\right), 47.4$ (1 C, d, $J_{\mathrm{PC}} 5.3$, allylic $\mathrm{CH}_{2}$ cis to P), 52.6 (2 C, s, OMe), 58.9 (4 C, m, PCHC and $\mathrm{CH}_{2}$ ), 63.8 ( $\left.1 \mathrm{C}, \mathrm{s}, \mathrm{NMe}\right), 83.8$ ( $1 \mathrm{C}, \mathrm{d}, J_{\mathrm{PC}} 27.8$, allylic $\mathrm{CH}_{2}$ trans to $\mathrm{P}$ ), $93.8\left(1 \mathrm{C}, \mathrm{s}, \mathrm{C}(\mathrm{OH})_{2}\right), 111.4\left(2 \mathrm{C}, \mathrm{s}, m-\mathrm{C}_{6} \mathrm{H}_{4}\right), 112.5\left(2 \mathrm{C}, \mathrm{s}, m-\mathrm{C}_{6} \mathrm{H}_{4}\right), 120.4(1$ C, d, $J_{\mathrm{PC}} 6.2$, allylic CH), $120.7\left(2 \mathrm{C}, \mathrm{d}, J_{\mathrm{PC}} 2.0, \mathrm{C}_{6} \mathrm{H}_{4}\right), 130.4\left(2 \mathrm{C}, \mathrm{d}, J_{\mathrm{PC}} 8.4\right.$, $\left.o-\mathrm{C}_{6} \mathrm{H}_{4}\right), 133.0\left(2 \mathrm{C}, \mathrm{d}, J_{\mathrm{PC}} 5.9, o-\mathrm{C}_{6} \mathrm{H}_{4}\right), 150.1\left(2 \mathrm{C}, \mathrm{s}, p-\mathrm{C}_{6} \mathrm{H}_{4}\right)$ and $169.6(2$ C, d, $\left.J_{\mathrm{PC}} 11.5, \mathrm{COO}\right) ; \quad$ P $\left(121 \mathrm{MHz} ; \mathrm{CDCl}_{3} ; \mathrm{H}_{3} \mathrm{PO}_{4}\right) 39.9(1 \mathrm{P}, \mathrm{s}) ; \quad \mathrm{N}(60 \mathrm{MHz}$; $\left.\mathrm{CD}_{2} \mathrm{Cl}_{2} ; \mathrm{MeNO}_{2}\right)-333\left(2 \mathrm{~N}, \mathrm{NMe}_{2}\right)$ and $-364(1 \mathrm{~N}, \mathrm{NMe})$.

Tentatively assigned by comparison to the theoretical gNMR spectrum (see Figure 3.5). 


\section{$\left[\mathrm{Pd}\left(\eta^{3}-\mathrm{C}_{3} \mathrm{H}_{5}\right)(65)\right] \mathrm{SbF}_{6}(84$ and 85$)$}

$\left[\mathrm{Pd}\left(\eta^{3}-\mathrm{C}_{3} \mathrm{H}_{5}\right)(\mathbf{6 5})\right] \mathrm{Cl}(0.21 \mathrm{~g}, 0.27 \mathrm{mmol})$ and $\mathrm{AgSbF}_{6}(0.09 \mathrm{~g}, 0.27 \mathrm{mmol})$ were combined in dichloromethane $\left(5 \mathrm{~cm}^{3}\right)$. The yellow reaction mixture was stirred for $1 \mathrm{hr}$ at room temperature then was filtered and centrifuged to remove $\mathrm{AgCl}$. The solvent was removed in vacuo and the residue was washed with hexane in the air and dried in vacuo to give the ketone (84) and hydrate (85) forms of the title compound in a 3:1 ratio as a creamy solid $(0.21 \mathrm{~g}, 82 \%)$ (Found: C, 41.5; H, 5.3; N, 4.1. $\mathrm{C}_{35} \mathrm{H}_{49} \mathrm{~N}_{3} \mathrm{O}_{5} \mathrm{~F}_{6} \mathrm{PPdSb}+\mathrm{CH}_{2} \mathrm{Cl}_{2}$ requires $\mathrm{C}$, 41.2; $\mathrm{H}, 4.9$; $\mathrm{N}, 4.0 \%) ; \quad \max (\mathrm{KBr}) / \mathrm{cm}^{1} 3370,1724,1702,1610,1521,1250,661 ; \mathrm{m} / z$ (ESI) $728.2451\left([\mathrm{M}]^{+} . \mathrm{C}_{35} \mathrm{H}_{49} \mathrm{~N}_{3} \mathrm{O}_{5} \mathrm{PPd}\right.$ requires 728.2444).

\section{Compound 84:}

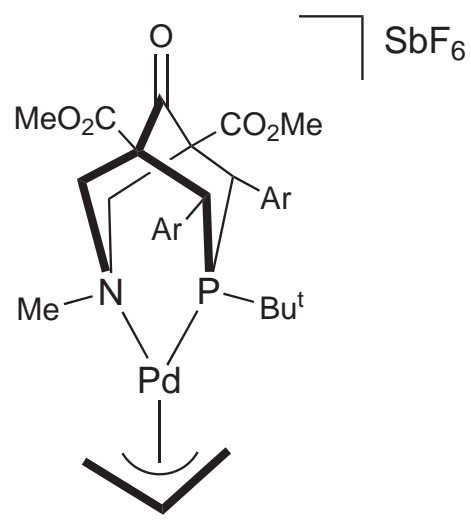

н $\left(600 \mathrm{MHz} ; \mathrm{CD}_{2} \mathrm{Cl}_{2} ; \mathrm{Me}_{4} \mathrm{Si}\right) 0.709\left(9 \mathrm{H}, \mathrm{d}, J_{\mathrm{PH}} 15.4, \mathrm{Bu}^{\mathrm{t}}\right), 2.95(12 \mathrm{H}, \mathrm{s}$, $\left.\mathrm{NMe}_{2}\right), 3.08\left(2 \mathrm{H}, \mathrm{d}, J_{\mathrm{HH}} 13.3, \mathrm{CH}_{2}\right), 3.37\left(2 \mathrm{H}, \mathrm{m}\right.$, allylic $\mathrm{CH}_{2}$ cis to P) 3.56 (3 H, s, NMe), 3.66 (6 H, s, OMe), $4.06\left(2 \mathrm{H}, \mathrm{d}, J_{\mathrm{HH}} 14.6, \mathrm{CH}_{2}\right), 4.23(2 \mathrm{H}, \mathrm{d}$, $J_{\mathrm{PH}}$ 15.4, $\left.\mathrm{PCH}\right), 4.47\left(1 \mathrm{H}, \mathrm{dd}, J_{\mathrm{HH}} 14.1, J_{\mathrm{PH}} 9.7\right.$, anti allylic $\mathrm{CH}_{2}$ trans to $\left.\mathrm{P}\right)$, $5.07\left(1 \mathrm{H}, \mathrm{dd}, J_{\mathrm{HH}} 7.8, J_{\mathrm{PH}} 7.1\right.$, syn allylic $\mathrm{CH}_{2}$ trans to $\left.\mathrm{P}\right), 6.14(1 \mathrm{H}$, dtd, $J_{\mathrm{HH}} 14.1,9.4,7.8$, allylic $\left.\mathrm{CH}\right)$, 6.64-6.75 (4 H, m, $\left.m-\mathrm{H}\right), 7.00(2 \mathrm{H}, \mathrm{m}, o)$ and $8.00\left(2 \mathrm{H}, \mathrm{d}, J_{\mathrm{HH}} 7.9, o\right)$; $\mathrm{C}\left(150 \mathrm{MHz} ; \mathrm{CD}_{2} \mathrm{Cl}_{2} ; \mathrm{Me}_{4} \mathrm{Si}\right) 26.7$ (3 C, d, J $\mathrm{PC}_{3.4}$, 
$\mathrm{CMe}_{3}$ ), 34.0 (1 C, d, $\left.J_{\mathrm{PC}} 15.1, \mathrm{CMe}_{3}\right), 39.9$ (4 C, s, $\left.\mathrm{NMe}_{2}\right), 42.2\left(2 \mathrm{C}, \mathrm{d}, J_{\mathrm{PC}}\right.$ 13.7, $\mathrm{PCH}), 49.9$ (1 C, d, $J_{\mathrm{PC}} 4.7$, allylic $\mathrm{CH}_{2}$ cis to $\left.\mathrm{P}\right), 52.7$ (2 C, s, OMe), 63.0 (1 C, s, NMe), 64.0 (2 C, d, J $\left.J_{\mathrm{PC}} 3.4, \mathrm{PCHC}\right), 64.2\left(2 \mathrm{C}, \mathrm{d}, J_{\mathrm{PC}} 2.5, \mathrm{CH}_{2}\right.$ ), $86.3\left(1 \mathrm{C}, \mathrm{d}, J_{\mathrm{PC}} 27.5\right.$, allylic $\mathrm{CH}_{2}$ trans to $\left.\mathrm{P}\right)$, 111.8-112.6 (2 C, m, $\left.m-\mathrm{C}_{6} \mathrm{H}_{4}\right)$, $118.2\left(2 \mathrm{C}, \mathrm{s}, \mathrm{C}_{6} \mathrm{H}_{4}\right), 121.8\left(1 \mathrm{C}, \mathrm{d}, J_{\mathrm{PC}} 6.2\right.$, allylic $\left.\mathrm{CH}\right), 130.3\left(2 \mathrm{C}, \mathrm{m}, o-\mathrm{C}_{6} \mathrm{H}_{4}\right)$, $132.7\left(2 \mathrm{C}, \mathrm{m}, o-\mathrm{C}_{6} \mathrm{H}_{4}\right), 150.6\left(2 \mathrm{C}, \mathrm{s}, p-\mathrm{C}_{6} \mathrm{H}_{4}\right), 166.3\left(2 \mathrm{C}, \mathrm{d}, J_{\mathrm{PC}} 9.9, \mathrm{COO}\right)$ and 199.0 (1 C, d, J $\left.J_{\mathrm{PC}} 1.4, \mathrm{CO}\right)$; $\mathrm{P}\left(121 \mathrm{MHz} ; \mathrm{CD}_{2} \mathrm{Cl}_{2} ; \mathrm{H}_{3} \mathrm{PO}_{4}\right) 38.8(1 \mathrm{P}, \mathrm{s})$; N $\left(60 \mathrm{MHz} ; \mathrm{CD}_{2} \mathrm{Cl}_{2} ; \mathrm{MeNO}_{2}\right)-332\left(2 \mathrm{~N}, \mathrm{NMe}_{2}\right)$ and $-363(1 \mathrm{~N}, \mathrm{NMe})$.

\section{Compound 85:}

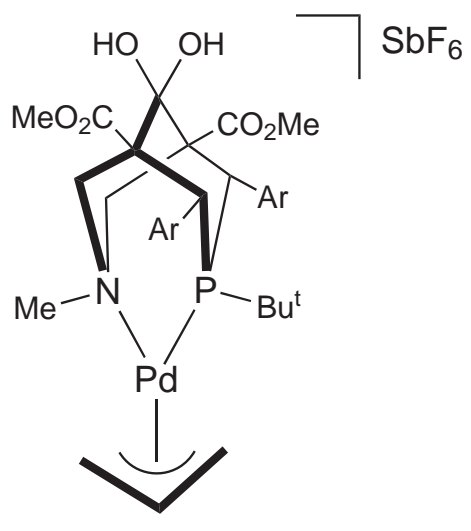

н $\left(600 \mathrm{MHz} ; \mathrm{CD}_{2} \mathrm{Cl}_{2} ; \mathrm{Me}_{4} \mathrm{Si}\right) 0.713\left(9 \mathrm{H}, \mathrm{d}, J_{\mathrm{PH}} 15.7, \mathrm{Bu}^{\mathrm{t}}\right), 2.96(12 \mathrm{H}, \mathrm{s}$, $\left.\mathrm{NMe}_{2}\right), 3.02\left(2 \mathrm{H}, \mathrm{d}, J_{\mathrm{HH}} 13.7, \mathrm{CH}_{2}\right), 3.48$ (3 H, s, NMe), 3.50 (6 H, s, OMe), $3.68\left(2 \mathrm{H}, \mathrm{m}, \mathrm{CH}_{2}\right), 4.31\left(1 \mathrm{H}, \mathrm{dd}, J_{\mathrm{HH}} 14.1, J_{\mathrm{PH}} 9.5\right.$, anti allylic $\mathrm{CH}_{2}$ trans to P), $4.46\left(2 \mathrm{H}, \mathrm{d}, J_{\mathrm{PH}} 16.1, \mathrm{PCH}\right), 4.89\left(1 \mathrm{H}, \mathrm{dd}, J_{\mathrm{HH}} 7.8, J_{\mathrm{PH}} 7.1\right.$, syn allylic $\mathrm{CH}_{2}$ trans to P), $5.99\left(1 \mathrm{H}, \mathrm{dtd}, J_{\mathrm{HH}} 14.1,9.4,7.8\right.$, allylic $\left.\mathrm{CH}\right), 6.35(1 \mathrm{H}, \mathrm{s}$, $\mathrm{OH})$ and $6.44(1 \mathrm{H}, \mathrm{s}, \mathrm{OH})$; $\mathrm{C}\left(150 \mathrm{MHz} ; \mathrm{CD}_{2} \mathrm{Cl}_{2} ; \mathrm{Me}_{4} \mathrm{Si}\right) 26.8\left(3 \mathrm{C}, \mathrm{d}, J_{\mathrm{PC}}\right.$ 3.6, $\mathrm{CMe}_{3}$ ), 33.7 (1 C, d, J $\left.J_{\mathrm{PC}} 16.6, \mathrm{CMe}_{3}\right), 39.8$ (4 C, s, $\mathrm{NMe}_{2}$ ), 40.0 (2 C, d, $\left.J_{\mathrm{PC}} 14.0, \mathrm{PCH}\right), 48.0$ (1 C, d, $J_{\mathrm{PC}} 5.9$, allylic $\mathrm{CH}_{2}$ cis to P), 52.8 (2 C, s, OMe), 58.4 (2 C, d, J $\left.J_{\mathrm{PC}} 2.8, \mathrm{PCHC}\right), 58.6$ (2 C, s, $\left.\mathrm{CH}_{2}\right), 63.6$ (1 C, s, NMe), 84.4 (1 
C, d, $J_{\mathrm{PC}} 28.3$, allylic $\mathrm{CH}_{2}$ trans to P), 94.1 (1 C, s, C(OH) $)_{2}$ ), 120.1 (2 C, br s, $\left.\mathrm{C}_{6} \mathrm{H}_{4}\right), 120.8\left(1 \mathrm{C}, \mathrm{d}, J_{\mathrm{PC}} 5.9\right.$, allylic $\left.\mathrm{CH}\right), 150.2\left(2 \mathrm{C}, \mathrm{s}, p-\mathrm{C}_{6} \mathrm{H}_{4}\right)$ and $170.1(2$ C, d, J $\left.J_{\mathrm{PC}} 11.5, \mathrm{COO}\right) ; \quad$ р $\left(121 \mathrm{MHz} ; \mathrm{CD}_{2} \mathrm{Cl}_{2} ; \mathrm{H}_{3} \mathrm{PO}_{4}\right) 37.5(1 \mathrm{P}, \mathrm{s}) ; \quad \mathrm{N}(60 \mathrm{MHz}$; $\left.\mathrm{CD}_{2} \mathrm{Cl}_{2} ; \mathrm{MeNO}_{2}\right)-331\left(2 \mathrm{~N}, \mathrm{NMe}_{2}\right)$ and $-364(1 \mathrm{~N}, \mathrm{NMe})$.

\section{$[\mathrm{Pt}(\operatorname{cod})(65)](86)$ and $\left[\mathrm{Pt}\left(1-3-\eta-\mathrm{C}_{8} \mathrm{H}_{13}\right)(65-\mathrm{H})\right](87)$}

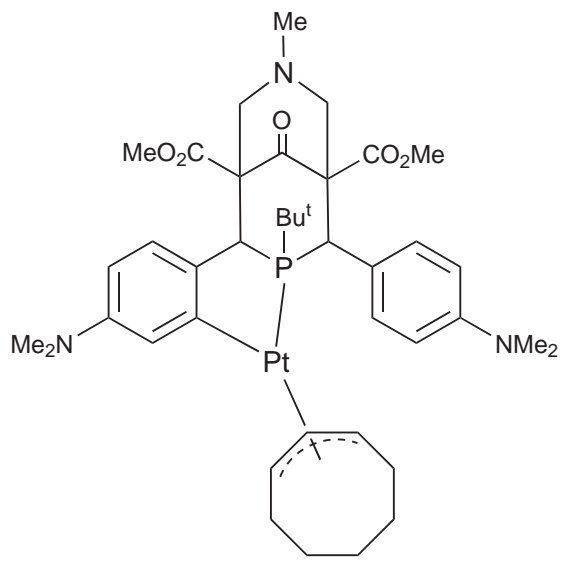

PN ligand 65 (0.14 g, $0.24 \mathrm{mmol})$ and $\left[\mathrm{Pt}(\operatorname{cod})_{2}\right](0.10 \mathrm{~g}, 0.24 \mathrm{mmol})$ were combined in benzene $\left(3 \mathrm{~cm}^{3}\right)$. The dark brown reaction mixture was stirred for 1 day at room temperature. Initially complex 86 was formed, but it was not possible to characterise it as it converted into complex 87. Hexane was added to the reaction mixture to precipitate complex 87 as a creamy solid. The precipitate was filtered in the air, washed with hexane and dried in vacuo $(0.17 \mathrm{~g}$, 79\%); (Found: C, 54.0; H, 6.3; N, 4.6. $\mathrm{C}_{40} \mathrm{H}_{56} \mathrm{~N}_{3} \mathrm{O}_{5}$ PPt requires C, 54.3; H, 6.4; $\mathrm{N}, 4.8 \%) ; \quad \max (\mathrm{KBr}) / \mathrm{cm}^{1} 1741,1702,1612,1521,1270 ; \quad$ н $\left(600 \mathrm{MHz} ; \mathrm{C}_{6} \mathrm{D}_{6}\right.$; $\left.\mathrm{Me}_{4} \mathrm{Si}\right) 1.17\left(9 \mathrm{H}, \mathrm{d}, J_{\mathrm{PH}} 13.0, \mathrm{Bu}^{\mathrm{t}}\right), 1.25\left(2 \mathrm{H}, \mathrm{m}, \mathrm{C}_{8} \mathrm{H}_{13}-\mathrm{CH}_{2}\right), 1.32(1 \mathrm{H}, \mathrm{m}$, $\left.\mathrm{C}_{8} \mathrm{H}_{13}-\mathrm{CH}_{2}\right), 1.54\left(2 \mathrm{H}, \mathrm{m}, \mathrm{C}_{8} \mathrm{H}_{13}-\mathrm{CH}_{2}\right), 1.72\left(1 \mathrm{H}, \mathrm{m}, \mathrm{C}_{8} \mathrm{H}_{13}-\mathrm{CH}_{2}\right), 1.83$ (1 $\left.\mathrm{H}, \mathrm{m}, \mathrm{C}_{8} \mathrm{H}_{13}-\mathrm{CH}_{2}\right), 1.89(3 \mathrm{H}, \mathrm{s}, \mathrm{NMe}), 2.20\left(1 \mathrm{H}, \mathrm{m}, \mathrm{C}_{8} \mathrm{H}_{13}-\mathrm{CH}_{2}\right), 2.28(1 \mathrm{H}$, m, $\left.\mathrm{C}_{8} \mathrm{H}_{13}-\mathrm{CH}_{2}\right), 2.48\left(6 \mathrm{H}, \mathrm{s}, \mathrm{NMe}_{2}\right), 2.71\left(1 \mathrm{H}, \mathrm{m}, \mathrm{C}_{8} \mathrm{H}_{13}-\mathrm{CH}_{2}\right), 2.74(1 \mathrm{H}, \mathrm{d}$, $\left.J_{\mathrm{HH}} 12.6, \mathrm{CH}_{2}\right), 2.78\left(6 \mathrm{H}, \mathrm{s}, \mathrm{NMe}_{2}\right), 2.80\left(1 \mathrm{H}, \mathrm{d}, J_{\mathrm{HH}} 11.4, \mathrm{CH}_{2}\right), 3.03(1 \mathrm{H}$, dd, $\left.J_{\mathrm{HH}} 11.3,3.3, \mathrm{CH}_{2}\right), 3.17\left(1 \mathrm{H}, \mathrm{dd}, J_{\mathrm{HH}} 12.4,3.4, \mathrm{CH}_{2}\right), 3.30$ (3 H, s, OMe), 
3.58 (3 H, s, OMe), 3.75 (1 H, m, $\left.\mathrm{C}_{8} \mathrm{H}_{13}-\mathrm{CH}\right), 4.29$ (1 H, m, $\left.\mathrm{C}_{8} \mathrm{H}_{13}-\mathrm{CH}\right), 4.99$ $\left(1 \mathrm{H}, \mathrm{d}, J_{\mathrm{PH}} 13.2, J_{\mathrm{PtH}} 52, \mathrm{PCH}\right), 5.08\left(1 \mathrm{H}, \mathrm{t}, J_{\mathrm{HH}} 7.9, J_{\mathrm{PtH}} 42, \mathrm{C}_{8} \mathrm{H}_{13}-\mathrm{CH}\right)$, $5.15\left(1 \mathrm{H}, \mathrm{d}, J_{\mathrm{PH}} 10.8, J_{\mathrm{PtH}} 27, \mathrm{PCH}\right), 6.52\left(2 \mathrm{H}, \mathrm{d}, J_{\mathrm{HH}} 6.9, m-\mathrm{H}\right), 6.66(1 \mathrm{H}$, $\left.\mathrm{dd}, J_{\mathrm{HH}} 8.6,2.5, m-\mathrm{H}\right), 7.34\left(1 \mathrm{H}, \mathrm{d}, J_{\mathrm{HH}} 8.6, J_{\mathrm{PtH}} 18, o-\mathrm{H}\right), 7.50(2 \mathrm{H}, \mathrm{br} \mathrm{s}$, $o-\mathrm{H})$ and $8.28\left(1 \mathrm{H}, \mathrm{d}, J_{\mathrm{HH}} 1.5, m-\mathrm{H}\right) ; \mathrm{C}\left(150 \mathrm{MHz} ; \mathrm{C}_{6} \mathrm{D}_{6} ; \mathrm{Me}_{4} \mathrm{Si}\right) 24.9(1 \mathrm{C}$, br s, $\mathrm{C}_{8} \mathrm{H}_{13}-\mathrm{CH}_{2}$ ), 27.6 (3 C, d, J $\mathrm{PC} 5.1, \mathrm{CMe}_{\mathbf{3}}$ ), $30.2\left(1 \mathrm{C}, \mathrm{s}, \mathrm{C}_{8} \mathrm{H}_{13}-\mathrm{CH}_{2}\right.$ ), $30.7\left(1 \mathrm{C}, \mathrm{d}, J_{\mathrm{PC}} 8.6, J_{\mathrm{PtC}} 31, \mathrm{C}_{8} \mathrm{H}_{13}-\mathrm{CH}_{2}\right), 33.0\left(1 \mathrm{C}, \mathrm{d}, J_{\mathrm{PC}} 5.6, J_{\mathrm{PtC}} 34\right.$, $\left.\mathrm{C}_{8} \mathrm{H}_{13}-\mathrm{CH}_{2}\right), 33.8\left(1 \mathrm{C}, \mathrm{s}, J_{\mathrm{PtC}} 20, \mathrm{C}_{8} \mathrm{H}_{13}-\mathrm{CH}_{2}\right), 35.3\left(1 \mathrm{C}, \mathrm{d}, J_{\mathrm{PC}} 19.8, J_{\mathrm{PtC}}\right.$ $\left.39, \mathrm{CMe}_{3}\right), 39.9\left(2 \mathrm{C}, \mathrm{s}, \mathrm{NMe}_{2}\right), 40.9\left(2 \mathrm{C}, \mathrm{s}, \mathrm{NMe}_{2}\right), 42.2\left(1 \mathrm{C}, \mathrm{d}, J_{\mathrm{PC}} 18.1, J_{\mathrm{PtC}}\right.$ $50, \mathrm{PCH}), 43.9$ (1 C, s, NMe), 51.2 (1 C, d, $\left.J_{\mathrm{PC}} 30.2, J_{\mathrm{PtC}} 77, \mathrm{PCH}\right), 51.9$ (1 C, s, OMe), $52.2(1 \mathrm{C}, \mathrm{s}, \mathrm{OMe}), 59.5\left(1 \mathrm{C}, \mathrm{s}, \mathrm{CH}_{2}\right), 59.6\left(1 \mathrm{C}, \mathrm{s}, \mathrm{CH}_{2}\right), 65.1(1 \mathrm{C}$, d, $\left.J_{\mathrm{PC}} 49.6, J_{\mathrm{PtC}} 237, \mathrm{C}_{8} \mathrm{H}_{13}-\mathrm{CH}\right), 65.14$ (1 C, d, $\left.J_{\mathrm{PC}} 1.1, \mathrm{PCHC}\right), 65.8$ (1 C, d, $\left.J_{\mathrm{PC}} 1.7, \mathrm{PCHC}\right), 73.0\left(1 \mathrm{C}, \mathrm{s}, J_{\mathrm{PtC}} 45, \mathrm{C}_{8} \mathrm{H}_{13}-\mathrm{CH}\right), 107.3\left(1 \mathrm{C}, \mathrm{d}, J_{\mathrm{PC}} 4.5\right.$, $\left.\mathrm{C}_{8} \mathrm{H}_{13}-\mathrm{CH}\right), 110.7\left(1 \mathrm{C}, \mathrm{s}, m-\mathrm{C}_{6} \mathrm{H}_{4}\right), 123.9\left(1 \mathrm{C}, \mathrm{d}, J_{\mathrm{PC}} 14.2, J_{\mathrm{PtC}} 55, o-\mathrm{C}_{6} \mathrm{H}_{4}\right)$, $125.3\left(1 \mathrm{C}, \mathrm{d}, J_{\mathrm{PC}} 3.6, \mathrm{C}_{6} \mathrm{H}_{4}\right), 129.5\left(1 \mathrm{C}, \mathrm{d}, J_{\mathrm{PC}} 4.3, J_{\mathrm{PtC}} 74, m-\mathrm{C}_{6} \mathrm{H}_{4}\right), 134.0$ $\left(2 \mathrm{C}\right.$, br s, o- $\left.\mathrm{C}_{6} \mathrm{H}_{4}\right), 141.5\left(1 \mathrm{C}, \mathrm{d}, J_{\mathrm{PC}} 18.8, J_{\mathrm{PtC}} 68, \mathrm{C}_{6} \mathrm{H}_{4}\right), 149.0\left(1 \mathrm{C}, \mathrm{s}, J_{\mathrm{PtC}}\right.$ 75, $\left.p-\mathrm{C}_{6} \mathrm{H}_{4}\right), 149.8\left(1 \mathrm{C}, \mathrm{s}, p-\mathrm{C}_{6} \mathrm{H}_{4}\right), 157.6$ (1 C, d, $\left.J_{\mathrm{PC}} 2.0, J_{\mathrm{PtC}} 1189, \mathrm{Pt}-\mathrm{C}\right)$, $169.0\left(1 \mathrm{C}, \mathrm{d}, J_{\mathrm{PC}} 7.2, \mathrm{COO}\right), 170.2\left(1 \mathrm{C}, \mathrm{d}, J_{\mathrm{PC}} 7.5, \mathrm{COO}\right)$ and 205.6 (1 C, d, $\left.J_{\mathrm{PC}} 2.8, \mathrm{CO}\right) ; \quad$ P $\left(121 \mathrm{MHz} ; \mathrm{C}_{6} \mathrm{D}_{6} ; \mathrm{H}_{3} \mathrm{PO}_{4}\right) 70.4\left(1 \mathrm{P}, \mathrm{s}, J_{\mathrm{PtP}} 3787\right) ; \quad$ N $(60 \mathrm{MHz}$; $\left.\mathrm{C}_{6} \mathrm{D}_{6} ; \mathrm{MeNO}_{2}\right)-336\left(1 \mathrm{~N}, \mathrm{NMe}_{2}\right),-339\left(1 \mathrm{~N}, \mathrm{NMe}_{2}\right)$ and $-354(1 \mathrm{~N}, \mathrm{NMe}) ; m / z$ (ESI) $885.3686\left([\mathrm{M}+\mathrm{H}] . \mathrm{C}_{40} \mathrm{H}_{57} \mathrm{~N}_{3} \mathrm{O}_{5} \mathrm{PPt}\right.$ requires 885.3684). 


\section{$\left[\mathrm{Pt}\left(1-\sigma, 4-5-\eta-\mathrm{C}_{8} \mathrm{H}_{13}\right)(65)\right] \mathrm{CH}\left(\mathrm{SO}_{2} \mathrm{CF}_{3}\right)_{2}(88)$}

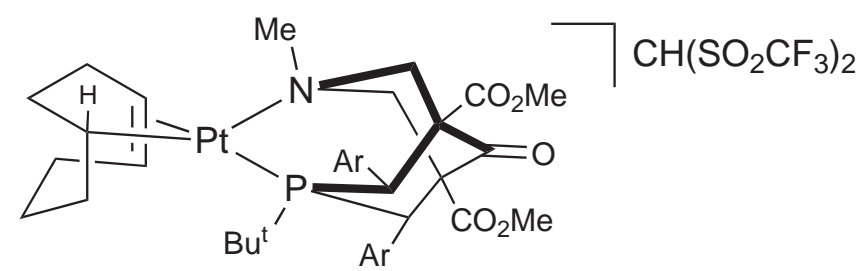

PN ligand 65 (0.14 g, $0.24 \mathrm{mmol}),\left[\mathrm{Pt}(\operatorname{cod})_{2}\right](0.10 \mathrm{~g}, 0.24 \mathrm{mmol})$ and $\mathrm{CH}_{2}\left(\mathrm{SO}_{2} \mathrm{CF}_{3}\right)_{2}(0.07 \mathrm{~g}, 0.24 \mathrm{mmol})$ were combined in dichloromethane $\left(4 \mathrm{~cm}^{3}\right)$. The dark brown reaction mixture was stirred for $2 \mathrm{hr}$ at room temperature. Hexane was added to the reaction mixture to precipitate the ketone (88) and hydrate forms in a 3:1 ratio as a white solid. The precipitate was filtered in the air, washed with hexane and dried in vacuo (0.23 g, 82\%); (Found: C, 44.5; H, 5.0; N, 3.9. $\mathrm{C}_{43} \mathrm{H}_{58} \mathrm{~N}_{3} \mathrm{O}_{9} \mathrm{~F}_{6} \mathrm{PS}_{2} \mathrm{Pt}$ requires $\mathrm{C}, 44.3 ; \mathrm{H}, 5.0 ; \mathrm{N}, 3.6 \%$ ); $\max (\mathrm{KBr}) / \mathrm{cm}^{1} 3441,1748,1740,1610,1520,1343,600 ;$ н $\left(600 \mathrm{MHz} ; \mathrm{CDCl}_{3}\right.$; $\left.\mathrm{Me}_{4} \mathrm{Si}\right) 0.85\left(9 \mathrm{H}\right.$, br s, $\left.\mathrm{Bu}^{\mathrm{t}}\right), 1.20\left(1 \mathrm{H}, \mathrm{m}, \mathrm{C}_{8} \mathrm{H}_{13}-\mathrm{CH}_{2}\right), 1.54(2 \mathrm{H}, \mathrm{m}$, $\left.\mathrm{C}_{8} \mathrm{H}_{13}-\mathrm{CH}_{2}\right), 1.91\left(1 \mathrm{H}, \mathrm{m}, \mathrm{C}_{8} \mathrm{H}_{13}-\mathrm{CH}_{2}\right), 2.10\left(2 \mathrm{H}, \mathrm{m}, \mathrm{C}_{8} \mathrm{H}_{13}-\mathrm{CH}_{2}\right), 2.43$ $\left(1 \mathrm{H}, \mathrm{m}, \mathrm{C}_{8} \mathrm{H}_{13}-\mathrm{CH}_{2}\right), 2.61\left(1 \mathrm{H}, \mathrm{m}, \mathrm{C}_{8} \mathrm{H}_{13}-\mathrm{CH}_{2}\right), 2.86\left(1 \mathrm{H}, \mathrm{m}, \mathrm{C}_{8} \mathrm{H}_{13}-\mathrm{CH}_{2}\right)$, 2.95 (3 H, s, NMe), 2.967 (6 H, s, $\left.\mathrm{NMe}_{2}\right), 2.97$ (6 H, s, NMe 2 ), 3.01 (1 H, d, J $J_{\mathrm{HH}}$ 14.3, $\left.\mathrm{CH}_{2}\right), 3.04\left(1 \mathrm{H}, \mathrm{m}, \mathrm{C}_{8} \mathrm{H}_{13}-\mathrm{CH}_{2}\right), 3.06\left(1 \mathrm{H}, \mathrm{d}, J_{\mathrm{HH}} 14.3, \mathrm{CH}_{2}\right), 3.08(1 \mathrm{H}$, m, Pt-CH), 3.62 (3 H, s, OMe), 3.63 (3 H, s, OMe), 3.91 (1 H, dd, J $J_{\mathrm{HH}} 13.9,2.1$, $\left.\mathrm{CH}_{2}\right), 3.95\left(1 \mathrm{H}, \mathrm{s}, \mathrm{CH}\left(\mathrm{SO}_{2} \mathrm{CF}_{3}\right)_{2}\right), 3.97\left(1 \mathrm{H}, \mathrm{dd}, J_{\mathrm{HH}} 14.2,2.1, \mathrm{CH}_{2}\right), 4.37(1$ $\left.\mathrm{H}, \mathrm{d}, J_{\mathrm{PH}} 14.2, \mathrm{PCH}\right), 4.42\left(1 \mathrm{H}, \mathrm{d}, J_{\mathrm{PH}} 13.7, \mathrm{PCH}\right), 6.38\left(1 \mathrm{H}, \mathrm{m}, \mathrm{C}_{8} \mathrm{H}_{13}-\mathrm{CH}\right)$, $6.45\left(1 \mathrm{H}, \mathrm{m}, \mathrm{C}_{8} \mathrm{H}_{13}-\mathrm{CH}\right), 6.62(3 \mathrm{H}, \mathrm{m}, m-\mathrm{H}), 6.71\left(1 \mathrm{H}, \mathrm{dd}, J_{\mathrm{HH}} 8.8,2.8\right.$, $m-\mathrm{H}), 6.98(2 \mathrm{H}, \mathrm{m}, o-\mathrm{H}) 8.78\left(1 \mathrm{H}, \mathrm{dd}, J_{\mathrm{HH}} 8.7,2.2, o-\mathrm{H}\right)$ and $8.88(1 \mathrm{H}, \mathrm{dd}$, $\left.J_{\mathrm{HH}} 8.7,2.2, o-\mathrm{H}\right) ; \quad$ с $\left(150 \mathrm{MHz} ; \mathrm{CDCl}_{3} ; \mathrm{Me}_{4} \mathrm{Si}\right) 18.0$ (1 C, s, $\left.J_{\mathrm{PtC}} 601, \mathrm{Pt}-\mathrm{C}\right)$, $24.3\left(1 \mathrm{C}, \mathrm{s}, \mathrm{C}_{8} \mathrm{H}_{13}-\mathrm{CH}_{2}\right), 26.1\left(1 \mathrm{C}, \mathrm{s}, \mathrm{C}_{8} \mathrm{H}_{13}-\mathrm{CH}_{2}\right), 28.1$ (3 C, s, $\left.\mathrm{CMe}_{3}\right), 31.7$ $\left(1 \mathrm{C}, \mathrm{s}, \mathrm{C}_{8} \mathrm{H}_{13}-\mathrm{CH}_{2}\right), 35.0\left(1 \mathrm{C}, \mathrm{d}, J_{\mathrm{PC}} 23.9, \mathrm{CMe}_{3}\right), 35.8\left(1 \mathrm{C}, \mathrm{s}, \mathrm{C}_{8} \mathrm{H}_{13}-\mathrm{CH}_{2}\right)$, 39.3 (1 C, s, $\mathrm{C}_{8} \mathrm{H}_{13}-\mathrm{CH}_{2}$ ), 40.17 (2 C, s, $\mathrm{NMe}_{2}$ ), 40.18 (2 C, s, $\mathrm{NMe}_{2}$ ), 42.3 (1 
C, d, $\left.J_{\mathrm{PC}} 21.9, \mathrm{PCH}\right), 43.1$ (1 C, d, J $\left.J_{\mathrm{PC}} 21.5, \mathrm{PCH}\right), 52.9$ (1 C, s, NMe), 52.996 (1 C, s, OMe), 52.999 (1 C, s, OMe), 53.8 (1 C, sept, $\left.J_{\mathrm{FC}} 2.6, \mathrm{CH}\left(\mathrm{SO}_{2} \mathrm{CF}_{3}\right)_{2}\right)$, $63.2\left(1 \mathrm{C}, \mathrm{d}, J_{\mathrm{PC}} 1.2, \mathrm{CH}_{2}\right), 63.4\left(1 \mathrm{C}, \mathrm{d}, J_{\mathrm{PC}} 1.7, \mathrm{PCHC}\right), 63.5\left(1 \mathrm{C}, \mathrm{d}, J_{\mathrm{PC}}\right.$ 1.7, PCHC), 63.9 (1 C, d, J $\left.J_{\mathrm{PC}} 1.2, \mathrm{CH}_{2}\right), 110.2$ (1 C, d, $J_{\mathrm{PC}} 8.7, \mathrm{C}_{8} \mathrm{H}_{13}-\mathrm{CH}$ ), $111.7\left(1 \mathrm{C}, \mathrm{s}, m-\mathrm{C}_{6} \mathrm{H}_{4}\right), 111.8\left(1 \mathrm{C}, \mathrm{s}, m-\mathrm{C}_{6} \mathrm{H}_{4}\right), 112.5\left(1 \mathrm{C}, \mathrm{s}, m-\mathrm{C}_{6} \mathrm{H}_{4}\right), 112.7(1$ C, s, $\left.m-\mathrm{C}_{6} \mathrm{H}_{4}\right), 113.3\left(1 \mathrm{C}, \mathrm{d}, J_{\mathrm{PC}} 10.8, \mathrm{C}_{8} \mathrm{H}_{13}-\mathrm{CH}\right), 117.4\left(1 \mathrm{C}, \mathrm{s}, \mathrm{C}_{6} \mathrm{H}_{4}\right), 118.1$ $\left(1 \mathrm{C}, \mathrm{s}, \mathrm{C}_{6} \mathrm{H}_{4}\right), 121.3\left(2 \mathrm{C}, \mathrm{q}, J_{\mathrm{FC}} 325.7, \mathrm{CH}\left(\mathrm{SO}_{2} \mathrm{CF}_{3}\right)_{2}\right), 132.0\left(1 \mathrm{C}, \mathrm{d}, J_{\mathrm{PC}}\right.$ 7.8, o- $\left.\mathrm{C}_{6} \mathrm{H}_{4}\right), 132.2\left(1 \mathrm{C}, \mathrm{d}, J_{\mathrm{PC}} 7.6, o-\mathrm{C}_{6} \mathrm{H}_{4}\right), 133.2\left(1 \mathrm{C}, \mathrm{d}, J_{\mathrm{PC}} 5.7, o-\mathrm{C}_{6} \mathrm{H}_{4}\right)$, $133.3\left(1 \mathrm{C}, \mathrm{d}, J_{\mathrm{PC}} 5.9, o-\mathrm{C}_{6} \mathrm{H}_{4}\right), 150.7\left(2 \mathrm{C}, \mathrm{s}, p-\mathrm{C}_{6} \mathrm{H}_{4}\right), 166.47\left(1 \mathrm{C}, \mathrm{d}, J_{\mathrm{PC}} 1.8\right.$, COO), 166.54 (1 C, d, J $\left.J_{\mathrm{PC}} 1.8, \mathrm{COO}\right)$ and 199.8 (1 C, s, CO); $\mathrm{P}(121 \mathrm{MHz}$; $\left.\mathrm{CDCl}_{3} ; \mathrm{H}_{3} \mathrm{PO}_{4}\right) 18.1\left(1 \mathrm{P}, \mathrm{s}, J_{\mathrm{PtP}} 4304\right) ; \mathrm{N}\left(60 \mathrm{MHz} ; \mathrm{CDCl}_{3} ; \mathrm{MeNO}_{2}\right)-331(2$ $\left.\mathrm{N}, \mathrm{NMe}_{2}\right)$ and $-356(1 \mathrm{~N}, \mathrm{NMe}) ; \mathrm{F}\left(282 \mathrm{MHz} ; \mathrm{CDCl}_{3} ; \mathrm{CCl}_{3} \mathrm{~F}\right)-81.0(6 \mathrm{~F}, \mathrm{~s}$, $\left.\mathrm{CH}\left(\mathrm{SO}_{2} \mathrm{CF}_{3}\right)_{2}\right) ; m / z(\mathrm{ESI}) 885.3689\left([\mathrm{M}]^{+} \cdot \mathrm{C}_{40} \mathrm{H}_{57} \mathrm{~N}_{3} \mathrm{O}_{5}\right.$ PPt requires 885.3684).

\section{$\left[\mathrm{Pt}\left(1-3-\eta-\mathrm{C}_{8} \mathrm{H}_{13}\right)(65)\right] \mathrm{CH}\left(\mathrm{SO}_{2} \mathrm{CF}_{3}\right)_{2}$ (89 and 90)}

A mixture of the ketone (88) and hydrate forms of the complex $\left[\mathrm{Pt}\left(1-\sigma, 4-5-\eta-\mathrm{C}_{8} \mathrm{H}_{13}\right)(\mathbf{6 5})\right] \mathrm{CH}\left(\mathrm{SO}_{2} \mathrm{CF}_{3}\right)_{2} \quad(0.10 \mathrm{~g}, 0.09 \mathrm{mmol})$ was dissolved in dichloromethane $\left(2 \mathrm{~cm}^{3}\right)$. The colourless solution was stirred for 1 week at room temperature. The solvent was removed in vacuo to give the ketone (89) and hydrate (90) forms of the title compound in a 3:1 ratio as a white solid (0.09 g, 87\%); (Found: C, 44.1; H, 5.3; N, 3.5. $\mathrm{C}_{43} \mathrm{H}_{58} \mathrm{~N}_{3} \mathrm{O}_{9} \mathrm{~F}_{6} \mathrm{PS}_{2} \mathrm{Pt}$ requires C, 44.3; H, 5.0; N, 3.6\%); $\max (\mathrm{KBr}) / \mathrm{cm}^{1} 3422,1743,1610,1521,1343,1165$, $600 ; m / z($ ESI $) 885.3687\left([\mathrm{M}]^{+} \cdot \mathrm{C}_{40} \mathrm{H}_{57} \mathrm{~N}_{3} \mathrm{O}_{5}\right.$ PPt requires 885.3684). 


\section{Compound 89:}

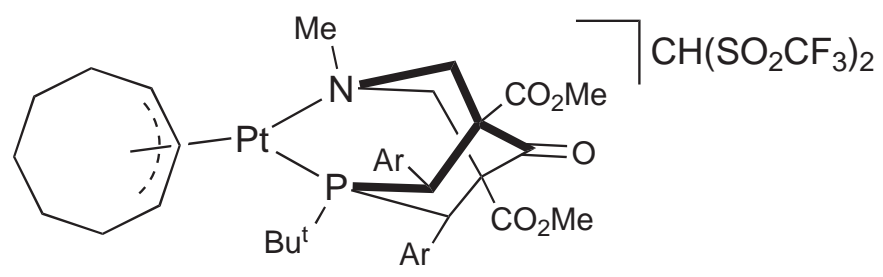

н $\left(600 \mathrm{MHz} ; \mathrm{CDCl}_{3} ; \mathrm{Me}_{4} \mathrm{Si}\right) 0.73\left(9 \mathrm{H}, \mathrm{d}, J_{\mathrm{PH}} 15.4, \mathrm{Bu}^{\mathrm{t}}\right), 1.58(3 \mathrm{H}, \mathrm{m}$, $\left.\mathrm{C}_{8} \mathrm{H}_{13}-\mathrm{CH}_{2}\right), 1.73\left(2 \mathrm{H}, \mathrm{m}, \mathrm{C}_{8} \mathrm{H}_{13}-\mathrm{CH}_{2}\right), 1.83\left(1 \mathrm{H}, \mathrm{m}, \mathrm{C}_{8} \mathrm{H}_{13}-\mathrm{CH}_{2}\right), 1.91$ $\left(1 \mathrm{H}, \mathrm{m}, \mathrm{C}_{8} \mathrm{H}_{13}-\mathrm{CH}_{2}\right), 2.08\left(1 \mathrm{H}, \mathrm{m}, \mathrm{C}_{8} \mathrm{H}_{13}-\mathrm{CH}_{2}\right), 2.30\left(1 \mathrm{H}, \mathrm{m}, \mathrm{C}_{8} \mathrm{H}_{13}-\mathrm{CH}_{2}\right)$, $2.83\left(1 \mathrm{H}, \mathrm{m}, \mathrm{C}_{8} \mathrm{H}_{13}-\mathrm{CH}_{2}\right), 2.92\left(6 \mathrm{H}, \mathrm{s}, \mathrm{NMe}_{2}\right), 2.96$ (6 H, s, $\left.\mathrm{NMe}_{2}\right), 3.23(2 \mathrm{H}$, m, $\left.\mathrm{CH}_{2}\right), 3.56(3 \mathrm{H}, \mathrm{s}, \mathrm{OMe}), 3.64(3 \mathrm{H}, \mathrm{s}, \mathrm{OMe}), 3.94\left(1 \mathrm{H}, \mathrm{s}, \mathrm{CH}\left(\mathrm{SO}_{2} \mathrm{CF}_{3}\right)_{2}\right)$, $4.01(3 \mathrm{H}, \mathrm{s}, \mathrm{NMe}), 4.15\left(1 \mathrm{H}, \mathrm{dd}, J_{\mathrm{HH}} 14.3,1.9, \mathrm{CH}_{2}\right), 4.20\left(2 \mathrm{H}, \mathrm{m}, \mathrm{CH}_{2}\right.$ and $\left.\mathrm{C}_{8} \mathrm{H}_{13}-\mathrm{CH}\right), 4.28\left(2 \mathrm{H}, \mathrm{dd}, J_{\mathrm{PH}} 13.8, J_{\mathrm{HH}} 2.9, \mathrm{PCH}\right), 5.55\left(1 \mathrm{H}, \mathrm{m}, \mathrm{C}_{8} \mathrm{H}_{13}-\mathrm{CH}\right)$, $5.85\left(1 \mathrm{H}, \mathrm{t}, J_{\mathrm{HH}} 8.4, J_{\mathrm{PtH}} 64, \mathrm{C}_{8} \mathrm{H}_{13}-\mathrm{CH}\right), 6.53\left(2 \mathrm{H}, \mathrm{dd}, J_{\mathrm{HH}} 8.6,2.6, m-\mathrm{H}\right)$, $6.65\left(1 \mathrm{H}, \mathrm{dd}, J_{\mathrm{HH}} 8.9,2.7, m-\mathrm{H}\right), 6.71\left(1 \mathrm{H}, \mathrm{dd}, J_{\mathrm{HH}} 8.9,2.7, m-\mathrm{H}\right), 6.88(2$ $\left.\mathrm{H}, \mathrm{dd}, J_{\mathrm{HH}} 8.6,1.9, o-\mathrm{H}\right)$ and $8.15(2 \mathrm{H}, \mathrm{m}, o-\mathrm{H}) ; \mathrm{C}\left(150 \mathrm{MHz} ; \mathrm{CDCl}_{3} ; \mathrm{Me}_{4} \mathrm{Si}\right)$ $24.4\left(1 \mathrm{C}, \mathrm{s}, \mathrm{C}_{8} \mathrm{H}_{13}-\mathrm{CH}_{2}\right), 27.2\left(3 \mathrm{C}, \mathrm{d}, J_{\mathrm{PC}} 2.7, \mathrm{CMe}_{\mathbf{3}}\right), 27.8$ (1 C, d, J $J_{\mathrm{PC}} 5.4$, $\mathrm{C}_{8} \mathrm{H}_{13}-\mathrm{CH}_{2}$ ), $28.5\left(1 \mathrm{C}, \mathrm{s}, \mathrm{C}_{8} \mathrm{H}_{13}-\mathrm{CH}_{2}\right), 32.6$ (1 C, d, J $\mathrm{PC}_{4.4} \mathrm{C}_{8} \mathrm{H}_{13}-\mathrm{CH}_{2}$ ), $33.3\left(1 \mathrm{C}, \mathrm{s}, \mathrm{C}_{8} \mathrm{H}_{13}-\mathrm{CH}_{2}\right), 34.5\left(1 \mathrm{C}, \mathrm{d}, J_{\mathrm{PC}} 24.5, \mathrm{CMe}_{3}\right), 40.1\left(2 \mathrm{C}, \mathrm{s}, \mathrm{NMe}_{2}\right)$, $40.23\left(2 \mathrm{C}, \mathrm{s}, \mathrm{NMe}_{2}\right), 41.4\left(1 \mathrm{C}, \mathrm{d}, J_{\mathrm{PC}} 18.4, \mathrm{PCH}\right), 43.0\left(1 \mathrm{C}, \mathrm{d}, J_{\mathrm{PC}} 21.7\right.$, $\mathrm{PCH}), 49.4$ (1 C, s, J $\left.\mathrm{PtC}_{2} 270, \mathrm{C}_{8} \mathrm{H}_{13}-\mathrm{CH}\right), 52.94$ (1 C, s, OMe), 52.99 (1 C, s, OMe), 53.8 (1 C, sept, $\left.J_{\mathrm{FC}} 2.5, \mathrm{CH}\left(\mathrm{SO}_{2} \mathrm{CF}_{3}\right)_{2}\right), 64.0$ (1 C, d, $\left.J_{\mathrm{PC}} 2.6, \mathrm{PCHC}\right)$, $64.2\left(1 \mathrm{C}, \mathrm{d}, J_{\mathrm{PC}} 1.7, \mathrm{PCHC}\right), 64.9\left(1 \mathrm{C}, \mathrm{d}, J_{\mathrm{PC}} 2.9, \mathrm{CH}_{2}\right), 65.3\left(1 \mathrm{C}, \mathrm{s}, \mathrm{CH}_{2}\right)$, 66.9 (1 C, s, NMe), 91.9 (1 C, d, $\left.J_{\mathrm{PC}} 30.7, \mathrm{C}_{8} \mathrm{H}_{13}-\mathrm{CH}\right), 109.6$ (1 C, d, J $J_{\mathrm{PC}} 2.2$, $\left.\mathrm{C}_{8} \mathrm{H}_{13}-\mathrm{CH}\right), 112.1\left(1 \mathrm{C}, \mathrm{s}, m-\mathrm{C}_{6} \mathrm{H}_{4}\right), 112.2\left(1 \mathrm{C}, \mathrm{s}, m-\mathrm{C}_{6} \mathrm{H}_{4}\right), 112.7$ (1 C, s, m$\left.\mathrm{C}_{6} \mathrm{H}_{4}\right), 112.8\left(1 \mathrm{C}, \mathrm{s}, m-\mathrm{C}_{6} \mathrm{H}_{4}\right), 117.8\left(1 \mathrm{C}, \mathrm{s}, \mathrm{C}_{6} \mathrm{H}_{4}\right), 118.3\left(1 \mathrm{C}, \mathrm{s}, \mathrm{C}_{6} \mathrm{H}_{4}\right), 121.3$ $\left(2 \mathrm{C}, \mathrm{q}, J_{\mathrm{FC}} 325.5, \mathrm{CH}\left(\mathrm{SO}_{2} \mathrm{CF}_{3}\right)_{2}\right), 131.3\left(2 \mathrm{C}, \mathrm{d}, J_{\mathrm{PC}} 5.2, o-\mathrm{C}_{6} \mathrm{H}_{4}\right), 132.7(1$ $\left.\mathrm{C}, \mathrm{d}, J_{\mathrm{PC}} 6.3, o-\mathrm{C}_{6} \mathrm{H}_{4}\right), 132.9\left(1 \mathrm{C}, \mathrm{d}, J_{\mathrm{PC}} 5.7, o-\mathrm{C}_{6} \mathrm{H}_{4}\right), 150.6\left(1 \mathrm{C}, \mathrm{s}, p-\mathrm{C}_{6} \mathrm{H}_{4}\right)$, 
150.7 (1 C, s, $\left.p-\mathrm{C}_{6} \mathrm{H}_{4}\right), 166.1$ (1 C, d, J $\left.J_{\mathrm{PC}} 10.5, \mathrm{COO}\right), 166.6$ (1 C, d, J $J_{\mathrm{PC}} 9.9$, COO) and 199.0 (1 C, s, CO); $\mathrm{P}\left(121 \mathrm{MHz} ; \mathrm{CDCl}_{3} ; \mathrm{H}_{3} \mathrm{PO}_{4}\right) 30.7$ (1 P, s, J $J_{\mathrm{PtP}}$ 4010); $\mathrm{N}\left(60 \mathrm{MHz} ; \mathrm{CDCl}_{3} ; \mathrm{MeNO}_{2}\right)-331\left(2 \mathrm{~N}, \mathrm{NMe}_{2}\right)$ and -369 (1 N, NMe); F $\left(282 \mathrm{MHz} ; \mathrm{CDCl}_{3} ; \mathrm{CCl}_{3} \mathrm{~F}\right)-81.0\left(6 \mathrm{~F}, \mathrm{~s}, \mathrm{CH}\left(\mathrm{SO}_{2} \mathrm{CF}_{3}\right)_{2}\right)$.

\section{Compound 90:}

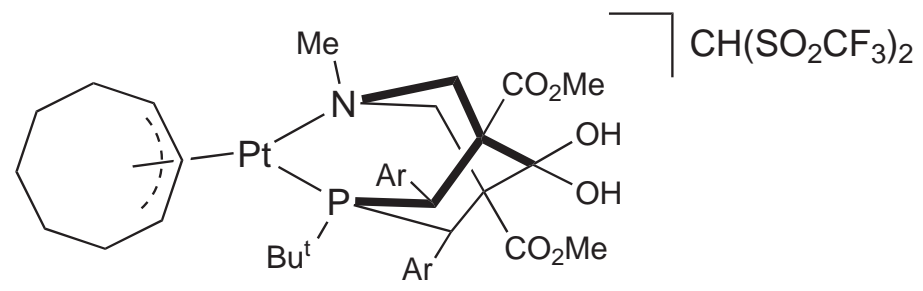

н $\left(600 \mathrm{MHz} ; \mathrm{CDCl}_{3} ; \mathrm{Me}_{4} \mathrm{Si}\right) 0.71\left(9 \mathrm{H}, \mathrm{d}, J_{\mathrm{PH}} 15.4, \mathrm{Bu}^{\mathrm{t}}\right), 1.58(3 \mathrm{H}, \mathrm{m}$, $\left.\mathrm{C}_{8} \mathrm{H}_{13}-\mathrm{CH}_{2}\right), 1.73\left(2 \mathrm{H}, \mathrm{m}, \mathrm{C}_{8} \mathrm{H}_{13}-\mathrm{CH}_{2}\right), 1.83\left(1 \mathrm{H}, \mathrm{m}, \mathrm{C}_{8} \mathrm{H}_{13}-\mathrm{CH}_{2}\right), 1.91$ $\left(1 \mathrm{H}, \mathrm{m}, \mathrm{C}_{8} \mathrm{H}_{13}-\mathrm{CH}_{2}\right), 2.08\left(1 \mathrm{H}, \mathrm{m}, \mathrm{C}_{8} \mathrm{H}_{13}-\mathrm{CH}_{2}\right), 2.30\left(1 \mathrm{H}, \mathrm{m}, \mathrm{C}_{8} \mathrm{H}_{13}-\mathrm{CH}_{2}\right)$, $2.83\left(1 \mathrm{H}, \mathrm{m}, \mathrm{C}_{8} \mathrm{H}_{13}-\mathrm{CH}_{2}\right), 2.91\left(6 \mathrm{H}, \mathrm{s}, \mathrm{NMe}_{2}\right), 2.95$ (6 H, s, $\left.\mathrm{NMe}_{2}\right), 3.15(1$ $\left.\mathrm{H}, \mathrm{d}, J_{\mathrm{HH}} 13.4, \mathrm{CH}_{2}\right), 3.23\left(1 \mathrm{H}, \mathrm{m}, \mathrm{CH}_{2}\right), 3.36(3 \mathrm{H}, \mathrm{s}, \mathrm{OMe}), 3.46(3 \mathrm{H}, \mathrm{s}$, OMe), 3.79 (2 H, dd, $\left.J_{\mathrm{HH}} 13.2,5.4, \mathrm{CH}_{2}\right), 3.98$ (3 H, s, NMe), 4.11 (1 H, d, $\left.J_{\mathrm{HH}} 8.5, \mathrm{C}_{8} \mathrm{H}_{13}-\mathrm{CH}\right), 4.50\left(1 \mathrm{H}, \mathrm{d}, J_{\mathrm{PH}} 14.5, \mathrm{PCH}\right), 4.53\left(1 \mathrm{H}, \mathrm{d}, J_{\mathrm{PH}} 14.5\right.$, PCH), $5.30\left(1 \mathrm{H}, \mathrm{m}, \mathrm{C}_{8} \mathrm{H}_{13}-\mathrm{CH}\right), 5.67\left(1 \mathrm{H}, \mathrm{t}, J_{\mathrm{HH}} 8.0, \mathrm{C}_{8} \mathrm{H}_{13}-\mathrm{CH}\right), 6.49(2 \mathrm{H}$, dd, $\left.J_{\mathrm{HH}} 8.9,2.3, m-\mathrm{H}\right), 6.52(1 \mathrm{H}, \mathrm{s}, \mathrm{OH}), 6.57(1 \mathrm{H}, \mathrm{s} \mathrm{OH}), 6.61\left(1 \mathrm{H}, \mathrm{dd}, J_{\mathrm{HH}}\right.$ 8.6, 2.7, $m-\mathrm{H}), 6.62\left(1 \mathrm{H}, \mathrm{dd}, J_{\mathrm{HH}} 8.6,2.7, m-\mathrm{H}\right), 6.97\left(1 \mathrm{H}, \mathrm{dd}, J_{\mathrm{HH}} 8.6,1.9\right.$, $o-\mathrm{H}), 6.99\left(1 \mathrm{H}, \mathrm{dd}, J_{\mathrm{HH}} 8.6,1.9, o-\mathrm{H}\right)$ and $8.39(2 \mathrm{H}, \mathrm{m}, o-\mathrm{H}) ; \quad \mathrm{C}(150 \mathrm{MHz}$; $\left.\mathrm{CDCl}_{3} ; \mathrm{Me}_{4} \mathrm{Si}\right) 24.6\left(1 \mathrm{C}, \mathrm{s}, \mathrm{C}_{8} \mathrm{H}_{13}-\mathrm{CH}_{2}\right), 27.4\left(3 \mathrm{C}, \mathrm{d}, J_{\mathrm{PC}} 2.6, \mathrm{CMe}_{3}\right), 28.0$ $\left(1 \mathrm{C}, \mathrm{d}, J_{\mathrm{PC}} 5.4, \mathrm{C}_{8} \mathrm{H}_{13}-\mathrm{CH}_{2}\right), 28.7\left(1 \mathrm{C}, \mathrm{s}, \mathrm{C}_{8} \mathrm{H}_{13}-\mathrm{CH}_{2}\right), 32.5$ (1 C, d, J JC 4.4, $\mathrm{C}_{8} \mathrm{H}_{13}-\mathrm{CH}_{2}$ ), $33.2\left(1 \mathrm{C}, \mathrm{s}, \mathrm{C}_{8} \mathrm{H}_{13}-\mathrm{CH}_{2}\right), 34.1$ (1 C, d, J $\left.\mathrm{PC}_{2} 24.5, \mathrm{CMe}_{3}\right), 39.0$ (1 C, d, $\left.J_{\mathrm{PC}} 18.8, \mathrm{PCH}\right), 40.24\left(2 \mathrm{C}, \mathrm{s}, \mathrm{NMe}_{2}\right), 40.3\left(2 \mathrm{C}, \mathrm{s}, \mathrm{NMe}_{2}\right), 40.9(1 \mathrm{C}, \mathrm{d}$, $\left.J_{\mathrm{PC}} 21.4, \mathrm{PCH}\right), 48.4\left(1 \mathrm{C}, \mathrm{s}, J_{\mathrm{PtC}} 268, \mathrm{C}_{8} \mathrm{H}_{13}-\mathrm{CH}\right), 53.0$ (1 C, s, OMe), 53.1 (1 C, s, OMe), $58.2\left(1 \mathrm{C}, \mathrm{d}, J_{\mathrm{PC}} 2.3, \mathrm{PCHC}\right), 58.4$ (1 C, d, J $\left.J_{\mathrm{PC}} 2.5, \mathrm{PCHC}\right)$, 
$59.3\left(1 \mathrm{C}, \mathrm{d}, J_{\mathrm{PC}} 3.0, \mathrm{CH}_{2}\right), 59.7\left(1 \mathrm{C}, \mathrm{s}, \mathrm{CH}_{2}\right), 67.5$ (1 C, s, NMe), $90.2(1$ C, d, $\left.J_{\mathrm{PC}} 29.7, \mathrm{C}_{8} \mathrm{H}_{13}-\mathrm{CH}\right), 94.5\left(1 \mathrm{C}, \mathrm{s}, \mathrm{C}(\mathrm{OH})_{2}\right), 108.6\left(1 \mathrm{C}, \mathrm{s}, \mathrm{C}_{8} \mathrm{H}_{13}-\mathrm{CH}\right)$, $111.36\left(1 \mathrm{C}, \mathrm{s}, m-\mathrm{C}_{6} \mathrm{H}_{4}\right), 111.4\left(1 \mathrm{C}, \mathrm{s}, m-\mathrm{C}_{6} \mathrm{H}_{4}\right), 112.57\left(1 \mathrm{C}, \mathrm{s}, m-\mathrm{C}_{6} \mathrm{H}_{4}\right), 112.6$ $\left(1 \mathrm{C}, \mathrm{s}, m-\mathrm{C}_{6} \mathrm{H}_{4}\right), 119.5\left(1 \mathrm{C}, \mathrm{s}, \mathrm{C}_{6} \mathrm{H}_{4}\right), 119.9\left(1 \mathrm{C}, \mathrm{s}, \mathrm{C}_{6} \mathrm{H}_{4}\right), 130.7\left(1 \mathrm{C}, \mathrm{d}, J_{\mathrm{PC}}\right.$ 7.6, o- $\left.\mathrm{C}_{6} \mathrm{H}_{4}\right), 131.0\left(1 \mathrm{C}, \mathrm{d}, J_{\mathrm{PC}} 7.6, o-\mathrm{C}_{6} \mathrm{H}_{4}\right), 133.2\left(2 \mathrm{C}, \mathrm{d}, J_{\mathrm{PC}} 5.2, o-\mathrm{C}_{6} \mathrm{H}_{4}\right)$, $150.3\left(1 \mathrm{C}, \mathrm{s}, p-\mathrm{C}_{6} \mathrm{H}_{4}\right), 150.4\left(1 \mathrm{C}, \mathrm{s}, p-\mathrm{C}_{6} \mathrm{H}_{4}\right), 170.2\left(1 \mathrm{C}, \mathrm{d}, J_{\mathrm{PC}} 11.3, \mathrm{COO}\right)$ and $170.9\left(1 \mathrm{C}, \mathrm{d}, J_{\mathrm{PC}} 11.7, \mathrm{COO}\right) ; \mathrm{P}\left(121 \mathrm{MHz} ; \mathrm{CDCl}_{3} ; \mathrm{H}_{3} \mathrm{PO}_{4}\right) 28.4(1 \mathrm{P}, \mathrm{s}$, $J_{\mathrm{PtP}}$ 3928).

\section{Protonation of $\left[\mathrm{Pt}\left(\mathrm{C}_{2} \mathrm{H}_{4}\right)_{2} 65\right]$ with $\mathrm{CH}_{2}\left(\mathrm{SO}_{2} \mathrm{CF}_{3}\right)_{2}$}

\section{$(91,92$ and 93$)$}

A solution of PN ligand $65(0.16 \mathrm{~g}, 0.28 \mathrm{mmol})$ in benzene $\left(2 \mathrm{~cm}^{3}\right)$ was added to a Schlenk tube containing $\left[\mathrm{Pt}\left(\mathrm{C}_{2} \mathrm{H}_{4}\right)_{3}\right](0.08 \mathrm{~g}, 0.28 \mathrm{mmol})$ under an ethene atmosphere. The colourless reaction mixture was stirred for $10 \mathrm{~min}$ at room temperature then a solution of $\mathrm{CH}_{2}\left(\mathrm{SO}_{2} \mathrm{CF}_{3}\right)_{2}(0.08 \mathrm{~g}, 0.28 \mathrm{mmol})$ in benzene $\left(0.5 \mathrm{~cm}^{3}\right)$ was added to it. Long-fine colourless needles crystallised out after a few days, which were separated by decanting the solvent under a nitrogen atmosphere and drying in vacuo. The needles were identified as complex 92 (0.06 g, 20\%). The solvent was taken to dryness in vacuo to give compounds 91 and 93 as a brown solid. 


\section{Compound 91:}

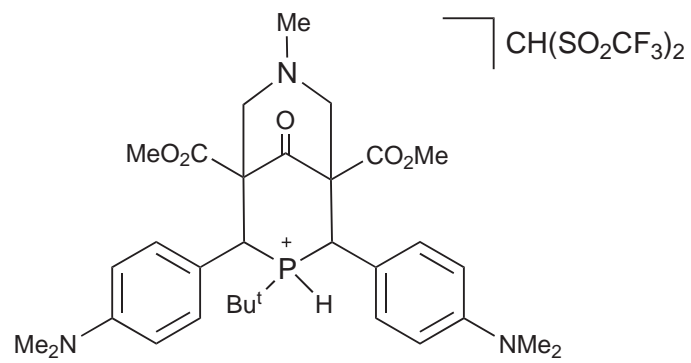

н $\left(500 \mathrm{MHz} ; \mathrm{CD}_{2} \mathrm{Cl}_{2} ; \mathrm{Me}_{4} \mathrm{Si}\right) 0.93\left(9 \mathrm{H}, \mathrm{d}, J_{\mathrm{PH}} 16.4, \mathrm{Bu}^{\mathrm{t}}\right), 2.77(3 \mathrm{H}, \mathrm{s}, \mathrm{NMe})$, $3.01\left(12 \mathrm{H}, \mathrm{s}, \mathrm{NMe}_{2}\right), 3.03\left(2 \mathrm{H}, \mathrm{d}, J_{\mathrm{HH}} 13.4, \mathrm{CH}_{2}\right), 3.13\left(1 \mathrm{H}, \mathrm{s}, \mathrm{CH}\left(\mathrm{SO}_{2} \mathrm{CF}_{3}\right)_{2}\right)$, $3.55\left(2 \mathrm{H}, \mathrm{d}, J_{\mathrm{HH}} 12.9, \mathrm{CH}_{2}\right), 3.76(6 \mathrm{H}, \mathrm{s}, \mathrm{OMe}), 4.48\left(2 \mathrm{H}, \mathrm{dd}, J_{\mathrm{PH}} 14.1, J_{\mathrm{HH}}\right.$ 10.9, $\mathrm{PCH}), 6.70\left(2 \mathrm{H}, \mathrm{dd}, J_{\mathrm{HH}} 8.8,2.2, m-\mathrm{H}\right), 6.92\left(2 \mathrm{H}, \mathrm{dd}, J_{\mathrm{HH}} 8.8,2.2\right.$, $m-\mathrm{H}), 7.10\left(2 \mathrm{H}, \mathrm{dd}, J_{\mathrm{HH}} 8.7,2.3, o-\mathrm{H}\right), 7.44\left(2 \mathrm{H}, \mathrm{dd}, J_{\mathrm{HH}} 8.9,2.3, o-\mathrm{H}\right)$ and $7.78\left(1 \mathrm{H}, \mathrm{dt}, J_{\mathrm{PH}} 546.1, J_{\mathrm{HH}} 10.8, \mathrm{PH}\right) ;{ }_{\mathrm{C}}\left(125 \mathrm{MHz} ; \mathrm{CD}_{2} \mathrm{Cl}_{2} ; \mathrm{Me}_{4} \mathrm{Si}\right) 26.3$ $\left(3 \mathrm{C}, \mathrm{s}, \mathrm{CMe}_{3}\right), 32.6\left(1 \mathrm{C}, \mathrm{d}, J_{\mathrm{PC}} 35.0, \mathrm{CMe}_{3}\right), 38.8\left(2 \mathrm{C}, \mathrm{d}, J_{\mathrm{PC}} 42.2, \mathrm{PCH}\right)$, 39.8 (4 C, s, $\mathrm{NMe}_{2}$ ), 44.2 (1 C, s, NMe), 53.0 (2 C, s, OMe), $59.5\left(2 \mathrm{C}, \mathrm{s}, \mathrm{CH}_{2}\right.$ ), $64.8\left(2 \mathrm{C}, \mathrm{d}, J_{\mathrm{PC}} 1.4, \mathrm{PCHC}\right), 110.0\left(1 \mathrm{C}, \mathrm{s}, \mathrm{CH}\left(\mathrm{SO}_{2} \mathrm{CF}_{3}\right)_{2}\right), 112.7(2 \mathrm{C}, \mathrm{s}$, $\left.m-\mathrm{C}_{6} \mathrm{H}_{4}\right), 113.0\left(2 \mathrm{C}, \mathrm{s}, m-\mathrm{C}_{6} \mathrm{H}_{4}\right), 114.3\left(2 \mathrm{C}, \mathrm{br} s, \mathrm{C}_{6} \mathrm{H}_{4}\right), 121.2\left(2 \mathrm{C}, \mathrm{q}, J_{\mathrm{FC}}\right.$ 324.4, $\mathrm{CH}\left(\mathrm{SO}_{2} \mathrm{CF}_{3}\right)_{2}, 130.3\left(2 \mathrm{C}, \mathrm{d}, J_{\mathrm{PC}} 8.6, o-\mathrm{C}_{6} \mathrm{H}_{4}\right), 132.5\left(2 \mathrm{C}, \mathrm{d}, J_{\mathrm{PC}} 8.6\right.$, $\left.o-\mathrm{C}_{6} \mathrm{H}_{4}\right), 151.2\left(2 \mathrm{C}, \mathrm{s}, p-\mathrm{C}_{6} \mathrm{H}_{4}\right), 166.0\left(2 \mathrm{C}, \mathrm{d}, J_{\mathrm{PC}}\right.$ 13.0, COO) and $199.3(1$ $\left.\mathrm{C}, \mathrm{d}, J_{\mathrm{PC}} 2.9, \mathrm{CO}\right) ; \quad$ p $\left(121 \mathrm{MHz} ; \mathrm{CD}_{2} \mathrm{Cl}_{2} ; \mathrm{H}_{3} \mathrm{PO}_{4}\right) 24.8(1 \mathrm{P}, \mathrm{s}) ; \quad$ F $(282 \mathrm{MHz}$; $\left.\mathrm{CD}_{2} \mathrm{Cl}_{2} ; \mathrm{CCl}_{3} \mathrm{~F}\right)-81.0\left(6 \mathrm{~F}, \mathrm{~s}, \mathrm{CPh}\left(\mathrm{SO}_{2} \mathrm{CF}_{3}\right)_{2}\right)$. 


\section{Compound 92:}

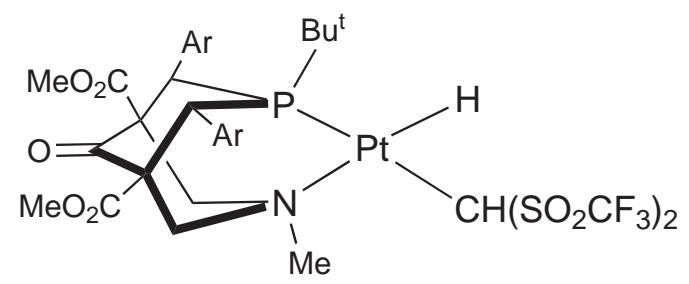

(Found: C, 40.0; H, 4.7; N, 3.8. $\mathrm{C}_{35} \mathrm{H}_{46} \mathrm{~N}_{3} \mathrm{O}_{9} \mathrm{~F}_{6} \mathrm{PS}_{2} \mathrm{Pt}$ requires C, 39.8; H, 4.4; $\mathrm{N}, 4.0 \%) ; \quad \max (\mathrm{KBr}) / \mathrm{cm}^{1} 2250,1746,1611,1261,802 ;$ н $\left(600 \mathrm{MHz} ; \mathrm{CD}_{2} \mathrm{Cl}_{2}\right.$; $\left.\mathrm{Me}_{4} \mathrm{Si}\right)-20.26\left(1 \mathrm{H}\right.$, br s, $\left.J_{\mathrm{PtH}} 1285, \mathrm{Pt}-\mathrm{H}\right), 0.65\left(9 \mathrm{H}, \mathrm{d}, J_{\mathrm{PH}} 16.1, \mathrm{Bu}^{\mathrm{t}}\right), 3.04$ $\left(12 \mathrm{H}, \mathrm{s}, \mathrm{NMe}_{2}\right), 3.20\left(2 \mathrm{H}, \mathrm{d}, J_{\mathrm{HH}} 13.1, \mathrm{CH}_{2}\right), 3.29(3 \mathrm{H}, \mathrm{s}, \mathrm{NMe}), 3.63(6 \mathrm{H}$, s, OMe), $4.14\left(2 \mathrm{H}, \mathrm{d}, J_{\mathrm{HH}} 14.0, \mathrm{CH}_{2}\right), 4.36\left(2 \mathrm{H}, \mathrm{d}, J_{\mathrm{PH}} 13.1, \mathrm{PCH}\right), 5.37$ (1 $\left.\mathrm{H}, \mathrm{d}, J_{\mathrm{PH}} 6.4, J_{\mathrm{PtH}} 64, \mathrm{CH}\left(\mathrm{SO}_{2} \mathrm{CF}_{3}\right)_{2}\right), 6.89\left(2 \mathrm{H}, \mathrm{d}, J_{\mathrm{HH}} 7.7, m-\mathrm{H}\right), 6.91(2$ $\left.\mathrm{H}, \mathrm{d}, J_{\mathrm{HH}} 8.6, m-\mathrm{H}\right), 7.07\left(2 \mathrm{H}, \mathrm{d}, J_{\mathrm{HH}} 7.5, o-\mathrm{H}\right)$ and $9.19\left(2 \mathrm{H}, \mathrm{d}, J_{\mathrm{HH}} 8.2\right.$, $o-\mathrm{H}) ; \quad$ C $\left(150 \mathrm{MHz} ; \mathrm{CD}_{2} \mathrm{Cl}_{2} ; \mathrm{Me}_{4} \mathrm{Si}\right) 26.2\left(3 \mathrm{C}, \mathrm{d}, J_{\mathrm{PC}} 2.5, \mathrm{CMe}_{\mathbf{3}}\right), 32.6(1 \mathrm{C}, \mathrm{d}$, $\left.J_{\mathrm{PC}} 31.7, \mathrm{CMe}_{3}\right), 42.0\left(4 \mathrm{C}, \mathrm{s}, \mathrm{NMe}_{2}\right), 42.2(2 \mathrm{C}, \mathrm{s}, \mathrm{PCH}), 52.6(2 \mathrm{C}, \mathrm{s}, \mathrm{OMe})$, 56.3 (1 C, s, NMe), 63.9 (2 C, s, $\mathrm{CH}_{2}$ ), 64.2 (2 C, s, PCHC), 67.6 (1 C, d, $\left.J_{\mathrm{PC}} 65.9, J_{\mathrm{PtC}} 469, \mathrm{CH}\left(\mathrm{SO}_{2} \mathrm{CF}_{3}\right)_{2}\right), 114.0\left(2 \mathrm{C}\right.$, br s, $\left.m-\mathrm{C}_{6} \mathrm{H}_{4}\right), 114.6(2 \mathrm{C}, \mathrm{br}$ s, $\left.m-\mathrm{C}_{6} \mathrm{H}_{4}\right), 121.0\left(2 \mathrm{C}, \mathrm{q}, J_{\mathrm{FC}} 324.8, \mathrm{CH}\left(\mathrm{SO}_{2} \mathrm{CF}_{3}\right)_{2}, 122.9\left(2 \mathrm{C}\right.\right.$, br s, $\left.\mathrm{C}_{6} \mathrm{H}_{4}\right)$, $132.8\left(2 \mathrm{C}, \mathrm{d}, J_{\mathrm{PC}} 5.3, o-\mathrm{C}_{6} \mathrm{H}_{4}\right), 133.4\left(2 \mathrm{C}, \mathrm{d}, J_{\mathrm{PC}} 5.9, o-\mathrm{C}_{6} \mathrm{H}_{4}\right), 148.5(2 \mathrm{C}, \mathrm{br}$ s, $\left.p-\mathrm{C}_{6} \mathrm{H}_{4}\right), 166.5\left(2 \mathrm{C}\right.$, d, J $\left.J_{\mathrm{PC}} 10.1, \mathrm{COO}\right)$ and $199.9(1 \mathrm{C}, \mathrm{s}, \mathrm{CO})$; $\mathrm{P}(121 \mathrm{MHz}$; $\left.\mathrm{CD}_{2} \mathrm{Cl}_{2} ; \mathrm{H}_{3} \mathrm{PO}_{4}\right) 35.5\left(1 \mathrm{P}, \mathrm{s}, J_{\mathrm{PtP}} 3724\right) ; \mathrm{N}\left(60 \mathrm{MHz} ; \mathrm{CD}_{2} \mathrm{Cl}_{2} ; \mathrm{MeNO}_{2}\right)-332$ $\left(2 \mathrm{~N}, \mathrm{NMe}_{2}\right)$ and $-367(1 \mathrm{~N}, \mathrm{NMe}) ; \mathrm{F}\left(282 \mathrm{MHz} ; \mathrm{CD}_{2} \mathrm{Cl}_{2} ; \mathrm{CCl}_{3} \mathrm{~F}\right)-74.9$ (6 F, s, $\left.J_{\mathrm{PtF}} 24, \mathrm{CPh}\left(\mathrm{SO}_{2} \mathrm{CF}_{3}\right)_{2}\right) ; m / z(\mathrm{ESI}) 777.2739\left([\mathrm{M}]^{+} \cdot \mathrm{C}_{32} \mathrm{H}_{45} \mathrm{~N}_{3} \mathrm{O}_{5} \mathrm{PPt}\right.$ requires $777.2744)$. 


\section{Compound 93:}

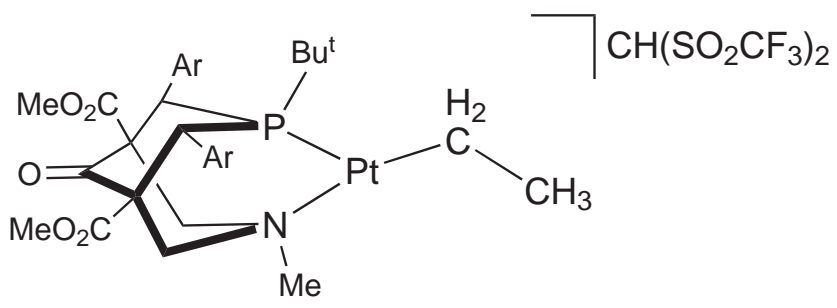

OR

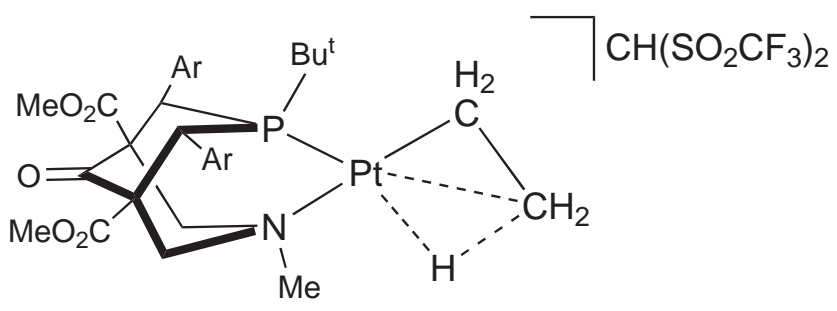

н $\left(500 \mathrm{MHz} ; \mathrm{C}_{6} \mathrm{D}_{6} ; \mathrm{Me}_{4} \mathrm{Si}\right) 0.53\left(9 \mathrm{H}\right.$, br d, $\left.J_{\mathrm{PH}} 14.9, \mathrm{Bu}^{\mathrm{t}}\right), 1.22\left(3 \mathrm{H}, \mathrm{t}, J_{\mathrm{HH}}\right.$ 7.5, Pt- $\left.-\mathrm{CH}_{3}\right), 1.91\left(2 \mathrm{H}, \mathrm{q}, J_{\mathrm{HH}} 6.7, \mathrm{Pt}-\mathrm{CH}_{2}\right), 2.45$ (3 H, s, NMe), 2.51 (12 $\left.\mathrm{H}, \mathrm{s}, \mathrm{NMe}_{2}\right), 2.99\left(2 \mathrm{H}, \mathrm{d}, J_{\mathrm{HH}} 13.9, \mathrm{CH}_{2}\right), 3.30$ (6 H, s, OMe), $3.42(1 \mathrm{H}, \mathrm{s}$, $\left.\mathrm{CH}\left(\mathrm{SO}_{2} \mathrm{CF}_{3}\right)_{2}\right), 4.28\left(4 \mathrm{H}, \mathrm{m}, \mathrm{CH}_{2}\right.$ and $\left.\mathrm{PCH}\right), 6.54\left(2 \mathrm{H}, \mathrm{d}, J_{\mathrm{HH}} 7.6, m-\mathrm{H}\right), 7.01$ $\left(2 \mathrm{H}, \mathrm{dd}, J_{\mathrm{HH}} 8.5,1.7, o-\mathrm{H}\right), 7.25\left(2 \mathrm{H}, \mathrm{d}, J_{\mathrm{HH}} 6.8, m-\mathrm{H}\right)$ and $9.85\left(2 \mathrm{H}, \mathrm{d}, J_{\mathrm{HH}}\right.$ 8.5, o-H); с (125 MHz; $\left.\mathrm{C}_{6} \mathrm{D}_{6} ; \mathrm{Me}_{4} \mathrm{Si}\right) 27.2\left(3 \mathrm{C}\right.$, br s, CMe $\left.\mathrm{CM}_{3}\right), 32.1$ (1 C, d, J $\mathrm{PC}$ 35.0, $\mathrm{CMe}_{3}$ ), 39.4 (4 C, s, $\mathrm{NMe}_{2}$ ), 40.1 (2 C, br s, PCH), 41.0 (1 C, s, NMe), $52.2(2 \mathrm{C}, \mathrm{s}, \mathrm{OMe}), 54.3\left(1 \mathrm{C}, \mathrm{br} \mathrm{s}, \mathrm{CH}\left(\mathrm{SO}_{2} \mathrm{CF}_{3}\right)_{2}\right), 63.0\left(2 \mathrm{C}, \mathrm{s}, \mathrm{CH}_{2}\right), 64.5(2$ C, s, PCHC), $112.6\left(2 \mathrm{C}, \mathrm{s}, m-\mathrm{C}_{6} \mathrm{H}_{4}\right), 113.5\left(2 \mathrm{C}\right.$, br s, $\left.m-\mathrm{C}_{6} \mathrm{H}_{4}\right), 120.1(2 \mathrm{C}$, br s, $\left.\mathrm{C}_{6} \mathrm{H}_{4}\right), 122.2\left(2 \mathrm{C}, \mathrm{q}, J_{\mathrm{FC}} 325.8, \mathrm{CH}\left(\mathrm{SO}_{2} \mathrm{CF}_{3}\right)_{2}, 133.2\left(2 \mathrm{C}, \mathrm{d}, J_{\mathrm{PC}} 5.8\right.\right.$, $\left.o-\mathrm{C}_{6} \mathrm{H}_{4}\right), 133.6\left(2 \mathrm{C}, \mathrm{d}, J_{\mathrm{PC}} 5.8, o-\mathrm{C}_{6} \mathrm{H}_{4}\right), 150.2\left(2 \mathrm{C}\right.$, br s, $\left.p-\mathrm{C}_{6} \mathrm{H}_{4}\right), 166.6(2 \mathrm{C}$, $\left.\mathrm{d}, J_{\mathrm{PC}} 11.0, \mathrm{COO}\right)$ and $200.4(1 \mathrm{C}, \mathrm{s}, \mathrm{CO}) ; \mathrm{p}\left(121 \mathrm{MHz} ; \mathrm{C}_{6} \mathrm{D}_{6} ; \mathrm{H}_{3} \mathrm{PO}_{4}\right) 11.3$ $\left(1 \mathrm{P}, \mathrm{s}, J_{\mathrm{PtP}} 5424\right) ; \quad \mathrm{F}\left(282 \mathrm{MHz} ; \mathrm{C}_{6} \mathrm{D}_{6} ; \mathrm{CCl}_{3} \mathrm{~F}\right)-80.6\left(6 \mathrm{~F}, \mathrm{~s}, \mathrm{CPh}\left(\mathrm{SO}_{2} \mathrm{CF}_{3}\right)_{2}\right)$; $m / z$ (ESI) $805.3057\left([\mathrm{M}]^{+} . \mathrm{C}_{34} \mathrm{H}_{49} \mathrm{~N}_{3} \mathrm{O}_{5} \mathrm{PPt}\right.$ requires 805.3057). 


\section{$\left[\operatorname{Pt}\left(\eta-\mathrm{C}_{7} \mathrm{H}_{11}\right)(65)\right] \mathrm{CPh}\left(\mathrm{SO}_{2} \mathrm{CF}_{3}\right)_{2}(94$ and 95$)$}

[Pt(norb)(65)] (74) (0.20 g, $0.23 \mathrm{mmol})$ was dissolved in benzene $\left(5 \mathrm{~cm}^{3}\right)$ and a solution of $\mathrm{CHPh}\left(\mathrm{SO}_{2} \mathrm{CF}_{3}\right)_{2}(0.08 \mathrm{~g}, 0.23 \mathrm{mmol})$ in benzene $\left(1 \mathrm{~cm}^{3}\right)$ was added. Immediately, lots of white solid formed which redissolved within minutes to give a yellow solution with some brown solid. The reaction mixture was stirred at room temperature for 1 day. The solvent was removed in vacuo to give a pale brown solid. This was crystallised from $\mathrm{CH}_{2} \mathrm{Cl}_{2}$ /ether to produce a white solid (0.20 g, 71\%) consisting of the ketone $(\mathbf{9 4})$ and hydrate $(\mathbf{9 5})$ forms in a 7:1 ratio. (Found: C, 46.2; H, 4.9; N, 3.4. $\mathrm{C}_{48} \mathrm{H}_{60} \mathrm{~N}_{3} \mathrm{O}_{9} \mathrm{~F}_{6} \mathrm{PS}_{2}$ Pt requires C, 46.9; H, 4.9; $\mathrm{N}, 3.4 \%) ; \quad \max (\mathrm{KBr}) / \mathrm{cm}^{1} 3424,1739,1610,1521,1344,1182,605 ; \mathrm{m} / z(\mathrm{ESI})$ $871.3537\left([\mathrm{M}]^{+} . \mathrm{C}_{39} \mathrm{H}_{55} \mathrm{~N}_{3} \mathrm{O}_{5} \mathrm{PPt}\right.$ requires 871.3527).

\section{Compound 94:}

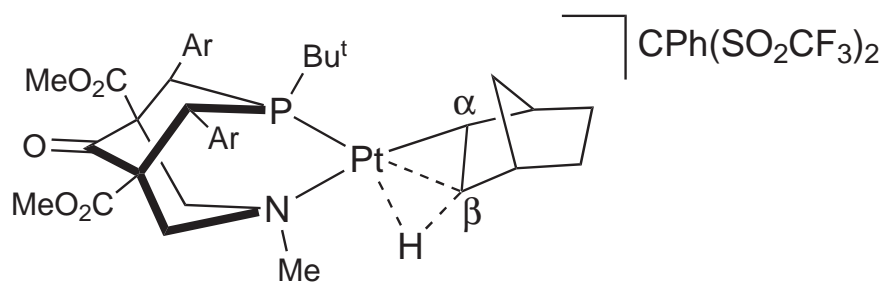

н $\left(600 \mathrm{MHz} ; \mathrm{CD}_{2} \mathrm{Cl}_{2} ; \mathrm{Me}_{4} \mathrm{Si}\right)-1.06\left(1 \mathrm{H}, \mathrm{dd}, J_{\mathrm{PH}} 50.3, J_{\mathrm{HH}} 13.6, \mathrm{PtH}\right), 0.76$ (9 $\left.\mathrm{H}, \mathrm{d}, J_{\mathrm{PH}} 16.8, \mathrm{Bu}^{\mathrm{t}}\right), 1.20-1.81\left(8 \mathrm{H}, \mathrm{m}, \mathrm{C}_{7} \mathrm{H}_{11}-\mathrm{CH}_{2}, \mathrm{C}_{7} \mathrm{H}_{11}-\mathrm{CH}\right.$ and $\left.\mathrm{C} \mathrm{H}\right), 2.48$ (1 H, br s, $\left.\mathrm{C}_{7} \mathrm{H}_{11}-\mathrm{CH}\right), 2.96\left(12 \mathrm{H}, \mathrm{s}, \mathrm{NMe}_{2}\right), 3.12(1 \mathrm{H}$, br s, C H), $3.24(2 \mathrm{H}, \mathrm{d}$, $J_{\mathrm{HH}}$ 13.6, $\left.\mathrm{CH}_{2}\right), 3.63$ (3 H, s, OMe), 3.65 (3 H, s, OMe), 3.77 (3 H, br s, NMe), $4.12\left(2 \mathrm{H}, \mathrm{d}, J_{\mathrm{HH}} 13.8, \mathrm{CH}_{2}\right), 4.38(2 \mathrm{H}, \mathrm{m}, \mathrm{PCH}), 6.61\left(1 \mathrm{H}, \mathrm{dd}, J_{\mathrm{HH}} 8.8,2.4\right.$, $m-\mathrm{H}), 6.65\left(1 \mathrm{H}, \mathrm{dd}, J_{\mathrm{HH}} 8.8,2.6, m-\mathrm{H}\right), 6.67\left(1 \mathrm{H}, \mathrm{dd}, J_{\mathrm{HH}} 8.8,2.6, m-\mathrm{H}\right), 6.70$ $\left(1 \mathrm{H}, \mathrm{dd}, J_{\mathrm{HH}} 8.8,2.4, m-\mathrm{H}\right), 7.00\left(1 \mathrm{H}, \mathrm{d}, J_{\mathrm{HH}} 7.0, o-\mathrm{H}\right), 7.01\left(1 \mathrm{H}, \mathrm{d}, J_{\mathrm{HH}} 7.0\right.$, $o-\mathrm{H}), 7.28\left(3 \mathrm{H}, \mathrm{m}, \mathrm{CPh}\left(\mathrm{SO}_{2} \mathrm{CF}_{3}\right)_{2}\right), 7.44\left(2 \mathrm{H}, \mathrm{m}, \mathrm{CPh}\left(\mathrm{SO}_{2} \mathrm{CF}_{3}\right)_{2}\right), 8.56(1 \mathrm{H}$, $\left.\mathrm{d}, J_{\mathrm{HH}} 9.7, o-\mathrm{H}\right)$ and $8.57\left(1 \mathrm{H}, \mathrm{d}, J_{\mathrm{HH}} 9.7, o-\mathrm{H}\right) ; \mathrm{C}\left(150 \mathrm{MHz} ; \mathrm{CD}_{2} \mathrm{Cl}_{2} ; \mathrm{Me}_{4} \mathrm{Si}\right)$ 26.3 (1 C, br s, C ), 26.7 (3 C, d, J $J_{\mathrm{PH}}$ 1.7, $\left.\mathrm{CMe}_{3}\right), 27.7\left(2 \mathrm{C}, \mathrm{br} \mathrm{s}, \mathrm{C}_{7} \mathrm{H}_{11}-\mathrm{CH}_{2}\right)$, 
28.0 (1 C, br s, $\mathrm{C}_{7} \mathrm{H}_{11}-\mathrm{CH}$ ), 36.4 (1 C, d, J $J_{\mathrm{PC}} 29.8, \mathrm{CMe}_{3}$ ), 38.7 (1 C, s, C ), $39.2\left(1 \mathrm{C}, \mathrm{s}, \mathrm{C}_{7} \mathrm{H}_{11}-\mathrm{CH}_{2}\right.$ ), 39.8 (4 C, s, $\mathrm{NMe}_{2}$ ), 41.1 (1 C, d, J $\left.J_{\mathrm{PC}} 27.0, \mathrm{PCH}\right)$, $41.2\left(1 \mathrm{C}\right.$, br s, $\left.\mathrm{C}_{7} \mathrm{H}_{11}-\mathrm{CH}\right), 42.1$ (1 C, d, J $\left.\mathrm{PC} 27.0, \mathrm{PCH}\right), 52.69$ (1 C, s, OMe), 52.72 (1 C, s, OMe), 62.8 (1 C, s, NMe), 63.6 (1 C, s, $\mathrm{CH}_{2}$ ), 64.0 (2 C, br s, PCHC), 64.1 (1 C, s, $\left.\mathrm{CH}_{2}\right), 69.7$ (1 C, sept, $\left.J_{\mathrm{FC}} 2.5, \mathrm{CPh}\left(\mathrm{SO}_{2} \mathrm{CF}_{3}\right)_{2}\right), 111.1(1$ C, s, $\left.m-\mathrm{C}_{6} \mathrm{H}_{4}\right), 112.0\left(1 \mathrm{C}, \mathrm{s}, m-\mathrm{C}_{6} \mathrm{H}_{4}\right), 112.3\left(1 \mathrm{C}, \mathrm{s}, m-\mathrm{C}_{6} \mathrm{H}_{4}\right), 112.5(1 \mathrm{C}, \mathrm{s}, m-$ $\left.\mathrm{C}_{6} \mathrm{H}_{4}\right), 121.9\left(2 \mathrm{C}, \mathrm{q}, J_{\mathrm{FC}} 328.7, \mathrm{CH}\left(\mathrm{SO}_{2} \mathrm{CF}_{3}\right)_{2}, 116.9\left(1 \mathrm{C}, \mathrm{s}, \mathrm{C}_{6} \mathrm{H}_{4}\right), 117.3(1 \mathrm{C}\right.$, s, $\left.\mathrm{C}_{6} \mathrm{H}_{4}\right), 127.4\left(2 \mathrm{C}, \mathrm{s}, \mathrm{CPh}\left(\mathrm{SO}_{2} \mathrm{CF}_{3}\right)_{2}\right), 131.0\left(1 \mathrm{C}, \mathrm{d}, J_{\mathrm{PC}} 5.9, o-\mathrm{C}_{6} \mathrm{H}_{4}\right), 131.1$ $\left(1 \mathrm{C}, \mathrm{d}, J_{\mathrm{PC}} 6.6, o-\mathrm{C}_{6} \mathrm{H}_{4}\right), 131.6\left(1 \mathrm{C}, \mathrm{s}, \mathrm{CPh}\left(\mathrm{SO}_{2} \mathrm{CF}_{3}\right)_{2}\right), 133.1$ (1 C, d, J $J_{\mathrm{PC}} 6.1$, $\left.o-\mathrm{C}_{6} \mathrm{H}_{4}\right), 133.2\left(1 \mathrm{C}, \mathrm{d}, J_{\mathrm{PC}} 6.0, o-\mathrm{C}_{6} \mathrm{H}_{4}\right), 136.2\left(2 \mathrm{C}, \mathrm{s}, \mathrm{CPh}\left(\mathrm{SO}_{2} \mathrm{CF}_{3}\right)_{2}\right), 150.7$ $\left(1 \mathrm{C}, \mathrm{s}, p-\mathrm{C}_{6} \mathrm{H}_{4}\right), 150.8$ (1 C, s, p- $\left.\mathrm{C}_{6} \mathrm{H}_{4}\right), 166.0$ (1 C, d, J $\mathrm{PC}_{10.7}$ COO), 166.2 $\left(1 \mathrm{C}, \mathrm{d}, J_{\mathrm{PC}} 10.7, \mathrm{COO}\right)$ and $198.6(1 \mathrm{C}, \mathrm{s}, \mathrm{CO}) ; \mathrm{p}\left(121 \mathrm{MHz} ; \mathrm{CD}_{2} \mathrm{Cl}_{2} ; \mathrm{H}_{3} \mathrm{PO}_{4}\right)$ $33.8\left(1 \mathrm{P}, \mathrm{s}, J_{\mathrm{PtP}} 6008\right) ; \mathrm{N}\left(60 \mathrm{MHz} ; \mathrm{CD}_{2} \mathrm{Cl}_{2} ; \mathrm{MeNO}_{2}\right)-332\left(2 \mathrm{~N}, \mathrm{NMe}_{2}\right)$ and $-355(1 \mathrm{~N}, \mathrm{NMe}) ; \quad \mathrm{F}\left(282 \mathrm{MHz} ; \mathrm{CD}_{2} \mathrm{Cl}_{2} ; \mathrm{CCl}_{3} \mathrm{~F}\right)-78.6\left(6 \mathrm{~F}, \mathrm{~s}, \mathrm{CPh}\left(\mathrm{SO}_{2} \mathrm{CF}_{3}\right)_{2}\right)$.

\section{Compound 95:}

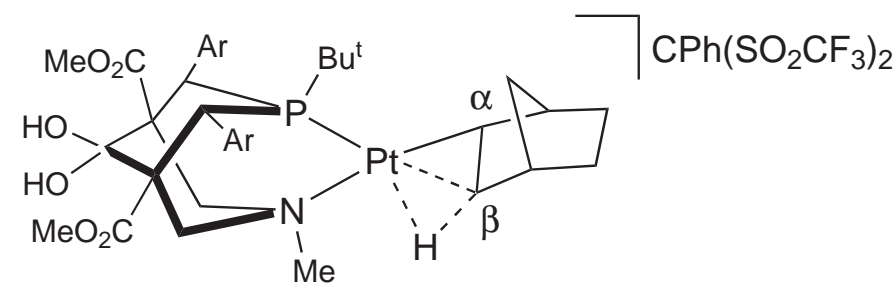

н $\left(600 \mathrm{MHz} ; \mathrm{CD}_{2} \mathrm{Cl}_{2} ; \mathrm{Me}_{4} \mathrm{Si}\right)-1.18\left(1 \mathrm{H}, \mathrm{dd}, J_{\mathrm{PH}} 48.5, J_{\mathrm{HH}} 13.0, \mathrm{PtH}\right), 0.75$ $\left(9 \mathrm{H}, \mathrm{d}, J_{\mathrm{PH}} 16.5, \mathrm{Bu}^{\mathrm{t}}\right), 1.20-1.81\left(8 \mathrm{H}, \mathrm{m}, \mathrm{C}_{7} \mathrm{H}_{11}-\mathrm{CH}_{2}, \mathrm{C}_{7} \mathrm{H}_{11}-\mathrm{CH}\right.$ and $\left.\mathrm{C} \mathrm{H}\right)$, 2.35 (1 H, br s, $\left.\mathrm{C}_{7} \mathrm{H}_{11}-\mathrm{CH}\right), 2.95\left(12 \mathrm{H}, \mathrm{s}, \mathrm{NMe}_{2}\right), 3.06$ (1 H, br s, C H), 3.20 $\left(2 \mathrm{H}, \mathrm{d}, J_{\mathrm{HH}} 13.2, \mathrm{CH}_{2}\right), 3.43(3 \mathrm{H}, \mathrm{s}, \mathrm{OMe}), 3.46$ (3 H, s, OMe), 3.71 (3 H, br s, NMe), $3.75\left(2 \mathrm{H}, \mathrm{m}, \mathrm{CH}_{2}\right), 4.57\left(1 \mathrm{H}, \mathrm{d}, J_{\mathrm{PH}} 14.5, \mathrm{PCH}\right), 4.62\left(1 \mathrm{H}, \mathrm{d}, J_{\mathrm{PH}}\right.$ 14.5, PCH), $6.19(1 \mathrm{H}, \mathrm{s}, \mathrm{OH}), 6.48(1 \mathrm{H}, \mathrm{s}, \mathrm{OH}), 6.61\left(1 \mathrm{H}, \mathrm{dd}, J_{\mathrm{HH}} 8.8,2.4\right.$, $m-\mathrm{H}), 6.65\left(1 \mathrm{H}, \mathrm{dd}, J_{\mathrm{HH}} 8.8,2.6, m-\mathrm{H}\right), 6.67$ (1 H, dd, $\left.J_{\mathrm{HH}} 8.8,2.6, m-\mathrm{H}\right), 6.70$ 
$\left(1 \mathrm{H}, \mathrm{dd}, J_{\mathrm{HH}} 8.8,2.4, m-\mathrm{H}\right), 7.00\left(1 \mathrm{H}, \mathrm{d}, J_{\mathrm{HH}} 7.0, o-\mathrm{H}\right), 7.01\left(1 \mathrm{H}, \mathrm{d}, J_{\mathrm{HH}}\right.$ 7.0, o- $\mathrm{H}), 7.28\left(3 \mathrm{H}, \mathrm{m}, \mathrm{CPh}\left(\mathrm{SO}_{2} \mathrm{CF}_{3}\right)_{2}\right), 7.44\left(2 \mathrm{H}, \mathrm{m}, \mathrm{CPh}\left(\mathrm{SO}_{2} \mathrm{CF}_{3}\right)_{2}\right), 8.61$ $\left(1 \mathrm{H}, \mathrm{d}, J_{\mathrm{HH}} 9.2, o-\mathrm{H}\right)$ and $8.63\left(1 \mathrm{H}, \mathrm{d}, J_{\mathrm{HH}} 9.2, o-\mathrm{H}\right) ; \mathrm{C}\left(150 \mathrm{MHz} ; \mathrm{CD}_{2} \mathrm{Cl}_{2}\right.$; $\left.\mathrm{Me}_{4} \mathrm{Si}\right) 25.7$ (1 C, br s, C ), 26.7 (3 C, d, J $J_{\mathrm{PH}}$ 1.7, $\mathrm{CMe}_{3}$ ), 27.0-28.0 (4 C, m, $\mathrm{C}_{7} \mathrm{H}_{11}-\mathrm{CH}_{2}$ and $\left.\mathrm{C}_{7} \mathrm{H}_{11}-\mathrm{CH}\right), 36.0$ (1 C, d, J $J_{\mathrm{PC}} 29.8, \mathrm{CMe}_{3}$ ), 38.4 (1 C, s, C ), 39.1 (1 C, m, PCH), 39.9 (4 C, s, $\mathrm{NMe}_{2}$ ), 40.2 (1 C, d, J $\left.\mathrm{PC} 26.7, \mathrm{PCH}\right), 43.3$ (1 C, br s, $\left.\mathrm{C}_{7} \mathrm{H}_{11}-\mathrm{CH}\right), 52.8$ (2 C, s, OMe), 58.0 (1 C, br s, $\mathrm{CH}_{2}$ ), 58.3 (1 C, br s, PCHC), 58.5 (2 C, br s, PCHC and $\mathrm{CH}_{2}$ ), 63.2 (1 C, s, NMe), 69.7 (1 C, sept, $\left.J_{\mathrm{FC}} 2.5, \mathrm{CPh}\left(\mathrm{SO}_{2} \mathrm{CF}_{3}\right)_{2}\right), 94.1\left(1 \mathrm{C}, \mathrm{s}, \mathrm{C}(\mathrm{OH})_{2}\right), 111.1\left(1 \mathrm{C}, \mathrm{s}, m-\mathrm{C}_{6} \mathrm{H}_{4}\right), 112.0$ $\left(1 \mathrm{C}, \mathrm{s}, m-\mathrm{C}_{6} \mathrm{H}_{4}\right), 112.3\left(1 \mathrm{C}, \mathrm{s}, m-\mathrm{C}_{6} \mathrm{H}_{4}\right), 112.5\left(1 \mathrm{C}, \mathrm{s}, m-\mathrm{C}_{6} \mathrm{H}_{4}\right), 118.6(1 \mathrm{C}, \mathrm{s}$, $\left.\mathrm{C}_{6} \mathrm{H}_{4}\right), 118.9\left(1 \mathrm{C}\right.$, br s, $\left.\mathrm{C}_{6} \mathrm{H}_{4}\right), 121.9$ (2 C, q, J $\mathrm{FC}_{328.7,} \mathrm{CH}\left(\mathrm{SO}_{2} \mathrm{CF}_{3}\right)_{2}, 127.4$ $\left(2 \mathrm{C}, \mathrm{s}, \mathrm{CPh}\left(\mathrm{SO}_{2} \mathrm{CF}_{3}\right)_{2}\right), 131.0\left(1 \mathrm{C}, \mathrm{d}, J_{\mathrm{PC}} 5.9, o_{-} \mathrm{C}_{6} \mathrm{H}_{4}\right), 131.1\left(1 \mathrm{C}, \mathrm{d}, J_{\mathrm{PC}}\right.$ 6.6, o- $\left.\mathrm{C}_{6} \mathrm{H}_{4}\right), 131.6\left(1 \mathrm{C}, \mathrm{s}, \mathrm{CPh}\left(\mathrm{SO}_{2} \mathrm{CF}_{3}\right)_{2}\right), 133.1$ (1 C, d, J $\left.J_{\mathrm{PC}} 6.1, o-\mathrm{C}_{6} \mathrm{H}_{4}\right)$, $133.2\left(1 \mathrm{C}, \mathrm{d}, J_{\mathrm{PC}} 6.0, o-\mathrm{C}_{6} \mathrm{H}_{4}\right), 136.2\left(2 \mathrm{C}, \mathrm{s}, \mathrm{CPh}\left(\mathrm{SO}_{2} \mathrm{CF}_{3}\right)_{2}\right), 150.5(2 \mathrm{C}, \mathrm{br}$ s, $\left.p-\mathrm{C}_{6} \mathrm{H}_{4}\right)$ and $169.9(2 \mathrm{C}, \mathrm{m}, \mathrm{COO}) ; \quad \mathrm{P}\left(121 \mathrm{MHz} ; \mathrm{CD}_{2} \mathrm{Cl}_{2} ; \mathrm{H}_{3} \mathrm{PO}_{4}\right) 31.6(1 \mathrm{P}$, s, $\left.J_{\mathrm{PtP}} 5886\right) ; \mathrm{N}\left(60 \mathrm{MHz} ; \mathrm{CD}_{2} \mathrm{Cl}_{2} ; \mathrm{MeNO}_{2}\right)-332\left(2 \mathrm{~N}, \mathrm{NMe}_{2}\right)$ and $-355(1 \mathrm{~N}$, $\mathrm{NMe}) ; \quad$ F $\left(282 \mathrm{MHz} ; \mathrm{CD}_{2} \mathrm{Cl}_{2} ; \mathrm{CCl}_{3} \mathrm{~F}\right)-78.6\left(6 \mathrm{~F}, \mathrm{~s}, \mathrm{CPh}\left(\mathrm{SO}_{2} \mathrm{CF}_{3}\right)_{2}\right)$. 


\section{trans- $\left[\mathrm{Pt}_{2}(\mu-\mathrm{OH})_{2}(65-\mathrm{H})_{2}\right](98)$ and cis- $\left[\mathrm{Pt}_{2}(\mu-\mathrm{OH})_{2}(65-\mathrm{H})_{2}\right](101)$}

NMR scale experiment: A solution of PN compound 65 (0.06 g, $0.10 \mathrm{mmol})$ in benzene- $\mathrm{d}_{6}\left(0.5 \mathrm{~cm}^{3}\right)$ was added to a Schlenk tube containing $\left[\mathrm{Pt}\left(\mathrm{C}_{2} \mathrm{H}_{4}\right)_{3}\right]$ (0.03 g, $0.10 \mathrm{mmol})$ under an ethene atmosphere. The colourless solution was then transferred into a NMR tube and was left at room temperature for 1 day to allow the formation of complex 76. Hydrogen gas was then bubbled through the pale yellow solution, which darkened overtime and some fine black suspension formed. After 20 days the synthesis of complexes 98 and 101 was complete, in which they formed in a 1:1 ratio. This sample was used to obtain all NMR data.

Large scale experiment: PN compound 65 (0.14 g, $0.25 \mathrm{mmol})$ and $\left[\mathrm{Pt}\left(\mathrm{C}_{2} \mathrm{H}_{4}\right)_{3}\right](0.07 \mathrm{~g}, 0.28 \mathrm{mmol})$ were combined in benzene $\left(4 \mathrm{~cm}^{3}\right)$ under an ethene atmosphere in a Fischer-Porter vessel. The yellow reaction mixture was stirred at room temperature for 2 days. An aliquot was removed from the reaction mixture and was analysed by ${ }^{1} \mathrm{H}$ and ${ }^{31} \mathrm{P}$ NMR. The spectra indicated that the dimetallated ethene precursor 76 had been formed. Hydrogen gas was then bubbled through the reaction mixture, and the vessel was sealed for 20 days. Another aliquot was taken and analysed by NMR, which indicated the formation of complexes 98 and 101. The pale yellow reaction mixture was transferred into a Schlenk tube under a nitrogen atmosphere, and the volume was reduced. The slow diffusion of diethyl ether into the benzene solution at $5 \mathrm{C}$ produced large yellow crystals of complex 98, which were used for $X$-ray crystallography, IR and mass spectrometry and elemental analysis. Small yellow crystals and some pale brown solid were also obtained of complex 101. 


\section{Compound 98:}

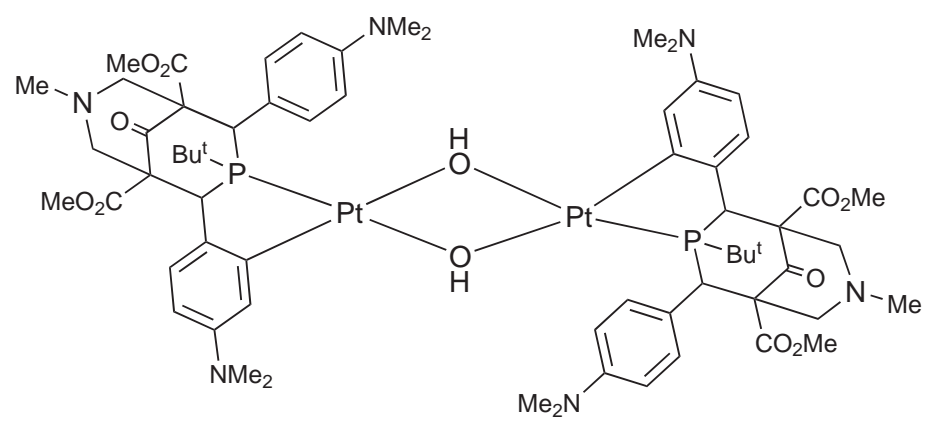

(Found: C, 48.7; H, 5.4; N, 5.1. $\mathrm{C}_{64} \mathrm{H}_{88} \mathrm{~N}_{6} \mathrm{O}_{12} \mathrm{P}_{2} \mathrm{Pt}_{2}$ requires $\mathrm{C}$, 48.5; H, 5.6; $\mathrm{N}, 5.3 \%) ; \quad \max (\mathrm{KBr}) / \mathrm{cm}^{1} 3564,1739,1707,1610,1521,1249 ; \quad$ н $(600 \mathrm{MHz}$; $\left.\mathrm{C}_{6} \mathrm{D}_{6} ; \mathrm{Me}_{4} \mathrm{Si}\right)-0.62\left(1 \mathrm{H}, \mathrm{d}, J_{\mathrm{PH}} 3.1, \mathrm{OH}\right), 1.47\left(9 \mathrm{H}, \mathrm{d}, J_{\mathrm{PH}} 13.6, \mathrm{Bu}^{\mathrm{t}}\right), 1.87(3$ H, s, NMe), 2.37 (6 H, s, $\left.\mathrm{NMe}_{2}\right), 2.63\left(6 \mathrm{H}, \mathrm{s}, \mathrm{NMe}_{2}\right), 2.71\left(1 \mathrm{H}, \mathrm{m}, \mathrm{CH}_{2}\right), 2.82$ $\left(1 \mathrm{H}, \mathrm{m}, \mathrm{CH}_{2}\right), 3.09\left(1 \mathrm{H}, \mathrm{m}, \mathrm{CH}_{2}\right), 3.26(3 \mathrm{H}, \mathrm{s}, \mathrm{OMe}), 3.30\left(1 \mathrm{H}, \mathrm{m}, \mathrm{CH}_{2}\right)$, $3.48(3 \mathrm{H}, \mathrm{s}, \mathrm{OMe}), 4.95\left(1 \mathrm{H}, \mathrm{d}, J_{\mathrm{PH}} 9.8, \mathrm{PCH}\right), 5.07$ (1 H, d, $\left.J_{\mathrm{PH}} 13.2, \mathrm{PCH}\right)$, $6.43(2 \mathrm{H}, \mathrm{m}, m-\mathrm{H}), 6.57\left(1 \mathrm{H}, \mathrm{d}, J_{\mathrm{HH}} 2.1, m-\mathrm{H}\right), 6.64\left(1 \mathrm{H}, \mathrm{dd}, J_{\mathrm{HH}} 8.9,2.7\right.$, $m-\mathrm{H}), 6.88\left(1 \mathrm{H}, \mathrm{d}, J_{\mathrm{HH}} 8.3, o-\mathrm{H}\right), 7.30\left(1 \mathrm{H}, \mathrm{d}, J_{\mathrm{HH}} 8.3, o-\mathrm{H}\right)$ and $9.10(1 \mathrm{H}$, d, $\left.J_{\mathrm{HH}} 8.1, o-\mathrm{H}\right) ; \quad$ с $\left(150 \mathrm{MHz} ; \mathrm{C}_{6} \mathrm{D}_{6} ; \mathrm{Me}_{4} \mathrm{Si}\right) 26.4\left(3 \mathrm{C}, \mathrm{br} \mathrm{s}, \mathrm{CMe}_{3}\right), 35.8(1$ C, d, $\left.J_{\mathrm{PC}} 32.3, \mathrm{CMe}_{3}\right), 39.5\left(2 \mathrm{C}, \mathrm{s}, \mathrm{NMe}_{2}\right), 40.6\left(2 \mathrm{C}, \mathrm{s}, \mathrm{NMe}_{2}\right), 41.9(1 \mathrm{C}$, d, $\left.J_{\mathrm{PC}} 26.6, \mathrm{PCH}\right), 43.8$ (1 C, s, NMe), 47.9 (1 C, d, J $\left.J_{\mathrm{PC}} 33.2, \mathrm{PCH}\right), 52.09$ (1 C, s, OMe), 52.4 (1 C, s, OMe), $59.5\left(1 \mathrm{C}, \mathrm{s}, \mathrm{CH}_{2}\right), 59.8$ (1 C, s, $\left.\mathrm{CH}_{2}\right), 65.0$ (1 C, d, $\left.J_{\mathrm{PC}} 2.9, \mathrm{PCHC}\right), 65.1$ (1 C, d, $\left.J_{\mathrm{PC}} 1.0, \mathrm{PCHC}\right), 109.2\left(2 \mathrm{C}, \mathrm{s}, m-\mathrm{C}_{6} \mathrm{H}_{4}\right)$, $111.5\left(1 \mathrm{C}, \mathrm{s}, m-\mathrm{C}_{6} \mathrm{H}_{4}\right), 115.9\left(1 \mathrm{C}, \mathrm{s}, m-\mathrm{C}_{6} \mathrm{H}_{4}\right), 122.2\left(1 \mathrm{C}, \mathrm{s}, o-\mathrm{C}_{6} \mathrm{H}_{4}\right), 123.1(1$ $\left.\mathrm{C}, \mathrm{d}, J_{\mathrm{PC}} 17.7, \mathrm{C}_{6} \mathrm{H}_{4}\right), 133.1\left(1 \mathrm{C}, \mathrm{d}, J_{\mathrm{PC}} 7.5, o-\mathrm{C}_{6} \mathrm{H}_{4}\right), 135.8\left(1 \mathrm{C}, \mathrm{d}, J_{\mathrm{PC}} 8.1\right.$, $\left.o-\mathrm{C}_{6} \mathrm{H}_{4}\right), 138.3\left(1 \mathrm{C}, \mathrm{d}, J_{\mathrm{PC}} 4.1, \mathrm{C}_{6} \mathrm{H}_{4}\right), 138.7$ (1 C, d, J $\left.J_{\mathrm{PC}} 15.9, \mathrm{C}_{6} \mathrm{H}_{4}\right), 147.1$ $\left(1 \mathrm{C}, \mathrm{s}, p-\mathrm{C}_{6} \mathrm{H}_{4}\right), 149.9\left(1 \mathrm{C}, \mathrm{s}, p-\mathrm{C}_{6} \mathrm{H}_{4}\right), 168.8$ (1 C, d, J $\left.J_{\mathrm{PC}} 8.1, \mathrm{COO}\right), 170.6$ $\left(1 \mathrm{C}, \mathrm{d}, J_{\mathrm{PC}} 8.3, \mathrm{COO}\right)$ and $205.9\left(1 \mathrm{C}, \mathrm{d}, J_{\mathrm{PC}} 6.4, \mathrm{CO}\right) ; \mathrm{p}\left(121 \mathrm{MHz} ; \mathrm{C}_{6} \mathrm{D}_{6}\right.$; $\left.\mathrm{H}_{3} \mathrm{PO}_{4}\right) 49.9\left(1 \mathrm{P}, \mathrm{s}, J_{\mathrm{PtP}} 4851\right)$; $\mathrm{N}\left(60 \mathrm{MHz} ; \mathrm{C}_{6} \mathrm{D}_{6} ; \mathrm{MeNO}_{2}\right)-333\left(2 \mathrm{~N}, \mathrm{NMe}_{2}\right)$ and -355 (1 N, NMe); $m / z$ (ESI) $1585.5349\left([\mathrm{M}]^{+} \cdot \mathrm{C}_{64} \mathrm{H}_{89} \mathrm{~N}_{6} \mathrm{O}_{12} \mathrm{P}_{2} \mathrm{Pt}_{2}\right.$ requires 
$1585.5308)$.

\section{Compound 101:}

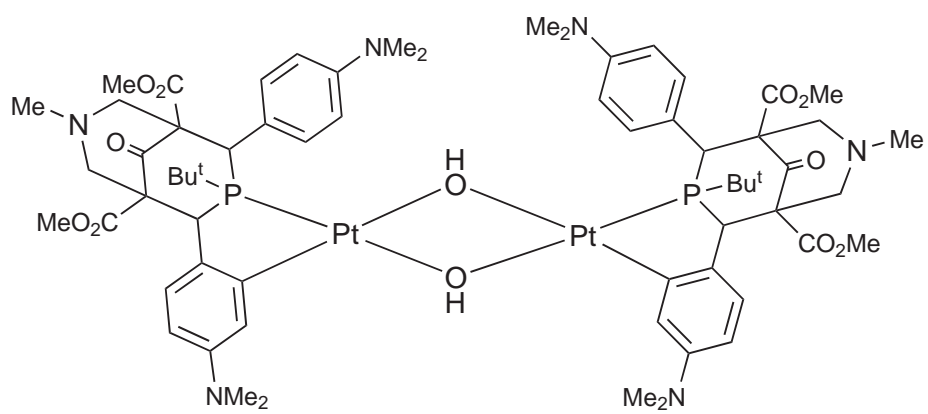

н $\left(600 \mathrm{MHz} ; \mathrm{C}_{6} \mathrm{D}_{6} ; \mathrm{Me}_{4} \mathrm{Si}\right) 0.06\left(1 \mathrm{H}, \mathrm{d}, J_{\mathrm{PH}} 1.9, \mathrm{OH}\right), 1.15\left(9 \mathrm{H}, \mathrm{d}, J_{\mathrm{PH}}\right.$ 13.6, $\left.\mathrm{Bu}^{\mathrm{t}}\right), 2.40\left(6 \mathrm{H}, \mathrm{s}, \mathrm{NMe}_{2}\right), 2.52\left(6 \mathrm{H}, \mathrm{s}, \mathrm{NMe}_{2}\right), 2.60$ (3 H, s, NMe), $2.94(1 \mathrm{H}$, m, $\left.\mathrm{CH}_{2}\right), 3.18\left(1 \mathrm{H}, \mathrm{m}, \mathrm{CH}_{2}\right), 3.30\left(1 \mathrm{H}, \mathrm{m}, \mathrm{CH}_{2}\right), 3.35(3 \mathrm{H}, \mathrm{s}, \mathrm{OMe}), 3.50(1 \mathrm{H}$, m, $\left.\mathrm{CH}_{2}\right), 3.55$ (3 H, s, OMe), $4.70\left(1 \mathrm{H}, \mathrm{d}, J_{\mathrm{PH}} 10.7, \mathrm{PCH}\right), 5.00\left(1 \mathrm{H}, \mathrm{d}, J_{\mathrm{PH}}\right.$ 13.6, PCH), $6.43(2 \mathrm{H}, \mathrm{m}, m-\mathrm{H}), 6.60\left(1 \mathrm{H}, \mathrm{d}, J_{\mathrm{HH}} 2.2, m-\mathrm{H}\right), 6.88\left(1 \mathrm{H}, \mathrm{d}, J_{\mathrm{HH}}\right.$ $8.3, m-\mathrm{H}), 6.95\left(1 \mathrm{H}, \mathrm{d}, J_{\mathrm{HH}} 8.3, o-\mathrm{H}\right), 7.21\left(1 \mathrm{H}, \mathrm{d}, J_{\mathrm{HH}} 7.9, o-\mathrm{H}\right)$ and $8.95(1$ $\left.\mathrm{H}, \mathrm{d}, J_{\mathrm{HH}} 7.9, o-\mathrm{H}\right) ; \quad$ C $\left(150 \mathrm{MHz} ; \mathrm{C}_{6} \mathrm{D}_{6} ; \mathrm{Me}_{4} \mathrm{Si}\right) 26.6\left(3 \mathrm{C}, \mathrm{d}, J_{\mathrm{PC}} 2.9, \mathrm{CMe}_{3}\right)$, $36.2\left(1 \mathrm{C}, \mathrm{d}, J_{\mathrm{PC}} 29.5, \mathrm{CMe}_{3}\right), 39.3\left(2 \mathrm{C}, \mathrm{s}, \mathrm{NMe}_{2}\right), 40.2\left(2 \mathrm{C}, \mathrm{s}, \mathrm{NMe}_{2}\right), 40.9(1$ C, d, $\left.J_{\mathrm{PC}} 27.1, \mathrm{PCH}\right), 44.3$ (1 C, s, NMe), 48.9 (1 C, d, J $\left.J_{\mathrm{PC}} 33.5, \mathrm{PCH}\right), 52.07$ (1 C, s, OMe), 52.3 (1 C, s, OMe), $59.6\left(1 \mathrm{C}, \mathrm{s}, \mathrm{CH}_{2}\right), 59.9\left(1 \mathrm{C}, \mathrm{s}, \mathrm{CH}_{2}\right), 64.8(1$ C, d, $\left.J_{\mathrm{PC}} 2.0, \mathrm{PCHC}\right), 65.8\left(1 \mathrm{C}, \mathrm{d}, J_{\mathrm{PC}} 0.8, \mathrm{PCHC}\right), 109.5\left(2 \mathrm{C}, \mathrm{s}, m-\mathrm{C}_{6} \mathrm{H}_{4}\right)$, $111.5\left(1 \mathrm{C}, \mathrm{s}, m-\mathrm{C}_{6} \mathrm{H}_{4}\right), 114.8\left(1 \mathrm{C}, \mathrm{s}, m-\mathrm{C}_{6} \mathrm{H}_{4}\right), 122.6\left(1 \mathrm{C}, \mathrm{s}, o-\mathrm{C}_{6} \mathrm{H}_{4}\right), 123.2(1$ $\left.\mathrm{C}, \mathrm{d}, J_{\mathrm{PC}} 16.7, \mathrm{C}_{6} \mathrm{H}_{4}\right), 133.6\left(1 \mathrm{C}, \mathrm{d}, J_{\mathrm{PC}} 4.6, o-\mathrm{C}_{6} \mathrm{H}_{4}\right), 133.8\left(1 \mathrm{C}, \mathrm{d}, J_{\mathrm{PC}} 4.6\right.$, $\left.o-\mathrm{C}_{6} \mathrm{H}_{4}\right), 137.8\left(1 \mathrm{C}, \mathrm{d}, J_{\mathrm{PC}} 15.6, \mathrm{C}_{6} \mathrm{H}_{4}\right), 138.2\left(1 \mathrm{C}, \mathrm{d}, J_{\mathrm{PC}} 4.4, \mathrm{C}_{6} \mathrm{H}_{4}\right), 147.5$ $\left(1 \mathrm{C}, \mathrm{s}, p-\mathrm{C}_{6} \mathrm{H}_{4}\right), 149.6\left(1 \mathrm{C}, \mathrm{s}, p-\mathrm{C}_{6} \mathrm{H}_{4}\right), 168.7$ (1 C, d, J $\left.J_{\mathrm{PC}} 8.1, \mathrm{COO}\right), 170.0$ $\left(1 \mathrm{C}, \mathrm{d}, J_{\mathrm{PC}} 9.2, \mathrm{COO}\right)$ and $205.3\left(1 \mathrm{C}, \mathrm{d}, J_{\mathrm{PC}} 4.7, \mathrm{CO}\right) ; \quad$ P $\left(121 \mathrm{MHz} ; \mathrm{C}_{6} \mathrm{D}_{6}\right.$; $\left.\mathrm{H}_{3} \mathrm{PO}_{4}\right) 47.8\left(1 \mathrm{P}, \mathrm{s}, J_{\mathrm{PtP}} 4874\right) ; \mathrm{N}\left(60 \mathrm{MHz} ; \mathrm{C}_{6} \mathrm{D}_{6} ; \mathrm{MeNO}_{2}\right)-339\left(2 \mathrm{~N}, \mathrm{NMe}_{2}\right)$ and -354 (1 N, NMe). 


\section{Reaction of $\mathrm{PN}$ ligand 66 with [PtMe 2 (1,5-hexadiene)]}

PN compound 66 (0.03 g, $0.082 \mathrm{mmol})$ and $\left[\mathrm{PtMe}_{2}(1,5\right.$-hexadiene)] (0.013 g, $0.041 \mathrm{mmol})$ were dissolved in either benzene- $\mathrm{d}_{6}$ or toluene- $\mathrm{d}_{8}\left(0.5 \mathrm{~cm}^{3}\right)$ in a NMR tube at room temperature. Cooling the sample immediately to $-20 \mathrm{C}$ allowed the observation of the complex cis- $\left[\mathrm{PtMe}_{2}(\mathbf{6 6})_{2}\right](\mathbf{1 0 2})$. Leaving the sample at room temperature resulted in the conversion of complex 102 into a 2:1 trans complex in which one of the PN ligands was metallated.

\section{Compound 102:}

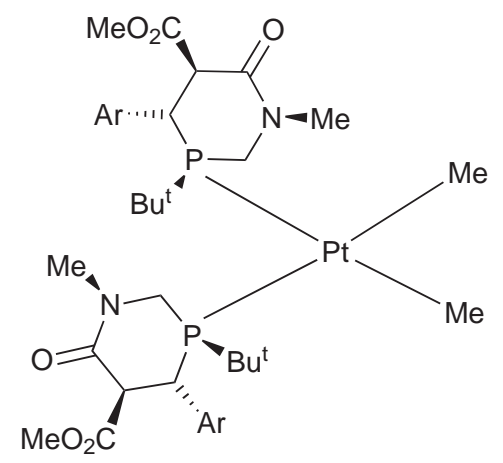

P (121 MHz; toluene-d ${ }_{8}$; $\mathrm{H}_{3} \mathrm{PO}_{4} ;-20$ C) 33.9 (2 P, s, J $\left.J_{\mathrm{PtP}} 1830\right)$.

\section{(trans-Metallated complex):}

н $\left(600 \mathrm{MHz} ;\right.$ toluene- $\left.\mathrm{d}_{8} ; \mathrm{Me}_{4} \mathrm{Si}\right)-0.17$ (1 C, t, $\left.J_{\mathrm{PH}} 5.5, J_{\mathrm{PtH}} 49, \mathrm{Me}\right), 0.80$ (9 $\left.\mathrm{H}, \mathrm{d}, J_{\mathrm{PH}} 13.8, \mathrm{Bu}^{\mathrm{t}}\right)$ and $1.25\left(9 \mathrm{H}, \mathrm{d}, J_{\mathrm{PH}} 13.3, \mathrm{Bu}^{\mathrm{t}}\right) ; \mathrm{C}_{\mathrm{C}}\left(150 \mathrm{MHz}\right.$; toluene-d $\mathrm{d}_{8}$; $\left.\mathrm{Me}_{4} \mathrm{Si}\right)-21.0\left(1 \mathrm{C}\right.$, br s, Me), 26.7 (3 C, d, $\left.J_{\mathrm{PC}} 3, \mathrm{CMe}_{\mathbf{3}}\right)$ and $27.8(3 \mathrm{C}, \mathrm{m}$, $\left.\mathrm{CMe}_{3}\right) ; \quad$ P $\left(121 \mathrm{MHz}\right.$; toluene-d $\left.{ }_{8} ; \mathrm{H}_{3} \mathrm{PO}_{4}\right) 28.1$ (1 P, d, J $\left.J_{\mathrm{PP}} 429, J_{\mathrm{PtP}} 3061\right)$ and $59.6\left(1 \mathrm{P}, \mathrm{d}, J_{\mathrm{PP}} 429, J_{\mathrm{PtP}} 3205\right)$. 


\section{Bibliography}

1. van Leeuwen, P. W. N. M. Homogeneous Catalysis; Kluwer Academic Publishers, 2004.

2. Astruc, D. Organometallic Chemistry and Catalysis; Springer, 2007.

3. Peacock, A. F. A.; Sadler, P. J. Chem. Asian J. 2008, 3, 1890-1899.

4. van Leeuwen, P. W. N. M.; Kamer, P. C. J.; Reek, J. N. H.; Dierkes, P. Chem. Rev. 2000, 100, 2741-2769.

5. Breslow, R.; Belvedere, S.; Gershell, L.; Leung, D. Pure Appl. Chem. 2000, 72, 333-342.

6. Mayer, H. A.; Kaska, W. C. Chem. Rev. 1994, 94, 1239-1272.

7. Togni, A.; Venanzi, L. M. Angew. Chem. Int. Ed. Engl. 1994, 33, 497-526.

8. Pettinari, C.; Masciocchi, N. J. Organomet. Chem. 2005, 690, 1871-1877.

9. Burrows, A. D. Science Progress 2002, 85, 199-217.

10. Slone, C. S.; Weinberger, D. A.; Mirkin, C. A. Prog. Inorg. Chem. 1999, 48, 233-350.

11. Braunstein, P.; Naud, F. Angew. Chem. Int. Ed. 2001, 40, 680-699.

12. Braunstein, P. J. Organomet. Chem. 2004, 689, 3953-3967.

13. Guiry, P. J.; Saunders, C. P. Adv. Synth. Catal. 2004, 346, 497-537.

14. von Matt, P.; Pfaltz, A. Angew. Chem. Int. Ed. Engl. 1993, 32, 566-568.

15. Sprinz, J.; Helmchen, G. Tetrahedron Lett. 1993, 34, 1769-1772.

16. Dawson, G. J.; Frost, C. G.; Williams, J. M. J.; Coote, S. J. Tetrahedron Lett. 1993, 34, 3149-3150.

17. Jeffrey, J. C.; Rauchfuss, T. B. Inorg. Chem. 1979, 18, 2658-2666.

18. Werner, H.; Hampp, A.; Windmüller, B. J. Organomet. chem. 1992, 435, 169-183. 
19. Yang, H.; Alvarez-Gressier, M.; Lugan, N.; Mathieu, R. Organometallics 1997, 16, 1401-1409.

20. Espino, G.; Jalón, F. A.; Maestro, M.; Manzano, B. R.; PérezManrique, M.; Bacigalupe, A. C. Eur. J. Inorg. Chem. 2004, 2542-2552.

21. Assmann, B.; Angermaier, K.; Schmidbaur, H. J. Chem. Soc., Chem. Commun. 1994, 941-942.

22. Phillips, A. D.; Gonsalvi, L.; Romerosa, A.; Vizza, F.; Peruzzini, M. Coord. Chem. Rev. 2004, 248, 955-993.

23. Phillips, A. D.; Bolaño, S.; Bosquain, S. S.; Daran, J.; Malacea, R.; Peruzzini, M.; Poli, R.; Gonsalvi, L. Organometallics 2006, 25, 2189-2200.

24. Caporali, M.; Bianchini, C.; Bolaño, S.; Bosquain, S. S.; Gonsalvi, L.; Oberhauser, W.; Rossin, A.; Peruzzini, M. Inorg. Chim. Acta 2008, 361, 3017-3023.

25. Renfrew, A. K.; Phillips, A. D.; Egger, A. E.; Hartinger, C. G.; Bosquain, S. S.; Nazarov, A. A.; Keppler, B. K.; Gonsalvi, L.; Peruzzini, M.; Dyson, P. J. Organometallics 2009, 28, 1165-1172.

26. Mannich, C.; Mohs, P. Chem. Ber. 1930, B63, 608-12.

27. Jeyaraman, R.; Avila, S. Chem. Rev. 1981, 81, 149-174.

28. Tramontini, M.; Angilini, L. Tetrahedron 1990, 46, 1791-1837.

29. Baliah, V.; Jeyaraman, R.; Chandrasekaran, L. Chem. Rev. 1983, 83, 379423.

30. Arend, M.; Westermann, B.; Risch, N. Angew. Chem. Int. Ed. 1998, 3\%, 1044-1070.

31. Black, D. S.; Deacon, G. B.; Rose, M. Tetrahedron 1995, 51, 2055-2076.

32. Gogoll, A.; Grennberg, H.; Axén, A. Organometallics 1997, 16, 1167-1178.

33. Comba, P.; Kerscher, M.; Schiek, W. Prog. Inorg. Chem. 2007, 55, 613704.

34. Breuning, M.; Steiner, M. Synthesis 2009, 18, 2841-2867.

35. Brandt, W.; Drosihn, S.; Haurand, M.; Holzgrabe, U.; Nachtsheim, C. Arch. Pharm. Pharm. Med. Chem. 1996, 329, 311-323.

36. Kögel, B.; Christoph, T.; Friderichs, E.; Hennies, H. H.; Matthiesen, T.; Schneider, J.; Holzgrabe, U. CNS Drug Reviews 1998, 4, 54-70.

37. Siener, T.; Cambareri, A.; Kuhl, U.; Englberger, W.; Haurand, M.; Kögel, B.; Holzgrabe, U. J. Med. Chem. 2000, 43, 3746-3751. 
38. Brandt, W.; Holzgrabe, U. J. Med. Chem. 2003, 46, 1383-1389.

39. Bailey, B. R.; Berlin, K. D.; Holt, E. M.; Scherlag, B. J.; Lazzara, R.; Brachmann, J.; van der Helm, D.; Powell, D. R.; Pantaleo, N. S.; Ruenitz, P. C. J. Med. Chem. 1984, 27, 758-767.

40. Thompson, M. D.; Smith, G. S.; Berlin, K. D.; Holt, E. M.; Scherlag, B. J.; van der Helm, D.; Muchmore, S. W.; Fidelis, K. A. J. Med. Chem. 1987, 30, 780-788.

41. Comba, P.; Kerscher, M. Cryst. Eng. 2003, 6, 197-211.

42. Bukowski, M. R.; Comba, P.; Limberg, C.; Merz, M.; Que, Jr., L.; Wistuba, T. Angew. Chem. Int. Ed. 2004, 43, 1283-1287.

43. Comba, P.; Merz, M.; Pritzkow, H. Eur. J. Inorg. Chem. 2003, 1711-1718.

44. Börzel, H.; Comba, P.; Hagen, K. S.; Kerscher, M.; Pritzkow, H.; Schatz, M.; Schindler, S.; Walter, O. Inorg. Chem. 2002, 41, 5440-5452.

45. Comba, P.; Kerscher, M.; Roodt, A. Eur. J. Inorg. Chem. 2004, 4640-4645.

46. Bukowski, M. R.; Comba, P.; Lienke, A.; Limberg, C.; de Laorden, C. L.; Mas-Ballesté, R.; Merz, M.; Que, Jr., L. Angew. Chem. Int. Ed. 2006, 45, 3446-3449.

47. Bautz, J.; Comba, P.; Lopez de Laorden, C.; Menzel, M.; Rajaraman, G. Angew. Chem. 2007, 119, 8213-8216.

48. Vagana, R. Novel Bicyclo/3.3.1/nonan-9-one Metal Complexes, M.Sc. thesis, Victoria University of Wellington, 2005.

49. Gogoll, A.; Grennberg, H.; Axén, A. Organometallics 1998, 17, 5248-5253.

50. Wright, E. G.; Spencer, J. L. Unpublished Results.

51. Shen, C. Electrophilic Metal Complexes, Ph.D. thesis, Victoria University of Wellington, 2000.

52. Mulekar, S. V.; Berlin, K. D. J. Org. Chem. 1989, 54, 4758-4767.

53. Arjunan, P.; Berlin, K. D.; Barnes, C. L.; van der Helm, D. J. Org. Chem. 1981, 46, 3196-3204.

54. Yu, V. K.; Praliev, K. D.; Fomicheva, E. E.; Mukhasheva, R. D.; Klepikova, S. G. Chem. Heterocycl. Compd. 2006, 42, 512-519.

55. Welcher, R. P.; Johnson, G. A.; Wystrach, V. P. J. Am. Chem. Soc. 1960, 82, 4437-4438.

56. Welcher, R. P.; Day, N. E. J. Org. Chem 1962, 27, 1824-1827. 
57. Blackburne, I. D.; Katritzky, A. R.; Read, D. M. J. Chem. Soc., Perkin Trans. 2, 1974, 1155-1160.

58. Rampal, J. B.; Macdonell, G. D.; Edasery, J. P.; Berlin, K. D.; Rahman, A.; van der Helm, D.; Pietrusiewicz, K. M. J. Org. Chem. 1981, 46, 1156-1165.

59. Rampal, J. B.; Berlin, K. D.; Edasery, J. P.; Satyamurthy, N.; van der Helm, D. J. Org. Chem. 1981, 46, 1166-1172.

60. Rampal, J. B.; Satyamurthy, N.; Bowen, J. M.; Purdie, N.; Berlin, K. D. J. Am. Chem. Soc. 1981, 103, 7602-7609.

61. Doherty, R.; Haddow, M. F.; Harrison, Z. A.; Orpen, A. G.; Pringle, P. G.; Turner, A.; Wingad, R. L. Dalton Trans. 2006, 36, 4310-4320.

62. Lim, T. H.; Spencer, J. L.; Vagana, R.; Borrmann, T. Unpublished Results.

63. Jones, Jr., M. Organic Chemistry; W. W. Norton \& company, Inc., 1997.

64. Enders, D.; Saint-Dizier, A.; Lannou, M.; Lenzen, A. Eur. J. Org. Chem. 2006, 29-49.

65. Snider, T. E.; Morris, D. L.; Srivastava, K. C.; Berlin, K. D. Org. Synth. 1988, 6, 932-935.

66. Jones, N.; Taylor, H. T. J. Chem. Soc. 1961, 1345-1347.

67. Reed, S. F. J. Org. Chem. 1962, 27, 4116-4117.

68. Japp, F. R.; Maitland, W. J. Chem. Soc. 1904, 85, 1473-1489.

69. Otto, H.; Ebner, U. Archiv der Pharmazie 1976, 309, 969-978.

70. Yates, P.; Yoda, N.; Brown, W.; Mann, B. J. Am. Chem. Soc. 1958, 80, 202-205.

71. Featherman, S. I.; Quin, L. D. J. Am. Chem. Soc. 1975, 97, 4349-4356.

72. Silverstein, R. M.; Webster, F. X. Spectrometric Identification of Organic Compounds, 6th ed.; John Wiley \& Sons, Inc., 1998.

73. Simova, S. Magn. Reson. Chem. 1998, 36, 505-510.

74. Reynold, W. F.; McLean, S.; Tay, L.; Yu, M.; Enriquez, R. G.; Estwick, D. M.; Pascoe, K. O. Magn. Reson. Chem. 1997, 35, 455-462.

75. Leon, I.; Enriquez, R. G.; McLean, S.; Reynold, W. F.; Yu, M. Magn. Reson. Chem. 1998, 36, S111-S117.

76. Fernandez, M. J.; Casares, J. M.; Galvez, E.; Bellantato, J. J. Heterocyclic Chem. 1993, 30, 815-817. 
77. Chen, C. H.; Reynolds, G. A.; Cossar, B. C. J. Org. Chem. 1981, 46, 2752-2757.

78. Azerbaev, N. I.; Omarov, T. T.; Gubasheva, A. S.; Al'Mukhanova, K. A.; Baisalbaeva, S. A. Vestnik Akademii Nauk Kazakhskoi SSR 1975, 2, 47-50.

79. Moss, J. R. J. Mol. Catal. A: Chem. 1996, 107, 169-174.

80. Hambley, T. W. Coord. Chem. Rev. 1997, 166, 181-223.

81. Comba, P.; Kerscher, M.; Merz, M.; Müller, V.; Pritzkow, H.; Remenyi, R.; Schiek, W.; Xiong, Y. Chem. Eur. J. 2002, 8, 5750-5760.

82. Comba, P.; de Laorden, C. L.; Pritzkow, H. Helv. Chim. Acta 2005, 88, 647-664.

83. Atanasov, M.; Comba, P.; Martin, B.; Müller, V.; Rajaraman, G.; Rohwer, H.; Wunderlich, S. J. Comput. Chem. 2006, 27, 1263-1277.

84. Knowles, W. S. Angew. Chem. Int. Ed. 2002, 41, 1998-2007.

85. Zeise, W. C. Mag. Pharm. 1830, 35, 105.

86. Mingos, D. M. P. J. Organomet. Chem. 2001, 635, 1-8.

87. Amatore, C.; Fuxa, A.; Jutand, A. Chem. Eur. J. 2000, 6, 1474-1482.

88. Tsuji, J. Pure Appl. Chem 1989, 61, 1673-1680.

89. Consiglio, G.; Waymouth, R. M. Chem. Rev. 1989, 89, 257-276.

90. Trost, B. M.; Van Vranken, D. L. Chem. Rev. 1996, 96, 395-422.

91. Carturan, G.; Belluco, U.; Del PRA, A.; Zanotti, G. Inorg. Chim. Acta 1979, 33, 155-160.

92. Kollmar, M.; Helmchen, G. Organometallics 2002, 21, 4771-4775.

93. Braunstein, P.; Naud, F.; Dedieu, A.; Rohmer, M.; DeCian, A.; Rettig, S. J. Organometallics 2001, 20, 2966-2981.

94. Braunstein, P.; Zhang, J.; Welter, R. Dalton Trans. 2003, 507-509.

95. Zhang, J.; Braunstein, P.; Welter, R. Inorg. Chem. 2004, 43, 4172-4177.

96. Rosenfeld, S. J. Am. Chem. Soc. 1997, 119, 8395-8396.

97. Dehand, J.; Pfeffer, M. Coord. Chem. Rev. 1976, 18, 327-352.

98. Bruce, M. I. Angew. Chem. Int. Ed. Engl. 1977, 16, 73-86.

99. Brookhart, M.; Green, M. L. H. J. Organomet. Chem. 1983, 250, 395-408.

100. Brookhart, M.; Green, M. L. H.; Parkin, G. PNAS 2007, 104, 6908-6914. 
101. Scherer, W.; McGrady, G. S. Angew. Chem. Int. Ed. 2004, 43, 1782-1806.

102. Koshar, R. J.; Mitsch, R. A. J. Org. Chem. 1973, 38, 3358-3363.

103. Siedle, A. R.; Newmark, R. A. J. Am. Chem. Soc. 1984, 106, 1510-1511.

104. Siedle, A. R.; Newmark, R. A.; Gleason, W. B. J. Am. Chem. Soc. 1986, 108, 767-773.

105. Siedle, A. R.; Newmark, R. A.; Pignolet, L. H. Inorg. Chem. 1986, 25, $3412-3418$.

106. Anderson, B. G.; Hoyte, S. A.; Spencer, J. L. Inorg. Chem. 2009, 48, 7977-7983.

107. Green, M.; Grove, D. M.; Spencer, J. L.; Stone, F. G. A. J. Chem. Soc., Dalton Trans. 1977, 2228-2234.

108. Mole, L.; Spencer, J. L.; Carr, N.; Orpen, A. G. Organometallics 1991, 10, $49-52$.

109. Carr, N.; Mole, L.; Orpen, A. G.; Spencer, J. L. J. Chem. Soc., Dalton Trans. 1992, 2653-2662.

110. Cracknell, R. B.; Orpen, A. G.; Spencer, J. L. J. Chem. Soc., Chem. Commun. 1984, 326-328.

111. Carr, N.; Dunne, B. J.; Mole, L.; Orpen, A. G.; Spencer, J. L. J. Chem. Soc., Dalton Trans. 1991, 863-871.

112. Jain, V. K. Curr. Sci. 1990, 59, 143-151.

113. Michelin, R. A.; Pizzo, E.; Scarso, A.; Sgarbossa, P.; Strukul, G.; Tassan, A. Organometallics 2005, 24, 1012-1017.

114. Sgarbossa, P.; Scarso, A.; Pizzo, E.; Sbovata, S. M.; Tassan, A.; Michelin, R. A.; Strukul, G. J. Mol. Catal. A: Chem. 2007, 261, 202-206.

115. Aullón, G.; Ujaque, G.; Lledós, A.; Alvarez, S. Chem. Eur. J. 1999, 5, 1391-1410.

116. Orpen, A. G.; Brammer, L.; Allen, F. H.; Kennard, O.; Watson, D. G.; Taylor, R. J. Chem. Soc., Dalton Trans. 1989, S1-S83.

117. Skapski, A. C.; Troughton, P. G. H. J. Chem. Soc. (A) 1969, 2772-2781.

118. Mintcheva, N.; Tanabe, M.; Osakada, K. Organometallics 2006, 25, 37763783 .

119. Vicente, J.; Arcas, A.; Gálvez-López, M.; Juliá-Hernández, F. Organometallics 2008, 27, 1582-1590.

120. Garrou, P. E. Chem. Rev. 1981, 81, 229-266. 
121. Marek, R.; Lyčka, A. Curr. Org. Chem. 2002, 6, 35-66.

122. Mason, J.; Larkworthy, L. F.; Moore, E. A. Chem. Rev. 2002, 102, 913-934.

123. Ryan, J. M. Novel Secondary Metabolites from New Zealand Marine Sponges, Ph.D. thesis, Victoria University of Wellington, 2007.

124. Toom, L.; Kutt, A.; Kaljurand, I.; Leito, I.; Ottosson, H.; Grennberg, H.; Gogoll, A. J. Org. Chem. 2006, 71, 7155-7164.

125. Buchanan, G. W. Tetrahedron 1989, 45, 581-604.

126. Appleton, T. G.; Hall, J. R.; Ralph, S. F. Inorg. Chem. 1985, 24, 46854693.

127. Pazderski, L.; Toušek, J.; Sitkowski, J.; Kozerski, L.; Szłyk, E. Magn. Reson. Chem. 2007, 45, 1045-1058.

128. Gottlieb, H. E.; Kotlyar, V.; Nudelman, A. J. Org. Chem. 1997, 62, 7512 7515 .

129. Harris, R. K.; Becker, E. D.; Cabral de Menezes, S. M.; Goodfellow, R.; Granger, P. Magn. Reson. Chem. 2002, 40, 489-505.

130. Sheldrick, G. M. Acta Crystallogr., Sect. A 2008, 64, 112-122.

131. Farrugia, L. J. J. Appl. Crystallogr. 1997, 30, 565. 